UNIVERSIDADE DE SÃO PAULO

FACULDADE DE MEDICINA DE RIBEIRÃO PRETO

\author{
ELVIRA REGINA TAMAROZZI
}

Caracterização estrutural de Dectin-1 humana e análise de interação com seus alvos moleculares $\beta$-glucanos e Syk 
ELVIRA REGINA TAMAROZZI

Caracterização estrutural de Dectin-1 humana e análise de interação com seus alvos moleculares $\beta$-glucanos e Syk

\section{Versão Original}

Tese apresentada à Faculdade de Medicina de Ribeirão Preto da Universidade de São Paulo para a obtenção do título de Doutora em Ciências.

Área de concentração: Genética

Orientadora: Prof. ${ }^{\text {a }} \mathrm{Dr}^{\mathrm{a}}$. Silvana Giuliatti

Ribeirão Preto 
Autorizo a reprodução e divulgação total ou parcial deste trabalho, por qualquer meio convencional ou eletrônico, para fins de estudo e pesquisa, desde que citada a fonte.

Catalogação de Publicação Preparada pela Biblioteca do Serviço de Biblioteca de Documentação da Faculdade de Medicina de Ribeirão Preto da Universidade de Ribeirão Preto

Tamarozzi, Elvira Regina

Caracterização estrutural de Dectin-1 humana e análise de interação com seus alvos moleculares $\beta$-glucanos e Syk. Ribeirão Preto, 2020.

201 p. : il. ; $30 \mathrm{~cm}$

Tese de doutorado, apresentada à Faculdade de Medicina de Ribeirão Preto/USP . Área de concentração: Genética.

Orientadora: Giuliatti, Silvana.

1. Dectin-1. 2. Receptor transmembranar. 3. Sinalização celular. 4. Análise estrutural. 
Nome: TAMAROZZI, Elvira Regina

Título: Caracterização estrutural de Dectin-1 humana e análise de interação com seus alvos moleculares $\beta$-glucanos e Syk

Tese apresentada à Faculdade de Medicina de Ribeirão Preto da Universidade de São Paulo, para obtenção do título de Doutora em Ciências.

Aprovada em:

Banca examinadora

Prof. Dr.

Instituição:

Julgamento:

Prof. Dr.

Instituição:

Julgamento:

Prof. Dr.

Instituição:

Julgamento:

Prof. Dr.

Instituição:

Julgamento:

Prof. Dr.

Instituição:

Julgamento: 
Dedicatória

Dedico este trabalho à minha mamãe Matilde que, todos os dias, sem exceção, me inspira e me incentiva a lutar por meus sonhos. Ela me mostrou, com seu exemplo de perseverança, que tudo que fazemos com amor e dedicação resulta em bons frutos. À minha mãe, meu porto seguro e meu exemplo de vida. Dedico este trabalho também à Luana, minha companheira de vida, amiga e cúmplice que, a qualquer hora e momento, sempre está segurando minhas mãos. 


\section{Agradecimentos}

Primeiramente, agradeço a Professora Dra. Silvana Giuliatti por todas as oportunidades que me foram dadas e por toda confiança que me foi depositada.

Agradeço imensamente às minhas amadas, Mamãe e Luana, por toda paciência e apoio, por todas as palavras de incentivo e por iluminarem meu caminho nos momentos em que me faltou clareza.

Agradeço aos meus irmãos Paulo e João por todo carinho e por toda alegria que trazem à minha vida.

Agradeço às minhas madrinhas Luzia e Isabel, que são minhas mães de coração e que, mesmo longe, sempre me colocam em suas orações.

Agradeço a todos os amigos que sempre me presentearam com palavras de incentivo e motivação, sempre acreditando no meu potencial e me colocando em suas orações.

Agradeço a todos os colegas de laboratório, funcionários, professores e alunos do programa de pós-graduação em genética que, de alguma forma, contribuíram para a realização desse trabalho.

À USP e Faculdade de Medicina pela oportunidade de realização dessa pós-graduação.

Pesquisa desenvolvida com o auxílio dos recursos de HPC disponibilizados pela Superintendência de Tecnologia da Informação da Universidade de São Paulo.

O presente trabalho foi realizado com apoio da Coordenação de Aperfeiçoamento de Pessoal de Nível Superior - Brasil (CAPES) - Código de Financiamento 001 
"A busca pelo conhecimento e o descobrimento de novas habilidades é a jornada do indivíduo para desbravar a si próprio."

Tamarozzi, E. R. (2020). 


\section{RESUMO}

TAMAROZZI, Elvira Regina. Caracterização estrutural de Dectin-1 humana e análise de interação com seus alvos moleculares $\beta$-glucanos e Syk. 2020. 201 f. Tese (Doutorado) Faculdade de Medicina de Ribeirão Preto, Universidade de São Paulo, Ribeirão Preto, 2020.

Dectin-1 humana é um receptor transmembranar expresso na maioria das células que atuam na imunidade inata, apresenta um único $C$-type lectin-like domain (CTLD) em sua porção extracelular e um único motivo imunorreceptor de ativação baseada em tirosina (hemITAM) na porção intracelular. O motivo hemITAM atua como mediador da ativação induzida pelo reconhecimento de $\beta$-glucanos e dá início a resposta de sinalização que leva à produção de vários imunomoduladores. Dectin-1, além de ser um componente fundamental na sinalização de infecções fúngicas, também tem importante papel nas respostas imunes antitumorais, está correlacionado à resistência à insulina e obesidade, participa no processo de desenvolvimento da aterosclerose, atua de forma importante em doenças que causam processos inflamatórios crônicos e, em determinadas situações, pode desencadear o surgimento de doenças autoimunes. Estruturalmente, devido à importância biológica e farmacêutica das proteínas transmembranares, esforços experimentais e computacionais consideráveis têm sido feitos para melhor entender a estrutura e função dessas proteínas em ambientes de membrana. O objetivo do presente estudo foi determinar a estrutura tridimensional completa de Dectin-1 e analisar a interação de seus domínios funcionais com os alvos moleculares descritos, $\beta$-glucanos e proteína Syk. Por meio de métodos in silico foi possível determinar o modelo para a estrutura completa de Dectin-1. Para simular o arranjo de Dectin-1 na membrana celular foi construído um sistema proteína/membrana que foi submetido a simulações de dinâmica molecular. A análise dessas simulações mostrou que existem regiões com características especificas que conferem flexibilidade à estrutura e que essa flexibilidade pode estar associada à sua capacidade de oligomerização. Os domínios funcionais de Dectin-1 foram usados em análises de interação com os alvos $\beta$-glucanos e Syk. Uma conformação dimérica estável de Dectin-1 foi obtida por meio de docking proteína-proteína, possibilitando a ampliação das análises de interação de Dectin-1 com $\beta$-glucanos. As análises de interação do CTLD com $\beta$-glucanos evidenciou que a conformação dimérica pode ser mais favorável para a interação e possível reconhecimento de $\beta$-glucanos quando comparado ao estado monomérico. $\mathrm{O}$ tempo de interação entre os $\beta$ glucanos e o sítio de reconhecimento sugeriu que, possivelmente, a organização estrutural e tamanho do $\beta$-glucano pode influenciar no processo de oligomerização de Dectin-1 e na localização do sítio de reconhecimento do CTLD. As análises de interação entre o motivo hemITAM e a proteína Syk mostraram que é possível Dectin-1 formar um complexo estável com Syk pela interação do motivo hemITAM fosforilado com apenas o domínio SH2-1, deixando o domínio SH2-2 livre para interagir com outro hemITAM, otimizando a interação com a proteína Syk. Assim, pode-se concluir que, a caracterização estrutural de Dectin-1 permitirá que este importante receptor tenha seus domínios explorados como alvos em estudos para o desenvolvimento de fármacos com potencial ativador ou inibidor de suas funções, podendo promover a terapêutica em diversas patologias. A estrutura tridimensional aqui descrita, também poderá ser usada como molde para a determinação estrutural de outras proteínas da família das lectinas, podendo ser empregada em estudos para ampliar o conhecimento de sua função nos processos de sinalização celular.

Palavras Chaves: Dectin-1, receptor transmembranar, sinalização celular, análise estrutural. 


\begin{abstract}
TAMAROZZI, Elvira Regina. Structural characterization of human Dectin-1 and analysis of interaction with the molecular targets $\beta$-glucans and Syk. 2020. $201 \mathrm{f}$. Tese (Doutorado) Medical School of Ribeirão Preto, University of São Paulo, Ribeirão Preto, 2020.

Human Dectin-1 is a transmembrane receptor expressed in most cells that act in innate immunity. Dectin-1 has a single C-type lectin-like domain (CTLD) in the extracellular part and a single immunoreceptor tyrosine-based activation motif (hemITAM) in the intracellular part. The hemITAM motif acts as a mediator of activation induced by the recognition of $\beta$-glucans and initiates the signaling response that leads to the production of several immunomodulators. Dectin-1, in addition to being a fundamental component in signaling fungal infections, is also important in anti-tumor immune responses, is correlated with insulin resistance and obesity, is involved in the process of developing atherosclerosis, has an important role in diseases that cause processes chronic inflammatory diseases and, in specific situations, can trigger the appearance of autoimmune diseases. Structurally, due to the biological and pharmaceutical importance of transmembrane proteins, considerable experimental and computational efforts have been made to better understand the structure and function of these proteins in membrane environments. The aim of the present study was to determine the complete three-dimensional structure of Dectin-1 and to analyze the interaction of its functional domains with the described molecular targets, $\beta$-glucans and Syk protein. It was possible to determine the model for the complete structure of Dectin-1 using in silico methods. To simulate the arrangement of Dectin1 in the cell membrane, a protein/membrane system was built and subjected to molecular dynamics simulations. The analysis of these simulations showed that there are regions with specific characteristics that give flexibility to the structure and that this flexibility may be associated with its oligomerization capacity. The functional domains of Dectin-1 were used in interaction analysis with the $\beta$-glucans and Syk targets. A stable dimeric conformation of Dectin-1 was obtained through protein-protein docking, enabling the expansion of the analysis of interaction of Dectin-1 with $\beta$-glucans. The analysis of CTLD interaction with $\beta$-glucans showed that the dimeric conformation may be more favorable for the interaction and possible recognition of $\beta$-glucans when compared to the monomeric state. The interaction time between $\beta$-glucans and the recognition site suggested that, possibly, the structural organization and size of $\beta$-glucan may influence the Dectin-1 oligomerization process and the location of the CTLD recognition site. Interaction analyzes between the hemITAM motif and the Syk protein showed that it is possible for Dectin-1 to form a stable complex with Syk by the interaction of the phosphorylated hemITAM motif with only the SH2-1 domain, leaving the SH2-2 domain free to interact with another hemITAM, optimizing the interaction with the Syk protein. Thus, it can be concluded that the structural characterization of Dectin-1 will allow this important receptor to have its domains explored as targets in studies for the development of drugs with a potential activator or inhibitor of its functions, being able to promote therapy in several pathologies. The three-dimensional structure described here, can also be used as a template for the structural determination of other proteins of the C-type lectin family, and can be used in studies to expand the knowledge of its function in cell signaling processes.
\end{abstract}

Keywords: Dectin-1, transmembrane receptor, immunoregulation, structural analysis. 


\section{Lista de Figuras}

Figura 1 - Localização genômica de Dectin-1 no cromossomo 12p13.2 na região do complexo natural killer.

Figura 2 - Representação esquemática das vias de sinalização mediadas por Dectin-1

Figura 3 - Caracterização estrutural de hDectin-1. 25

Figura 4 - Representação do conhecimento estrutural de mDectin-1 e hDectin-1. 26

Figura 5 - Oligomerização de Dectin-1 30

Figura 6 - Fluxograma do processo de determinação e análise estrutural in silico de hDectin1.

Figura 7 - Arranjo topológico da estrutura primária de hDectin-1. 51

Figura 8 - Alinhamento global feito por meio do software EMBOSS Needle entre as sequências primárias de hDectin-1 e mDectin-1.

Figura 9 - Resultado da predição de elementos secundários de hDectin-1 e mDectin-1. 53

Figura 10 - Resultado da predição da região transmembranar para hDectin-1. 54

Figura 11 - Alinhamento global entre as sequências primárias do molde e o alvo. 56

Figura 12 - Avaliação da estrutura E1-hD, que compreende os aminoácidos 118 a 244 da porção extracelular de hDectin-1 obtida por modelagem por homologia. 58

Figura 13 - Estrutura tridimensional de parte da porção extracelular de hDectin-1 denominada E1-hD que compreende os aminoácidos 118 ao 244.

Figura 14 - Comportamento estrutural do CTLD de hDectin-1 ao longo da simulação de DM.

Figura 15 - Comportamento estrutural do CTLD de mDectin-1 ao longo da simulação de DM....... 64

Figura 16 - Avaliação da estrutura E2-hD, que compreende os aminoácidos 66 a 117 da porção extracelular de hDectin-1 obtida por threading. 66

Figura 17 - Domínio transmembranar de hDectin-1 68

Figura 18 - Alinhamentos locais feitos por meio do software EMBOSS Matcher. 69

Figura 19 - Alinhamentos locais feitos por meio do software EMBOSS Matcher. 70 
Figura 20 - Avaliação da estrutura TM, que compreende os aminoácidos 45 a 65 correspondente a porção transmembranar de hDectin-1 obtida por modelagem por homologia........... 72

Figura 21 - Domínio intracelular de hDectin-1............................................................. 73

Figura 22 - Avaliação da estrutura E3-hD, que compreende os aminoácidos 1 a 44 correspondentes a porção intracelular de hDectin-1 obtida por ab initio..................... 75

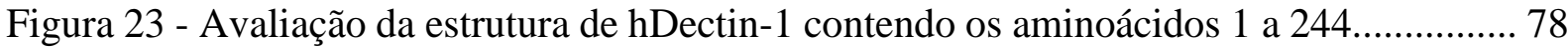

Figura 24 - Análise para verificar a confiança da estrutura em relação a possíveis erros realizada por meio do software ERRAT.............................................................................. 79

Figura 25 - Avaliação da estrutura completa de hDectin-1 obtida após modelagem por ab initio

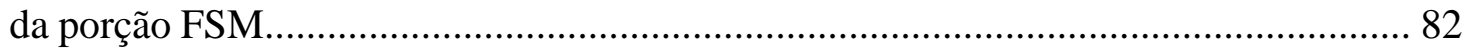

Figura 26 - Reavaliação da estrutura completa de hDectin-1 após refinamento dos loops....... 85

Figura 27 - Sistema proteína/membrana gerado pelo servidor CHARMM-GUI para simulação

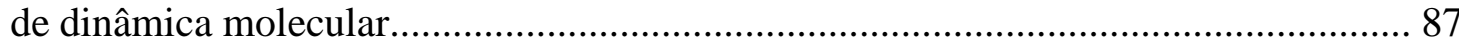

Figura 28 - Trajetória da simulação de DM da estrutura completa de hDectin-1 ..................... 88

Figura 29 - Alinhamento das estruturas inicial e final da simulação de DM e $b$-factors de cada uma das três simulações de DM......................................................................... 90

Figura 30 - Predição de regiões com desordem intrínseca.................................................. 91

Figura 31 - Predição de regiões com desordem intrínseca as para as sequências primárias de camundongo, rato, bovino, primata macaca mulata e primata pan troglodytes........... 92

Figura 32 - Comportamento dos elementos secundários analisado ao longo do tempo da triplicata de simulação de DM da estrutura completa de hDectin-1. Estrutura inicial (0 $\mathrm{ns}), 50 \mathrm{~ns}$ e $100 \mathrm{~ns}$.

Figura 33 - Comparativo dos resultados das simulações de DM do CTDL de hDectin-1 e sua estrutura completa. Alinhamento das estruturas inicial e final de hDectin-1 completa. 97

Figura 34 - Trajetória da simulação de DM do dímero de mDectin-1 (PDB ID: 2CL8) e alinhamento das estruturas inicial e final............................................................. 100

Figura 35 - Interface de interação entre os monômeros do Dímero de mDectin-1 ................. 102

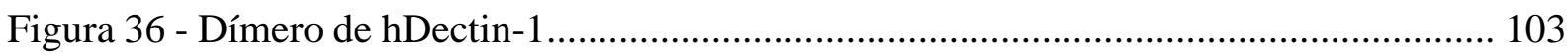

Figura 37 - Sistema dímero/membrana gerado pelo servidor CHARMM-GUI para simulação

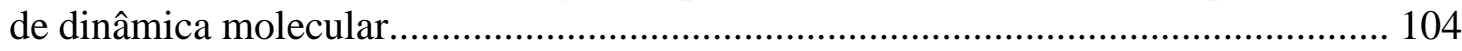


Figura 38 - Figura 38 - Analises da simulação de DM do dímero de hDectin-1 na membrana celular......

Figura 39 - Trajetória da simulação de DM do dímero de hDectin-1 (apenas CTLD) e alinhamento das estruturas inicial e final.

Figura 40 - Diagrama das interações entre os monômeros de CTLD de hDectin-1 que compõem o dímero nos tempos inicial (0 ns), $50 \mathrm{~ns}$ e aos $100 \mathrm{~ns}$

Figura 41 - Alinhamento das conformações do dímero CTLD-hD ao longo da simulação de DM, interface de interação e diagrama das interações entre os monômeros que compõem o dímero formado pelos CTLD de hDectin-1

Figura 42 - Alinhamento das sequencias primarias de mDectin-1 e hDectin-1 para destacar a correspondências dos aminoácidos W, H e Y que compõe o sítio de reconhecimento de $\beta$-glucanos.

Figura 43 - Resultado da predição dos sítios de ligação realizada por meio do software FTSite.

Figura 44 - Sítio 3 predito por meio do software FTSite.

Figura 45 - Perfil de hidrofobicidade e potencial eletrostático da superfície do CTLD da estrutura de hDectin-1.

Figura 46 - Região correspondente aos aminoácidos T210, W222, H224, Y229, D230 e Q231 do CTLD de hDectin-1 que foram usados o para direcionamento do docking com $\beta$ glucanos.

Figura 47 - Estruturas 2D dos $\beta$-glucanos Laminarin, Zymosan, Scleroglucan e Sizofiran......117

Figura 48 - Resultado do docking entre o CTDL de hDectin-1 e $\beta$-glucanos.

Figura 49 - Complexo CTLD/Zymosan.

Figura 50 - Complexo CTLD/Laminarin.

Figura 51 - Complexo CTLD/Scleroglucan..

Figura 52 - Complexo CTLD/Sizofiran.

Figura 53 - Resultado do docking entre o dímero dos CTDL de hDectin-1 e $\beta$-glucanos.

Figura 54 - Complexo Dímero/Zymosan.

Figura 55 - Complexo Dímero/Laminarin.

Figura 56 - Complexo Dímero/Scleroglucan.

Figura 57 - Complexo Dímero/Sizofiran.. 
Figura 58 - Complexo monômero/b-glucano

Figura 59 - Sequências primarias das estruturas de motivos ITAM depositadas no PDB

Figura 60 - Adição de um grupo fosfato $\mathrm{PO}_{4}{ }^{3-}$ na tirosina presente no motivo hemITAM de hDectin-1

Figura 61 - Domínio SH2 1, domínio SH2 2 e interdominío A de Syk................................. 141

Figura 62 - Resultado da predição de sítios de ligação do software FTSite.......................... 142

Figura 63 - Interface de interação entre o Chain A (domínios SH2) e Chain B (motivo ITAM de CD3E) do complexo PDB ID: 1A81 ............................................................... 143

Figura 64 - Complexo proteína-proteína formado pela estrutura completa de hDectin-1 e domínios SH2-1, SH2-2 e Interdominío A de Syk 146

Figura 65 - Sistema com o complexo hemITAM/SH2 na membrana celular gerado pelo servidor CHARMM-GUI para simulação de dinâmica molecular.

Figura 66 - Trajetória da simulação de DM do complexo hemITAM/SH2 149

Figura 67 - Comportamento estrutural ao longo do tempo da simulação de DM do complexo hemITAM/SH2.

Figura 68 - Diagrama das interações entre o motivo hemITAM e domínio SH2-1 com a estrutura inicial do complexo hemITAM/SH2, aos $100 \mathrm{~ns}$ e aos $200 \mathrm{~ns}$. 153 


\section{Lista de Tabelas}

Tabela 1 - Estruturas tridimensionais de Dectin-1 depositadas no Protein Data Bank............. 55

Tabela 2 - Comparativo entre a avaliação do melhor modelo obtido por modelagem por homologia e a estrutura 2BPD-A obtida experimentalmente usada como molde.

Tabela 3 - Região de hDectin-1 modelada e metodologia empregada................................... 76

Tabela 4 - Identificadores dos $\beta$-glucanos selecionados para o docking com hDectin- 1

Tabela 5 - Tempo de interação dos $\beta$-glucanos com o sítio de reconhecimento presente no CTLD de hDectin-1 no monômero e no dímero e quantidade de interações entre os $\beta$ glucanos e sítio nos complexos obtidos por docking....

Tabela 6 - Comparativo do tempo de interação dos $\beta$-glucanos com o sítio de reconhecimento presente no CTLD de hDectin-1 na primeira e na segunda etapa de docking com o monômero e com o dímero.

Tabela 7 - Resíduos ativos na interação entre os domínios SH2 e motivo ITAM da estrutura PDB ID: 1A81. Em vermelho estão os resíduos que interagem diretamente (distância de até $3 \AA$ ) com a fosfotirosina (pTyr) do motino ITAM YxxL........................................ 178 


\section{Lista de Siglas}

$\begin{array}{ll}\text { CTLD } & \text { C-type lectin-like domain } \\ \text { DC } & \text { Células dendríticas } \\ \text { DM } & \text { Dinâmica molecular } \\ \text { DNA } & \text { Deoxyribonucleic Acid } \\ \text { hDectin-1 } & \text { Dectin-1 humana } \\ \text { hemITAM } & \text { Motivo imunorreceptor de ativação baseada em tirosina } \\ \text { ID } & \text { Identificador } \\ \text { mDectin-1 } & \text { Dectin-1 de camundongo } \\ \text { PDB } & \text { Protein Data Bank } \\ \text { RMSD } & \text { Root Mean Square Deviation } \\ \text { RMSF } & \text { Root Mean Square Fluctuations } \\ \text { RNA } & \text { Ribonucleic Acid } \\ \text { SH2 } & \text { Src Homology 2 } \\ \text { SYK } & \text { Tyrosine-protein kinase }\end{array}$




\section{Sumário}

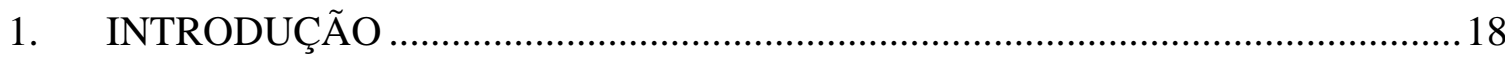

1.1. Caracterização genômica de Dectin-1 e vias de sinalização .................................... 18

1.2. Dectin-1, muito além da sinalização de infecções fúngicas....................................22

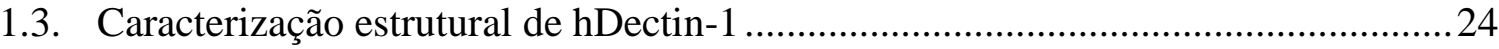

1.4. Reconhecimento de $\beta$-glucanos pelo CTLD e sinalização via Syk pelo hemITAM de Dectin-1

1.5. Oligomerização cooperativa de Dectin-1 no reconhecimento de $\beta$-glucanos 29

1.6. O progresso do desenvolvimento de novas terapias a partir do conhecimento estrutural de proteínas 31

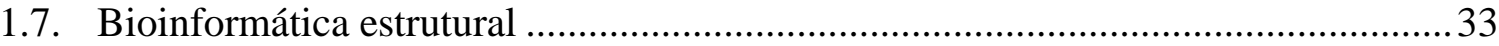

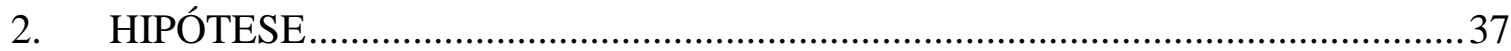

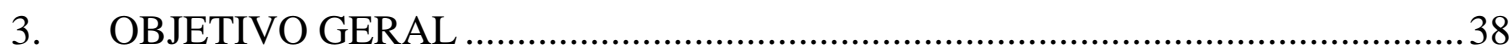

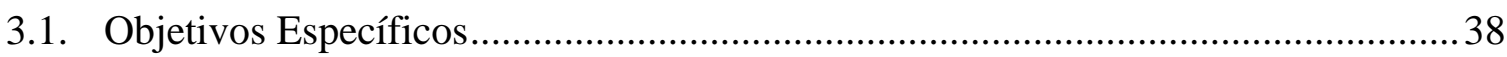

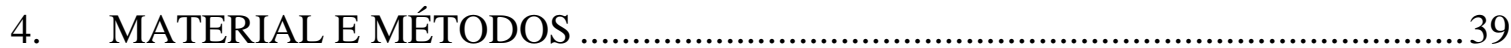

4.1. Obtenção da sequência primaria e análise das estruturas secundárias.....................40

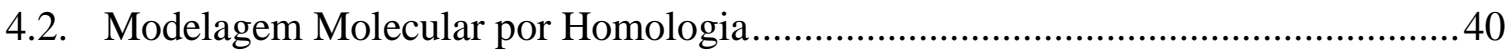

4.3. Modelagem Molecular por Threading ................................................................. 41

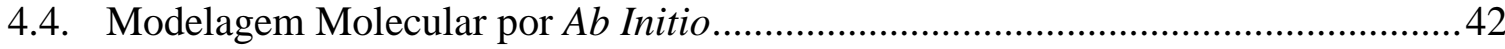

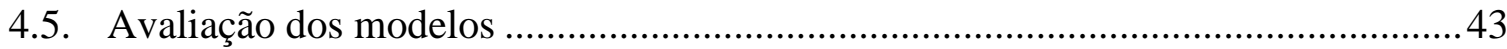

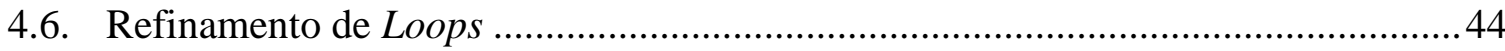

4.7. Construção do sistema proteína/membrana celular ............................................... 44

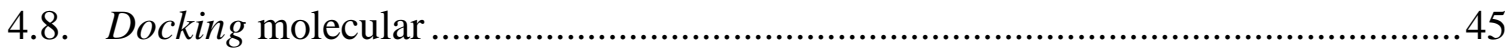

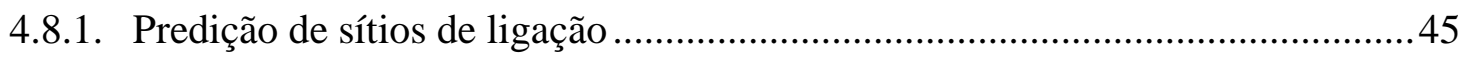

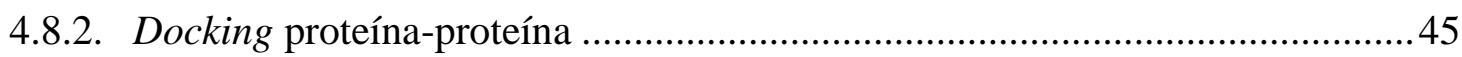

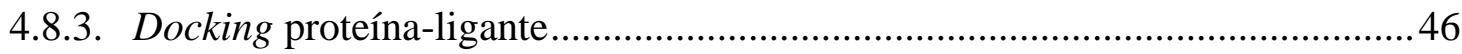

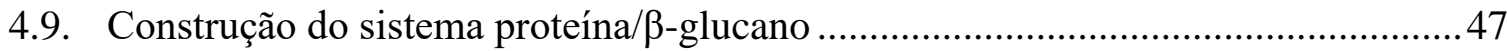




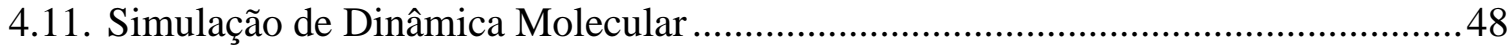

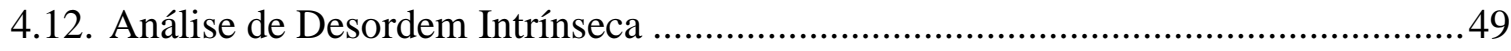

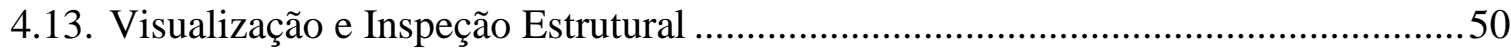

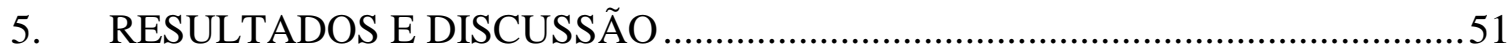

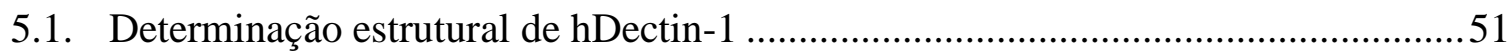

5.1.1. Análises da estrutura primária e secundária...................................................51

5.1.2. Predição da região do domínio transmembranar ............................................53

5.1.3. Modelagem por homologia do C-type lectin-like domain de hDectin-1...........55

5.2. Simulação de DM de hDectin-1 completa na membrana celular............................. 85

5.2.1. Construção do sistema proteína/membrana celular ........................................85

5.2.2. Simulação de dinâmica molecular do sistema proteína/membrana ...................87

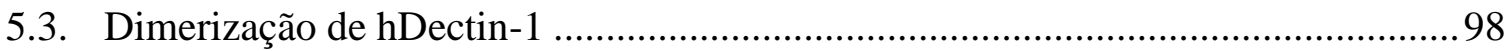

5.3.1. Simulação de DM para análise da estabilidade do dímero de mDectin-1 ........98

5.3.2. Dimerização de hDectin-1 completa por meio de Docking proteína-proteína 101

5.4. Análise da interação molecular entre hDectin-1 e seus alvos moleculares por meio de docking molecular com $\beta$-glucanos e proteína Syk ....................................................... 113

5.4.1. Docking molecular de $\beta$-glucanos com o CTLD de hDectin-1...................... 113

5.4.2. Docking dos $\beta$-glucanos com o dímero CTLD-hD ....................................... 126

5.4.3. Docking molecular do motivo hemITAM com Syk ..................................... 139

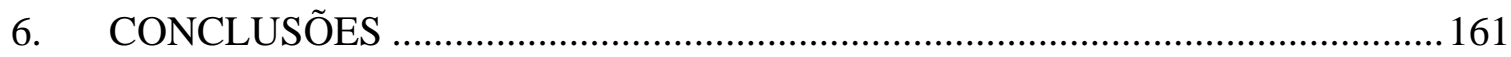

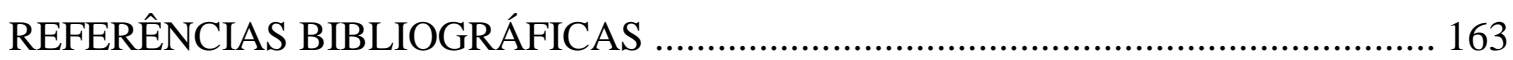

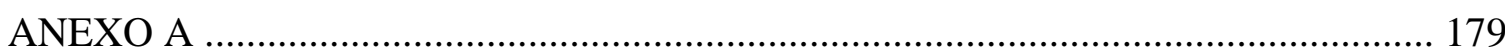




\section{INTRODUÇÃO}

\subsection{Caracterização genômica de Dectin-1 e vias de sinalização}

A proteína lectina do tipo $\mathrm{C}$, membro A da família 7 (do inglês $C$-type lectin domain family 7 member A), também conhecida como Dectin-1 e CLEC7A, pertence ao grupo de receptores de lectina de tipo C (C-type lectin receptors, CLR) (REID et al., 2009; SOBANOV et al., 2001), que possuem um ou mais domínios iguais ao de lectina do tipo C (C-type lectinlike domains), estruturalmente relacionados (WILLMENT; BROWN, 2008).

O mapeamento, caracterização genômica e primeiras análises de expressão de Dectin1 humana (hDectin-1) foram descritas inicialmente em 2001 por Brown e Gordon (2001), Hernanz-Falcon e colaboradores (2001) e Yokota e colaboradores (2001), um ano após a identificação e caracterização genômica de Dectin-1 de camundongo (mDectin-1) ter sido relatada por Ariizumi e colaboradores em 2000.

Dectin-1 é amplamente expressa e está presente em todas as populações de monócitos, macrófagos, células dendríticas (DC), neutrófilos e eosinófilos. Ela também é expressa em células $\mathrm{B}$ e em subpopulações de células $\mathrm{T}$, demonstrando não estar restrita a células da linhagem mieloide monocítica (DALEY et al., 2017; WILLMENT et al., 2005; WILLMENT et al., 2001). Ela é codificada a partir do gene CLEC7A, mapeado no cromossomo 12p13.2 (OMIM 606264), na região genômica conhecida como complexo natural killer (BROWN, 2006; YOKOTA et al., 2001) (figura 1).

Figura 1 - Localização genômica de Dectin-1 no cromossomo 12p13.2 na região do complexo natural killer.

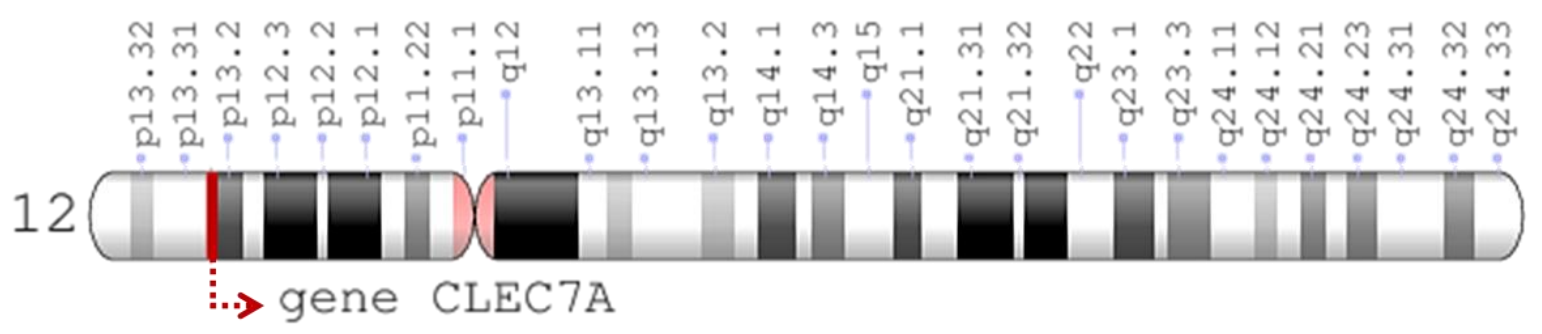

Fonte: Imagem gerada por meio do software Genome Decoration Page do National Center for Biotechnology Information (NCBI). 
Dectin-1 pertence a uma classe de Receptores de Reconhecimento de Padrão (PRRs) que confere ao sistema imunológico a capacidade de reconhecer e responder imediatamente à infecção. Os PRRs interagem com estruturas conservadas presentes nos patógenos, denominadas Padrões Moleculares Associados aos Patógenos (do inglês Pathogen Associated Molecular Patterns, PAMPs). São conhecidas diversas famílias de PRRs, localizadas em meio intracelular e extracelular (OSTROP; LANG, 2017; BROWN, 2006; HERNANZ-FALCON et al., 2001).

Atualmente, conhecida como um importante receptor transmembranar, a proteína Dectin-1 inicialmente foi descrita como sendo um receptor específico de DC, mas, com a ampliação dos estudos, foi visto que esse receptor é expresso por muitos outros tipos de células. Nas principais portas de entrada de patógenos, como o pulmão e intestino, Dectin-1 é expressa em níveis elevados, o que é consistente com seu papel de receptor na vigilância imune. Em humanos, este receptor também é expresso em células B e eosinófilos, porém isso não ocorre em camundongos (SANCHO; REIS; SOUSA, 2012; BROWN, 2006; WILLMENT et al., 2005).

Dectin-1 é um componente fundamental para a habilidade do sistema imune inato em sinalizar infecções fúngicas pelo reconhecimento de $\beta$-glucanos. Os polissacarídeos complexos compostos por moléculas de glicose, denominados $\beta$-glucanos, têm atividade imunomoduladora e são provenientes, principalmente, da parede celular de fungos, plantas e algumas bactérias (DALEY et al., 2017; GOODRIDGE et al., 2011).

Após o reconhecimento de $\beta$-glucanos, Dectin-1 atua como mediador e regulador de diversas funções celulares, incluindo fagocitose, autofagia, produção de lipídios, maturação de espécies reativas de oxigênio (ROS) em DC e indução de padrões de expressão de citocinas e quimiocinas, como o TNF, IL-1 $\alpha$, IL-1 $\beta$, IL-23 (p19), IL-10, IL-12 (p35), IL-12 (p70), IL-12/23 (p40), IL-6, CXCL2, CCL3 e GM-CSF (CASTOLDI et al., 2017; DAMBUZA; BROWN; 2015; DRUMMOND; BROWN, 2013; GRINGHUIS et al., 2011; HARDISON; BROWN, 2012).

Em células mieloides, a sinalização de Dectin-1 se inicia após o reconhecimento de seus ligantes e ocorre a possível formação de dímeros (SANCHO; REIS; SOUSA, 2012; XU et al., 2009). Esse processo envolve cascatas de sinalização dependentes da proteína tirosina quinase do baço (do inglês Tyrosine-protein kinase, Syk), juntamente com receptores auxiliares como TLRs (OSTROP; LANG, 2017; DEL FRESNO et al., 2013; KERRIGAN e BROWN, 2010). 
A sinalização via Dectin-1 resulta na ativação de fator nuclear $\kappa \mathrm{B}$ (do inglês nuclear

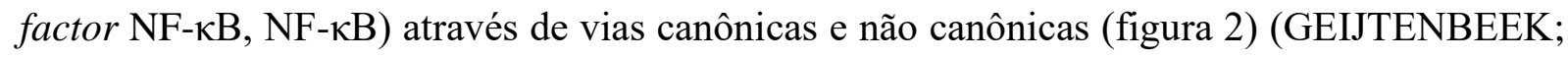
GRINGHUIS, 2016; SANCHO; REIS; SOUSA, 2012; KERRIGAN; BROWN, 2010; GRINGHUIS et al, 2009).

O motivo hemilTAM de Dectin-1 fosforilado cria um sítio de ligação para a proteína Syk (BLANCO-MENÉNDEZ et al., 2015) e desencadeia o recrutamento de CARD9 para a membrana ou para o fagosoma contendo partículas fúngicas fagocíticas. O complexo CARD9/BCL10/MALT-1 modula a ativação do complexo IKB quinase (IKK) para a sinalização da via canônica de NF-KB, onde IKK $\alpha$ fosforila IKB promovendo sua degradação, permitindo que membros da família NF-KB se conduzam para o núcleo celular. Dectin-1 pode ativar a via não canônica de NF-кB dependente da quinase indutora de NF-kB (do inglês, $N F$ kappa-B-inducing kinase, NIK) e independente de CARD9. A ativação de NF-kB é a base do programa inflamatório de ativação de células mieloides que leva à maturação de DC e secreção de citocinas. A hDectin-1 também pode induzir uma segunda via de sinalização mediada pela quinase RAF-1 independentemente de Syk, embora convirja com a via canônica acoplada a Syk ao nível de NF-KB (GEIJTENBEEK; GRINGHUIS, 2016; ZHAO et al., 2016; GRINGHUIS et al, 2009). 
Figura 2 - Representação esquemática das vias de sinalização mediadas por Dectin-1.

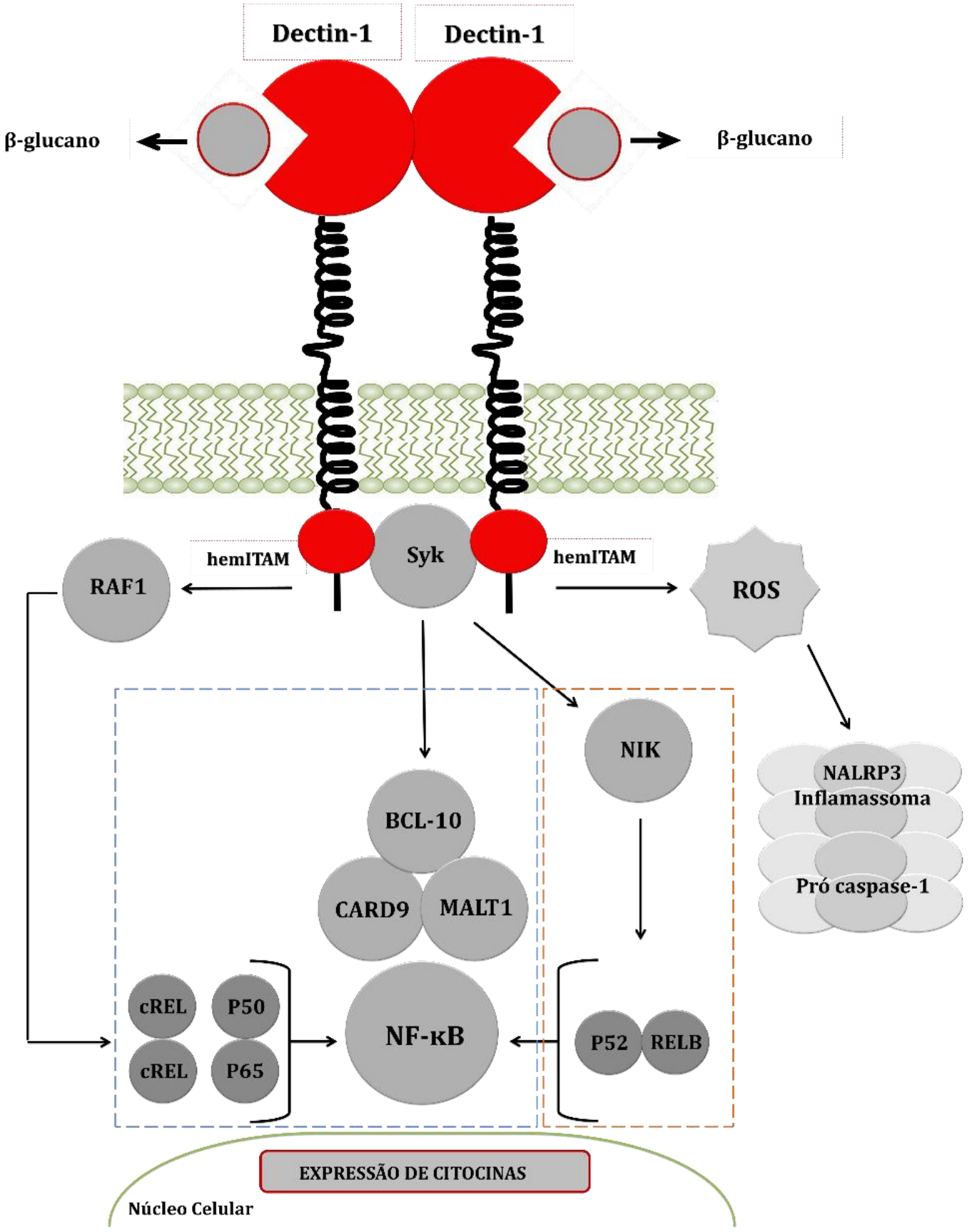

Após o reconhecimento de alvos moleculares, Dectin-1 recruta Syk através de uma fosfotirosina no motivo hemITAM localizado em sua porção intracelular. Syk induz a produção de ROS que atua como agente microbicida e colabora para a ativação do inflamassoma NALRP3. Syk também leva à ativação de NF-kB por diferentes vias. Pela via canônica (sessão marcada com pontilhado azul), Syk recruta CARD9/BCL-10/MALT-1 para ativar p65/p50, que ativa cREL em células dendríticas humanas. Independente de CARD9, Syk também leva à ativação de NIK pela via não-canônica (sessão marcada com pontilhado laranja). Finalmente, a sinalização mediada por Dectin-1 também conduz à ativação de RAF-1 independente de Syk, o que também modula a atividade de NF-kB. Fonte: Imagem modificada de Ostrop e Lang (2017) e Wüthrich et al. (2012). 


\subsection{Dectin-1, muito além da sinalização de infecções fúngicas}

Inicialmente, a ampliação dos estudos com Dectin-1 foi estimulada pelo aumento preocupante da ocorrência de infecções fúngicas devido ao aumento do número de pacientes imunossuprimidos, seja por medicamentos ou agentes imunoterápicos que são utilizados em alergias, doenças autoimunes, doenças oncológicas, entre outras, e pacientes imunodeprimidos por doenças como câncer e AIDS (DAMBUZA; BROWN, 2015; DRUMMOND; BROWN, 2011).

$\mathrm{Na}$ última década foram descritos novos mecanismos moleculares de Dectin-1 e sua função foi relacionada à sinalização colaborativa com os receptores Toll-like (TLRs) e Syk, que têm implicações no papel de outros receptores de reconhecimento padrão não-TLR. A ativação de Dectin-1 pode influenciar a resposta imune resultante de uma infecção e, em situações específicas, pode desencadear o surgimento de doenças autoimunes (GOODRIDGE et al., 2011; BROWN, 2008).

O interesse em Dectin-1 se expandiu, gerando o desenvolvimento de novas pesquisas para a compreensão de seus mecanismos subjacentes à imunidade protetora contra patógenos fúngicos (OSTROP; LANG, 2017). Chiba e colaboradores (2014) sugerem que seja necessário a realização de análises estruturais mais detalhadas da interação de Dectin-1 com seus alvos moleculares para que sua função seja melhor compreendida. Porém, a estrutura completa de hDectin-1 ainda não era desconhecida.

Embora outras proteínas com função de receptor tenham sido associadas à sinalização decorrente do reconhecimento de $\beta$-glucanos e, consequentemente, ao reconhecimento de patógenos fúngicos, a utilização de antagonistas específicos e anticorpos monoclonais mostrou claramente que Dectin-1 é o principal receptor mediador dessa atividade em leucócitos, especialmente em macrófagos e DC (ROGERS et al, 2005; WILLMENT et al., 2005; GANTNER et al., 2003). Dectin-1 também pode se ligar a outras moléculas que não os $\beta$ glucanos, como as micobactérias, que não contêm $\beta$-glucanos em sua parede celular, sugerindo que ainda pode haver ligantes exógenos não identificados para Dectin-1 a serem descobertos (WAGENER et al., 2018; YADAV; SCHOREY, 2006; ARIIZUMI et al., 2000).

Além de estar envolvida na sinalização de infecções fúngicas, foi descrito que Dectin1 desempenha um importante papel nas respostas imunes antitumorais, sendo observado que alguns tumores cresceram mais rapidamente em camundongos que não possuíam a proteína Dectin-1 ativa (CHIBA et al., 2014). Também foi demonstrado recentemente por Castoldi e 
colaboradores (2017) que Dectin-1 está correlacionada com a polarização de macrófagos próinflamatórios, com a resistência à insulina e obesidade.

Dectin-1 afeta a polarização de macrófagos ativando o fator regulador de interferon 5 (IRF5) na via Dectin-1/Syk durante respostas imunes à infecção fúngica (DEL FRESNO et al., 2013). O IRF5 é necessário para a diferenciação dos macrófagos inflamatórios presentes no tecido adiposo, que desempenham um papel importante na resistência à insulina induzida pela obesidade (KRAUSGRUBER et al., 2011). Foi visto que, no tecido adiposo de indivíduos obesos, ocorre uma maior expressão de Dectin-1 e que isso estimula a polarização de macrófagos M1, podendo contribuir para a diminuição da sensibilidade à insulina e indicando que a ativação de Dectin-1 contribui para o desenvolvimento de resistência à insulina e obesidade em humanos (CASTOLDI et al., 2017).

Em macrófagos, Dectin-1 também pode ser ativada diretamente por vimentina, proteína da família dos filamentos intermediários encontrada em muitos tipos de células e presentes em placas ateroscleróticas (PLUMMER et al., 2012). A associação de Dectin-1 e vimentina contribui para que ocorra oxidação de lipídeos, acúmulo de colesterol e desenvolvimento de aterosclerose, porém essa interação de Dectin-1 e vimentina necessita de mais estudos para ser melhor compreendida (CASTOLDI et al. 2017; THIAGARAJAN et al., 2013; ELSORI et al., 2011). A expressão aumentada de vimentina no tecido adiposo de humanos obesos e a interação direta entre Dectin-1 e vimentina no tecido adiposo (CASTOLDI et al. 2017) destacam o potencial de Dectin-1 em pesquisas para o desenvolvimento de alvos terapêuticos para a obesidade em seres humanos.

Foi identificado um importante papel para a Dectin-1 em doenças que causam processos inflamatórios crônicos (CASTOLDI et al., 2017), indicando que Dectin-1 pode ter implicações terapêuticas como um possível biomarcador para doenças que causem quadro de desregulação metabólica em humanos. O estudo de Castoldi e colaboradores (2017) mostrou que Dectin-1 é importante para a homeostase da glicose sistêmica, controlando o acúmulo de macrófagos pró-inflamatórios no tecido adiposo e mantendo o estado saudável de microbiota intestinal. Portanto, Dectin-1 pode ser um importante alvo terapêutico para o tratamento da inflamação crônica não resolutiva associada à pacientes obesos e resistentes à insulina.

Apesar de Dectin-1 ser mais conhecida por sua função no reconhecimento de $\beta$ glucanos, essa proteína de membrana foi originalmente identificada como um receptor para células T e, logo, também pode reconhecer ligantes endógenos (KIMBERG; BROWN, 2008; ARIIZUMI et al., 2000). No entanto, houve pouco progresso na identificação da natureza e papel fisiológico da interação de Dectin-1 com células T. O gene que codifica Dectin-1 está 
localizado dentro de um grande aglomerado de moléculas com características e funções semelhantes, o complexo natural killer. É possível que Dectin-1 reconheça alvos proteicos endógenos, sendo está uma implicação apoiada por evidências de que esse ligante de células T é sensível a proteases (KIMBERG; BROWN, 2008; WILLMENT et al., 2001). Também foi proposto que a interação de Dectin-1 com seu alvo endógeno estimulasse e ativasse a proliferação de células T (GRÜNEBACH et al., 2002; ARIIZUMI et al., 2000), sendo já comprovado que o reconhecimento de células T não é inibível por $\beta$-glucanos, indicando que Dectin-1 pode ter dois sítios de reconhecimento específicos, um para $\beta$-glucanos e outro para células T (KIMBERG; BROWN, 2008).

Daley e colaboradores (2017), descreveram a interação de Dectin-1 com a proteína galectin-9 em células de carcinoma ductal do pâncreas de camundongos e humanos. Essa interação Dectin-1/galectin-9 resultou na ativação de macrófagos tolerogênicos e supressão da atividade imune adaptativa que desencadeou a progressão tumoral. Os autores também relataram que, a interrupção da interação entre Dectin-1 e galectin-9 ou o bloqueio da interação de Dectin-1 com Syk após ativação por galectin-9, retardou a progressão do tumor em células de camundongo e humanas, sugerindo que o direcionamento da sinalização de Dectin-1 pode ser uma estratégia valiosa para o desenvolvimento de imunoterapia para carcinoma ductal do pâncreas.

\subsection{Caracterização estrutural de hDectin-1}

A hDectin-1 é uma proteína de membrana do tipo II, classificada como uma lectina do tipo C não clássica, pertencente ao grupo V (REDELINGHUYS; BROWN, 2011; HOLLMIG et al., 2009). É composta por 247 aminoácidos, possui uma porção citoplasmática N-terminal, seguida por um domínio transmembranar e uma porção extracelular C-terminal que é dividida em duas porções, sendo a primeira porção um domínio denominado Stalk (traduzido para o português como Haste) que se inicia logo após o domínio transmembranar (KIMURA et al., 2014; TSONI; BROWN, 2008) e a segunda porção é o C-type lectin-like domain (CTLD) (figura 3A) (YOKOTA et al., 2001; HOLLMIG et al., 2009).

Diferente de muitos CLRs, Dectin-1 apresenta um único CTLD na porção extracelular e um único motivo imunorreceptor de ativação baseada em tirosina (ITAM) no domínio intracelular (REDELINGHUYS; BROWN, 2011; KERRIGAN; BROWN, 2009) (figura 3B). 
Figura 3 - Caracterização estrutural de hDectin-1.

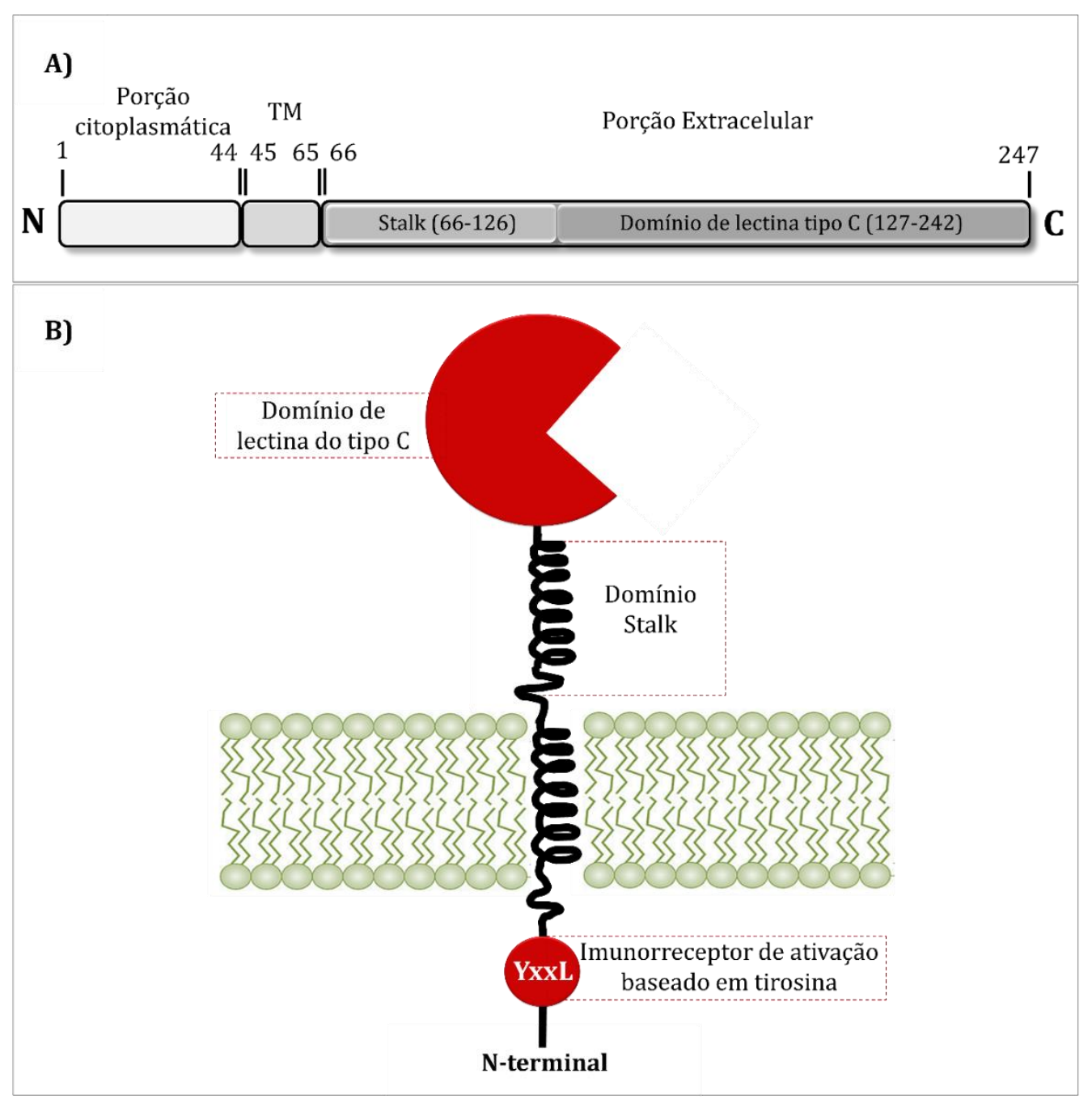

A) A região N-terminal intracelular é composta por 44 aminoácidos, seguida por uma porção transmembranar de 21 aminoácidos e a porção extracelular C-terminal composta por 182 aminoácidos. Fonte: Imagem criada com base em informações disponíveis no UniProt (Q9BXN2, CLC7A_HUMAN). B) Estruturalmente, o C-type lectinlike domain é conectado pelo domínio stalk à região transmembranar e, posteriormente, a região citoplasmática $\mathrm{N}$ terminal, que apresenta um motivo hemITAM. Fonte: Imagem modificada de Ostrop e Lang (2017) e Tsoni e Brown (2008).

O motivo ITAM de hDectin-1 é denominado hemITAM por ser formado por uma única sequência YxxL em sua porção citoplasmática N-terminal. A sinalização via Dectin-1 depende do seu motivo hemITAM citoplasmático, que se assemelha a sequências encontradas em outras proteínas sinalizadoras (MONTEIRO; LEPENIES, 2017).

As sequências ITAM tradicionais consistem de uma repetição em tandem de sequências YxxL/I que, durante a interação com seu alvo molecular e no agrupamento com outras proteínas como, por exemplo, NIK e RAF1, é fosforilado pela proteína tirosina quinase (do inglês, tyrosine-protein kinase SRC). Isso leva a interação e ativação de Syk ou ZAP-70 (proteína quinase associada à cadeia zeta 70 em linfócitos) e promove o início dos eventos de 
sinalização subsequentes, como fagocitose ou ativação celular (KERRIGAN; BROWN, 2011 b).

Até o momento não são conhecidas estruturas tridimensionais de nenhum domínio ou fragmento da proteína hDectin-1, apenas estruturas tridimensionais do domínio extracelular de mDectin-1, permanecendo o domínio intracelular e transmembranar sem estrutura conhecida (figura 4).

Figura 4 - Representação do conhecimento estrutural de mDectin-1 e hDectin-1.

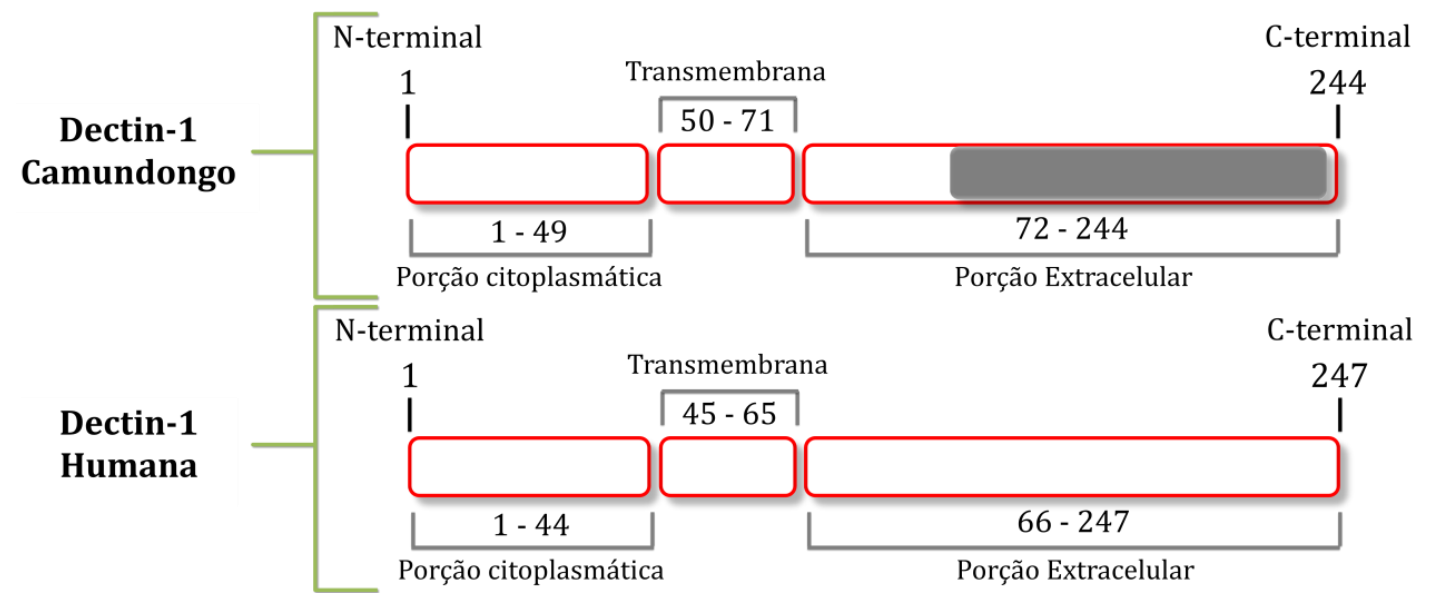

Os retângulos com contorno em vermelho e sem preenchimento mostram as porções das proteínas que não possuem estrutura conhecida. Representada pelo retângulo preenchido em cinza, apenas a estrutura tridimensional de grande parte da porção extracelular de mDectin-1 é conhecida. Todas as estruturas tridimensionais, disponíveis no PDB, do domínio extracelular de mDectin-1 compreendem os aminoácidos de 113 a 244 . Fonte: Arquivo pessoal.

Até o momento quatro estruturas de parte do domínio extracelular de mDectin-1 obtidas experimentalmente por meio de cristalografia e difração de raios-X estão depositadas no Protein Data Bank ${ }^{1}$ (PDB) (PDB_ID: 2BPD, 2BPE, 2BPH e 2CL8). Essas estruturas depositadas no PDB foram determinadas por Brown e colaboradores (2007), que investigaram o reconhecimento de $\beta$-glucanos pelo domínio extracelular de mDectin-1 e apresentaram resultados estruturais e funcionais que descrevem um possível sítio de ligação de mDectin-1 para $\beta$-glucanos e o provável mecanismo de sinalização celular mediada por Dectin-1, porém ainda não é conhecida a estrutura do domínio intracelular e transmembranar de mDectin-1.

Visto que, para melhor compreender a função de uma proteína e como ocorre sua interação com alvos moleculares é importante conhecer e analisar sua estrutura tridimensional

\footnotetext{
${ }^{1}$ http://www.rcsb.org/
} 
completa (PETREY et al., 2015), destaca-se a importância dos estudos para determinação estrutural de proteínas.

\subsection{Reconhecimento de $\beta$-glucanos pelo CTLD e sinalização via Syk pelo hemITAM de Dectin-1}

A interação de Dectin-1 com $\beta$-glucanos é possível devido à presença do C-type lectinlike domain em Dectin-1. Ao interagir com um $\beta$-glucano particulado, o motivo ITAM é fosforilado e fica pronto para interagir com Syk. Essa sinalização transmembranar pode induzir a produção de várias citocinas e quimiocinas, incluindo fator de necrose tumoral (TNF), ligante de quimiocina CXC 2 (CXCL2, também conhecido como MIP2), IL-2, IL-10 e IL-12, também pode induzir o estouro respiratório e captação de ligantes por fagocitose e, possivelmente, endocitose (LEGENTIL et al., 2015; BROWN, 2006).

Os glucanos são os polissacarídeos mais difundidos na natureza. A maioria desempenha o papel de componente estrutural da parede celular em diferentes organismos, outros são usados como fonte energética para o metabolismo. Existe uma grande diversidade em relação ao peso molecular e conformação, dependendo da fonte de origem (SYNYTSYA; NOVAK, 2014; SUGAWARA et al., 2004). Apesar da composição monossacarídica simples, os glucanos podem ter centenas ou milhares de unidades monossacarídicas, demonstrando grande variabilidade estrutural e configuração anomérica das unidades de D-glicose (Dglucopiranose, D-Glcp), posição e distribuição das ligações glicosídicas, tamanho molecular, tipo e grau de ramificação. Existem três tipos estruturais principais destes polissacarídeos: $\alpha$ glucanos, $\beta$-glucanos e $\alpha, \beta$-glucanos mistos (RUTHES et al., 2015; SYNYTSYA; NOVAK, 2014; SYNYTSYA; NOVAK, 2013).

De acordo com a estrutura anomérica da D-Glcp, é possível distinguir $\alpha$-D-glucanos, $\beta$-D-glucanos e mistos $\alpha, \beta$-D-glucanos. Outras diferenciações podem ser feitas com base na posição de ligação glicosídica no anel piranóide, distribuição de ligações glicosídicas específicas ao longo de uma cadeia, ramificação e massa molecular. A diferenciação adicional pode ser feita com base nas posições de ligação glicosídicas (comumente $(1 \rightarrow 3)$ ), mas também por ligações do tipo $(1 \rightarrow 3 ; 1 \rightarrow 6),(1 \rightarrow 6),(1 \rightarrow 3 ; 1 \rightarrow 4)$ ou massa molecular (SYNYTSYA; NOVAK, 2013).

Os $(1 \rightarrow 3)-\beta$-D-glucanos são conhecidos por terem atividades imunomoduladoras e antitumorais (CHIFFOLEAU, 2018; ZHAO et al., 2016; SYNYTSYA; NOVAK, 2013). 
Diversos estudos tem usado $\beta$-D-glucanos agonistas da Dectin-1 para induzir respostas imunológicas antitumorais em vários tipos de câncer (CHIFFOLEAU, 2018).

Outros estudos, como o de Baldwin e colaboradores (2015), mostrou que a administração intraocular de $\beta$-D-glucanos particulados induziu regeneração axonal por meio da interação com Dectin-1, exibindo células imunitárias na retina. Bao e colaboradores (2017) relataram ter obtido um potente efeito similar ao uso de antidepressivos mediado por Dectin-1 após administração do $\beta$-D-glucano lentinan. Assim, a compreensão dos mecanismos de interação entre Dectin-1 e $\beta$-glucanos tem grande importância terapêutica. Outros estudos apresentam $\beta$-glucanos fúngicos que foram quimicamente modificados para se obter derivados solúveis em água com potencial importância industrial ou medicinal (WIATER et al., 2011).

O reconhecimento de $\beta$-glucanos e substâncias imunogênicas de um patógeno por células apresentadoras de antígenos, como DC e macrófagos, pode aumentar a ativação de células $\mathrm{T}$ específicas para patógenos. Por tanto, Dectin-1 pode modular várias respostas imunológicas para doenças infecciosas, não apenas pela ativação da imunidade inata, mas também pela imunidade adquirida específica do antígeno (ADACHI et al., 2004).

A modulação dessas respostas está diretamente ligada às interações proteína-proteína que, para serem totalmente compreendidas, é necessário o conhecimento estrutural da proteína e seus domínios. Logo, os $\beta$-glucanos agonistas da Dectin-1 possuem potencial como adjuvantes de vacinas que podem facilitar respostas imunes protetoras contra patógenos ou câncer em camundongos modelo e pacientes humanos. Dado esse potencial, é importante caracterizar em detalhes a função da hDectin-1 em comparação com as evidências acumuladas para a mais estudada mDectin-1 (TAKANO et al., 2017).

A sinalização celular iniciada por Dectin-1 ocorre por meio do recrutamento de Syk, esta interage diretamente com o motivo hemITAM fosforilado de Dectin-1 por meio dos seus domínios SH2. Após o reconhecimento de $\beta$-glucanos pelo CTLD localizado na porção extracelular C-terminal de Dectin-1, o motivo hemITAM intracelular de Dectin-1 é fosforilado por proteínas tirosina quinases da família Src e atrai Syk, ocorrendo a transdução de sinal (KIMURA et al, 2014; BATBAYAR et al., 2012; BROWN, 2006; ROGERS et al., 2005).

A proteína Syk contém dois domínios SH2 em tandem e um domínio de tirosina cinase no terminal C. Os domínios SH2 são ligados por regiões especificas da proteína, denominadas Interdominíos A e B. O Interdomínio A se localiza entre os dois domínios SH2-1 e SH2-2 e o Interdomínio B entre o domínio SH2-2 e o domínio quinase (MÓCSAI et al., 2010).

Inicialmente, se pensava que dois resíduos de tirosina fosforilada eram necessários na composição de uma única cadeia peptídica (como em um motivo ITAM clássico) para que 
houvesse o recrutamento e ativação de Syk. Entretanto, a família de lectinas do tipo C, incluindo os receptores Dectin-1 e CLEC2, são capazes de ativar Syk, embora esses receptores tenham apenas um único motivo YxxL (hemITAM) em sua porção citoplasmática (ROGERS et al., 2005). Alguns estudos sugerem que Syk é autossuficiente e pode fosforilar as tirosinas dos ITAM ou a tirosina de um hemITAM (MÓCSAI et al., 2010; ROGERS et al., 2005; TURNER et al., 2000).

Embora a natureza exata da interação entre Syk e Dectin-1 não esteja totalmente clara (MARAKALALA et al., 2011), alguns estudos sugerem que Syk constrói uma ponte sobre duas moléculas monofosforiladas de Dectin-1 (BROWN, 2006; FULLER et al., 2007; GOODRIDGE et al., 2009; ROGERS et al., 2005). O desenvolvimento de estudos para a análise estrutural da interação entre Dectin-1 e Syk podem trazer mais informações sobre os mecanismos de interação entre essas duas proteínas. A estrutura de partes da proteína Syk humana é conhecida. Algumas estruturas dos domínios SH2 e Interdominíos foram obtidas experimentalmente por meio de cristalografia e difração de raios-X e estão depositadas no Protein Data Bank (PDB_ID: 4FL3, 4FL2, 1A81, 1CSZ e 1CSY), viabilizando o desenvolvimento de estudos in silico para análise de interação entre hDectin-1 e Syk, faltando apenas o conhecimento da estrutura de hDectin-1.

\subsection{Oligomerização cooperativa de Dectin-1 no reconhecimento de $\beta$-glucanos}

Os domínios de lectina do tipo $\mathrm{C}$, presentes na conservada família de proteínas lectinas, se associam através de várias superfícies diferentes para formar dímeros e trímeros, a partir dos quais os sítios de ligação se projetam em uma variedade de orientações diferentes (DRICKAMER, 1999) (figura 5A).

A observação do evento de oligomerização de Dectin-1 foi descrito em alguns estudos ao longo das últimas duas décadas (ANAYA et al., 2020; DULAL et al. 2018; BROWN et al., 2007). Dos três estudos, dois utilizaram apenas o $\beta$-glucano laminarin e observaram a indução da oligomerização cooperativa desencadeada por este $\beta$-glucano (DULAL et al. 2018; BROWN et al., 2007). Em 2007, Brown e colaboradores descreveram que conseguiram, por meio de métodos experimentais in vitro, obter a estrutura de um dímero para mDectin-1 (figura 5B) que, naquele momento, foi considerado possivelmente inviável in vivo devido a ausência de informações que sustentassem a possibilidade daquela conformação ocorrer naturalmente. Em 2018, Dulal e colaboradores descreveram a observação da formação de tetrâmeros de mDectin1 induzidos pelo $\beta$-glucano laminarin (figura 5C) e relataram não ter observado a presença de 
dímeros ou trímeros. Em 2020, Anaya e colaboradores também descreveram a observação da oligomerização de Dectin-1, porém, a forma como esse evento ocorreu foi vinculada ao tipo, tamanho e quantidade de $\beta$-glucanos disponíveis na superfície celular. Assim, ainda não existe um consenso para como ocorre a oligomerização de Dectin-1, se ela está ou não vinculada ao tipo e/ou biodisponibilidade desses $\beta$-glucanos.

Figura 5 - Oligomerização de Dectin-1.

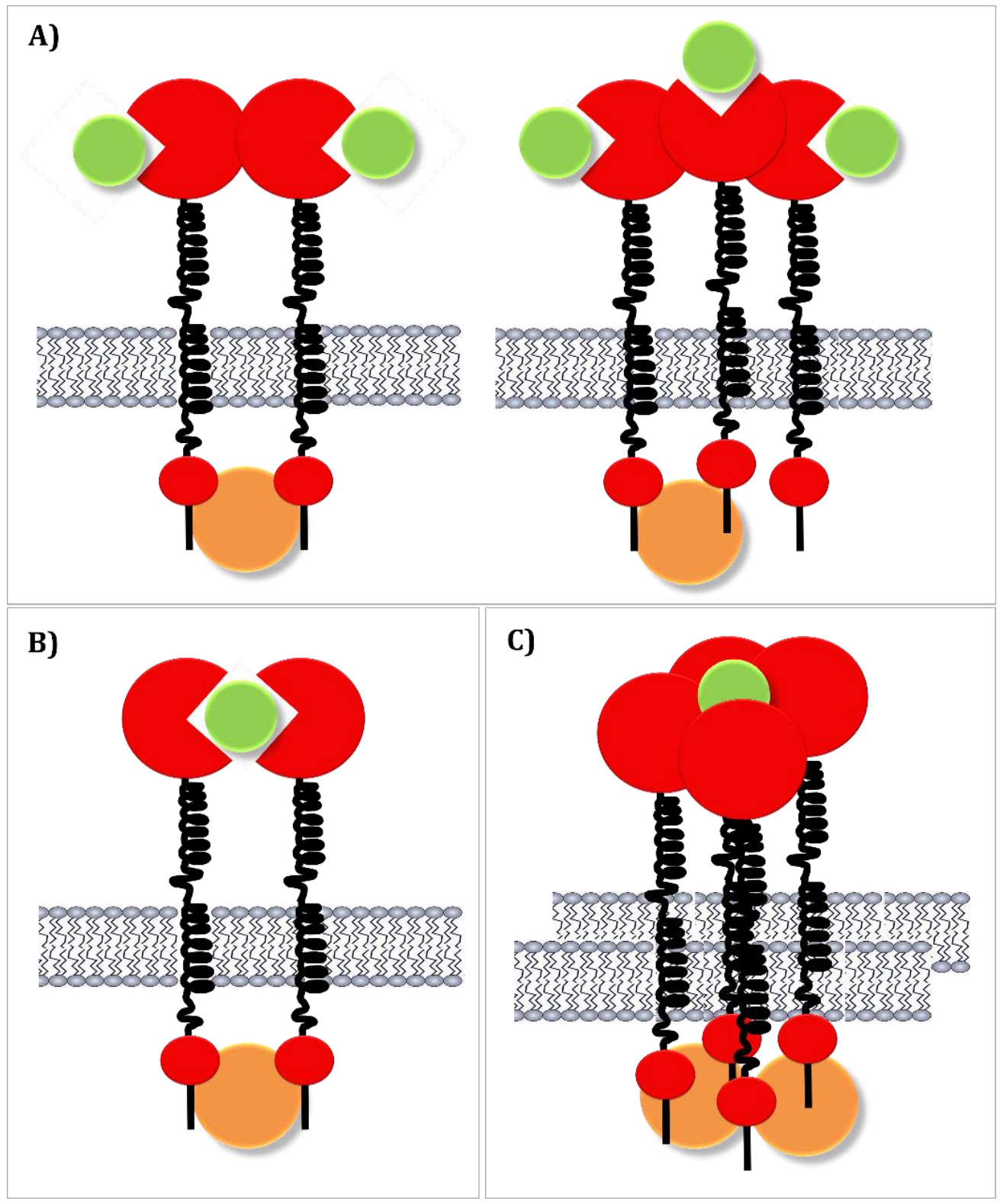

O CTLD de Dectin-1 é representado pelas esferas vermelhas maiores, o motivo hemITAM é representado pelas esferas vermelhas menores, os $\beta$-glucanos são representados pelas esferas verdes, Syk é representada pelas esferas laranja e a membrana celular está representada em cinza. A) Oligomerização dos CTLD de proteínas da família das lectinas sugerida por Drickamer (1999). B) Representação da conformação dimérica descrita por Brown e colaboradores (2007). C) Representação da conformação tetramérica induzida por $\beta$-glucanos descrita por Dulal e colaboradores (2018) e Anaya e colaboradores (2020). Fonte: Arquivo pessoal. 
É provável que, a oligomerização cooperativa do CTLD de Dectin-1 induzida por $\beta$ glucanos, ocorra subjacente ao agrupamento desses receptores para formar regiões de alta densidade de hemITAM na superfície celular interna, facilitando a interação com Syk e consequente propagação de sinais intracelulares. Faltam informações estruturais para melhor compreensão desses eventos, mas um tetrâmero com domínios intracelulares de Dectin-1 na superfície celular pode aumentar a chance de atividades de interação com Syk e fosforilação da tirosina presente no hemITAM, mais do que o alcançado pela ponte de apenas dois monômeros receptores (DULAL et al., 2018). Assim, se fazem necessários mais estudos estruturais para ampliar o conhecimento dos mecanismos pelo qual ocorre a oligomerização de Dectin-1.

\subsection{O progresso do desenvolvimento de novas terapias a partir do conhecimento estrutural de proteínas}

Na última década, houve o crescimento das pesquisas que exploraram o potencial dos medicamentos baseados em genes para estender os tratamentos atuais empregando proteínas e compostos químicos. No entanto, o progresso foi mais lento do que o previsto originalmente, devido ao conhecimento limitado dos componentes genéticos das principais doenças, à complexidade do desenvolvimento de agentes biológicos ativos como terapias e aos testes rigorosos e demorados necessários para garantir a segurança antes da administração dessas substâncias (DYER; HERRLING, 2020). A tecnologia do DNA recombinante deu origem ao desenvolvimento de proteínas recombinantes e proteínas de fusão como alternativa promissora de tratamento para as mais diversas patologias genéticas (DYER; HERRLING, 2020; YANG et al., 2016).

As proteínas de fusão ou quiméricas são proteínas criadas por meio da união de dois ou mais genes que originalmente codificam proteínas distintas. Originalmente, as proteínas de fusão mutantes ou quiméricas ocorrem naturalmente quando uma mutação complexa, como translocação cromossômica, duplicação em tandem ou retrotransposição, cria uma nova sequência de codificação contendo partes das sequências de codificação de dois genes diferentes (YANG et al., 2016). As proteínas de fusão de ocorrência natural são comumente encontradas em células cancerígenas, onde podem funcionar como oncoproteínas. Atualmente, as proteínas de fusão são desenvolvidas usando o conhecimento estrutural e funcional prévio que permite construir uma proteína com características funcionais que supram ou cumpram uma determinada função (DYER; HERRLING, 2020; YANG et al., 2016). 
A construção de proteínas de fusão é empregada para melhorar as propriedades ou conferir novas funcionalidades às proteínas. As características bioquímicas de enzimas ou proteínas funcionais aprimoradas por fusão incluem melhoria da eficiência catalítica, estabilidade, atividade, expressão, secreção e solubilidade (YANG et al., 2016).

$\mathrm{Na}$ última década, novas enzimas quiméricas ou proteínas recombinantes com atividade ou estabilidade catalítica melhorada foram construídas pela tecnologia de fusão, que se tornou um método novo e eficaz para a construção de enzimas (YANG et al., 2016; YANG et al. 2014; LU et al. 2013).

A fusão de proteínas tornou-se uma estratégia importante na indústria farmacêutica (SCHMIDT et al. 2015). Foi demonstrado que tratamentos criados a partir de partes especificas de proteínas em fusão com partes do domínio Fc de anticorpos ou proteínas transportadoras (por exemplo, albumina sérica humana) podem alcançar efeitos terapêuticos aprimorados (YANG et al., 2016; CHEN et al. 2013 (a); GRUBB et al. 2008).

Alguns medicamentos com proteínas de fusão foram aprovados pela Food and Drug Administration (FDA), e estão disponíveis no mercado. Entre esses medicamentos estão o Ontak ${ }^{\circledR}$, desenvolvido com a fusão das proteínas interleucina-2 e toxina diftérica, e o Arcalyst ${ }^{\circledR}$ desenvolvido com a fusão do domínio extracelular do receptor da interleucina-1 e Fc-IgG1 (CHEN et al. 2013 (b)). Recentemente, Le Quellec e colaboradores (2019) relataram que obtiveram sucesso na criação da proteína de fusão hFIX empregada no tratamento da hemofilia B. As propriedades pró-coagulantes da proteína de fusão hFIX foram comparáveis ao hFIX do tipo selvagem, se mostrando um grande avanço para o desenvolvimento de terapia eficiente para o controle da hemofilia B.

Petrey e colaboradores (2015) destacaram a importância dos estudos para determinar estruturas de proteínas para poder, a partir da estrutura, melhorar a compreensão da função e definir como ocorre a interação dela com seus alvos moleculares.

Se as proteínas alvo e os parceiros proteicos tiverem estruturas conhecidas, seja a partir da determinação estrutural in silico ou experimental, a fusão de proteínas para o desenvolvimento de terapias especificas pode ser otimizada por simulações computacionais de dinâmica molecular (YANG et al., 2016). Assim, é vista mais uma importante aplicação do conhecimento estrutural de proteínas no desenvolvimento de métodos terapêuticos, ampliação do conhecimento na área da biologia molecular e medicina personalizada. 


\subsection{Bioinformática estrutural}

Dados estimados pelo UNIPROT CONSORTIUM e colaboradores (2011), mostram que uma parte muito pequena (menos de 1\%) das sequências de proteínas encontradas em bancos de dados de sequências tiveram suas funções analisadas experimentalmente (SAYERS et al., 2011).

As abordagens computacionais oferecem uma solução viável para este problema. A bioinformática estrutural é a área da bioinformática relacionada à análise e predição de estruturas tridimensionais de macromoléculas biológicas, como proteínas, RNAs e DNAs. Os métodos de bioinformática para determinar a estrutura e inferir a função de proteína continuam sendo desenvolvidos e melhorados (PETREY et al., 2015; PETREY; HONIG, 2014).

Os métodos experimentais mais conhecidos para a determinação da estrutura tridimensional de proteínas são a cristalografia e difração de raio- $X$ e espectroscopia mediante ressonância magnética nuclear. Esses e outros métodos experimentais são muito eficientes quanto à precisão da predição estrutural, porém, a grande diversidade de proteínas existentes limita o sucesso desses métodos para todas elas. As limitações estão diretamente relacionadas ao tamanho da sequência de aminoácidos de determinadas proteínas ou ao fato de que uma quantidade considerável de proteínas ou segmentos delas não forma estruturas cristalinas como, por exemplo, proteínas transmembranares (PETREY et al., 2015; KRYSHTAFOVYCH; FIDELIS, 2009; FLOUDAS et al., 2006).

A modelagem de estruturas de proteínas por métodos in silico tem como objetivo determinar como uma sequência primária de aminoácidos se dobra para atingir sua conformação funcional. Essa estrutura modelada poderá ser empregada em estudos com objetivo final de alcançar novas informações sobre sua função e comportamento estrutural (KHAN et al., 2016; DWYER, 2001). O folding (em português dobramento) de proteínas é um processo inteiramente físico que depende da sequência primária de aminoácidos da proteína e do solvente circundante (KHAN et al., 2016).

A estrutura tridimensional de uma proteína é composta por diferentes níveis estruturais, sendo eles: A estrutura primária, composta unicamente pelos aminoácidos em ordem transcricional; estrutura secundária, definida pelo padrão das ligações de hidrogênio entre os aminoácidos, é a forma tridimensional de segmentos locais da proteínas, se formam espontaneamente como intermediário antes que a proteína se dobre em sua estrutura terciária (NADEAU; DEBER, 2013; PIROVANO; HERINGA, 2010); a estrutura terciária é o arranjo tridimensional das estruturas secundárias, determinado por ligações não covalentes entre as 
cadeias laterais dos aminoácidos ou, em alguns casos, por ligações covalentes como as pontes de dissulfeto (KYTE, 2006); e a estrutura quaternária corresponde a duas ou mais cadeias polipeptídicas, idênticas ou não, que, por meio de ligações não covalentes ou covalentes, interagem para formar a estrutura total da proteína, sendo que, em determinadas situações, essa será a conformação funcional da proteína (NADEAU; DEBER, 2013; KLOTZ et al., 1970).

Os métodos de modelagem in silico de proteínas fornecem o caminho para obtenção de novas e estáveis estruturas (KHAN et al., 2016). Os métodos mais empregados na modelagem de proteínas in silico são: a modelagem comparativa ou por homologia; a modelagem por threading; e a modelagem por ab initio.

A modelagem por homologia continua sendo o método mais preciso em contraste com outros métodos disponíveis, pois a determinação da estrutura desconhecida de uma proteína parte da estrutura de uma proteína já conhecida como molde. A precisão estrutural global atingida por modelos obtidos por homologia, podem ser semelhantes aos obtidos experimentalmente por espectroscopia com ressonância magnética nuclear (RMN) ou cristalografia com difração de raios-X, estando a precisão estrutural relacionada a qualidade do molde e percentual de identidade entre as sequências de aminoácidos do molde e alvo (KHAN et al., 2016; SANCHEZ; ŠALI, 1997). Quando não são encontradas estruturas molde com percentual de identidade satisfatório (superior a 30\%) entre as sequências ou relação funcional previamente descrita (WATERHOUSE et al., 2018; XU et al., 2005), poderão ser utilizados métodos de predição de estrutura por threading ou ab initio.

O método de modelagem por threading, ou reconhecimento de dobras, determina a estrutura de uma proteína alinhando fragmentos da sequência alvo com diferentes estruturas tridimensionais já conhecidas, cada fragmento pode ser modelado usando uma estrutura molde, ao final, os fragmentos são unidos e ajustados. A fragmentação da proteína para a determinação de sua estrutura parte da premissa que: o número de dobras diferentes existentes na natureza é pequeno; e que $90 \%$ das novas estruturas depositadas no PDB nos últimos anos têm dobras estruturais semelhantes às já existentes e previamente identificadas (KHAN et al., 2016; XU et al., 2005).

Os métodos de predição de estruturas por $a b$ initio ou de novo, referem-se a um processo algorítmico pelo qual a estrutura terciária da proteína é prevista a partir de sua sequência primária de aminoácidos, com ou sem informações estruturais prévias para a sequência alvo (XU; ZHANG, 2012). Os métodos de modelagem por ab initio usam, em maioria, algoritmos baseados em estatística com informações prévias sobre sequências para 
otimizar o processo de predição da estrutura nativa (XU; ZHANG, 2013; OSGUTHORPE, 2000).

Além dos métodos in silico para predição de estruturas de proteínas, existem métodos de ancoragem (do inglês docking). O principal objetivo dos métodos de docking molecular é a predição do "encaixe" (interação) entre estruturas tridimensionais, sejam elas proteínas, RNAs, DNAs, peptídeos ou pequenas moléculas químicas (VAKSER et al., 2014). Assim como os métodos de predição de estruturas, os métodos de ancoragem também passam por etapa de avaliação por meio de métodos com funções de pontuação para identificar as estruturas e interações estruturais mais prováveis de ocorrer na natureza (VAKSER et al., 2014; LIWO et al., 2008).

A predição de sítios ativos e dokcing molecular, associados a informações experimentais, são ferramentas fundamentais para a compreensão das interações entre estruturas tridimensionais de biomoléculas. Esse conhecimento é a via para a compreensão de como as complexas redes de interação regulatória e metabólica nos sistemas vivos ocorrem (KHAN et al., 2016). O docking molecular é um método computacional que tenta prever a orientação mais favorável de uma estrutura molecular em relação a estrutura de outra molécula para formar um complexo estável (SHAKIL et al., 2012). Os sítios ativos ou de ligação nas superfícies das proteínas desempenham um papel central em suas funções. A identificação desses sítios de ligação é frequentemente o primeiro passo para estudar as funções das proteínas e o design de fármacos com base em estrutura. $\mathrm{O}$ sítio ativo pode ser previsto usando várias ferramentas de bioinformática, com a possibilidade de comparar a sequência de aminoácidos da proteína com o modelo e outras proteínas semelhantes para identificar características funcionais semelhantes e conservadas (KHAN et al., 2016).

Estruturas tridimensionais de proteínas preditas in silico ou experimentalmente precisam ser avaliadas. Além da avaliação estática dos modelos, também deve ser realizada avaliação dinâmica por meio de simulação de dinâmica molecular com objetivo de observar o comportamento estrutural da proteína em um ambiente similar ao sistema biológico onde ela estaria naturalmente inserida (DURRANT; MC CAMMON., 2011; KUKOL et al., 2008).

A simulação de dinâmica molecular (DM) compreende um conjunto de metodologias computacionais que calcula o comportamento dependente do tempo e outras variáveis de um sistema molecular. Este método é muito valioso para a compreensão do comportamento dinâmico de proteínas em diferentes escalas de tempo, para analisar mudanças conformacionais ou mesmo o processo de enovelamento de proteínas e o comportamento de complexos proteicos (DURRANT; MC CAMMON, 2011). Também é possível analisar o comportamento das 
moléculas de determinados solventes em conjunto com a estrutura de proteínas, obtendo informações importantes sobre a estabilidade e propriedades do sistema biomolecular (DURRANT; MC CAMMON, 2011; VAN GUNSTEREN et al., 2008).

As simulações de DM podem ser implementadas para avaliar as preferências conformacionais de estruturas de proteína, assim como para buscar informações mais profundas sobre suas funções e interações com os ambientes circundantes ao nível atômico (KHAN et al., 2016; KARPLUS; MCCAMMON, 2002).

O estudo analítico das propriedades de tais sistemas complexos é uma tarefa desafiadora e, portanto, as simulações de DM fornecem uma solução por meio de métodos matemáticos. Representa uma interface entre estudos experimentais e in silico, e pode ser usada como um experimento efetivo, investigando a ligação entre estrutura molecular, função e seu movimento (CHAVENT et al., 2016; KHAN et al., 2016).

As simulações de DM são utilizadas em diversas áreas das ciências biológicas, para estudar os processos dinâmicos e complexos que ocorrem em sistemas biológicos, incluindo o folding de proteínas, estabilidade estrutural de proteínas, reconhecimento e interação molecular, mudanças conformacionais, desenvolvimento de fármacos, determinação de estruturas tridimensionais, reações enzimáticas e transporte de íons em sistemas biológicos (CHAVENT et al., 2016; KARPLUS; KURIYAN, 2005).

Os métodos descritos acima viabilizaram a modelagem da estrutura tridimensional completa da proteína hDectin-1 e seu emprego em estudos para ampliar a compreensão dos mecanismos pelo qual ocorre sua interação com alvos moleculares já conhecidos como os $\beta$ glucanos e proteínas relacionadas à sua via de sinalização celular como a proteína Syk. Sendo o conhecimento estrutural algo que muito pode contribuir no desenvolvimento de estudos que ampliem a compreensão funcional e interação entre proteínas e seus alvos moleculares, a determinação da estrutura tridimensional do receptor celular hDectin-1 foi de extrema importância, uma vez que esse conhecimento estrutural poderá ser empregado em estudos de interação proteína-proteína e proteína-ligante onde Dectin-1 poderá ser usada como objeto de estudo ou alvo terapêutico. 


\section{HIPÓTESE}

A partir do conhecimento da estrutura tridimensional completa de hDectin-1 se torna possível ampliar o conhecimento acerca dos locais de interação com alvos moleculares e alcançar mais informações sobre sua atuação nas vias de sinalização celular, melhorando assim a compreensão da sua função. 


\section{OBJETIVO GERAL}

Determinar a estrutura tridimensional completa de hDectin-1 e analisar a interação com seus alvos moleculares $\beta$-glucanos e Syk.

\subsection{Objetivos Específicos}

- Analisar o comportamento dinâmico da estrutura completa e domínios funcionais de hDectin-1 por meio de simulações de dinâmica molecular;

- $\quad$ Analisar o sítio de ligação de hDectin-1 presente no C-type lectin-like domain que reconhece $\beta$-glucanos e o motivo hemITAM presente no domínio intracelular;

- Analisar a interação molecular entre hDectin-1 e seus alvos moleculares por meio de docking molecular com $\beta$-glucanos e proteína Syk. 


\section{MATERIAL E MÉTODOS}

A figura 6 representa o fluxograma das atividades que foram desenvolvidas durante o processo de determinação da estrutura tridimensional de Dectin-1 humana e análises de interação proteína-proteína e proteína-ligante com a estrutura obtida. Para simplificar a leitura e arranjo dos resultados em figuras e tabelas, a partir deste ponto, Dectin-1 humana será denominada hDectin-1 ao longo do texto, em imagens e legendas.

Figura 6 - Fluxograma do processo de determinação e análise estrutural in silico de hDectin-1.

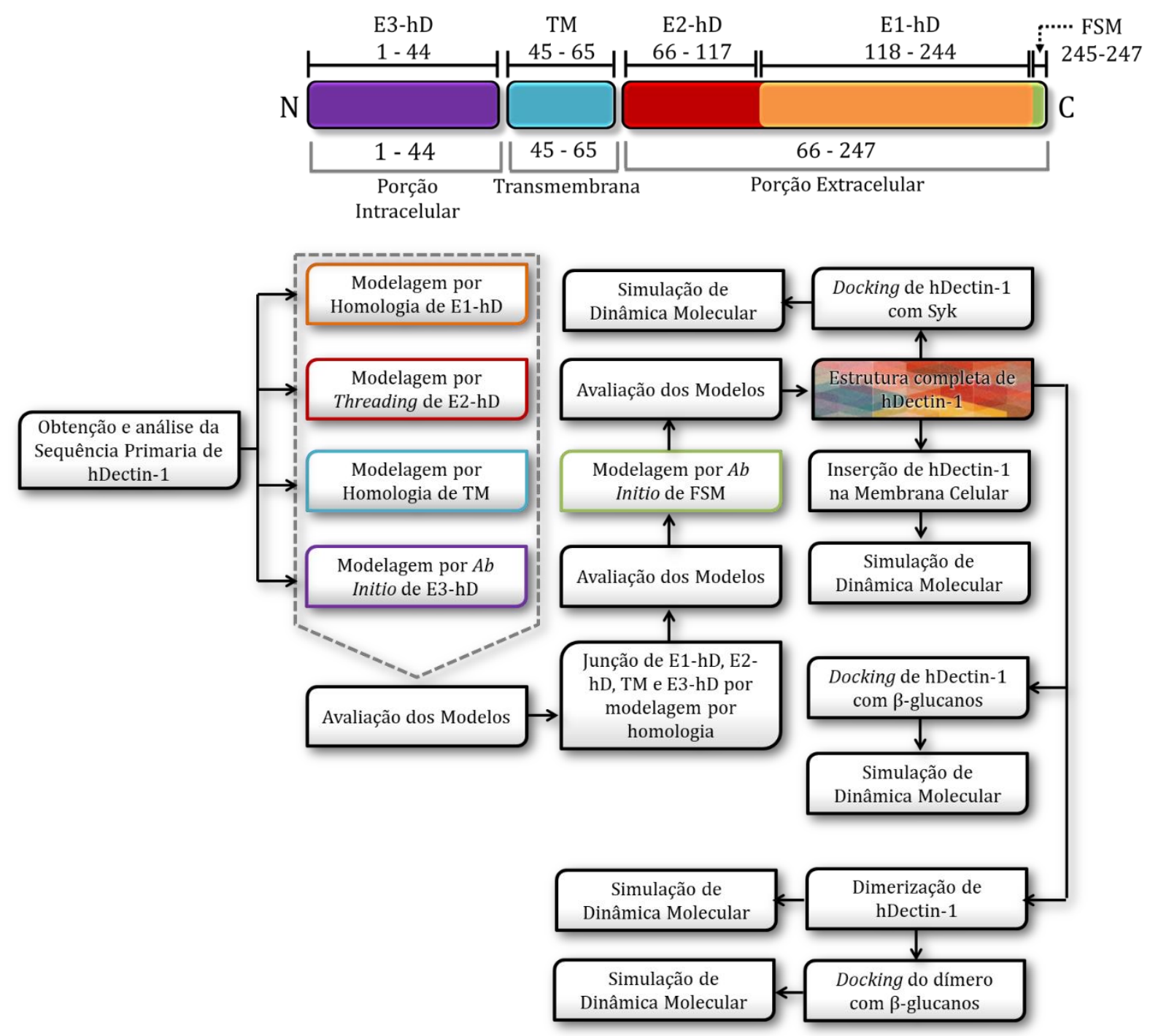

Fonte: Arquivo pessoal. 


\subsection{Obtenção da sequência primaria e análise das estruturas secundárias}

As sequências primárias de hDectin-1 e mDectin-1 foram obtidas nos repositórios públicos $\mathrm{NCBI}^{2}$ e UniProt ${ }^{3}$, os identificadores são: hDectin-1 AY026769.2 (GenBank) e Q9BXN2 (UniProt); mDectin-1 AF262985.1 (GenBank) e Q6QLQ4 (UniProt).

A predição de estrutura secundária e domínio transmembranar foram realizados por meio do servidor PRALINE (SIMOSSIS; HERINGA, 2005).

Para a predição de estrutura secundária o servidor PRALINE (SIMOSSIS; HERINGA, 2005) implementa os softwares DSSP (KABSCH; SANDER, 1983) e PSIPRED (JONES, 1999), fornecendo como resultado final o consenso dos resultados dos dois softwares.

A predição da região de domínio transmembranar foi realizada também pelo servidor PRALINE (SIMOSSIS; HERINGA, 2005), que oferece a opção de predição realizada por três softwares diferentes: HMMTOP v2.1 (TUSNADY; SIMON, 2001), PHOBIUS (KÄLL et al., 2005) e TMHMM v2.0 (KROGH et al., 2001). O software HMMTOP v2.1 prevê a localização de $\alpha$-hélices transmembranares na topologia de proteínas transmembranares usando modelo oculto de Markov (TUSNADY; SIMON, 2001), PHOBIUS faz a predição da localização de $\alpha$ hélices transmembranares na topologia de proteínas usando modelo oculto de Markov combinado com informações obtidas em banco de dados de sequências de proteínas como o Uniprot (KÄLL et al., 2005) e TMHMM v2.0 que também prevê a localização de $\alpha$-hélices transmembranares na topologia de proteínas usando modelo oculto de Markov (KROGH et al., 2001). Os diferentes softwares são usados para que o usuário do servidor PRALINE tenha a opção de verificar o consenso dos resultados obtidos pelos três softwares na predição da localização de $\alpha$-hélices transmembranares.

\subsection{Modelagem Molecular por Homologia}

O método de modelagem por homologia foi empregado na determinação das estruturas tridimensionais de parte da porção extracelular (E1-hD) e domínio transmembranar (TM) de hDectin-1. Também foi usado para fazer a junção de todas as porções modeladas por diferentes métodos in silico.

\footnotetext{
${ }^{2}$ http://www.ncbi.nlm.nih.gov

${ }^{3} \mathrm{http}: / /$ www.uniprot.org/
} 
Para realizar a modelagem por homologia nas diferentes etapas da presente pesquisa, foi usado o software MODELLER 9.19 (WEBB; SALI, 2016; WEBB; SALI, 2014). O software MODELLER 9.19 determina a estrutura tridimensional para uma sequência de aminoácidos (alvo) fundamentada, principalmente, no alinhamento da sequência alvo com uma ou mais sequências de proteínas com estruturas já conhecidas (molde). Sua metodologia é dividida em três principais etapas: Identificação e seleção da proteína molde; alinhamento entre a sequência alvo e o(s) molde(s); e construção das coordenadas do modelo (WEBB; SALI, 2016).

Em cada etapa de modelagem por homologia foram gerados dez modelos que, posteriormente, foram avaliados e o melhor, com base nos resultados da avaliação, foi escolhido para representar a estrutura tridimensional da sequência de interesse.

\subsection{Modelagem Molecular por Threading}

Para a modelagem da porção corresponde ao domínio Stalk (E2-hD), localizado na porção extracelular de hDectin-1, foi usado o método threading implementado pelo servidor ITasser $^{4}$ (ROY et al., 2010).

Diferente da modelagem por homologia, que se baseia na disponibilidade de uma estrutura homóloga e alinhamento total da sequência alvo com o molde, o método de modelagem por threading tem como principal diferença a fragmentação da sequência alvo, seguida pela busca de homólogos estruturais para cada fragmento. Por meio de uma biblioteca de estruturas tridimensionais já conhecida e a sequência primária de uma proteína de estrutura desconhecida, são construídos diversos modelos aproximados usando diferentes alinhamentos possíveis dos fragmentos da sequência alvo com as sequências das estruturas já conhecidas (BAKER; SALI, 2001). O método de modelagem por threading normalmente é empregado para determinar estruturas tridimensionais para sequências de proteínas que não possuem estruturas homólogas conhecidas (ZHANG, 2009).

O servidor I-Tasser determina a estrutura tridimensional de uma proteína a partir de sua sequência primária. Ele localiza estruturas já resolvidas e depositadas no PDB por uma técnica chamada de reconhecimento de dobras (do inglês fold recognition ou threading). A estrutura completa para uma sequência alvo é construída a partir da remontagem dos fragmentos localizados na etapa do reconhecimento de dobras usando o método Parallel tempering Monte Carlo (ZHANG, 2019). O servidor I-Tasser tem sido o mais utilizado para predições de

\footnotetext{
${ }^{4}$ https://zhanglab.ccmb.med.umich.edu/I-TASSER/
} 
estruturas pelo método de threading devido a sua excelente classificação como preditor de estruturas tridimensionais nas avaliações CASP (Critical Assessment of Structure Prediction) (ZHANG, 2019).

\subsection{Modelagem Molecular por Ab Initio}

Duas partes da estrutura de hDectin-1 foram modeladas por métodos ab initio. A porção intracelular (E3-hD) foi modelada por meio do servidor QUARK (XU; ZHANG, 2013; XU; ZHANG, 2012) e os três últimos aminoácidos do C-terminal (FSM) foram modelados por meio do protocolo Rosetta (BRADLEY et al., 2003).

Quando não são conhecidas estruturas tridimensionais homologas à sequência alvo e outros métodos como, por exemplo, o threading não apresentarem resultados satisfatórios, pode-se recorrer ao método de determinação de estruturas ab initio para predizer novas conformações (LESK, 2014; ZHANG, 2009).

O servidor QUARK ${ }^{5}$ (XU; ZHANG, 2013; XU; ZHANG, 2012) realiza a modelagem de proteínas por ab initio para sequências com até 200 aminoácidos. A sequência alvo é dividida em pequenos fragmentos com tamanho variável entre 1 a 20 aminoácidos, após esse processo, os fragmentos são modelados e a determinação da estrutura total ocorre a partir da montagem dos fragmentos de estruturas tridimensionais, usando como guia as informações contidas em campos de força com funções especificas de energia e potenciais interatômicos (XU; ZHANG, 2012).

O protocolo Rosetta (BRADLEY et al., 2003) inclui o software Rosetta e o servidor Robetta. A metodologia desse protocolo é dividida em duas partes principais: A primeira gera uma biblioteca de fragmentos e a segunda constrói os modelos a partir da biblioteca de fragmentos (OVCHINNIKOV et al., 2016; BRADLEY et al., 2003). Similar ao básico da metodologia do servidor QUARK (XU; ZHANG, 2013), o protocolo de modelagem ab initio do software Rosetta se distingue por ser mais complexo quanto a quantidade de informações (funções especificas de energia e potenciais interatômicos) usadas durante a montagem dos fragmentos. A complexidade do método também impõe a limitação do tamanho da sequência de aminoácidos que será modelada, nesse caso sequências de, no máximo, 10 aminoácidos (DAS; BAKER, 2008).

\footnotetext{
${ }^{5}$ https://zhanglab.ccmb.med.umich.edu/QUARK/
} 


\subsection{Avaliação dos modelos}

Foram usados diferentes softwares para a avaliação das estruturas tridimensionais modeladas pelos métodos in silico. Cada software foi responsável por avaliar um conjunto de características especificas dessas estruturas. A avaliação das estruturas foi feita por meio dos softwares QMEAN (BENKERT et al., 2010; BENKERT et al., 2008) e PROCHECK (LASKOWSKI et al., 1993) disponíveis no servidor SWISS-MODEL Workspace ${ }^{6}$ (ARNOLD et al., 2006), software ERRAT (COLOVOS; YEATES, 1993) disponível no servidor SAVES ${ }^{7}$, software ProSA-Web (WIEDERSTEIN; SIPPL, 2007), software QMEANBrane (STUDER et a., 2014) disponíveis no servidor SWISS-MODEL Workspace e software ModFOLD 4.0 (MCGUFFIN et al., 2013).

O software QMEAN (BENKERT et al., 2008) apresenta resultados para uma função de pontuação composta que estima a qualidade global da estrutura tridimensional avaliada. A função de pontuação QMEAN (sigla do inglês para Qualitative Model Energy ANalysis) consiste da combinação de descritores estruturais que comparam as características geométricas do modelo avaliado com as características geométricas de estruturas de proteínas obtidas experimentalmente com alta resolução (BENKERT et al., 2010; BENKERT et al., 2008).

O software PROCHECK (LASKOWSKI et al., 1993) calcula parâmetros estereoquímicos para estruturas tridimensionais de proteínas e os compara com valores ideais provenientes de estruturas de proteína determinadas experimentalmente com alta resolução e bem refinadas disponíveis no PDB. Os resultados correspondentes à geometria dos aminoácidos são apresentados no gráfico de Ramachandran (LASKOWSKI et al., 2006; LASKOWSKI et al., 1993).

O software ERRAT (COLOVOS; YEATES, 1993) verifica interações atômicas específicas em estruturas de proteínas afim de estimar se existem regiões com a probabilidade de conter erros. O software classifica os átomos de carbono, nitrogênio e oxigênio da estrutura avaliada e verifica se as características da distribuição das interações átomo-átomo não ligados do modelo avaliado correspondem à correta distribuição estabelecida a partir de um banco de dados de estruturas confiáveis obtidas experimentalmente com alta resolução (COLOVOS; YEATES, 1993). O software ERRAT (COLOVOS; YEATES, 1993), inicialmente, foi desenvolvido para a avaliação de estruturas tridimensionais de proteínas obtidas

\footnotetext{
${ }^{6} \mathrm{http}: / /$ swissmodel.expasy.org/workspace

${ }^{7} \mathrm{http}$ ://services.mbi.ucla.edu/SAVES
} 
experimentalmente, mas tem sido amplamente utilizado para a avaliação de estruturas tridimensionais obtidas por meio de metodologias in silico.

O software ProSA-Web (WIEDERSTEIN; SIPPL, 2007) atribui um Z-score para a estrutura tridimensional avaliada. O Z-score indica a qualidade geral do modelo e quantifica o desvio da energia total da estrutura em relação a uma distribuição de energia derivada de conformações aleatórias provenientes de estruturas de proteínas depositadas no PDB determinadas experimentalmente por espectroscopia de ressonância magnética nuclear (RMN) e cristalografia com difração de raios-X (WIEDERSTEIN e SIPPL, 2007).

O software QMEANBrane (STUDER et a., 2014) apresenta resultados para uma função de pontuação composta que estima a qualidade global da estrutura tridimensional avaliada. O software verifica se as características geométricas do modelo avaliado são compatíveis com estruturas de domínios transmembranares por meio da análise de características geométricas estruturais pré-determinadas obtidas pela análise de um conjunto não redundante de estruturas transmembranares determinadas experimentalmente com alta resolução (STUDER et a., 2014).

O software ModFOLD 4.0 (MCGUFFIN et al., 2013) faz a estimativa da qualidade global e local de estruturas tridimensionais de proteínas avaliando a compatibilidade da sua sequência de aminoácidos com a estrutura tridimensional predita (MCGUFFIN et al., 2013).

\subsection{Refinamento de Loops}

O refinamento de loops da estrutura de hDectin-1 foi feito por meio do software Modeller 9.19 (WEBB; SALI, 2014) usando o protocolo loopmodel, que permite definir a região especifica do loop a ser refinada na estrutura da proteína (FISER et al., 2000).

\subsection{Construção do sistema proteína/membrana celular}

Para a construção do sistema proteína/membrana celular que posteriormente foi submetido a simulação de DM, foi o usado o servidor CHARMM-GUI que disponibiliza o protocolo Membrane Builder (LEE et al., 2015, WU et al., 2014; JO et al., 2009; JO e KIM, 2007).

O protocolo é composto por seis etapas sequencialmente realizadas na seguinte ordem: leitura da estrutura tridimensional da proteína; orientação espacial da proteína; determinação do tamanho do sistema; determinação dos componentes da bicamada lipídica; construção dos 
componentes da bicamada lipídica; e equilíbrio do sistema (WU et al., 2014; JO et al., 2009; JO e KIM, 2007).

\subsection{Docking molecular}

\subsubsection{Predição de sítios de ligação}

A predição de possíveis sítios de ligação no CTLD de hDectin-1 e nos domínios SH2 da proteína Syk foi realizada por meio do software FTSite (NGAN et al., 2011) que faz a predição de possíveis Hot Spots na superfície da proteína.

Os Hot Spots são o subconjunto de resíduos presentes na interface da proteína que constituem a maior parte da energia livre de ligação. Esses grupos de resíduos desempenham papéis essenciais na estabilidade da ligação de proteínas. Identificar quais resíduos específicos na interface de complexos proteína-proteína ou proteína-ligante formam os hot spots é essencial para a compreensão dos princípios dessas interações, ampliando a perspectiva de aplicação em estudos para a compreensão da função de proteínas e desenvolvimento de fármacos (LIU; LIU; DENG, 2018).

\subsubsection{Docking proteína-proteína}

O docking proteína/proteína para a dimerização de hDectin-1 e o docking proteína/proteína entre o motivo hemITAM presente no domínio intracelular de hDectin-1 com os domínios SH2 da proteína Syk foram realizados por meio do servidor HADDOCK 2.2 (VAN ZUNDERT et al., 2016).

Para o docking proteína-proteína, o servidor HADDOCK 2.2 faz uso de dados experimentais como restrições de posição entre átomos para orientar o processo de ancoragem associado a cálculos de energia. Antecedendo a etapa de docking, são informados pelo usuário os resíduos ativos. Esses resíduos tem importância central para a interação proteína-proteína e durante a simulação de docking, esses resíduos ativos são restringidos para fazer parte da interface de interação entre as proteínas (VAN ZUNDERT et al., 2016).

O servidor HADDOCK emprega a metodologia de docking flexível e tem seu processo divido em três etapas principais: 1) Distribuição aleatória das orientações e minimização de energia das estruturas. As estruturas são tratadas como corpos rígidos, todos os parâmetros geométricos, como comprimentos das ligações, ângulos de ligação e ângulos diédricos, são 
congelados. As estruturas são giradas aleatoriamente sobre seus centros de massa, seguida pela etapa de minimização de energia das estruturas ainda rígidas na qual elas podem girar e se posicionar para otimizar a interação; 2) Reposicionamento das estruturas em estado semiflexível (variação dos ângulos de torção). Essa etapa introduz flexibilidade às estruturas por meio de um refinamento baseado em dinâmica molecular, a fim de otimizar a interação dos resíduos que compõem a interface de interação entre as duas estruturas; 3) Refinamento do complexo em espaço cartesiano com solvente. Essa etapa final do protocolo de docking insere o complexo em solvente (água modelo TIP3P), a fim de melhorar a energia da interação. $\mathrm{O}$ complexo é submetido a uma curta simulação de DM com temperatura de $300 \mathrm{~K}$, com restrições de posição nos átomos que não participam da interface de interação entre as proteínas (VAN ZUNDERT et al., 2016; DOMINGUEZ et al., 2003).

O protocolo HADDOCK padrão gera 1000 modelos na etapa 1, em seguida, refina os 200 melhores. Os modelos finais são agrupados automaticamente em clusters com base em uma medida de similaridade específica iL-RMSD. O ranqueamento dos clusters é feito por meio do HADDOCK score, que é a soma ponderada dos seguintes termos: energia intermolecular de Van der Waals, energia intermolecular eletrostática, energia das restrições de distância, energia de dessolvatação, energia das restrições de distância e superfície enterrada (VAN ZUNDERT et al., 2016).

\subsubsection{Docking proteína-ligante}

Os dockings entre o domínio extracelular de hDectin-1 (CTLD) e os $\beta$-glucanos foram realizados por meio do software AutoDock Vina (TROTT; OLSON, 2010) e pacote AutoDock Tolls (HUEY; MORRIS, 2008).

AutoDock Vina é um software de docking que permite prever como pequenas moléculas, como substratos ou candidatos a fármacos, se ligam a um receptor com estrutura tridimensional conhecida (TROTT; OLSON, 2010). O processo de docking por meio do AutoDock Vina é iniciado com a preparação dos arquivos (conversão para o formato PDBQT) e escolha do espaço de busca para o docking. Essa preparação é feita por meio do software AutoDock Tools (MORRIS et al., 2009), que também é uado na visualização dos resultados.

O software AutoDock Vina (TROTT; OLSON, 2010) oferece resultados para predições de conformações proteína-ligante. Seu algoritmo faz uso de uma função de pontuação empiricamente ponderada, que inclui termos para valores como ligação de hidrogênio, interação hidrofóbica (van der Waals) e busca local baseada no método do gradiente (ou declive máximo 
- steepest descent) para otimizar a busca pelo mínimo local. Diversas execuções são realizadas a partir de conformações aleatórias das moléculas. A otimização do processo mantém a seleção dos mínimos locais relevantes encontrados e os ajusta por meio do processo de refinamento e agrupamento das moléculas (TROTT; OLSON, 2010; MORRIS et al., 2009).

Cada simulação de docking com o software AutoDock Vina (TROTT; OLSON, 2010) gerou 10 estruturas em diferentes posicionamentos (poses) ranqueadas pelo score de energia das ligações em $\mathrm{kcal} / \mathrm{mol}$.

\subsection{Construção do sistema proteína/ß-glucano}

Para a construção do sistema proteína/ $\beta$-glucano que posteriormente foi submetido a simulação de DM, foi o usado o servidor CHARMM-GUI que disponibiliza o protocolo Glycan Reader \& Modeler (PARK et al., 2019; JO e KIM, 2007).

O protocolo é composto por quatro etapas principais realizadas na seguinte ordem: detecção automática e/ou informação manual da existência de estruturas sugar-like em complexo com estruturas de proteínas; determinação e atribuição do tipo correto de açúcar com base em suas características geométricas e estereoquímicas; reconhecimento de ligações glicosídicas e cadeias dos glicanos; e criação dos arquivos de topologia e campos de força (PARK et al., 2019; PARK et al., 2017).

\subsection{Análise de Interação Proteína-Ligante e Proteína-Proteína}

Os resultados provenientes dos dockings proteína/proteína foram analisados por meio do software PyMol (HOLEC; HACKEL, 2016), que permitiu identificar e descrever a interação molecular entre a superfície das proteínas por meio do script InterfaceResidues.py.

Também foi usado o servidor PDBSum (LASKOWSKI, 2001) que apresenta os resultados das análises estruturais detalhadas geradas pelos softwares PROMOTIF (HUTCHINSON; THORNTON, 1996) e PROCHECK (LASKOWSKI et al., 1993). O servidor PDBSum também apresenta os principais aspectos da estrutura, como os domínios da proteína e padrões de interações proteína-proteína e proteína-ligante que são preditos pelo software LIGPLOT (WALLACE et al., 1995). LIGPLOT fornece uma representação esquemática das ligações de hidrogênio e interações entre átomos não ligados presentes nas estruturas submetidas para análise (WALLACE et al., 1995). 


\subsection{Simulação de Dinâmica Molecular}

Foram realizadas simulações de dinâmica molecular (DM) em diferentes etapas dessa pesquisa para que todas as estruturas fossem devidamente avaliadas e analisadas.

O processo de simulações de DM ao longo do projeto consistiu de: 1) simulação de DM da estrutura tridimensional de mDectin-1 que foi usada como molde; 2) simulação de DM do domínio extracelular de hDectin-1 obtido por modelagem por homologia; 3) simulação de DM da estrutura completa de hDectin-1 na membrana celular; 4) simulação de DM dímero de mDectin-1 PDB ID 2CL8; 5) simulação de DM do dímero da estrutura completa de hDectin-1 na membrana; 6) simulação de DM do dímero do CTLD de hDectin-1; 7) simulação de DM dos complexos obtidos por docking do CTLD de hDectin-1 com $\beta$-glucanos; 8) simulação de DM dos complexos obtidos por docking do dímero dos CTLDs de hDectin-1 com $\beta$-glucanos; 9) simulação de DM do complexo obtido por docking do domínio intracelular de hDectin-1 (motivo hemITAM) e proteína Syk (PDB_ID: 1A81).

As simulações de DM foram realizadas por meio do software GROMACS (HESS et al., 2008), que implementou o campo de força CHARMM27 (SAPAY; TIELEMAN, 2011) e CHARMM36m (HUANG et al., 2017; HUANG; MACKERELL, 2013). Todos os sistemas submetidos a simulação de DM passaram por uma etapa prévia de minimização de energia e, após a minimização, os sistemas foram equilibrados por meio do próprio software GROMACS (HESS et al., 2008).

O comportamento atômico é calculado ao longo da evolução temporal dos átomos que compõe o sistema (trajetória) e, ao final do tempo de simulação de DM, foram gerados arquivos com essas informações pelo próprio software GROMACS (HESS et al., 2008). Para a análise visual das trajetórias obtidas nas simulações de DM foram gerados gráficos por meio do software Microsoft Excel (Microsoft Office 2016). As estruturas tridimensionais obtidas ao longo das trajetórias de DM foram visualizadas por meio de software PyMol (HOLEC; HACKEL, 2016).

Para cada simulação de DM foram calculados os valores de Root Mean Square Deviation (RMSD) e o Root Mean Square Fluctuation (RMSF) usando como referência os carbonos $\alpha(\mathrm{C} \alpha)$ da estrutura inicial. Para algumas simulações de DM também foi calculado o $b$-factor usando como referência a proteína total. Esses cálculos foram realizados por meio do software GROMACS (HESS et al., 2008).

O RMSD é o cálculo do desvio médio quadrático entre todos os átomos de uma estrutura tridimensional em relação a uma estrutura de referência (COHEN; STERNBERG, 
1980) e o RMSF é o cálculo do desvio médio quadrático da flutuação das posições de cada átomo da estrutura em relação a uma estrutura de referência (FUGLEBAKK et al., 2012), ao longo do tempo de simulação determinado.

Os valores de RMSF calculados a partir de simulações de DM medem a mobilidade de cada aminoácido em torno de sua posição mediana na estrutura e permitem avaliar a flexibilidade da proteína (GOGUET et al., 2017).

O b-factor, também conhecido como fator de temperatura, é uma medida de deslocamento e vibração atômica dependentes de temperatura. Apresenta uma indicação quantitativa da flexibilidade de uma estrutura proteica (SUN et al., 2019).

\subsection{Análise de Desordem Intrínseca}

Com base nas diferentes metodologias existentes, foram escolhidos três softwares para predição de regiões de desordem intrínseca na proteína hDectin-1: Softwares PONDR (XUE et al., 2010), IUPred (DOSZTÁNYI et al., 2005) e PrDOS (ISHIDA; KINOSHITA, 2007).

PONDR ${ }^{\circledR}$ apresenta como resultado o consenso da unificação das metodologias de quatro preditores, sendo eles o VL-XT, VL3, VSL2 e XL1-XT. Os preditores verificam cada aminoácido ao longo da sequência levando em consideração as características dos aminoácidos adjacentes (XUE et al., 2010; OBRADOVIC et al., 2005).

O algoritmo do servidor IUPred prevê regiões de desordem intrínseca, estimando a energia total de interação inter-resíduos com base na hipótese de que as sequências desordenadas não se enovelem devido à sua incapacidade para formar interações inter-residuos suficientemente estáveis (DOSZTÁNYI et al., 2005).

O servidor PrDOS é composto por dois preditores. O primeiro se baseia na informação contida nas interações inter-resíduos da sequência de aminoácidos e o segundo se baseia nas caraterísticas de proteínas modelo. PrDOS combina os resultados dos preditores e fornece como resultado uma previsão de dois estados (ordem/desordem) e a probabilidade de desordem para cada resíduo (ISHIDA; KINOSHITA, 2007).

Os resultados da predição de desordem intrínseca dos três preditores usados são disponibilizados em formato de tabela que exibe a pontuação individual de cada um dos aminoácidos da sequência, indicando a probabilidade de cada resíduo ser desordenado ou não. 


\subsection{Visualização e Inspeção Estrutural}

As estruturas tridimensionais foram visualizadas e inspecionadas por meio dos softwares UCSF Chimera (PETTERSEN et al., 2004) e PyMol (HOLEC; HACKEL, 2016). 


\section{RESULTADOS E DISCUSSÃO}

\subsection{Determinação estrutural de hDectin-1}

\subsubsection{Análises da estrutura primária e secundária}

Antecedendo a etapa de determinação da estrutura terciaria, foram realizadas análises para a caracterização das estruturas primária e secundária de hDectin-1. Foram também realizadas análises comparativas com sua homóloga mDectin-1 que, posteriormente, foi empregada como molde para a modelagem por homologia de parte da porção extracelular de hDectin-1.

As informações contidas no banco de dados UniProt mostram que a proteína hDectin1 (ID UniProt: Q9BXN2) é composta por 247 aminoácidos topologicamente divididos em três porções principais: Porção intracelular, transmembrana e extracelular (figura 7A). Na porção extracelular C-terminal está localizado o CTLD, que compreende os aminoácidos 127 a 242 (116 aminoácidos) e na porção citoplasmática N-terminal está localizado o motivo hemITAM que é composto pelos aminoácidos Y15, T16, Q17 e L18 (figura 7B).

Figura 7 - Arranjo topológico da estrutura primária de hDectin-1.

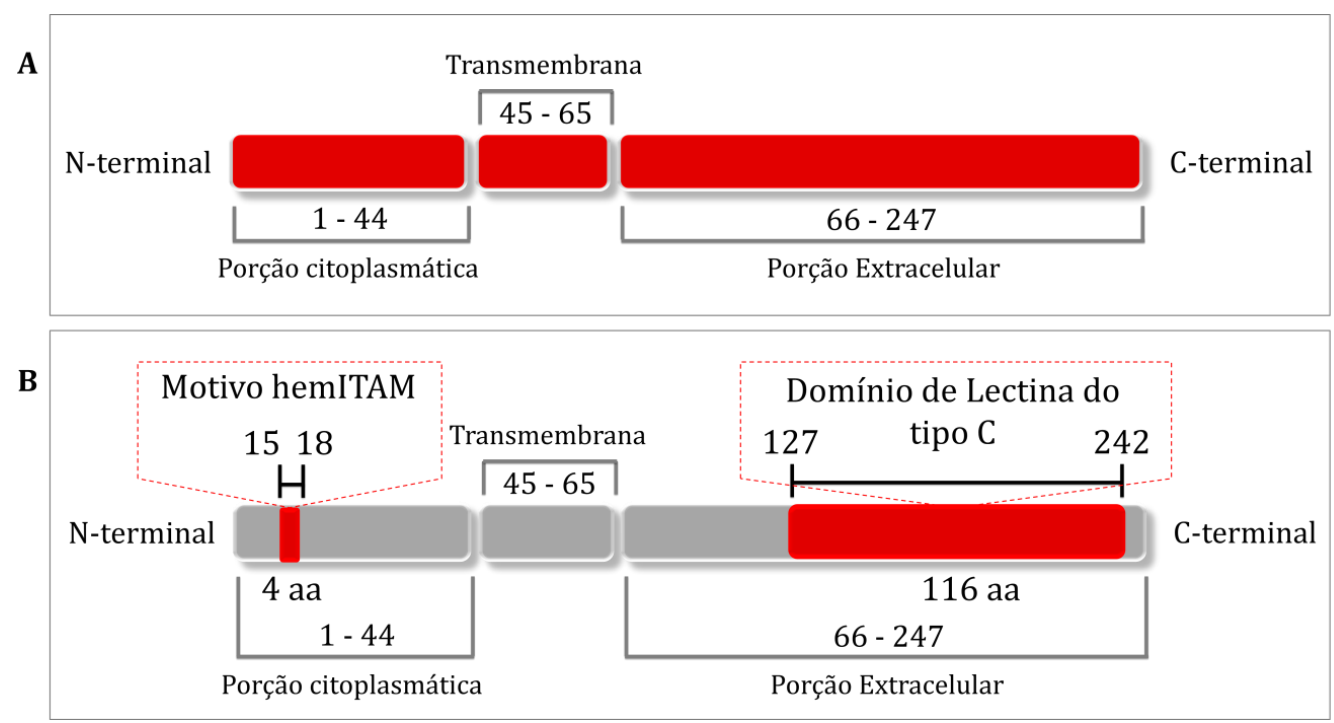

A) Região N-terminal citoplasmática composta por 44 aminoácidos, seguida por uma porção transmembranar de 21 aminoácidos e a porção extracelular C-terminal composta por 182 aminoácidos. B) Na porção citoplasmática $\mathrm{N}$-terminal é destacado em vermelho a região correspondente ao motivo hemITAM composta por 4 aminoácidos. Na porção extracelular C-terminal é desacatado em vermelho a região correspondente ao C-type lectin-like domain composto por 116 aminoácidos. Imagem criada com base em informações disponíveis no UniProt (Q9BXN2, CLC7A_HUMAN). Fonte: Arquivo pessoal. 
Foi realizado alinhamento entre as sequências primárias de hDectin-1 e mDectin-1 com o software EMBOSS Needle (LI et al., 2015). O alinhamento global das sequências completas de hDectin-1 (ID UniProt: Q9BXN2) e mDectin-1 (ID UniProt: Q6QLQ4) mostrou haver $59.5 \%$ de identidade e $71.3 \%$ de similaridade entre elas (figura 8 ).

Figura 8 - Alinhamento global feito por meio do software EMBOSS Needle entre as sequências primárias de hDectin-1 e mDectin-1.

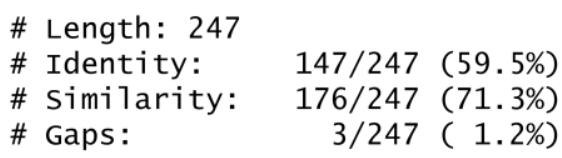

HUMAN-Q9BXN2

MOUSE-Q6QLQ4

151 LGSNLLKIDSSNELGFIVKQVSSQPDNSFWIGLSRPQTEVPWLWEDGSTF ||$::|||||:| .|\ldots||\ldots| .|| \ldots|:||||||| .|:| .|| .|||||$.

HUMAN-Q9BXN2

MOUSE-Q6QLQ4

Os aminoácidos coloridos em roxo correspondem a porção intracelular, em azul o domínio transmembranar e em vermelho a porção extracelular. Os retângulos preenchidos em laranja demarcam a localização dos C-type lectinlike domains das duas sequencias. Fonte: Arquivo pessoal.

Para complementar as análises das estruturas primárias, foi realizada a predição de estrutura secundária e região transmembranar por meio do servidor PRALINE (SIMOSSIS; HERINGA, 2003). Essas análises foram feitas com o objetivo de obter informações quanto à quantidade e localização de elementos secundários que seriam esperados nos resultados das etapas de modelagem molecular por homologia, ab initio e/ou threading.

A predição de estrutura secundária mostrou que proteína hDectin-1 é composta por 9 folhas- $\beta$ e $4 \alpha$-hélices, e mDectin-1 é composta por 9 folhas- $\beta$ e $5 \alpha$-hélices. Apesar do percentual de identidade e similaridade entre as sequências primárias não ser alto, a análise das estruturas secundárias mostrou haver alta semelhança na localização e quantidade de elementos 
secundários entre hDectin-1 e mDectin-1, sendo identificada apenas uma $\alpha$-hélice a mais em mDectin-1 composta por 6 aminoácidos (posição 97 à 102) (figura 9).

Figura 9 - Resultado da predição de elementos secundários de hDectin-1 e mDectin-1.

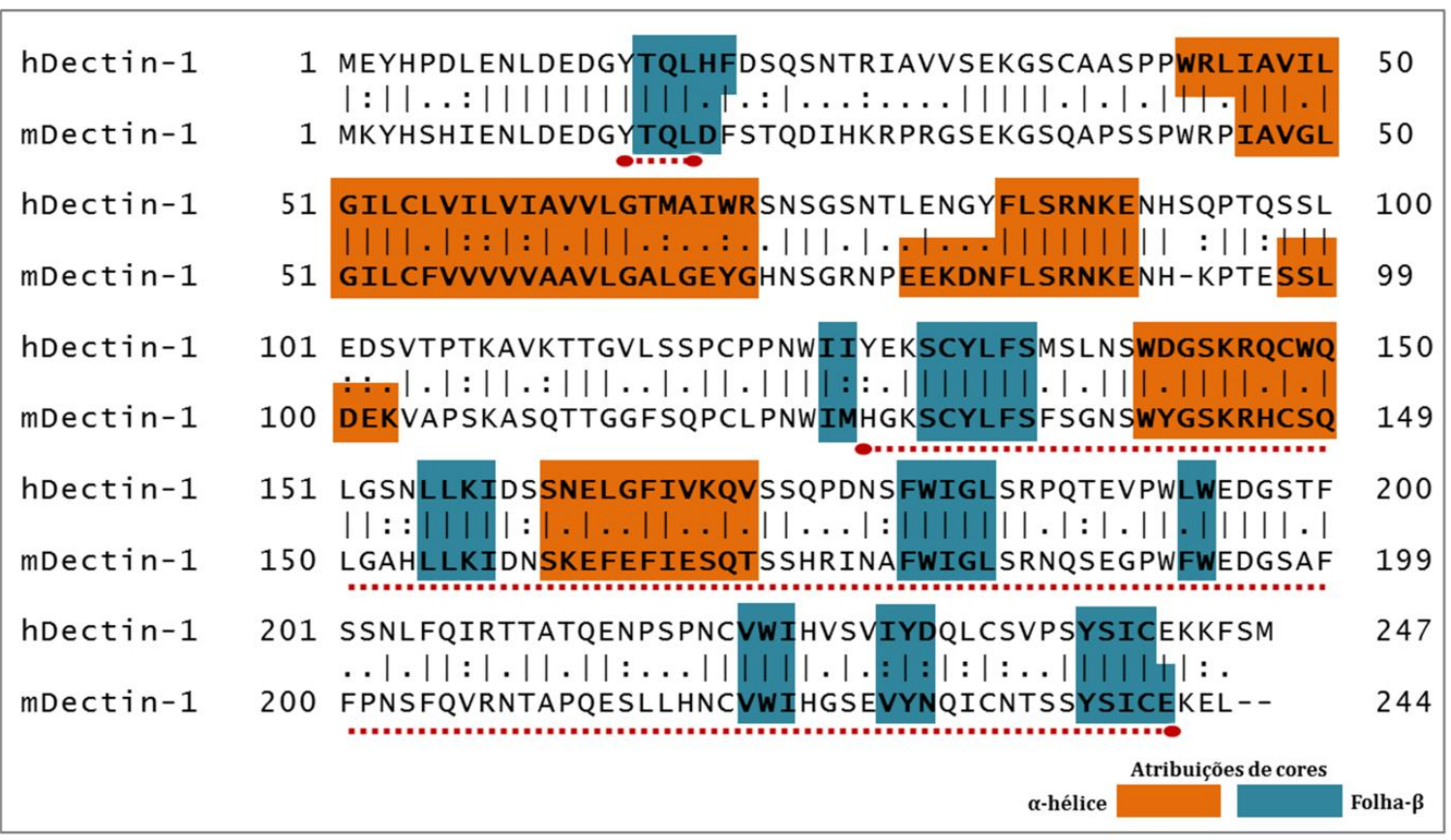

As regiões correspondentes a $\alpha$-hélices são realçadas em laranja e as folhas- $\beta$ em azul. A menor linha tracejada em vermelho mostra a localização do motivo hemITAM presente na porção citoplasmática e a maior linha tracejada em vermelho mostra a localização do C-type lectin-like domain. Fonte: Arquivo pessoal.

Apesar das estruturas primárias de hDectin-1 e mDectin-1 apresentarem apenas 59.5\% de identidade e $71.3 \%$ de similaridade, a predição de elementos secundários mostrou que a composição estrutural delas é muito semelhante, indicando que a estrutura terciária também deverá apresentar boa similaridade estrutural, uma vez que o gene CLEC7A, codificador de hDectin-1, tem alta relação filogenética com o gene de mDectin-1 (HERNANZ-FALCON et al., 2001) e que as características funcionais da proteína Dectin-1 é semelhantes nas duas espécies (WILLMENT et al., 2001).

\subsubsection{Predição da região do domínio transmembranar}

Segundo informações obtidas no banco de dados UniProt, a região transmembranar de hDectin-1 (ID: Q9BXN2) corresponde aos aminoácidos 45 a 65 e as análises experimentais realizadas por XIE e colaboradores (2006) descrevem que a região transmembranar de hDectin1 compreende os aminoácidos 44 à 68. Para verificar qual das duas informações encontradas 
na literatura deveria ser usada como referência no processo de modelagem molecular do domínio transmembranar, foi realizada a predição da região transmembranar de hDectin-1 por meio de três softwares disponíveis no servidor PRALINE (SIMOSSIS; HERINGA, 2003). Foram usados três softwares diferentes, PHOBIUS (KÄLL et al., 2005), TMHMM v2.0 (KROGH et al., 2001) e HMMTOP v2.1 (TUSNADY; SIMON, 2001) com o objetivo de verificar se também haveria discrepância entre os resultados das três ferramentas assim como foi observado na literatura.

Os resultados obtidos foram semelhantes entre os três softwares, sendo observada uma pequena variação na posição de início e termino da região transmembranar (figura 10). A predição da posição da $\alpha$-hélice transmembranar com os softwares PHOBIUS (KÄLL et al., 2005), TMHMM v2.0 (KROGH et al., 2001) e HMMTOP v2.1 (TUSNADY; SIMON, 2001) para hDectin-1 foi, respectivamente, 44-69, 43-65 e 45-69. Essa variação observada no presente resultado nas posições de início e final do domínio transmembranar de hDectin-1 apoiam as variações também encontradas da literatura (UniProt ID:Q9BXN2; XIE et al., 2006). Deste modo, serão usados como referência para a determinação estrutural do domínio transmembranar de hDectin-1 as informações obtidas no banco de dados UniProt ID:Q9BXN2 que descreve a localização do domínio transmembranar dentro dos resultados obtidos pelos três softwares e por XIE e colaboradores (2006) (figura 10).

Figura 10 - Resultado da predição da região transmembranar para hDectin-1.

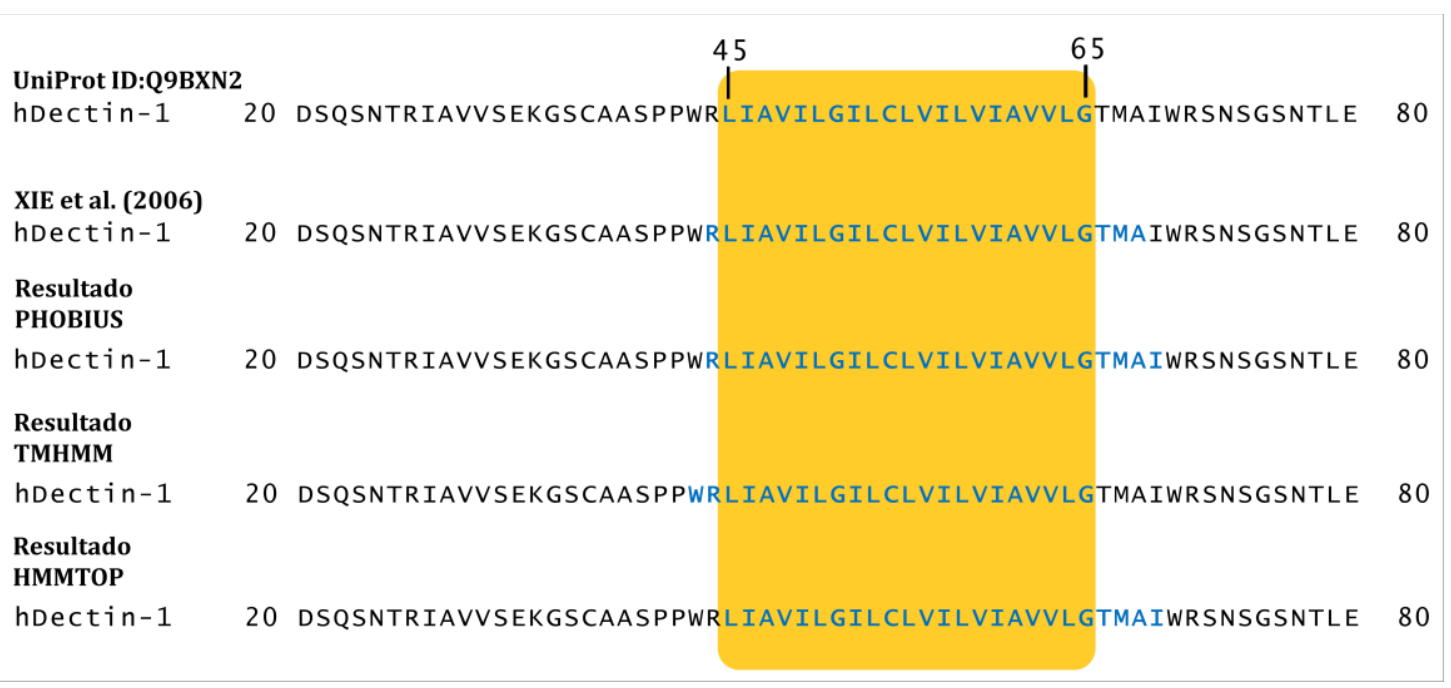

Os aminoácidos em azul correspondem a região do domínio transmembranar de hDectin-1 descritos na base de dados UniProt (ID: Q9BXN2), por XIE et al. (2006) e resultados dos softwares PHOBIUS (KÄLL et al., 2005), TMHMM v2.0 (KROGH et al., 2001) e HMMTOP v2.1 (TUSNADY; SIMON, 2001). O retângulo laranja mostra o consenso dos aminoácidos que compõe o domínio transmembranar nas duas referências e três predições. Fonte: Arquivo pessoal. 


\subsubsection{Modelagem por homologia do C-type lectin-like domain de hDectin-1}

A determinação estrutural da porção extracelular de hDectin-1 foi iniciada pela modelagem molecular por homologia do CTLD presente na porção extracelular. No Protein Data Bank, foram identificadas quatro estruturas que poderiam ser usadas como moldes. Todas foram obtidas experimentalmente por cristalografia com difração de raios-X. Os identificadores (ID), organismo e resolução das estruturas estão expressos na tabela 1.

Tabela 1 - Estruturas tridimensionais de Dectin-1 depositadas no Protein Data Bank.

\begin{tabular}{ccc}
\hline PDB ID & Organismo & Resolução \\
\hline 2BPD & Mus musculus & $1.5 \AA$ \\
2BPH & Mus musculus & $2.2 \AA$ \\
2BPE & Mus musculus & $2.25 \AA$ \\
2CL8 & Mus musculus & $2.8 \AA$ \\
\hline
\end{tabular}

Fonte: Arquivo pessoal.

A estrutura molde foi escolhida com base na resolução da cristalografia, inspeção visual das estruturas e análise das sequências, portanto, o molde escolhido para modelagem por homologia foi a cadeia A da estrutura com ID 2BPD (2BPD_A). A estrutura 2BPD_A abrange 127 aminoácidos (117 a 243) dos 174 (72 a 244) que compõem a porção extracelular de mDectin-1 e apresenta divergência de três aminoácidos, P118S, T209A e A210V em relação a sequência de mDectin-1 (ID UniProt: Q6QLQ4) (BROWN et al., 2007).

O alinhamento global feito por meio do software EMBOSS Needle (LI et al., 2015) entre as sequências primárias de 2BPD_A (molde) e o alvo (porção extracelular de hDectin-1) apresentou $42.3 \%$ de identidade (77 de 182) e 50.0\% de similaridade (91 de 182), restando $30.2 \%$ (55 de 183) de aminoácidos sem cobertura do molde (figura 11). Na figura 11 observase que a região da porção extracelular de hDectin-1 que ficou sem cobertura do molde corresponde ao domínio Stalk (aminoácidos 66 ao 117). Desta forma, em relação à função da proteína no reconhecimento de patógenos (DALEY et al., 2017; GOODRIDGE et al., 2011), a principal região da porção extracelular de hDectin-1 (C-type lectin-like domain) teve total cobertura do molde (figura 11). 
Figura 11 - Alinhamento global entre as sequências primárias do molde e o alvo.

\begin{tabular}{|c|c|c|c|c|}
\hline Q9BXN2:A1 Vo & 1 & \multicolumn{2}{|c|}{ TMAIWRSNSGSNTLENGYFLSRNKENHSQPTQSSLEDSVTPTKAVKTTGV } & 50 \\
\hline 2 BPDA: Mo $1 \mathrm{de}$ & 1 & 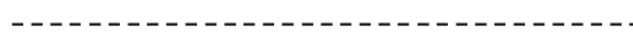 & $---1--1--1--$ & 0 \\
\hline Q9BXN2: A 1 vo & 51 & $\begin{array}{l}\text { LSSPCPPNWIIYEKSCYLFSMSLNSWDGSKRQ } \\
\quad \cdots|\cdot||||:: .||||||| \cdot|\cdot||| \cdot|||| l\end{array}$ & $\begin{array}{l}\text { LGSNLLKIDSSNELG } \\
||::|||||:| . \mid . .\end{array}$ & 100 \\
\hline 2BPDA: Mo $1 \mathrm{de}$ & 1 & - -QSCLPNWIMHGKSCYLFSFSGNSWYGSKRHC & LGAHLLKIDNSKEFE & 48 \\
\hline Q9BXN2:A1 vo & 101 & $\begin{array}{l}\text { FIVKQVSSQPDNSFWIGLSRPQTEVPWLWEDG } \\
1 \ldots 1.11 \ldots 1: 1\end{array}$ & $\begin{array}{l}\text { SSNLFQIRTTATQEN } \\
\ldots|.||:| \ldots|| \ldots:\end{array}$ & 150 \\
\hline 2BPDA: Mo $1 \mathrm{de}$ & 49 & FIESQTSSHRINAFWIGLSRNQSEGPWFWEDG & FPNSFQVRNAVPQES & 98 \\
\hline Q9BXN2: A1vo & 151 & $\begin{array}{l}\text { PSPNCVWIHVSVIYDQLCSVPSYSICEKKFSM } \\
\cdots,|||||| \cdot|\cdot:|:|:|: \ldots|||||| \mid l:\end{array}$ & 182 & \\
\hline 2 BPDA: Molde & 99 & LLHNCVWIHGSEVYNQICNTSSYSICEKE--- & 127 & \\
\hline
\end{tabular}

Os aminoácidos coloridos em verde correspondem aos C-type lectin-like domain das duas proteínas e os coloridos em vermelho mostram os aminoácidos divergentes presentes da estrutura 2BPD_A (molde) em relação à sequência primária de mDectin-1. Fonte: Arquivo pessoal.

A modelagem por homologia de parte da porção extracelular de hDectin-1 (hD-E1) foi realizada por meio do software MODELLER 9.19 (WEBB; SALI, 2014). Dez modelos de hDectin-1 foram gerados para que o melhor pudesse ser escolhido com base nos resultados da avaliação das estruturas tridimensionais.

Os dez modelos gerados para hD-E1 foram igualmente avaliados pelos softwares ERRAT (COLOVOS; YEATES, 1993), ProSA-Web (WIEDERSTEIN; SIPPL, 2007), PROCHECK (LASKOWSKI et al., 1993) e QMEAN (BENKERT et al., 2008). Cada software foi responsável por avaliar um conjunto de características estruturais específicas já descritas na metodologia.

A escolha da melhor estrutura para $\mathrm{E} 1-\mathrm{hD}$ foi feita com base na análise comparativa entre os resultados da avaliação de todos os dez modelos e o modelo escolhido foi o que apresentou o melhor resultado na maioria dos softwares usados na avaliação. A seguir estão descritos os resultados do melhor modelo para E1-hD.

$\mathrm{Na}$ análise, por meio do software ERRAT, foram verificadas as interações entre os átomos não ligados, atribuindo um fator de qualidade global expresso em porcentagem para a estrutura avaliada. O resultado do fator de qualidade global do software ERRAT para E1-hD foi de $93.5 \%$. O fator de qualidade global acima de $95 \%$ é considerando a pontuação ideal para estruturas preditas experimentalmente com alta resolução $(<2.5 \AA)$ e para estruturas com resolução mais baixa (2.5 a $3 \AA$ ) o fator de qualidade global é de 91\% (COLOVOS; YEATES, 1993). O fator de qualidade global de $93.5 \%$ de $\mathrm{E} 1-\mathrm{hD}$ está entre a faixa de $95 \%$ e $91 \%$. Assim, pode-se considerar que a qualidade global do modelo avaliado segundo os parâmetros do software (COLOVOS; YEATES, 1993) é satisfatória. 
O valor de Z-score atribuído pelo software ProSA-Web fornece um comparativo entre o modelo avaliado e Z-scores de estruturas de proteínas depositadas no PDB determinadas experimentalmente por cristalografia com difração de raios-x e RMN de tamanho similar. É esperado que o Z-score de modelos obtidos com boa qualidade esteja dentro do intervalo de distribuição de Z-scores de estruturas obtidas experimentalmente com tamanho similar, atribuindo ao modelo pouca probabilidade de erro em relação à energia conformacional da estrutura avaliada (WIEDERSTEIN; SIPPL, 2007). O Z-score para E1-hD foi -5.21, indicando que a estrutura avaliada apresenta pouca probabilidade de erro em relação a energia conformacional por exibir o Z-score dentro do intervalo de distribuição de Z-scores tipicamente encontrados para proteínas obtidas experimentalmente.

A qualidade estereoquímica foi avaliada por meio do software PROCHECK que expressa os resultados da avaliação no gráfico de Ramachandran. Com base em estruturas obtidas por métodos experimentais de alta resolução $(<2 \AA)$, é esperado que um modelo de boa qualidade tenha mais de $90 \%$ de seus aminoácidos localizados em regiões muito favoráveis (LASKOWSKI et al., 1993). Os resultados obtidos para o modelo correspondente a região E1hD mostra que, dos 127 aminoácidos que compõem o modelo, 91\% estão em regiões muito favoráveis, $7.2 \%$ estão em regiões favoráveis, nenhum aminoácido se localizou em regiões pouco favoráveis e apenas $1.8 \%$ estão em regiões desfavoráveis, deste modo, a qualidade estereoquímica de E1-hD é satisfatória (figura 12A).

A avaliação feita por meio do software QMEAN atribui um score global de qualidade para o modelo avaliado. O score global é apresentado no intervalo entre 0 e 1, onde 1 é considerado ideal. O score global é também expresso como Z-score para que seja possível relacionar esse valor com valores provenientes de estruturas obtidas experimentalmente por cristalografia com difração de raios-X de alta resolução. Valores de Z-score QMEAN próximos de zero indicam que o modelo avaliado tem qualidade compatível com estruturas obtidas experimentalmente por cristalografia com difração de raios-X de alta resolução de tamanho similar (número de aminoácidos) e valores de -4.0 ou inferiores indicam que o modelo avaliado tem baixa qualidade estrutural quando também comparado a estruturas obtidas experimentalmente com alta resolução e tamanho similar (BENKERT et al., 2010; BENKERT et al., 2008). Os valores de score global e Z-score obtidos para E1-hD são, respectivamente, 0.747 e 0.09 . No intervalo entre 0 e 1 , o score global para E1-hD de 0.747 está próximo do valor de 1 considerado ideal. O Z-score de 0.09 indica que a estrutura de E1-hD tem qualidade compatível com estruturas resolvidas experimentalmente com alta resolução como observado na figura $12 \mathrm{~B}$. 
Figura 12 - Avaliação da estrutura E1-hD, que compreende os aminoácidos 118 a 244 da porção extracelular de hDectin-1 obtida por modelagem por homologia.

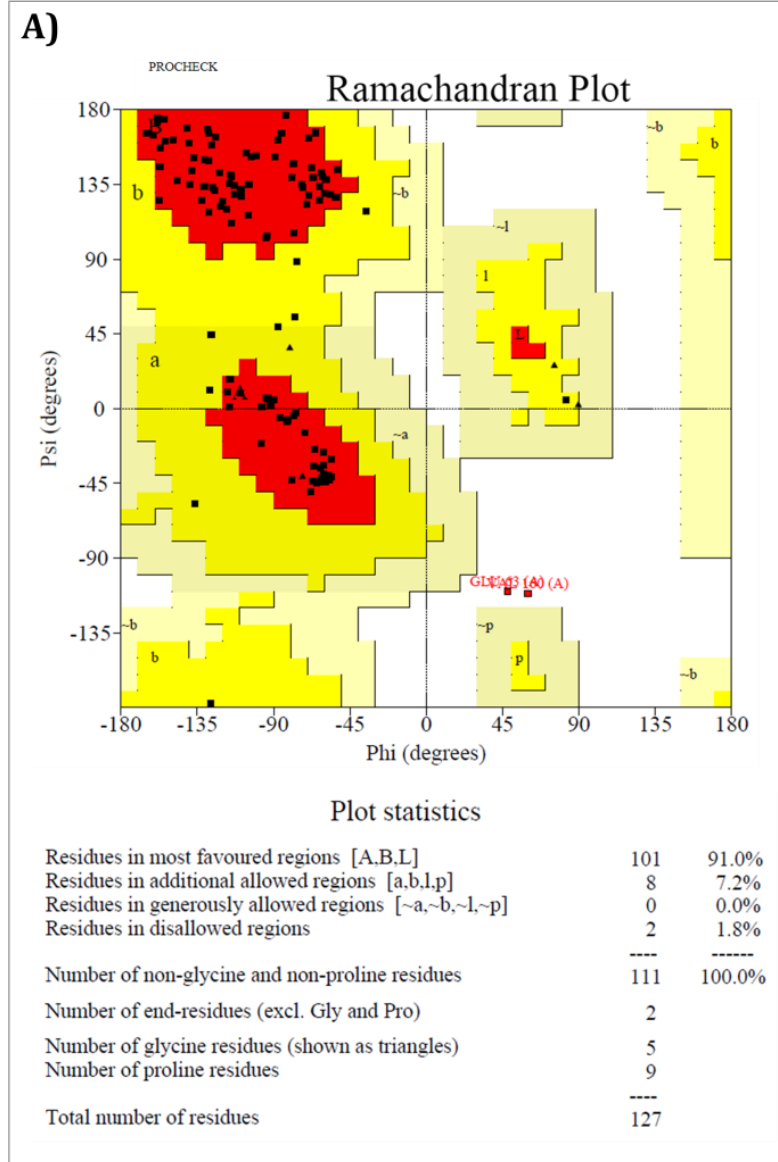

B)

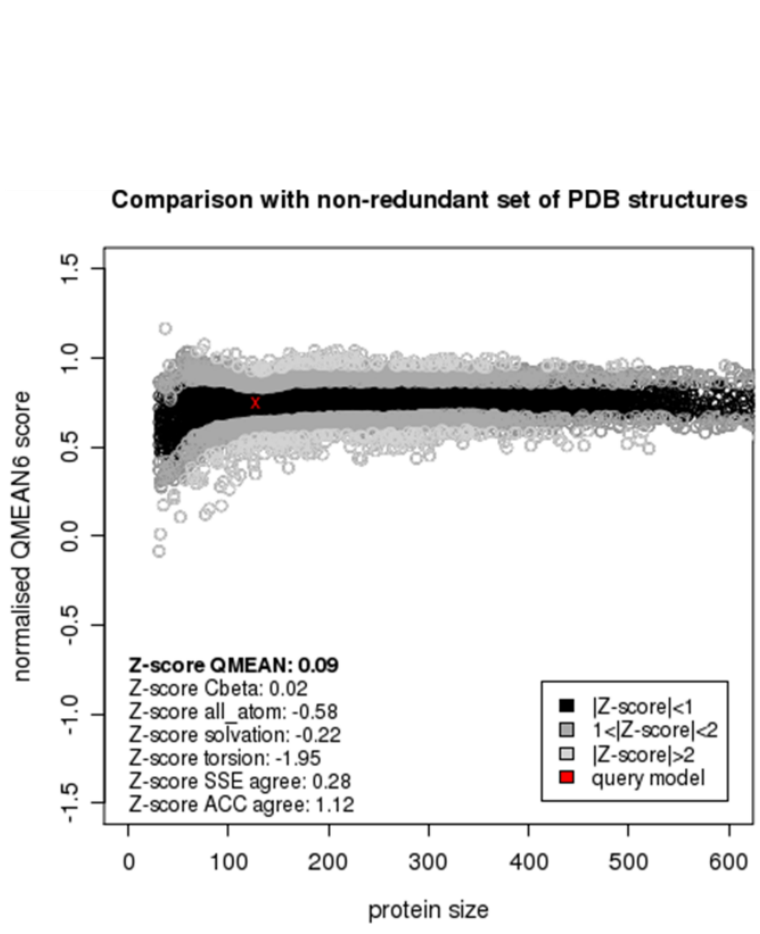

Comparison with non-redundant set of PDB structures

A) Resultados do software PROCHECK expressos no gráfico de Ramachandran (LASKOWSKI et al., 1993). Áreas em vermelho representam regiões muito favoráveis, em amarelo regiões favoráveis, em amarelo claro regiões pouco favoráveis e branco regiões desfavoráveis. Os quadrados pretos representam o posicionamento dos aminoácidos no gráfico e os triângulos pretos representam as glicinas. Modelos de boa qualidade devem apresentar mais de 90\% de seus aminoácidos localizados em regiões muito favoráveis (LASKOWSKI et al., 1993). B) Resultados do Z-score QMEAN (BENKERT et al., 2008) para a estimativa do grau de confiança das características estruturais observadas no modelo a fim de determinar o quanto a estrutura está próxima do seu enovelamento nativo. Valores de Z-score QMEAN próximos de zero indicam que o modelo avaliado tem qualidade compatível com estruturas obtidas experimentalmente por cristalografia com difração de raios-X de alta resolução de tamanho similar e valores inferiores a -4.0 indicam que o modelo avaliado tem baixa qualidade (BENKERT et al., 2008). Resultado do Z-score, onde o X vermelho indica a posição da estrutura avaliada na mesma faixa de valores $Z$ score que estruturas preditas experimentalmente. Fonte: Arquivo pessoal.

Anteriormente à etapa de modelagem por homologia da porção E1-hD, a estrutura 2BPD_A usada como molde foi igualmente avaliada pelos mesmos softwares que avaliaram E1-hD. Esse procedimento foi realizado a fim de verificar e garantir que a estrutura molde tivesse boa qualidade, uma vez que grande parte do sucesso do método de modelagem por homologia é a escolha correta de um molde com boa qualidade estrutural (MOULT et al., 2014). Os parâmetros avaliados e valores de referência foram os mesmos descritos na avaliação de E1 hD. Os resultados da avaliação do molde são vistos ao lado da avaliação de E1-hD na tabela 2. 
Tabela 2 - Comparativo entre a avaliação do melhor modelo obtido por modelagem por homologia e a estrutura 2BPD-A obtida experimentalmente usada como molde.

\begin{tabular}{|c|c|c|c|}
\hline Softwares & Valores de Referência & E1-hD & $\begin{array}{l}\text { Molde } \\
\text { 2BPD-A }\end{array}$ \\
\hline ERRAT & $>95 \%$ ou $>91 \% *$ & $93.5 \%$ & $86.23 \%$ \\
\hline ProSA-Web & $\begin{array}{l}\text { Z-score dentro do intervalo } \\
\text { de distribuição de } Z \text {-scores } \\
\text { de proteínas obtidas } \\
\text { experimentalmente com } \\
\text { tamanho similar }\end{array}$ & -5.21 & -5.79 \\
\hline QMEAN & $\begin{array}{c}\text { Valores entre } 0 \text { e } 1 \text {, sendo } 1 \\
\text { ótimo }\end{array}$ & 0.747 & 0.76 \\
\hline $\begin{array}{c}\text { PROCHECK } \\
\text { (Ramachandran } \\
\text { Plot) } * *\end{array}$ & $\begin{array}{l}>90 \% \text { de aminoácidos em } \\
\text { regiões muito favoráveis }\end{array}$ & $\begin{array}{l}\text { (A) } 91 \% \\
\text { (B) } 7.2 \% \\
\text { (C) } 0.0 \% \\
\text { (D) } 1.8 \%\end{array}$ & $\begin{array}{l}\text { (A) } 92.9 \% \\
\text { (B) } 7.1 \% \\
\text { (C) } 0.0 \% \\
\text { (D) } 0.0 \%\end{array}$ \\
\hline
\end{tabular}

*Fator de qualidade global acima de $95 \%$ é considerando a pontuação ideal para estruturas preditas experimentalmente com alta resolução $(<2.5 \AA)$ e para estruturas com resolução mais baixa $(2.5$ a $3 \AA)$ o fator de qualidade global médio é de $91 \%$ (COLOVOS e YEATES, 1993).

**Descrição das regiões energeticamente (A) Muito Favoráveis, (B) Regiões Favoráveis, (C) Regiões Pouco Favoráveis e (D) Regiões Desfavoráveis.

Fonte: Arquivo pessoal.

O comparativo dos resultados da avaliação de E1-hD e o molde mostram valores semelhantes para os resultados dos softwares ProSA-Web (WIEDERSTEIN; SIPPL, 2007) e QMEAN (BENKERT et al., 2008), deste modo é possível inferir que E1-hD modelada por homologia usando como molde a estrutura 2BPD-A obtida experimentalmente com alta

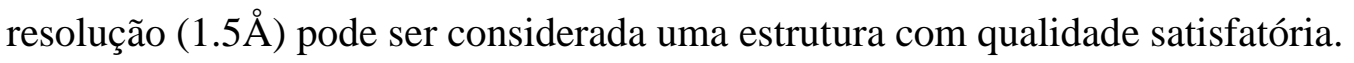

O resultado do fator de qualidade global do software ERRAT (COLOVOS; YEATES, 1993) para E1-hD (93.5\%) se mostrou melhor do que para o molde (86.23\%), deste modo, verificou-se que possíveis erros na distribuição dos átomos de carbono, nitrogênio e oxigênio não foram transferidos para a estrutura de $\mathrm{E} 1-\mathrm{hD}$ durante a modelagem por homologia. A figura 13 representa a estrutura E1-hD obtida por modelagem molecular por homologia. 
Figura 13 - Estrutura tridimensional de parte da porção extracelular de hDectin-1 denominada E1-hD que compreende os aminoácidos 118 ao 244.

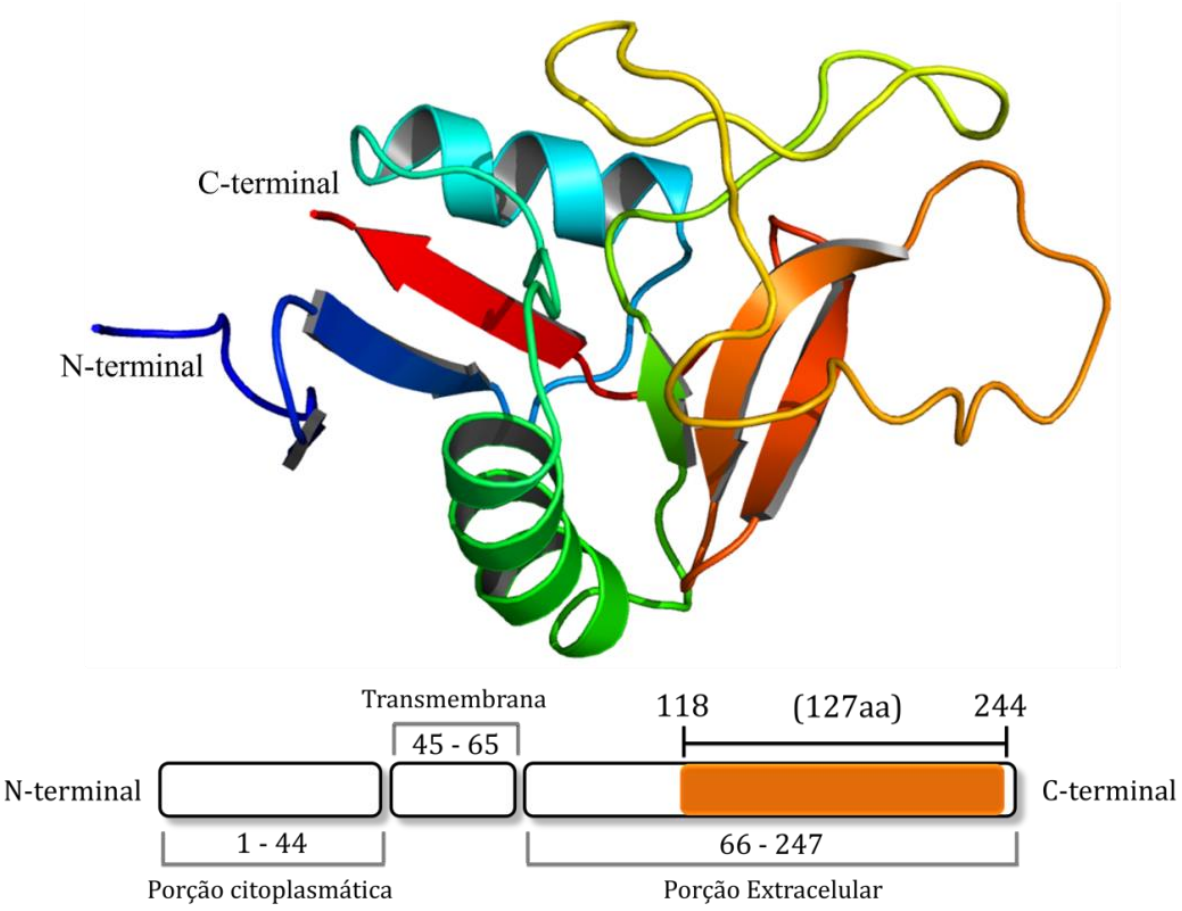

Fonte: Arquivo pessoal.

\subsubsection{Simulação de dinâmica molecular de E1-hD e molde PDB ID: 2BPD-A}

Ambas as estruturas, E1-hD e molde PDB ID: 2BPD-A, foram submetidas a simulação de dinâmica molecular (DM) para verificar se apresentariam estabilidade estrutural satisfatória e similar. Foram feitas triplicatas de simulação de DM de 100 ns para cada uma das duas estruturas.

Para as simulações de DM realizadas nessa etapa foi utilizado o software GROMACS versão 5.1.4 (ABRAHAM et al., 2015) que implementou o campo de força CHARMM27 (MACKERELL et al., 2004; MACKERELL et al., 1998). O sistema proteína/solvente para a simulação de DM foi construído com moléculas de água e íons ( $\mathrm{Na}+$ e $\mathrm{Cl}-$ ). A concentração de íons $\mathrm{Na}+$ e $\mathrm{Cl}$ - usada no sistema foi $0.15 \mathrm{M} \mathrm{KCl}$, estando essa concentração próxima da concentração fisiológica de íons (JO et al., 2008; JO et al., 2007). O sistema é do tipo cúbico, com dimensões de $72 \AA$ para hDectin-1 e $73 \AA$ A para mDectin-1 ao longo dos eixos x, y e z, sendo composto pela proteína, moléculas de água (TIP3) e íons, caracterizando o ambiente celular. 
A simulação de DM do sistema proteína-solvente foi realizada em condições físicoquímicas controladas, com temperatura máxima de $310 \mathrm{~K}\left(36.85^{\circ} \mathrm{C}\right)$ e pressão constante de 1 atm.

O comportamento molecular das estruturas ao longo do tempo foi analisado por meio do RMSD, RMSF, raio de giro e alinhamento das estruturas nos tempos inicial e final de simulação de DM.

A figura 14A apresenta os resultados de RMSD, RMSF e raio de giro, o alinhamento das estruturas nos tempos inicial e final de simulação de DM para a estrutura E1-hD modelada por homologia e que compreende o CTLD de hDectin-1 é visto na figura 14B.

A estrutura do CTLD de hDectin-1 (E1-hD) apresentou estabilidade estrutural e trajetória semelhante ao longo das três simulações de DM de 100 ns. A estrutura atingiu o platô de estabilidade antes de 5 ns e permaneceu estável até o final das simulações.

Analisando o gráfico do RMSF gerado para a estrutura E1-hD foi observado na região C-terminal o aumento aproximado de $3 \AA$ do RMFS dos dois últimos aminoácidos em relação aos demais, sendo esse aumento esperado, pois esses aminoácidos compõem um loop e é esperada uma maior movimentação estrutural para essas regiões (SUBRAMANI; FLOUDAS,

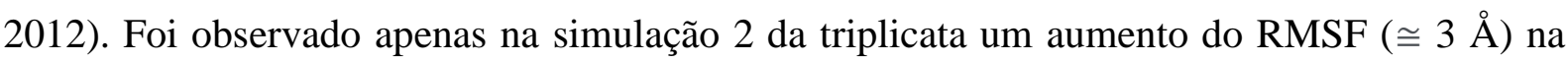
região dos aminoácidos 212 ao 215. Essa região está localizada no maior loop da estrutura (região e aminoácidos destacados na figura 14B). No geral, os loops, além de conferir flexibilidade estrutural, comumente compõem regiões de sítios ativos e de interação proteínaproteína (YU et al., 2017; SUBRAMANI; FLOUDAS, 2012).

A análise da compactação da estrutura (contração e expansão) ao longo do tempo apresentada no gráfico do raio de giro $\left(R_{g}\right)$ mostrou que a estrutura E1-hD não apresentou variações significantes em relação ao seu estado de compactação inicial.

O alinhamento das estruturas nos tempos inicial e final de simulação de DM (figura 14B) evidenciou que os locais com maior movimentação estrutural estão em regiões de loops e mostrou também que, em relação a quantidade de elementos secundários, houve apenas o desaparecimento de uma pequena folha- $\beta$ composta por três aminoácidos (I125, I126 e Y127) ao final do tempo de $100 \mathrm{~ns}$ da simulação de DM. Assim, considera-se que houve boa conservação dos elementos secundários que compõe a estrutura.

Figura 14 - Comportamento estrutural do CTLD de hDectin-1 ao longo da simulação de DM. 

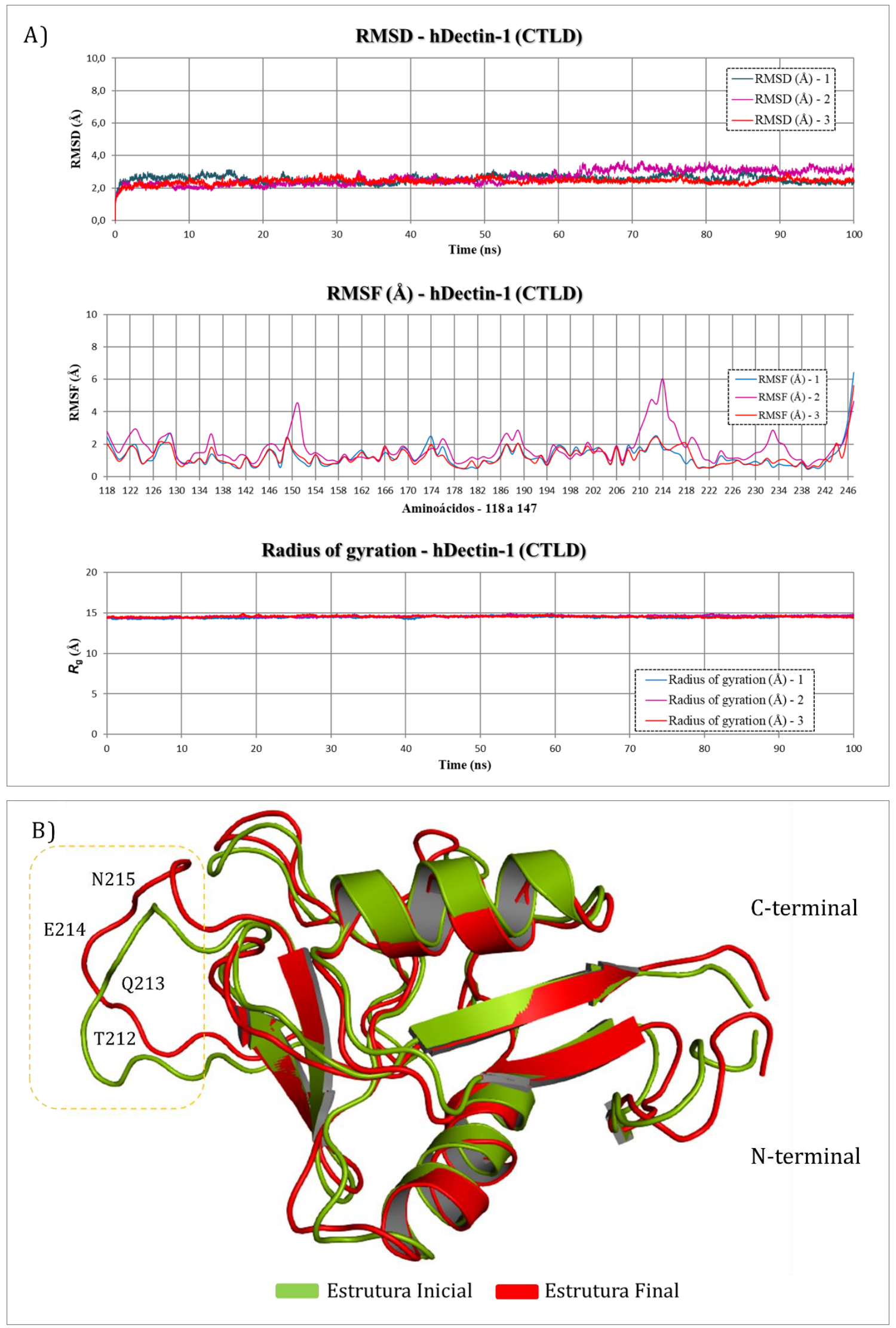

A) RMSD, RMSF e Raio de Giro da triplicata de simulação de DM da estrutura modelada por homologia do CTLD hDectin-1. B) Alinhamento das estruturas inicial em 0 ns (verde) e final em 100 ns (vermelho) da simulação de DM. O Retângulo pontilhado em laranja destaca a região que apresentou maior RMSF na simulação 2. Fonte: Arquivo pessoal. 
A figura 15A apresenta os resultados de RMSD, RMSF e raio de giro, o alinhamento das estruturas nos tempos inicial e final de simulação de DM para a estrutura PDB ID 2BPD_A correspondente ao CTLD de Dectin-1 murina (mDectin-1) usada como molde é visto na figura $15 \mathrm{~B}$.

O gráfico do RMSD mostrou que a estrutura PDB ID 2BPD_A apresentou estabilidade estrutural e trajetória semelhante ao longo das três simulações de DM de 100 ns, sendo este resultado satisfatório.

No gráfico do RMSF gerado para a estrutura PDB ID 2BPD_A foi observado na região N-terminal o aumento aproximado de $3 \AA$ do RMFS dos dois primeiros aminoácidos em relação aos demais em duas das três simulações de DM, sendo esse aumento esperado, pois essa região compõe um loop, e regiões de loop tendem a ser mais flexíveis (YU et al., 2017; SUBRAMANI; FLOUDAS, 2012).

A análise da compactação da estrutura (contração e expansão) ao longo do tempo apresentada no gráfico do raio de giro $\left(R_{g}\right)$ mostrou que a estrutura PDB ID 2BPD_A não apresentou variações significantes em relação ao seu estado de compactação inicial.

O alinhamento das estruturas nos tempos inicial e final de simulação de DM (figura 15B) evidenciou que os locais com maior movimentação estrutural estão em regiões de loops e mostrou também que, em relação a quantidade de elementos secundários, houve apenas o desaparecimento de uma pequena folha- $\beta$ composta por três aminoácidos (I124, M125 e H126) ao final do tempo de 100 ns da simulação de DM. Assim, considera-se que houve boa conservação dos elementos secundários que compõe a estrutura.

Figura 15 - Comportamento estrutural do CTLD de mDectin-1 ao longo da simulação de DM. 

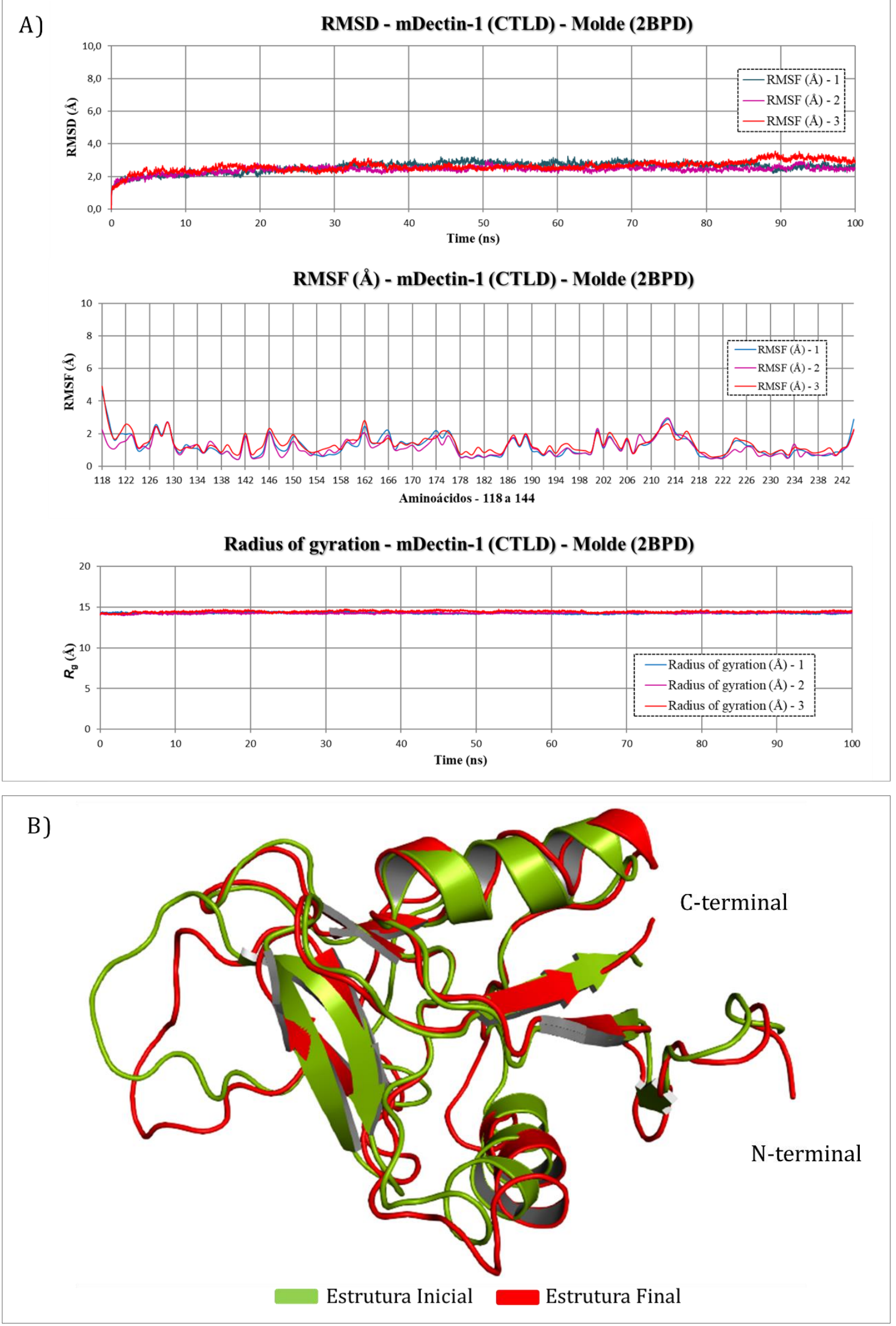

A) RMSD, RMSF e Raio de Giro da triplicata de simulação de DM da estrutura 2BPD do CTLD de Dectin-1 murina (mDectin-1) usada como molde. B) Alinhamento das estruturas inicial em $0 \mathrm{~ns}$ (verde) e final em $100 \mathrm{~ns}$ (vermelho) da simulação de DM. Fonte: Arquivo pessoal. 
O resultado da simulação de DM mostrou que a estrutura E1-hD se apresentou estável ao longo das três simulações de 100 ns, assim como a estrutura 2BPD do CTLD de mDectin-1 usada como molde. Deste modo, pode-se considerar que a estrutura E1-hD modelada por homologia e que corresponde ao CTLD de hDectin-1 pôde ser usada nas análises de interação com seus alvos moleculares, os $\beta$-glucanos.

\subsubsection{Modelagem por threading do domínio Stalk}

A região correspondente ao domínio Stalk, que compreendem os aminoácidos 66 a 117 foi, a partir deste ponto, denominada $\mathrm{E} 2-\mathrm{hD}$.

Inicialmente, foram realizadas buscas no PDB para encontrar possíveis estruturas molde para E2-hD. A busca foi feita usando a sequência primária da região de interesse, porém, nenhuma estrutura similar à sequência alvo foi encontrada para que fosse feita a modelagem por homologia. Portanto, optou-se por realizar a determinação estrutural de E2-hD por meio do método de threading.

A região E2-hD, que compreende os aminoácidos 66 a 117, foi determinada por threading por meio do servidor I-TASSER (YANG et al., 2015; ROY et al., 2010). A modelagem por threading resultou de cinco possíveis modelos para a sequência alvo. Os cinco modelos foram ranqueados pelo $C$-score, que é o índice de confiança para estimar a qualidade dos modelos previstos pelo I-TASSER. O C-score é calculado com base na significância dos alinhamentos dos modelos e dos parâmetros de convergência das simulações na montagem da estrutura. É esperado que modelos com boa qualidade estrutural apresentem o resultado do $C$ score no intervalo de valores -5 e 2 (ROY et al., 2010).

O melhor modelo foi escolhido com base no C-score fornecido pelo I-TASSER, qualidade estereoquímica avaliada por meio do software PROCHECK (LASKOWSKI et al., 1993), Z-score QMEAN (BENKERT et al., 2010), software ERRAT (COLOVOS; YEATES, 1993), software ProSA-Web (WIEDERSTEIN; SIPPL, 2007) e inspeção visual realizada por meio do software PyMol (HOLEC; HACKEL, 2016).

O C-score do melhor modelo para E2-hD foi -3.22 , estando este valor dentro do intervalo [-5, 2] que atribui confiança a estrutura modelada (YANG et al., 2015).

A qualidade estereoquímica avaliada por meio do software PROCHECK para o modelo E2-hD também foi satisfatória, onde $91.1 \%$ dos aminoácidos se localizaram em regiões muito favoráveis, $8.9 \%$ em regiões favoráveis e nenhum aminoácido em regiões pouco favoráveis ou desfavoráveis no gráfico de Ramachandran (figura 16A). É esperado que modelos 
com boa qualidade apresentem mais de $90 \%$ de seus aminoácidos localizados em regiões muito favoráveis (LASKOWSKI et al., 1993).

$\mathrm{O}$ resultado do Z-score QMEAN para E2-hD foi -1.17, sendo que valores de Z-score QMEAN próximos de zero indicam que o modelo avaliado tem qualidade compatível com estruturas obtidas experimentalmente com alta resolução e tamanho similar e valores de -4.0 ou inferiores indicam que o modelo avaliado tem baixa qualidade estrutural (BENKERT et al., 2010; BENKERT et al., 2008). Assim, o modelo E2-hD apresentou Z-score dentro da faixa de valores de estruturas obtidas experimentalmente por cristalografia com difração de raios-X com alta resolução de tamanho similar (BENKERT et al., 2008) (figura 16B).

O fator de qualidade do software ERRAT foi $86.05 \%$ para E2-hD estando este valor abaixo do considerando ideal para estruturas preditas experimentalmente com alta resolução (95\%) e para estruturas com resolução mais baixa (91\%) (COLOVOS e YEATES, 1993).

O Z-score do software ProSA-Web para E2-hD foi - 0.49 , indicando que a estrutura avaliada apresenta pouca probabilidade de erro em relação a energia conformacional por exibir o Z-score dentro do intervalo de distribuição de Z-scores tipicamente encontrados para proteínas obtidas experimentalmente de tamanho similar (WIEDERSTEIN; SIPPL, 2007).

A estrutura de E2-hD é composta por uma $\alpha$-hélice entre duas alças e está representada na figura $16 \mathrm{C}$. 
Figura 16 - Avaliação da estrutura E2-hD, que compreende os aminoácidos 66 a 117 da porção extracelular de hDectin-1 obtida por threading.

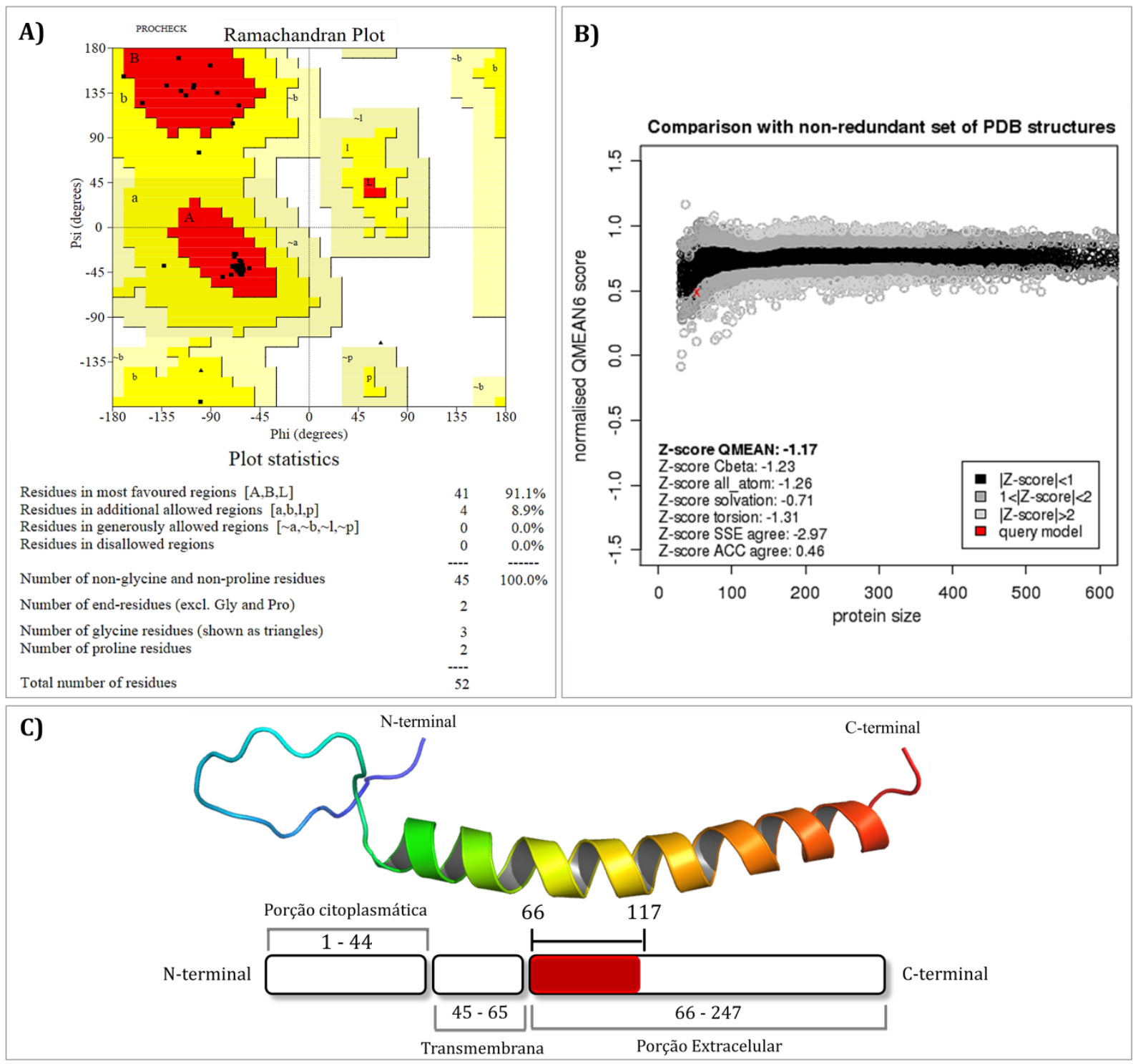

A) Resultados do software PROCHECK expressos no gráfico de Ramachandran (LASKOWSKI et al., 1993). Áreas em vermelho representam regiões muito favoráveis, em amarelo regiões favoráveis, em amarelo claro regiões pouco favoráveis e branco regiões desfavoráveis. Os quadrados pretos representam o posicionamento dos aminoácidos no gráfico e os triângulos pretos representam as glicinas. Modelos de boa qualidade devem apresentar mais de $90 \%$ de seus aminoácidos localizados em regiões muito favoráveis (LASKOWSKI et al., 1993). B) Resultados do Z-score QMEAN (BENKERT et al., 2008) para a estimativa do grau de confiança das características estruturais observadas no modelo a fim de determinar o quanto a estrutura está próxima do seu enovelamento nativo. Valores de Z-score próximos de zero indicam que o modelo avaliado tem qualidade compatível com estruturas obtidas experimentalmente por cristalografia com difração de raios-X de alta resolução de tamanho similar e valores inferiores a -4.0 indicam que o modelo avaliado tem baixa qualidade (BENKERT et al., 2008). $\mathrm{O}$ gráfico com o resultado do $Z$-score mostra o modelo para $\mathrm{E} 2-\mathrm{hD}$ representado pelo $\mathrm{X}$ vermelho na mesma faixa de valores Z-score que estruturas preditas experimentalmente. C) Estrutura tridimensional correspondente ao segmento dos aminoácidos 66 a 117. Fonte: Arquivo pessoal. 


\subsubsection{Modelagem por homologia do domínio transmembranar de hDectin-1}

O domínio transmembranar de hDectin-1, segundo informações coletadas no banco de dados UniProt (Q9BXN2), compreende os aminoácidos 45 a 65 (figura 17).

Figura 17 - Domínio transmembranar de hDectin-1.

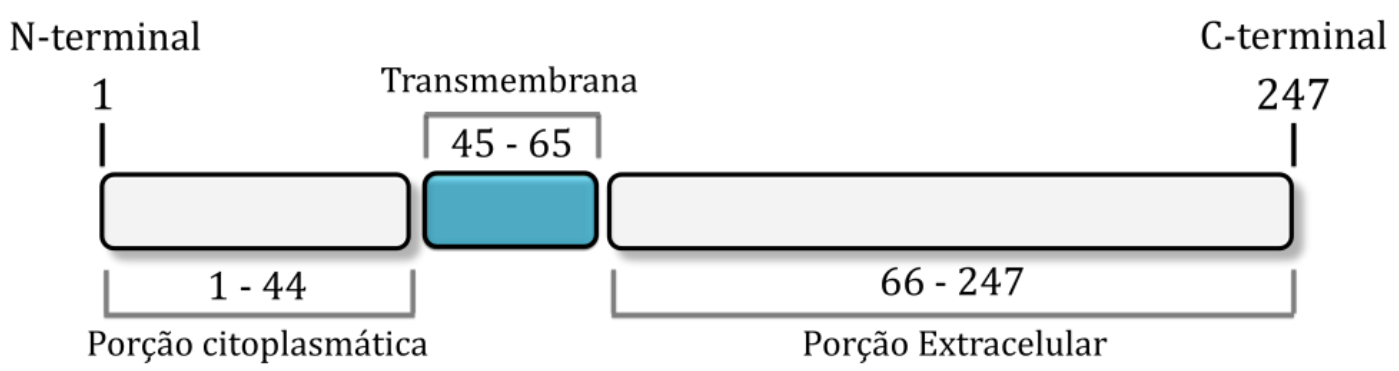

O retângulo preenchido em azul mostra a porção correspondente aos resíduos 45 a 65 que compõem a porção transmembranar. Fonte: Arquivo pessoal.

A determinação estrutural da $\alpha$-hélice transmembranar de hDectin-1 (TM) foi iniciada pela busca de estruturas que poderiam ser usadas como molde para a modelagem por homologia da mesma.

Inicialmente, a busca por estruturas molde realizada no PDB não retornou nenhum resultado, pois o limite mínimo de identidade considerado útil entre os alinhamentos da sequência alvo com as sequências do banco dados é de 30\%, sendo os alinhamentos com porcentual de identidade inferiores a esse desconsiderados (ROSE et al., 2016). Em continuidade à busca por estruturas molde optou-se por utilizar o servidor Swiss-model (BIASINI et al. 2014) que permite encontrar estruturas molde relacionadas evolutivamente ao alvo (WATERHOUSE et al., 2018).

O resultado obtido pelo servidor Swiss-model não forneceu nenhum molde que cobrisse todos os aminoácidos de TM. Entretanto, as estruturas das proteínas integrina $\alpha \operatorname{IIb} \beta 3$ (LAU et al., 2009) (PDB ID: 2M3E) e proteína transportadora de íons A0L5S6_MAGMM (PDB ID: 3ZJZ) (BAGNÉRIS et al., 2013), ambas proteínas transmembranares, foram sugeridas como possíveis moldes para a modelagem por homologia do domínio transmembranar de hDectin-1.

A estrutura 2M3E foi obtida no PDB e corresponde à porção transmembranar da proteína integrina $\alpha \operatorname{Ilb} \beta 3$ determinada experimentalmente por espectroscopia de RMN (20 conformações depositadas) e a estrutura de 3ZJZ determinada por cristalografia com difração 
de raios-X com resolução de $2.92 \AA$, também obtida no PDB, corresponde a proteína de membrana transportadora de íons A0L5S6_MAGMM (BAGNÉRIS et al., 2013). Como a estrutura tridimensional de 3ZJZ é composta por quatro cadeias iguais, apenas a cadeia A foi usada.

O alinhamento local feito por meio do software EMBOSS Matcher (RICE et al., 2000) entre a sequência de TM com 2M3E e 3ZJZ retornou os seguintes resultados: Alinhamento entre TM e 2M3E apresentou $27.8 \%$ de identidade e $72.2 \%$ de similaridade e o alinhamento entre TM e 3ZJZ apresentou $27.3 \%$ de identidade e 59.1\% de similaridade (figura 18).

Figura 18 - Alinhamentos locais feitos por meio do software EMBOSS Matcher.

\begin{tabular}{|c|c|c|c|c|c|}
\hline A) & & & B) & & \\
\hline \# Identity: & $5 / 18(27.8 \%)$ & & \# Identity: & $6 / 22(27.3 \%)$ & \\
\hline \# Similarity: & $13 / 18 \quad(72.2 \%)$ & & \# Similarity: & $13 / 22(59.1 \%)$ & \\
\hline \# Gaps: & $0 / 18(0.0 \%)$ & & \# Gaps: & $0 / 22(0.0 \%)$ & \\
\hline TM & $\begin{array}{c}1 \text { LIAVILGILCLVILVIAV } \\
:::|.|:|.|:::|.| \text {. }\end{array}$ & 18 & TM & $\begin{array}{l}4 \text { VILGILCLVILVIAVVLGTMAI } \\
\quad::|\ldots \ldots::| .|.::: \ldots|||\end{array}$ & 25 \\
\hline $2 \mathrm{M} 3 \mathrm{E}$ & 16 VLSGIGGLLLLLLIFIVL & 33 & 3ZJZ_A & 78 IMLTTFTVLNLFIGIIVDAMAI & 99 \\
\hline
\end{tabular}

A) Alinhamento entre a sequência de TM e 2M3E. B) Alinhamento entre a sequência de TM e 3ZJZ_A. Fonte: Arquivo pessoal.

Valores de identidade considerados ideais para que uma estrutura modelada por homologia possa ter precisão equivalente a uma estrutura determinada experimentalmente são de $30 \%$ ou mais de identidade entre a sequência alvo e a sequência do molde, sendo que, quanto maior o porcentual de identidade, maiores as chances de se obter um bom modelo (XIANG, 2006). Entretanto, é possível determinar uma estrutura por modelagem por homologia usando um molde com menos de $30 \%$ de identidade entre as sequências. As chances de se obter um bom modelo quando o percentual de identidade é inferior a 30\% aumenta se a estrutura molde apresentar função relacionada ao alvo (XIANG, 2006). A similaridade entre as sequências é, normalmente, menos conservada que a similaridade estrutural, principalmente com referência às regiões funcionais da proteína, pois a conservação da estrutura é fundamental para o cumprimento de funções específicas (KRYSHTAFOVYCH; FIDELIS, 2009). Deste modo, apesar do porcentual de identidade entre a sequência alvo e moldes estarem abaixo dos 30\% ideais, o fato dos moldes serem estruturas de proteínas transmembranares assim como o alvo possibilita que a determinação de TM seja feita por modelagem por homologia (XIANG, 2006). 
A análise dos alinhamentos entre as sequências das proteínas molde 2M3E e 3ZJZ mostrou que ambas não cobriram individualmente toda a sequência de aminoácidos de TM, ficando 3 aminoácidos no N-terminal sem cobertura do molde no alinhamento com 3ZJZ e 7 aminoácidos no C-terminal sem cobertura do molde no alinhamento com 2M3E (figura 19). Entretanto, foi observado que os dois moldes juntos cobriram toda a sequência de TM. Deste modo, optou-se por realizar a modelagem por homologia com múltiplos moldes por meio do software MODELLER 9.19 (WEBB; SALI, 2014). Neste tipo de modelagem por homologia duas ou mais sequências de estruturas moldes são alinhadas com a sequência alvo para garantir a melhor cobertura de toda sequência e, consequentemente, obter um modelo completo para a sequência alvo (WEBB; SALI, 2014).

Figura 19 - Alinhamentos locais feitos por meio do software EMBOSS Matcher.

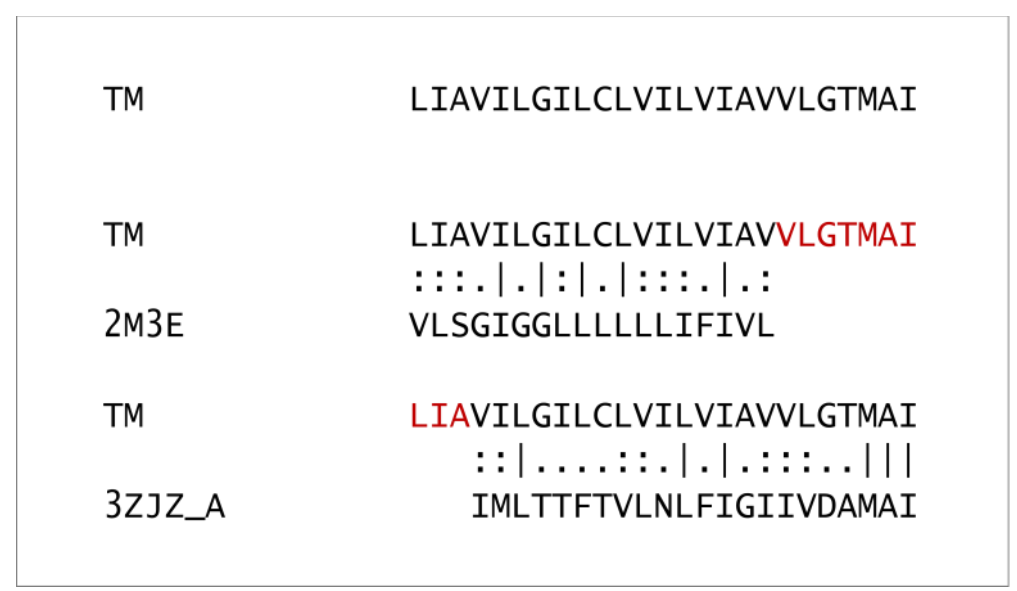

Os alinhamentos mostram que as sequências dos moldes não cobriram individualmente toda a sequência de aminoácidos de TM (aminoácidos em vermelho indicam a parte da sequência de TM que ficou sem a cobertura da sequência de cada molde) mas que os dois moldes juntos cobriram toda a sequência de TM. Fonte: Arquivo pessoal.

Foram modeladas dez estruturas por homologia para TM por meio do software MODELLER 9.19 (WEBB; SALI, 2014), que foram igualmente avaliadas pelos softwares QMEAN (BENKERT et al., 2010), PROCHECK (LASKOWSKI et al., 1993) e QMEANBrane sendo escolhido o modelo que apresentou o melhor resultado nos três softwares usados na avaliação. Outros softwares utilizados em etapas anteriores de avaliação de estruturas não foram utilizados na avaliação destes modelos. Tais softwares são adequados para a avaliação de proteínas solúveis, sendo a precisão deles limitada para proteínas transmembranares (STUDER et a., 2014). 
O Z-score QMEAN (BENKERT et al., 2010) para o melhor modelo de TM foi -0.18, estando este valor dentro da faixa de valores de Z-score de estruturas resolvidas experimentalmente com boa resolução e tamanho similar (figura 20A).

A qualidade estereoquímica avaliada por meio do software PROCHECK também foi satisfatória para o modelo de TM, apresentando 97\% dos aminoácidos em região muito favoráveis, 3\% em regiões favoráveis e nenhum aminoácido em regiões pouco favoráveis ou desfavoráveis no gráfico de Ramachandran, sendo esperado que modelos de boa qualidade apresentem mais de $90 \%$ de seus aminoácidos localizados em regiões muito favoráveis (LASKOWSKI et al., 1993).

O software QMEANBrane foi utilizado para avaliar a compatibilidade do modelo de TM com estruturas transmembranares. O software faz a detecção da porção transmembranar do modelo avaliado e verifica se essa porção é compatível com estruturas de domínios transmembranares por meio da análise de características estruturais obtidas na análise de um conjunto de estruturas transmembranares determinadas experimentalmente com alta resolução (STUDER et a., 2014). A análise dos resultados do software QMEANBrane (STUDER et a., 2014) indicou que o perfil energético do modelo TM e suas características estruturais são compatíveis com os perfis de energia de proteínas inseridas em membranas determinadas experimentalmente. O gráfico de energia com os resultados obtidos para o modelo TM com software QMEANBrane está representado na figura 20B. 
Figura 20 - Avaliação da estrutura TM, que compreende os aminoácidos 45 a 65 correspondente a porção transmembranar de hDectin-1 obtida por modelagem por homologia.
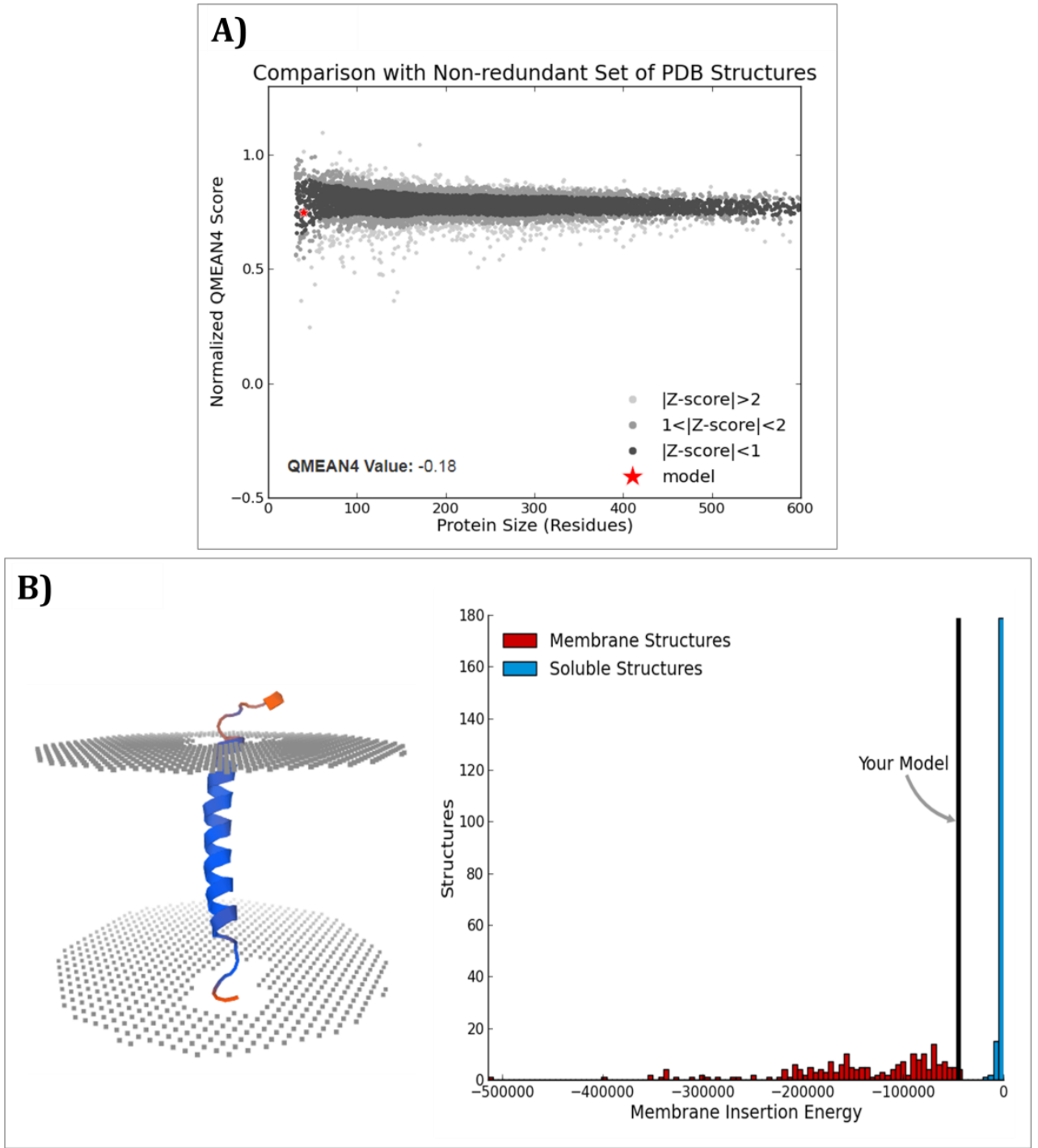

A) Resultados do Z-score QMEAN (BENKERT et al., 2010) para a estimativa do grau de confiança das características estruturais observadas no modelo a fim de determinar o quanto a estrutura está próxima do seu enovelamento nativo. Valores de Z-score QMEAN próximos de zero indicam que o modelo avaliado tem qualidade compatível com estruturas obtidas experimentalmente por cristalografia com difração de raios-X de alta resolução de tamanho similar e valores inferiores a -4.0 indicam que o modelo avaliado tem baixa qualidade (BENKERT et al., 2008). O gráfico com o resultado do Z-score mostra o modelo TM representado pelo X vermelho na mesma faixa de valores Z-score de estruturas preditas experimentalmente. B) Resultado do software QMEANBrane (STUDER et a., 2014) para determinar a compatibilidade do modelo de TM com estruturas de domínios transmembranares. Nos eixos X e Y do gráfico à direita da imagem estão dispostos, respectivamente, o número de estruturas $(\mathrm{X})$ e valores de energia para proteínas inseridas na membrana obtidas experimentalmente (Y). São observadas linhas verticais vermelhas que representam estruturas de proteínas transmembranares determinadas experimentalmente e linhas verticais azuis que representam estruturas de proteínas solúveis. A linha vertical preta representa o modelo avaliado. É esperado que o modelo avaliado esteja entre as linhas vermelhas para indicar a compatibilidade do modelo avaliado com estruturas transmembranares. A imagem a esquerda representa a estrutura da $\alpha$-hélice transmembranar de hDectin-1 modelada e a predição do local onde ela está inserida na membrana, sendo a membrana representada pelos pontos cinza. Fonte: Arquivo pessoal. 
De Brevern (2010), expõe que, devido à falta de estruturas tridimensionais transmembranares disponíveis, a modelagem por homologia nem sempre é um método simples para determinar modelos estruturais com qualidade. A maioria dos modelos estruturais de proteínas transmembranares são determinados por meio de protocolos que envolvem várias etapas como: predição de estrutura secundária para aumentar a chance de sucesso em relação a localização do domínio transmembranar na sequência da proteína; modelagem por homologia, muitas vezes mais de um processo; etapas de refinamento; e avaliação dos modelos gerados.

A modelagem de TM seguiu as indicações de protocolo descritas por De Brevern (2010) e a estrutura obtida se mostrou satisfatória na avaliação realizada.

\subsubsection{Determinação estrutural da porção intracelular de hDectin-1 por ab initio}

A porção intracelular de hDectin-1 é composta pelos 44 primeiros aminoácidos do Nterminal (figura 21).

Figura 21 - Domínio intracelular de hDectin-1.

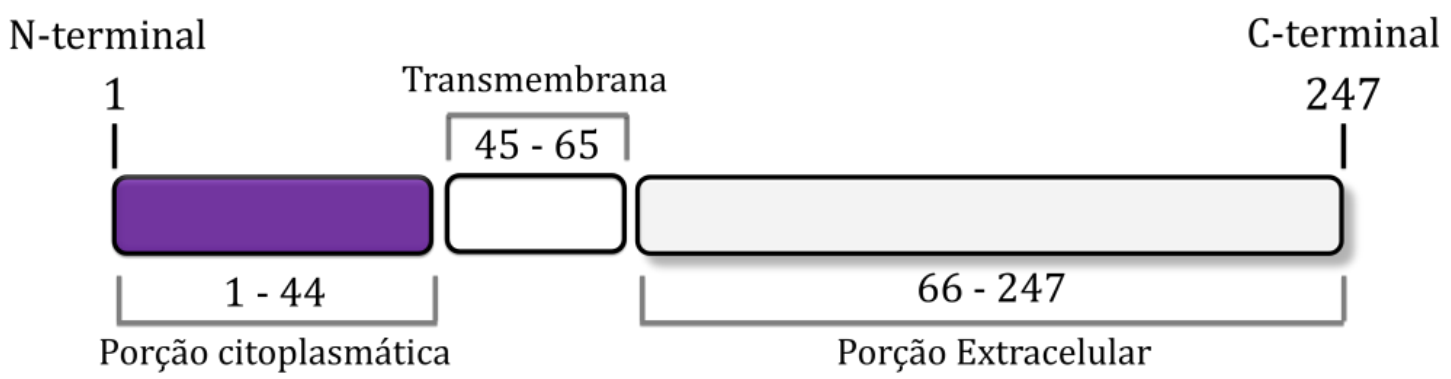

O retângulo preenchido em roxo mostra a porção correspondente aos resíduos 1 a 44 que compõem a porção intracelular. Fonte: Arquivo pessoal.

A modelagem deste segmento, a partir deste pondo denominado $\mathrm{E} 3-\mathrm{hD}$, foi feita pelo método de ab initio por meio do servidor QUARK (XU; ZHANG, 2013; XU; ZHANG, 2012). O servidor QUARK gera cinco mil modelos para a sequência alvo e fornece como resultado final os cinco melhores modelos ranqueados pelo TM-score do próprio servidor QUARK (ZHANG, 2012; ZHANG; SKOLNICK, 2004).

Os cinco modelos para E3-hD obtidos pelo servidor QUARK (XU; ZHANG, 2013; XU; ZHANG, 2012) foram igualmente avaliados por meio dos softwares PROCHECK (LASKOWSKI et al., 1993), QMEAN (BENKERT et al., 2010), ERRAT (COLOVOS; 
YEATES, 1993) e ProSA-Web (WIEDERSTEIN; SIPPL, 2007) e o modelo escolhido foi o que apresentou o melhor resultado na maioria dos softwares usados na avaliação. A inspeção visual do melhor modelo foi feita por meio do software PyMol (HOLEC; HACKEL, 2016). A seguir estão descritos os resultados do melhor modelo para E3-hD.

A qualidade estereoquímica avaliada por meio do software PROCHECK para o modelo E3-hD foi satisfatória, onde $97.3 \%$ dos aminoácidos se localizaram em regiões muito favoráveis, nenhum aminoácido em regiões favoráveis ou pouco favoráveis e apenas $2.7 \%$ (1 aminoácido) em regiões desfavoráveis no gráfico de Ramachandran (figura 22A). O esperado para modelos de boa qualidade é que mais de $90 \%$ dos aminoácidos estejam localizados em regiões muito favoráveis (LASKOWSKI et al., 1993).

$\mathrm{O}$ resultado do Z-score QMEAN para E3-hD foi -0.86, estando este valor dentro da faixa de valores de Z-score de estruturas resolvidas experimentalmente com boa resolução e tamanho similar (BENKERT et al., 2010) (figura 22B).

$\mathrm{O}$ fator de qualidade global do software ERRAT para E3-hD foi $66.66 \%$ para E3-hD, estando este valor abaixo do considerando ideal para estruturas preditas experimentalmente com alta resolução (95\%) e para estruturas com resolução mais baixa (91\%) (COLOVOS; YEATES, 1993).

O Z-score do software ProSA-Web para E3-hD foi -2.13, indicando que a estrutura avaliada apresenta pouca probabilidade de erro em relação a energia conformacional por exibir o Z-score dentro do intervalo de distribuição de Z-scores tipicamente encontrados para proteínas obtidas experimentalmente com tamanho similar (WIEDERSTEIN; SIPPL, 2007). A estrutura de E3-hD está representada na figura 22C. 
Figura 22 - Avaliação da estrutura E3-hD, que compreende os aminoácidos 1 a 44 correspondentes a porção intracelular de hDectin-1 obtida por ab initio.

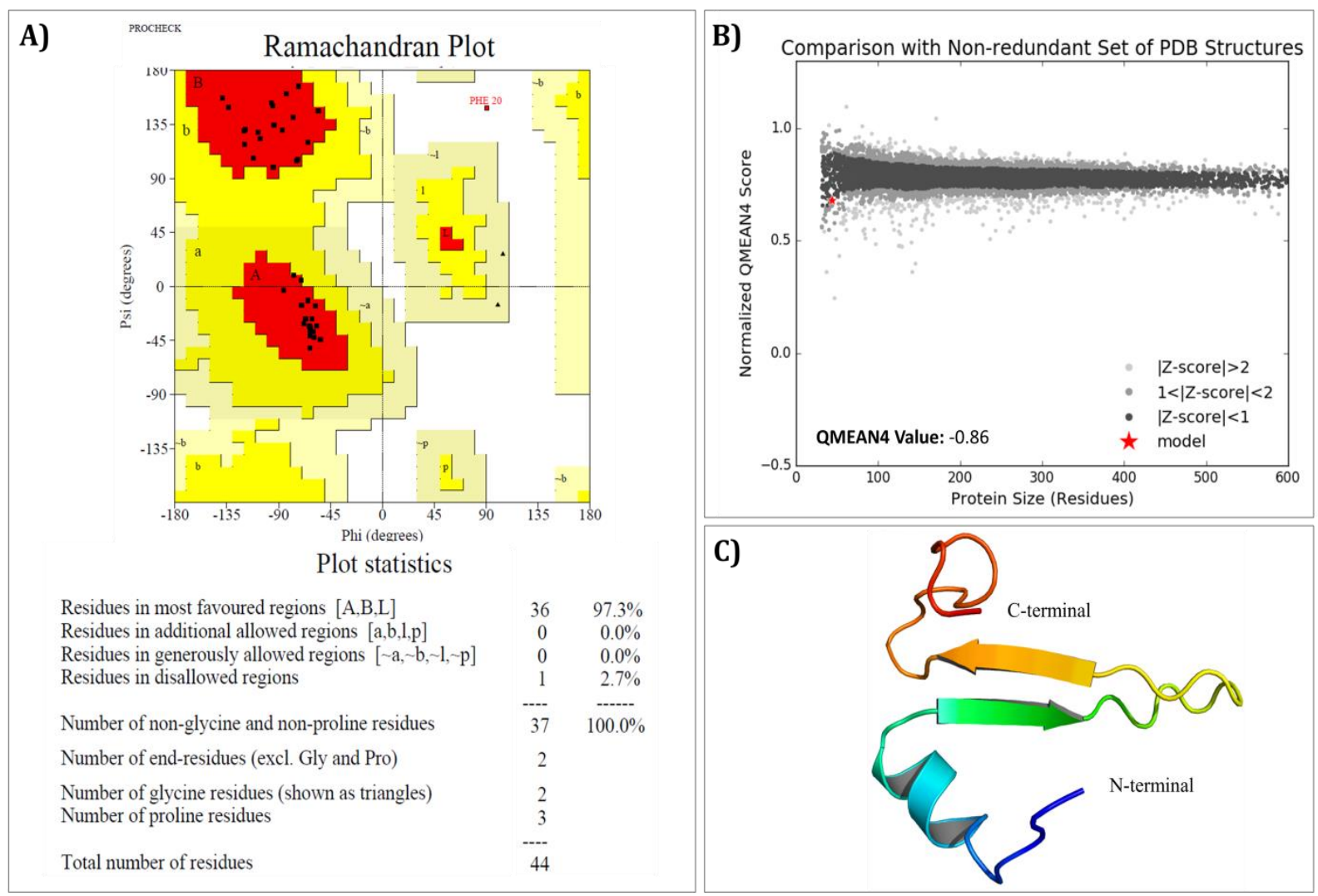

A) Resultados do software PROCHECK expressos no gráfico de Ramachandran (LASKOWSKI et al., 1993). Áreas em vermelho representam regiões muito favoráveis, em amarelo regiões favoráveis, em amarelo claro regiões pouco favoráveis e branco regiões desfavoráveis. Os quadrados pretos representam o posicionamento dos aminoácidos no gráfico e os triângulos pretos representam as glicinas. Modelos de boa qualidade devem apresentar mais de $90 \%$ de seus aminoácidos localizados em regiões muito favoráveis (LASKOWSKI et al., 1993). B) Resultados do Z-score QMEAN (BENKERT et al., 2010) para a estimativa do grau de confiança das características estruturais observadas no modelo a fim de determinar o quanto a estrutura está próxima do seu enovelamento nativo. Valores de Z-score QMEAN próximos de zero indicam que o modelo avaliado tem qualidade compatível com estruturas obtidas experimentalmente por cristalografia com difração de raios-X de alta resolução de tamanho similar e valores inferiores a -4.0 indicam que o modelo avaliado tem baixa qualidade (BENKERT et al., 2008). gráfico com o resultado do Z-score mostra o modelo E3-hD representado pelo $\mathrm{X}$ vermelho na mesma faixa de valores Z-score que estruturas preditas experimentalmente. C) Estrutura tridimensional E3-hD que correspondente a porção intracelular de hDectin-1 que compreende os aminoácidos 1 à 44. Fonte: Arquivo pessoal. 


\subsubsection{Junção das partes E1-hD, E2-hD, TM e E3-hD para determinação da estrutura de hDectin-1}

A tabela 3 apresenta as regiões de hDectin-1 modeladas e as metodologias empregadas na modelagem de cada parte.

Tabela 3 - Região de hDectin-1 modelada e metodologia empregada.

\begin{tabular}{cccc}
\hline Região de hDectin-1 & Nomenclatura & Metodologia & Aminoácidos \\
\hline $\begin{array}{c}\text { Parte da porção extracelular que } \\
\text { contém o C-type lectin-like domain }\end{array}$ & E1-hD & $\begin{array}{c}\text { Modelagem por } \\
\text { Homologia }\end{array}$ & $118-244$ \\
Domínio Stalk & E2-hD & Threading & $66-117$ \\
Domínio Transmembranar & TM & $\begin{array}{c}\text { Modelagem por } \\
\text { Homologia }\end{array}$ & $45-65$ \\
Porção Intracelular & E3-hD & Ab initio & $1-44$ \\
\hline
\end{tabular}

Fonte: Arquivo pessoal.

A determinação da estrutura de hDectin-1 foi realizada por meio de modelagem por homologia usando como moldes as estruturas E1-hD, E2-hD, TM e E3-hD. Essa modelagem por homologia foi realizada com o software MODELLER 9.19 (WEBB; SALI, 2014).

Foram gerados dez modelos e todos foram igualmente avaliados por meio dos softwares PROCHECK (LASKOWSKI et al., 1993), QMEAN (BENKERT et al., 2010), ERRAT (COLOVOS; YEATES, 1993) e ProSA-Web (WIEDERSTEIN; SIPPL, 2007). O modelo escolhido foi o que apresentou o melhor resultado na maioria dos softwares usados na avaliação. A inspeção visual do melhor modelo foi feita por meio do software PyMol (HOLEC; HACKEL, 2016). A seguir estão descritos os resultados do melhor modelo que, a partir deste ponto, foi denominado $\mathrm{hD}$.

A qualidade estereoquímica avaliada por meio do software PROCHECK do para o modelo hD apresentou resultados abaixo do satisfatório, onde $89.5 \%$ dos aminoácidos se localizaram em regiões muito favoráveis, $9.1 \%$ em regiões favoráveis, $0.9 \%$ em regiões pouco favoráveis e $0.5 \%$ em regiões desfavoráveis no gráfico de Ramachandran (figura 23A). O esperado para modelos com boa qualidade é que $90 \%$ ou mais dos aminoácidos estejam localizados em regiões muito favoráveis (LASKOWSKI et al., 1993) e em relação ao modelo 
$\mathrm{hD}$, a qualidade estereoquímica não atingiu o padrão de qualidade de estruturas determinadas experimentalmente com alta resolução, entretanto, o resultado ficou apenas $0.5 \%$ abaixo do considerado ideal, correspondendo esse percentual a apenas um aminoácido.

$\mathrm{O}$ resultado do Z-score QMEAN para o modelo $\mathrm{hD}$ foi -2.55, estando este valor dentro do limite na faixa de valores de Z-score de estruturas resolvidas experimentalmente e tamanho similar (BENKERT et al., 2010) (figura 23B).

O fator de qualidade global do software ERRAT foi $72.69 \%$ para hD estando este valor abaixo do considerando ideal para estruturas preditas experimentalmente com alta resolução (95\%) e para estruturas com resolução mais baixa (91\%) (COLOVOS; YEATES, 1993).

O Z-score do software ProSA-Web foi -3.03, indicando que a estrutura avaliada apresenta pouca probabilidade de erro em relação a energia conformacional por exibir o Z-score dentro do intervalo de distribuição de Z-scores de proteínas obtidas experimentalmente com tamanho similar (WIEDERSTEIN; SIPPL, 2007).

A figura 23C representa a estrutura de hDectin-1 contendo os aminoácidos 1 a 244, faltando apenas os últimos três aminoácidos da porção extracelular localizados no C-terminal.

Figura 23 - Avaliação da estrutura de hDectin-1 contendo os aminoácidos 1 a 244. 


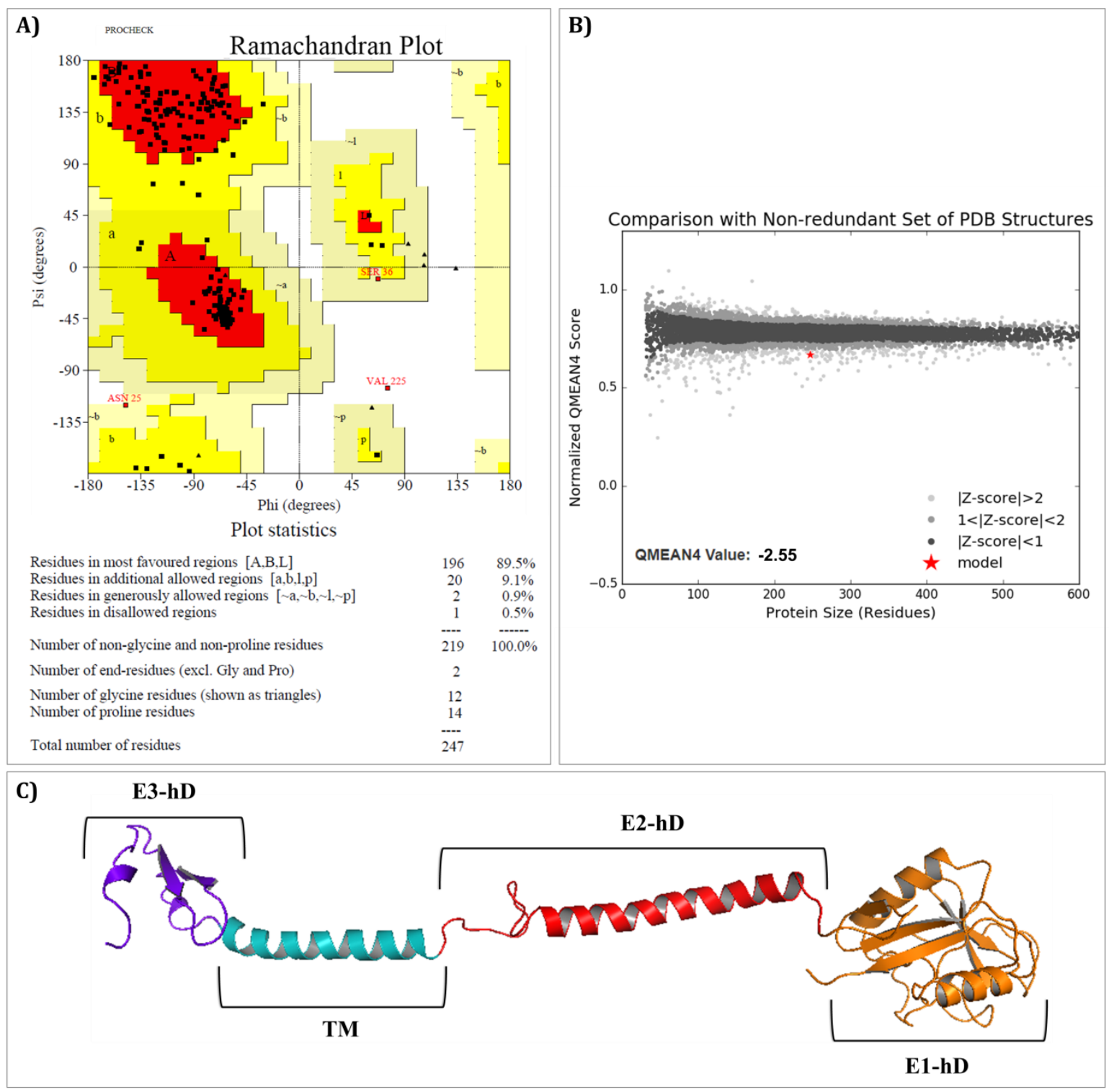

A) Resultados do software PROCHECK expressos no gráfico de Ramachandran (LASKOWSKI et al., 1993). Áreas em vermelho representam regiões muito favoráveis, em amarelo regiões favoráveis, em amarelo claro regiões pouco favoráveis e branco regiões desfavoráveis. Os quadrados pretos representam o posicionamento dos aminoácidos no gráfico e os triângulos pretos representam as glicinas. Modelos de boa qualidade devem apresentar mais de $90 \%$ de seus aminoácidos localizados em regiões muito favoráveis (LASKOWSKI et al., 1993). B) Resultados do Z-score QMEAN (BENKERT et al., 2010) para a estimativa do grau de confiança das características estruturais observadas no modelo a fim de determinar o quanto a estrutura está próxima do seu enovelamento nativo. Valores de Z-score QMEAN próximos de zero indicam que o modelo avaliado tem qualidade compatível com estruturas obtidas experimentalmente por cristalografia com difração de raios-X de alta resolução de tamanho similar e valores inferiores a -4.0 indicam que o modelo avaliado tem baixa qualidade (BENKERT et al., 2008). $\mathrm{O}$ resultado do $Z$-score que mostra o modelo $\mathrm{hD}$ representado pelo $\mathrm{X}$ vermelho no limite da faixa de valores $Z$ score de estruturas preditas experimentalmente. C) Estrutura tridimensional hD obtida por modelagem molecular por homologia. A imagem ilustra a localização dos moldes E1-hD, E2-hD, TM e E3-hD em diferentes cores: em laranja está representada parte da porção extracelular onde está localizado o CTLD que foi modelado por homologia; em vermelho está representada o domínio Stalk modelado por threading que se localiza entre o CTLD e o domínio transmembranar; em azul a porção correspondente ao domínio transmembranar modelada por homologia; e em roxo a porção intracelular modelada por ab initio. Nessa estrutura faltam apenas os três últimos aminoácidos do C-terminal. Fonte: Arquivo pessoal. 
O fator de qualidade global do software ERRAT (COLOVOS; YEATES, 1993) que foi $72.69 \%$ para $\mathrm{hD}$ se apresentou abaixo do considerando ideal para estruturas preditas experimentalmente com alta resolução $(95 \%)$ e para estruturas com resolução mais baixa $(91 \%)$. A análise do gráfico que mostra a probabilidade de erros locais nas interações atômicas entre átomos de carbono, nitrogênio e oxigênio exibiu quatro regiões com possibilidade de conter erros: região dos aminoácidos 67 a 74; 114 a 128; 184 a 186; e 198 a 207 (figura 24A). Essas quatro regiões são regiões de loops (figura 24B) que serão refinadas nas etapas seguintes.

Figura 24 - Análise para verificar a confiança da estrutura em relação a possíveis erros realizada por meio do software ERRAT.
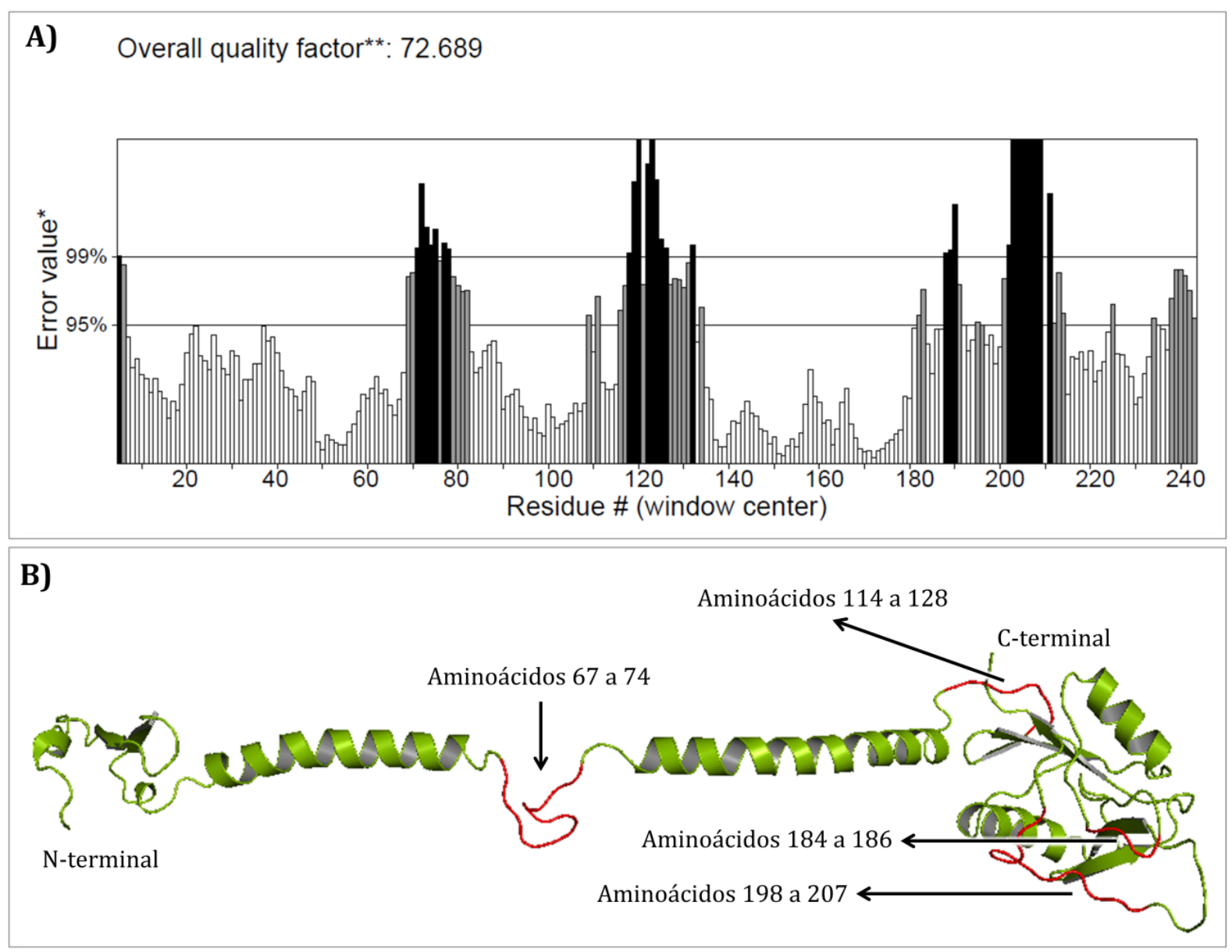

A) $\mathrm{O}$ fator de qualidade ERRAT considerado ideal para estruturas preditas experimentalmente com alta resolução é de 95\% e para estruturas com resolução mais baixa é de 91\% (COLOVOS; YEATES, 1993). A imagem destaca com barras verticais pretas as regiões entre os aminoácidos 67 a 74, 114 a 128, 184 a 186 e 198 a 207 com qualidade abaixo do desejado indicado a possibilidade de erro nas interações atômicas entre átomos de carbono, nitrogênio e oxigênio nessas regiões. B) Estrutura de hD em verde com as regiões de loop com qualidade abaixo do desejado e destacadas em vermelho. Fonte: Arquivo pessoal. 
Um loop é um segmento proteico que une dois elementos secundários (CANUTESCU; DUNBRACK, 2003). As regiões de loops são as que, mais frequentemente, apresentam erros em estruturas de proteínas modeladas tanto por homologia quanto por ab initio devido à necessidade de ajustes estruturais para que esse segmento una corretamente dois elementos secundários (XIANG 2006; CANUTESCU; DUNBRACK, 2003; FISER et al., 2000).

\subsubsection{Modelagem por $a b$ initio do final da região C-terminal de hDectin-1}

A região extracelular de hDectin-1 que compreende os três últimos aminoácidos do Cterminal, 245F, 246S e 247M (a partir deste ponto denominada FSM), foi determinada pelo método ab initio por meio do software Rosetta (OVCHINNIKOV et al., 2016).

Inicialmente foi gerada uma biblioteca de fragmentos por meio servidor Robetta (KIM et al., 2004), em seguida a construção dos modelos por ab initio foi feita pelo software Rosetta (OVCHINNIKOV et al., 2016).

A escolha do protocolo de modelagem ab initio por meio do software Rosetta (OVCHINNIKOV et al., 2016) foi determinada pelo resultado obtido na predição de estruturas secundárias, onde foi visto que os três últimos aminoácidos, 245 a 247, do C-terminal compõem um pequeno loop. Desta forma, foi empregado o protocolo CCD (sigla do inglês para cyclic coordinate descente) para modelagem de loops. Esse protocolo determina os loops por inserção de fragmentos na estrutura alvo a partir da biblioteca de fragmentos gerada com o servidor Robetta e pontua favoravelmente as conformações que melhor completarem o loop (WANG et al., 2007; CANUTESCU; DUNBRACK, 2003). Em seguida é feito o refinamento global das estruturas por meio de etapas de minimização de energia e otimização das conformações das cadeias laterais (WANG et al., 2007; ROHL et al., 2004).

Foram gerados mil modelos para a região FSM na estrutura de hDectin-1 para que a melhor fosse escolhida. A escolha da melhor estrutura completa de hDectin-1 foi feita com base nos resultados do software ModFOLD 4.0 (MCGUFFIN et al., 2013) e do software QMEAN (BENKERT et al., 2010).

Todos os mil modelos foram primeiramente avaliados pelo software ModFOLD 4.0 (MCGUFFIN et al., 2013) e os 100 melhores, segundo o score global de qualidade do ModFOLD, foram reavaliados pelo software QMEAN (BENKERT et al., 2010) para que o melhor fosse escolhido. Em seguida, o melhor modelo para a estrutura completa de hDectin-1 também foi avaliado pelo software ERRAT (COLOVOS; YEATES, 1993), software 
PROCHECK (LASKOWSKI et al., 1993) e inspeção visual feita por meio do software PyMol (HOLEC; HACKEL, 2016).

O melhor modelo para a estrutura completa de hDectin-1 apresentou o score global de qualidade ModFOLD 0.47 e p-value <0.05 (MCGUFFIN et al., 2013).

O Z-score QMEAN foi -0.92, valores de Z-score QMEAN próximos de zero indicam que o modelo avaliado tem qualidade compatível com estruturas obtidas experimentalmente por cristalografia com difração de raios-X de alta resolução de tamanho similar (BENKERT et al., 2008) (figura 25A).

Além da avaliação do fator de qualidade global com software ERRAT, ele também foi usado para verificar a confiança da estrutura em relação a possíveis erros locais nas interações atômicas entre átomos de carbono, nitrogênio e oxigênio. $\mathrm{O}$ resultado para o fator de qualidade global foi $88.1 \%$, sendo este valor inferior ao considerado ideal para estruturas preditas experimentalmente com alta resolução (95\%) e para estruturas com resolução mais baixa (91\%) (COLOVOS; YEATES, 1993). A análise realizada por meio do software ERRAT mostrou uma região entre os aminoácidos 118 e 125 que apresentam qualidade abaixo do desejado (figura 25B).

A qualidade estereoquímica avaliada por meio do software PROCHECK para a estrutura completa de hDectin-1 vista no gráfico de Ramachandran mostrou que $90.0 \%$ dos aminoácidos estão em regiões muito favoráveis, $9.1 \%$ estão em regiões favoráveis, $0.9 \%$ em regiões pouco favoráveis e $0.0 \%$ estão em regiões desfavoráveis. O esperado para modelos de boa qualidade é $90 \%$ ou mais dos aminoácidos estejam localizados em regiões muito favoráveis (LASKOWSKI et al., 1993) e no caso do modelo para a estrutura completa de hDectin-1, a qualidade estereoquímica atingiu os padrões de qualidade de estruturas determinadas experimentalmente (figura 25C). A estrutura completa de hDectin-1 está representada na figura $25 \mathrm{D}$. 
Figura 25 - Avaliação da estrutura completa de hDectin-1 obtida após modelagem por $a b$ initio da porção FSM.

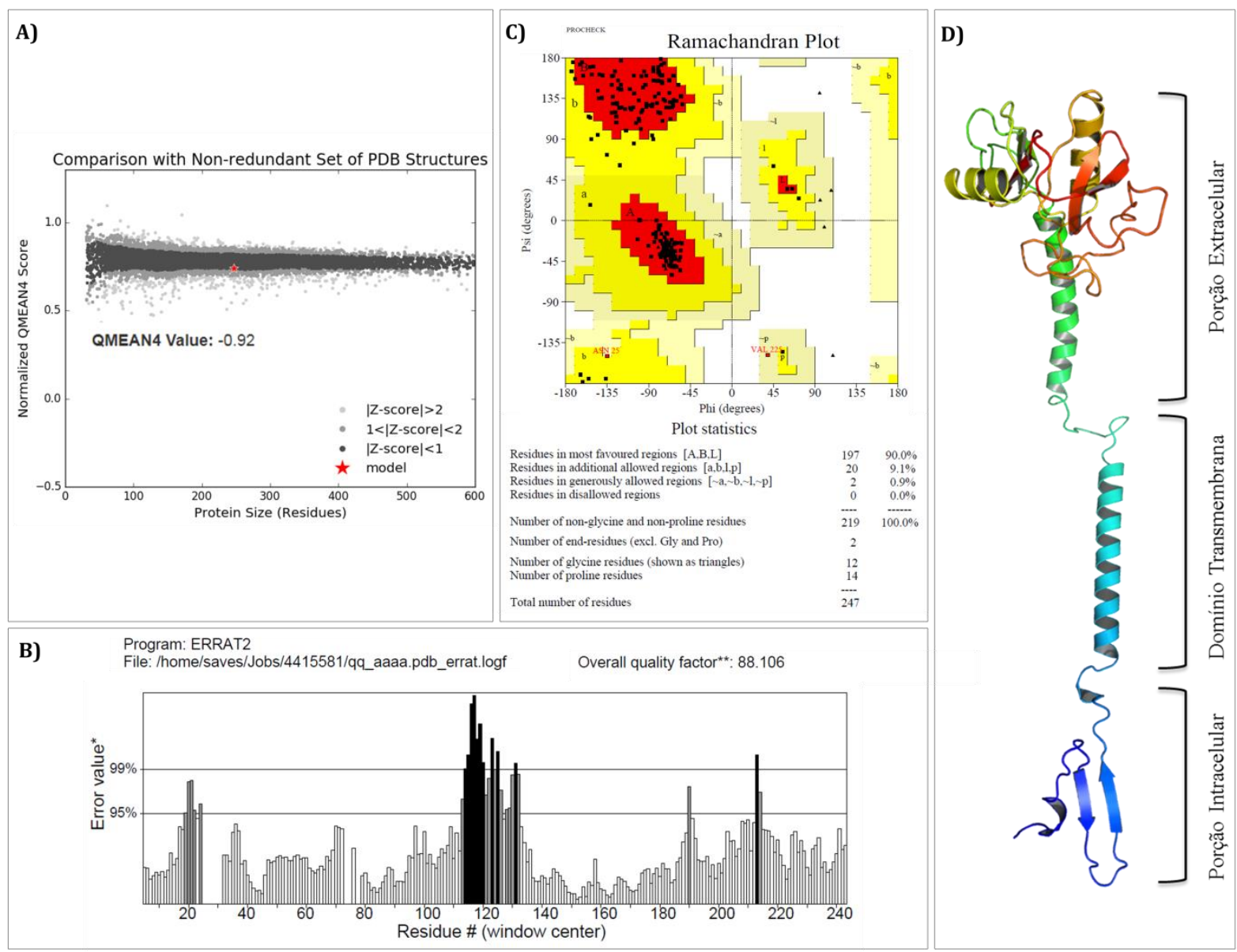

A) Resultados do Z-score QMEAN (BENKERT et al., 2010) para a estimativa do grau de confiança das características estruturais observadas no modelo a fim de determinar o quanto a estrutura está próxima do seu enovelamento nativo. Valores de Z-score QMEAN próximos de zero indicam que o modelo avaliado tem qualidade compatível com estruturas obtidas experimentalmente por cristalografia com difração de raios-X de alta resolução de tamanho similar e valores inferiores a -4.0 indicam que o modelo avaliado tem baixa qualidade (BENKERT et al., 2008). O resultado do $Z$-score que mostra a estrutura completa de hDectin- 1 representado pelo $X$ vermelho na mesma faixa de valores $Z$-score que estruturas preditas experimentalmente com tamanho similar. B) Análise para verificar a confiança da estrutura em relação a possíveis erros realizada por meio do software ERRAT (COLOVOS e YEATES, 1993). O fator de qualidade ERRAT considerado ideal para estruturas preditas experimentalmente com alta resolução é de 95\% e para estruturas com resolução mais baixa é de 91\% (COLOVOS e YEATES, 1993). A imagem destaca com barras verticais pretas a região entre os aminoácidos 118 e 125 com qualidade abaixo do desejado indicado a possibilidade de erro nas interações atômicas entre átomos de carbono, nitrogênio e oxigênio nessas regiões. C) Resultados do software PROCHECK expressos no gráfico de Ramachandran (LASKOWSKI et al., 1993). Áreas em vermelho representam regiões muito favoráveis, em amarelo regiões favoráveis, em amarelo claro regiões pouco favoráveis e branco regiões desfavoráveis. Os quadrados pretos representam o posicionamento dos aminoácidos no gráfico e os triângulos pretos representam as glicinas. Modelos de boa qualidade devem apresentar mais de $90 \%$ de seus aminoácidos localizados em regiões muito favoráveis (LASKOWSKI et al., 1993). D) Estrutura tridimensional completa de hDectin-1. Fonte: Arquivo pessoal. 
A análise realizada por meio do software ERRAT (COLOVOS; YEATES, 1993) para verificar a confiança da estrutura completa de hDectin-1 em relação a possíveis erros locais mostrou que apenas uma região apresentou possibilidade de conter erros (aminoácidos entre as posições 118 e 125) onde, anteriormente, a análise do mesmo gráfico para a estrutura hD mostrou quatro regiões com possibilidades de conter erros (aminoácidos entre as posições 67 a 74, 114 a 128, 184 a 186 e 198 a 207). Assim, foi observado que, das quatro regiões com possibilidade de erros na estrutura $\mathrm{hD}$, apenas uma não foi totalmente refinada na estrutura completa de hDectin-1 pelas etapas de refinamento do protocolo CCD (WANG et al., 2007; CANUTESCU; DUNBRACK, 2003) do software Rosetta (OVCHINNIKOV et al., 2016).

\subsubsection{Refinamentos de loops da estrutura completa de hDectin-1}

A estrutura completa de hDectin-1 foi determinada por meio da combinação de diferentes métodos de predição estrutural. As porções E1-hD, E2-hD, TM e E3-hD foram unidas por modelagem por homologia e a porção FSM foi determinada na estrutura por modelagem ab initio.

Apesar da estrutura completa de hDectin-1 ter apresentado qualidade estrutural satisfatória em relação a qualidade estereoquímica avaliada por meio do software PROCHECK (LASKOWSKI et al., 1993) e Z-score QMEAN (BENKERT et al., 2010) compatível com estruturas resolvidas experimentalmente de tamanho similar (resultados apresentados no item anterior), as regiões que mantiveram possibilidade de conter erros na avaliação com o software ERRAT (COLOVOS; YEATES, 1993) foram submetidas a uma etapa de refinamento estrutural.

A avaliação da estrutura completa de hDectin-1 com o software ERRAT (COLOVOS; YEATES, 1993) mostrou haver possibilidade de erro na região entre os aminoácidos 118 e 125. Essa região corresponde a um loop localizado no ponto de junção entre o domínio Stalk (E2hD) e CTLD (E1-hD). O ponto de junção entre os domínios transmembranar (TM) e Stalk (E2-

hD) também apresentou um grande loop como estrutura e compreende os aminoácidos 68 a 83, mesmo não sendo observados possíveis erros nessa região, ela também passou pela etapa de refinamento com o objetivo de melhorar ainda mais a qualidade da estrutura completa de hDectin-1. Deste modo, as regiões que passaram por refinamento de loop foram: Aminoácidos $68-83$ e $118-125$. 
O refinamento dos loops dessas duas regiões foi feito por meio do software Modeller 9.19 (WEBB; SALI, 2014) usando o protocolo loopmodel, que permite definir a região especifica do loop a ser refinada na estrutura da proteína (FISER et al., 2000).

Após o refinamento dos loops, a reavaliação da estrutura completa de hDectin-1 realizada por meio do software QMEAN (BENKERT et al., 2010) apresentou o Z-score -0.63 (figura 26A), mostrando melhora dessa pontuação em relação à estrutura antes dessa etapa (Zscore -0.92).

A reavaliação para verificar a confiança da estrutura em relação a possíveis erros realizada com o software ERRAT apresentou melhora do fator de qualidade global para 91.22\% onde, antes do refinamento, o fator de qualidade global era $88.1 \%$ (figura 26B). O valor para o fator de qualidade global considerado ideal para estruturas preditas experimentalmente com alta resolução deve estar acima de $95 \%$ e para estruturas com resolução mais baixa, mas ainda considerados bons, devem estar acima de 91\% (COLOVOS; YEATES, 1993). Esse resultado indica que as duas regiões dos loops que foram refinados apresentaram melhora da sua qualidade estrutural em relação à estrutura antes dessa etapa.

A reavaliação feita por meio do software PROCHECK (LASKOWSKI et al., 1993) mostrou que o refinamento dos loops promoveu um pequeno aumentou na quantidade de aminoácidos em regiões muito favoráveis, de $90.0 \%$ para $90.9 \%$, melhorando também a qualidade estereoquímica da estrutura.

No geral, a avaliação da estrutura completa de hDectin-1, após refinamento dos loops, apresentou resultados satisfatórios. Com base no Z-score QMEAN (BENKERT et al., 2010) a qualidade global da estrutura é compatível com estruturas preditas experimentalmente, pois valores de Z-score próximos de zero indicam que o modelo avaliado tem qualidade compatível com estruturas obtidas experimentalmente com alta resolução e tamanho similar (BENKERT et al., 2008) e a qualidade estereoquímica atingiu o valor de $90 \%$ ou mais de aminoácidos localizados em regiões muito favoráveis, sendo a estrutura considerada de boa qualidade (LASKOWSKI et al., 1993). O consenso dos resultados da avaliação indica que a estrutura completa de hDectin-1 determinada in silico apresenta boa qualidade estrutural. 
Figura 26 - Reavaliação da estrutura completa de hDectin-1 após refinamento dos loops.

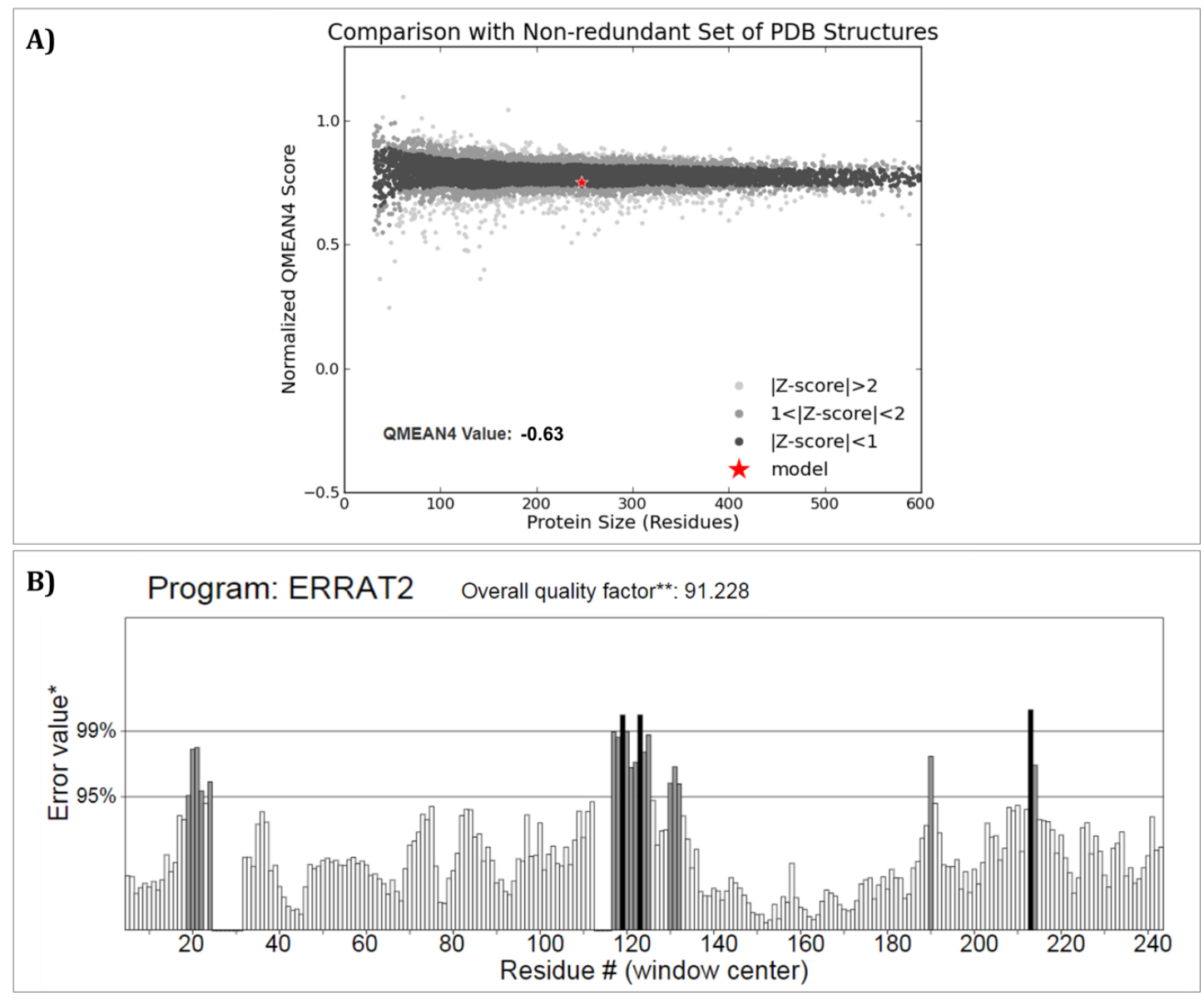

A) Resultado do Z-score QMEAN (BENKERT et al., 2010) para a estimativa do grau de confiança das características estruturais observadas no modelo a fim de determinar o quanto a estrutura está próxima do seu enovelamento nativo. Valores de Z-score QMEAN próximos de zero indicam que o modelo avaliado tem qualidade compatível com estruturas obtidas experimentalmente por cristalografia com difração de raios-X de alta resolução de tamanho similar e valores inferiores a -4.0 indicam que o modelo avaliado tem baixa qualidade (BENKERT et al., 2008). O gráfico com o resultado do Z-score mostra a estrutura completa de hDectin-1 representado pelo $\mathrm{X}$ vermelho na mesma faixa de valores $Z$-score que estruturas preditas experimentalmente com tamanho similar. B) Análise para verificar a confiança da estrutura em relação a possíveis erros realizada por meio do software ERRAT (COLOVOS e YEATES, 1993). O fator de qualidade ERRAT considerado ideal para estruturas preditas experimentalmente com alta resolução é de $95 \%$ e para estruturas com resolução mais baixa é de $91 \%$ (COLOVOS e YEATES, 1993). A imagem destaca com barras verticais pretas as regiões com possibilidade de conter erro nas interações atômicas entre átomos de carbono, nitrogênio e oxigênio nessas regiões. Fonte: Arquivo pessoal.

\subsection{Simulação de DM de hDectin-1 completa na membrana celular}

\subsubsection{Construção do sistema proteína/membrana celular}

As membranas biológicas são altamente heterogêneas e compostas por várias biomoléculas com diferentes concentrações. Ter um modelo relativamente preciso do ambiente de membrana é crucial para estudar as interações proteína-lipídio, a função e orientação das 
proteínas da membrana (WU et al., 2014). A estrutura básica de todas as membranas celulares é a bicamada fosfolipídica, que consiste de dois folhetos de moléculas fosfolipídicas cujos ácidos graxos formam o interior hidrofóbico da bicamada e suas cabeças polares e hidrofílicas revestem ambas as superfícies da membrana (LODISH et al., 2000).

Com o objetivo de simular o arranjo de hDectin-1 na membrana celular foi construído um sistema proteína/membrana por meio do servidor CHARMM-GUI (JO et al., 2008).

A estrutura completa de hDectin-1 obtida no presente estudo foi inserida em uma bicamada fosfolipídica composta por moléculas de DLPA (fosfolipídio, do inglês 1,2Dilauroyl-sn-glycero-3-phosphate). Os aminoácidos iniciais e finais que compõem a $\alpha$-hélice transmembranar foram usados para determinar a posição por onde passa a bicamada e o posicionamento adequado de hDectin-1 na membrana celular. Os aminoácidos G65 e L45 indicaram, respectivamente, o início o e final do domínio transmembranar.

Após determinar o posicionamento de hDectin-1 na bicamada fosfolipídica, foi construído um sistema com moléculas de água e íons (Na+ e Cl-). A concentração de íons Na+ e Cl- usada no sistema foi $0.15 \mathrm{M} \mathrm{KCl}$, estando essa concentração próxima da concentração fisiológica de íons (JO et al., 2008; JO et al., 2007).

O sistema final obtido por meio do servidor CHARMM-GUI (JO et al., 2008) é do tipo paralelepipédico, com dimensões de $127.4 \AA$ A no eixo x, $127.4 \AA$ A no eixo y e $188.9 \AA$ no eixo z, sendo composto pela proteína hDectin-1 inserida na bicamada fosfolipídica, com moléculas de água (TIP3) e íons que caracterizam o ambiente intracelular e extracelular.

Após essa etapa, o sistema hDectin-1/membrana foi submetido a simulação de DM para que fosse analisado o comportamento da proteína na membrana celular. O sistema completo e pronto para simulação de DM está exposto na figura 27. 
Figura 27 - Sistema proteína/membrana gerado pelo servidor CHARMM-GUI para simulação de dinâmica molecular.

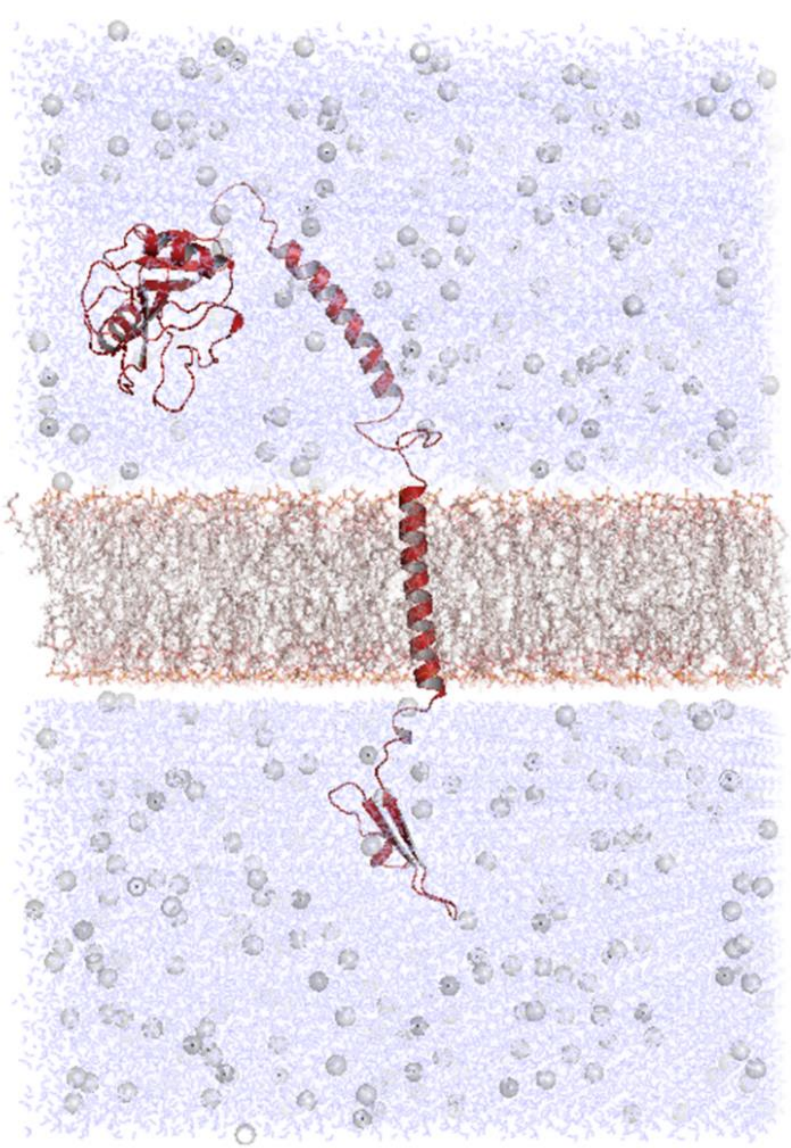

Sistema hDectin-1/membrana contendo água (azul), íons Na+ e Cl- (esferas cinza), proteína hDectin-1 (vermelho) e membrana celular composta de bicamada de fosfolipídios DLPA (cinza e vermelho). Fonte: Arquivo pessoal.

\subsubsection{Simulação de dinâmica molecular do sistema proteína/membrana}

Foi realizada simulação de DM em triplicata de 100 ns da proteína hDectin-1 completa na membrana celular em condições físico-químicas controladas, com temperatura máxima de $310 \mathrm{~K}$ e pressão constante de $1 \mathrm{~atm}$.

O comportamento molecular das estruturas ao longo do tempo foi analisado por meio do RMSD, RMSF, $b$-factor e alinhamento das estruturas nos tempos inicial e final de simulação de DM.

A análise do RMSD (figura 28A) mostrou que, ao longo das três simulações de DM, as três trajetórias da estrutura completa de hDectin-1 na membrana foram similares. No gráfico observa-se que o RMSD se eleva gradativamente durante os primeiros 45 ns, após esse tempo de simulação a estrutura se estabiliza consideravelmente e se mantem até o final dos 100 ns. No 
intervalo de tempo de 43 ns a 100 ns o RMSD oscila, aproximadamente, $7 \AA$ dentro do intervalo de $17 \AA ̊$ a $23 \AA$ no eixo y, sem variações bruscas (figura 28A).

$\mathrm{Na}$ análise do gráfico do RMSF (figura 28B) foi observada consistência na variação estrutural por resíduos nas três simulações de DM, entretanto, são observadas regiões que exibem um aumento do RMSF, são elas: 1-3, 11-14, 21-26, 72-84, 99-125, 148-151, 172-177, 186-191, 200-204, 212-206 e 243-247. Todas essas regiões correspondem predominantemente a loops. A região com maior quantidade de aminoácidos com valor alto de RMSF em sequência faz parte do domínio Stalk que conecta o domínio transmembranar ao CTLD. As duas maiores regiões são as que compreendem os aminoácidos 72 a 84 (13 resíduos) e 99 a 125 (27 resíduos).

Figura 28 - Trajetória da simulação de DM da estrutura completa de hDectin-1.

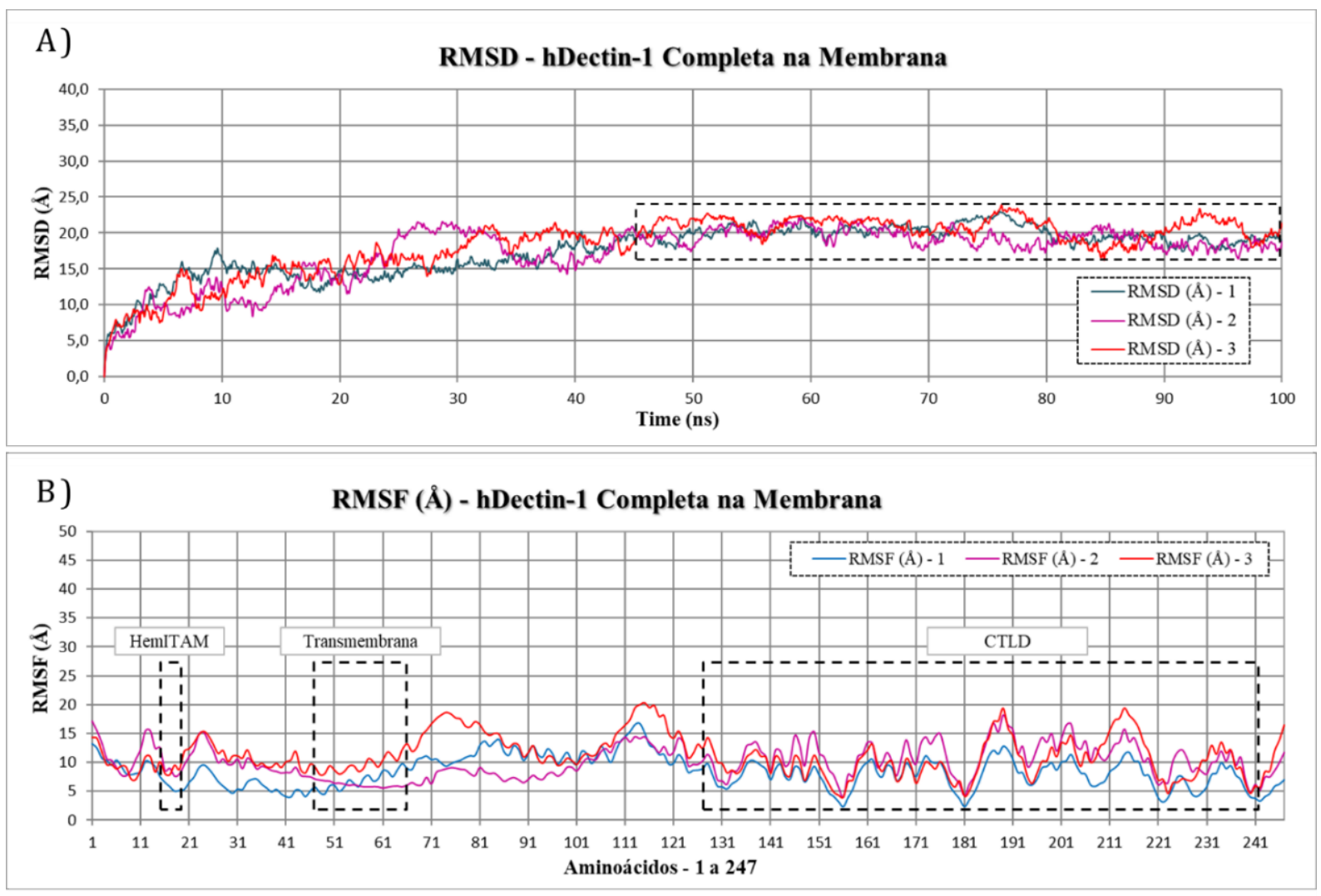

A) Valores de RMSD das coordenadas dos átomos C $\alpha$ em função do intervalo de tempo de simulação em triplicata de 100 ns. O retângulo pontilhado em preto no gráfico destaca o intervalo de tempo em que a estrutura se estabilizou após os primeiros $45 \mathrm{~ns}$ de simulação mantendo o padrão de estabilidade até o final dos $100 \mathrm{~ns}$. B) Comparativo da variação estrutural por aminoácido das três simulações. Valores de RMSF das coordenadas dos átomos $\mathrm{C} \alpha$ em relação à estrutura inicial. Os retângulos pontilhados em preto destacam, respectivamente, as regiões correspondentes ao motivo hemITAM, domínio transmembranar e CTLD da sequência completa de hDectin- 1 . Fonte: Arquivo pessoal. 
O alinhamento das estruturas nos tempos inicial e final da simulação de DM foi feito usando o domínio transmembranar como referência (figura 29). O alinhamento mostra que houve grande deslocamento da porção extracelular e intracelular em relação a posição da estrutura inicial, o que justifica a alta variação do RMSF nas regiões correspondentes a loops e RMSD acima de $15 \AA$ após os primeiros 43 ns com oscilação de, aproximadamente, $7 \AA$.

Como recurso para analisar as regiões com maior deslocamento atômico da proteína, foi realizada análise por meio do $b$-factor. $\mathrm{O} b$-factor indica quantitativamente a flexibilidade da estrutura proteica. A medida do deslocamento atômico está diretamente relacionada a variação de temperatura ao longo do tempo de simulação de DM (SUN et al., 2019). A análise do b-factor (figura 29) confirma a localização das regiões com maior variação estrutural por resíduos observadas no gráfico de RMSF que correspondem, predominantemente, a loops. As maiores variações estrutural observadas no RMSF frequentemente estão associadas a loops por se tratarem de estruturas com função principal de conectar os elementos secundários e conferir a flexibilidade estrutural necessária para a proteína desempenhar sua função (SUN et al., 2019; GOGUET et al., 2017; YU et al., 2017; SUBRAMANI; FLOUDAS, 2012). 
Figura 29 - Alinhamento das estruturas inicial e final da simulação de DM e $b$-factors de cada uma das três simulações de DM.

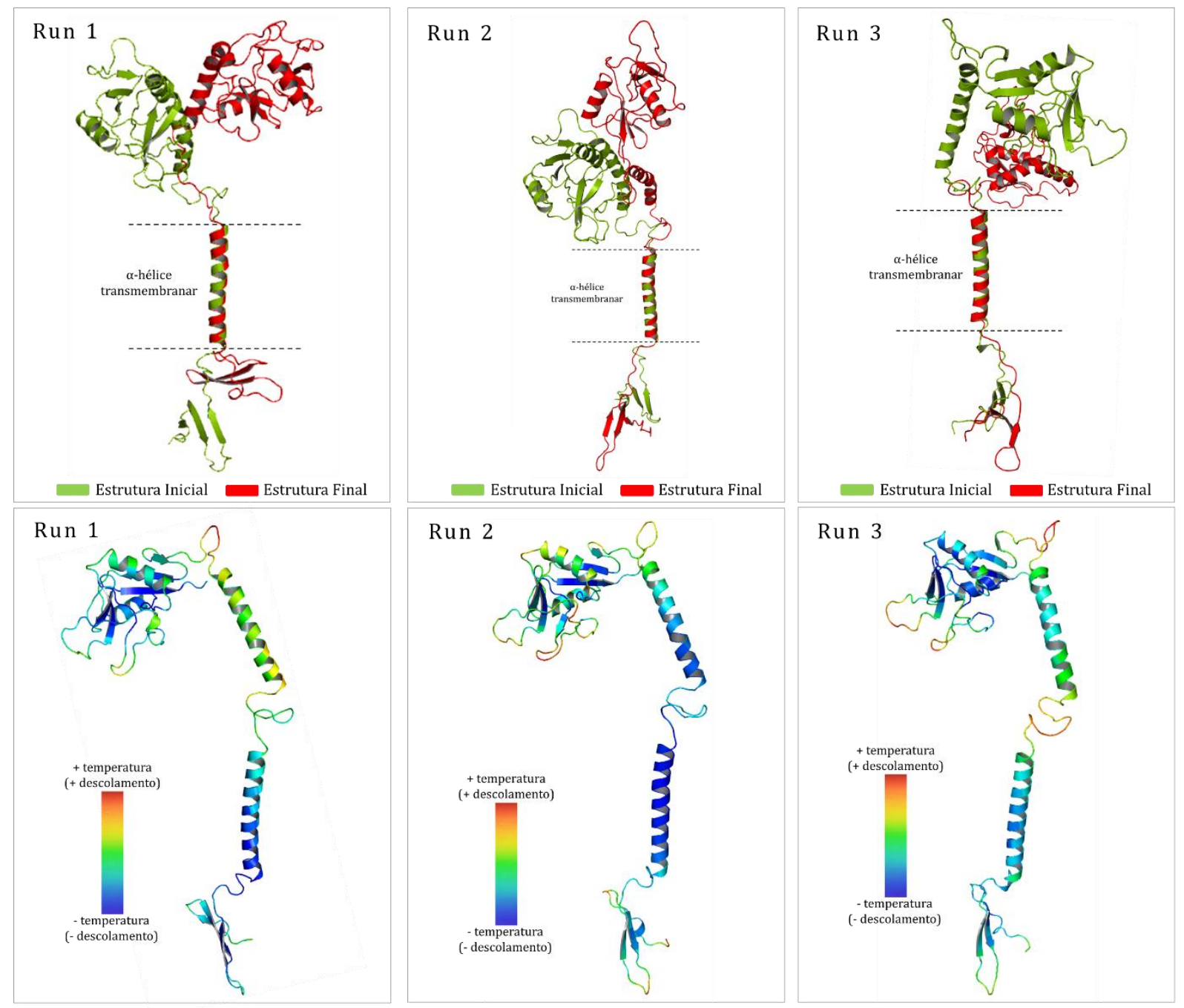

Alinhamento das estruturas inicial em $0 \mathrm{~ns}$ (verde) e final em $100 \mathrm{~ns}$ (vermelho) da simulação de DM e $b$-factors de cada uma das três simulações de DM. Fonte: Arquivo pessoal.

A observação de regiões especificas com alto $b$-factor na estrutura completa de hDectin-1, principalmente na região que corresponde ao domínio Stalk e porção intracelular, levantou a hipótese de que pudesse haver regiões com desordem intrínseca que pudessem justificar a grande variação estrutural observada. Uma vez que é confirmada a correlação entre o alto $b$-factor e regiões intrinsecamente desordenadas (RADIVOJAC et al., 2004), foi feita a predição de regiões de desordem intrínseca para a sequência primária de hDectin-1.

A predição de regiões de desordem intrínseca na proteína hDectin-1 foi feita por meio dos softwares IUPred (DOSZTÁNYI et al., 2005), PrDOS (ISHIDA; KINOSHITA, 2007) e PONDR (XUE et al., 2010). Esses softwares foram descritos no estudo de Pryor e Wiener (2014), onde apresentaram bons resultados na predição de desordem intrínseca em proteínas integrais de membrana. Para os três softwares a pontuação é crescente, indicando que valores 
inferiores a 0,49 representam aminoácidos que compõem regiões estruturadas e superiores a 0,5 representam os aminoácidos que compõem regiões desordenadas. A representação dos resultados é fornecida em formato de gráfico.

As regiões de desordem intrínseca em proteínas são constituídas por sequências de aminoácidos com características típicas, com baixa quantidade de resíduos hidrofóbicos e alta quantidade de resíduos polares e carregados, o que permite a confiável identificação por meio de ferramentas especificas de bioinformática (BÜRGI et al., 2016).

A predição apresentou os seguintes resultados: IUPred (DOSZTÁNYI et al., 2005) detectou dois segmentos intrinsecamente desordenados localizados do resíduo 1-9 e 87-105 (figura 30A); PrDOS (ISHIDA; KINOSHITA, 2007) detectou três segmentos intrinsecamente desordenados localizados do resíduo 1-12, 24-36 e 90-100 (figura 30B); PONDR (XUE et al., 2010) detectou dois segmentos intrinsecamente desordenados localizados do resíduo 1-12 e 84116 (figura 30C).

Figura 30 - Predição de regiões com desordem intrínseca.
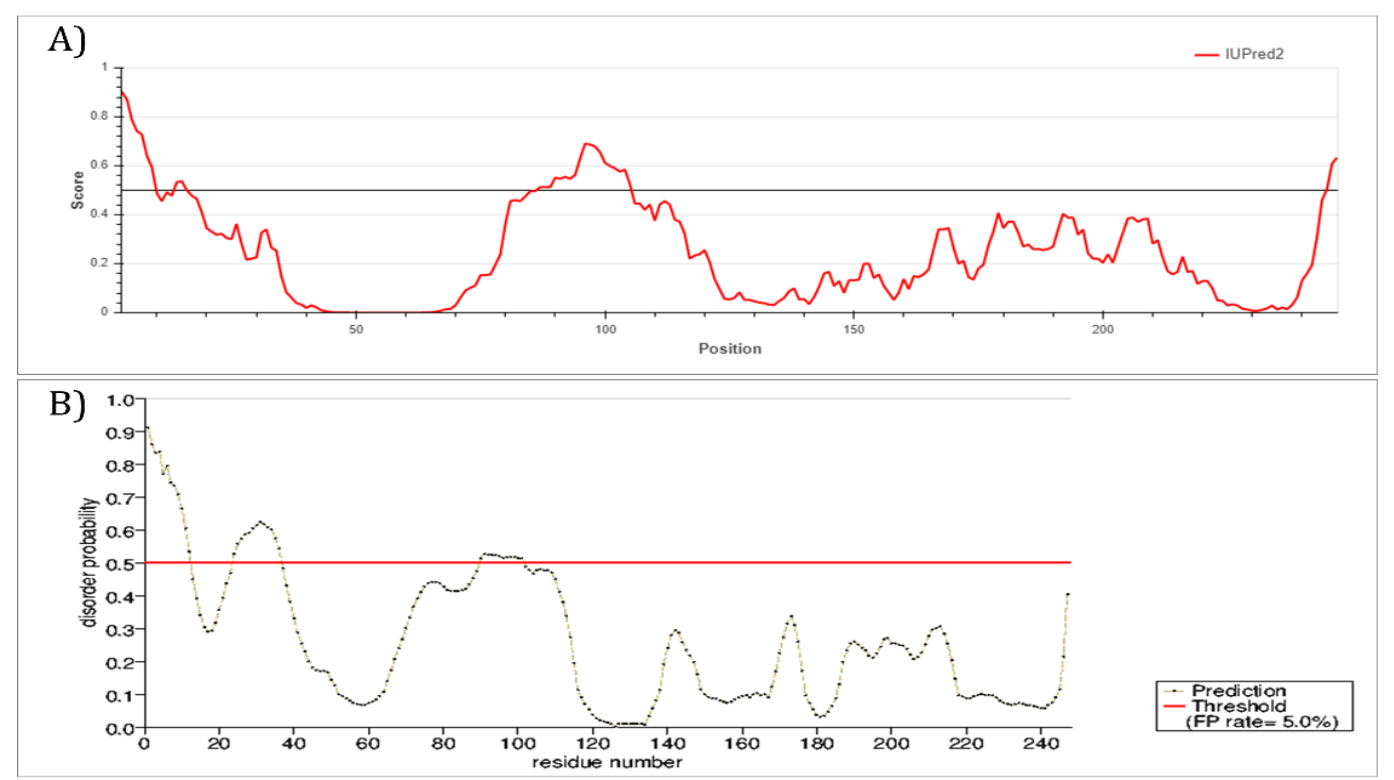

C)

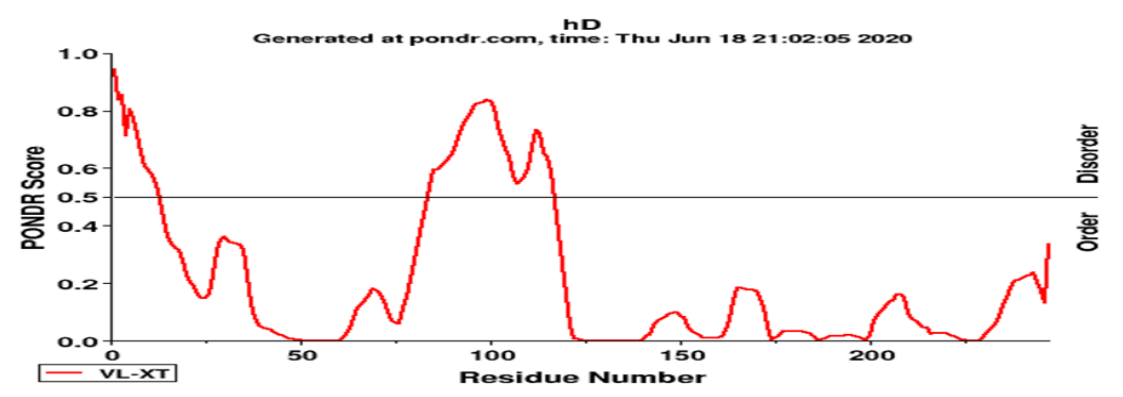

Para cada aminoácido é atribuída uma pontuação individual: valores superiores a 0,5 representam os aminoácidos com características intrinsecamente desordenadas. Fonte: Arquivo pessoal. 
Para verificar se essas regiões de desordem intrínseca presentes em hDectin-1 seriam conservadas nas proteínas Dectin-1 de outros mamíferos, foi feita a predição de desordem intrínseca com o software IUPred (DOSZTÁNYI et al., 2005) para as sequências primárias de camundongo (UniProt ID Q6QLQ4), rato (UniProt ID B5BUZ1), bovino (UniProt ID Q49BZ4), primata macaca mulatta (UniProt ID Q8HZR8) e primata pan troglodytes (Chimpanzee) (UniProt ID A0A2J8QQS0).

Os resultados da predição confirmaram a conservação das regiões de desordem intrínseca nas sequências analisadas (figura 31). Mesmo para as sequências com menor percentual de identidade, neste caso camundongo (UniProt ID Q6QLQ4) e rato (UniProt ID B5BUZ1) com, respectivamente, $60,25 \%$ e 58,30\%. As sequências mais distantes filogeneticamente também foram as que apresentaram mais aminoácidos compondo as regiões de desordem intrínseca. Assim, pode-se inferir que, possivelmente, a desordem intrínseca presente em regiões especificas das proteínas Dectin-1 estejam relacionadas a sua função e seja uma importante propriedade a ser melhor investigada, uma vez que nenhuma referência sobre essa característica foi descrita na literatura até o momento.

Figura 31 - Predição de regiões com desordem intrínseca as para as sequências primárias de camundongo, rato, bovino, primata macaca mulata e primata pan troglodytes.

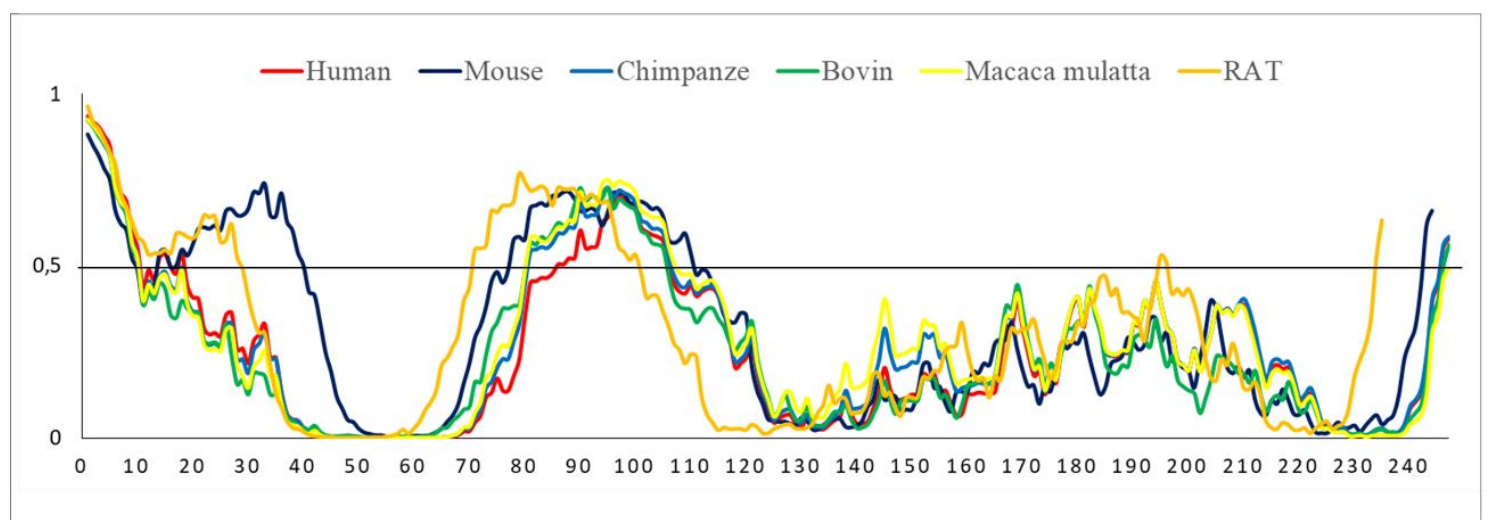

Para cada aminoácido é atribuída uma pontuação individual: valores superiores a 0,5 representam os aminoácidos com características intrinsecamente desordenadas.

Um grande desafio técnico nos estudos de determinação e análise estrutural com proteínas de membrana é a abundância de regiões intrinsecamente desordenadas presentes nessas proteínas. A estimativa é de que, aproximadamente, $70 \%$ das proteínas integrais de membrana contenham regiões intrinsecamente desordenadas, em comparação com, aproximadamente, 35\% nas proteínas solúveis (PRYOR; WIENER, 2014; YANG et al., 2008). 
Os resultados obtidos demostram que a estrutura completa de hDectin-1 apresenta regiões com alta flexibilidade estrutural, correspondentes as regiões que apresentaram desordem intrínseca nos resultados de predição.

Os valores observados no RMSD e RMSF da estrutura completa de hDectin-1 ficaram acima dos valores obtidos anteriormente na simulação de DM do CTLD de hDectin-1. Para verificar se a estrutura completa de hDectin-1 apresenta estabilidade estrutural e garantir que não ocorreu o desenovelamento de seus domínios, as análises de comportamento estrutural ao longo do tempo foram complementadas com a verificação do estado conformacional da estrutura em três momentos diferentes da simulação de DM: Estrutura inicial ( $0 \mathrm{~ns}), 50 \mathrm{~ns}$ e 100 ns para as três simulações (figura 32). Essa análise foi realizada por meio do servidor PDBSum (LASKOWSKI, 2001) que gera uma imagem linear da composição da estrutura tridimensional submetida ao servidor.

A simulação de DM 1 (figura 32A), apresentou apenas pequenas variações no tamanho de seus elementos secundários ao longo do tempo, são elas: A folha- $\beta$ 1, composta pelos aminoácidos N9-L10 (antiparalela a folha- $\beta$ 2), presente na estrutura inicial está ausente aos 50 ns e novamente presente aos $100 \mathrm{~ns}$; As folhas- $\beta 2$ e 3 antiparalelas, compostas, respectivamente, pelos aminoácidos T16-Q17 e V30-V31, variam sua extensão para Q17-D21 e R27-V31, retornando ao seu estado inicial aos 100 ns; A $\alpha$-hélice transmembranar $(\mathrm{H} 1)$ composta inicialmente por P42-A68 varia para L45-M67 aos $50 \mathrm{~ns}$ e retorna quase ao mesmo tamanho inicial aos 100 ns (P42-M67); As $\alpha$-helices H2 e H3 estão localizadas no domínio Stalk, compostas inicialmente pelos aminoácidos F84-E90 e Q94-T107 respectivamente, apresentaram pequena variação aos 50 ns (H2 Y83-E90 e H3 Q94-T107), aos 100 ns foi observada apenas a ausência de uma parte da $\alpha$-hélice que corresponde ao aminoácido L100 (perda momentânea de uma ponte de hidrogênio entre os grupamentos $\mathrm{NH}$ e CO que formam essa parte da $\alpha$-hélice); As folhas- $\beta$ antiparalelas 4 e 5, compostas pelos aminoácidos I125Y127 e S130-N139, variaram apenas por um aminoácido aos 50 ns (I125-I126 e C131-N139) e 100 ns (W124-I127 e S130-N139); A $\alpha$-hélice H4, inicialmente composta por W141-L151, permaneceu igual aos $50 \mathrm{~ns}$ e apresentou dois aminoácidos a menos aos $100 \mathrm{~ns}$ (W141-W149); A folha- $\beta 6$ é composta por apenas dois aminoácidos (N154-L155) e não apresentou nenhuma variação aos 50 e 100 ns; A $\alpha$-hélice H5, composta pelos aminoácidos S161-S172, apresentou apenas a diminuição de tamanho correspondente a um aminoácidos (S161-V171) aos 50 ns e aos $100 \mathrm{~ns}$ retornou ao tamanho inicial (S161-S172); As folhas- $\beta$ antiparalelas 6 e 7, compostas por F179-S184 e L193-W194 respectivamente, não apresentaram nenhum tipo de variação aos 50 e 100 ns; As folhas- $\beta$ antiparalelas 8 e 9, compostas por C220-W222 e Y229-Q231 
respectivamente, apresentaram apenas a variação de um aminoácido na folha- $\beta 9$ no tempo de 100 ns (I228-Q231); A folha- $\beta$ 10, composta por S237-K244, apresentou apenas a variação de um aminoácidos aos 50 ns (S237-K243), retornando ao estado inicial aos 100 ns.

A $\alpha$-hélice presente no domínio Stalk é visualizada na representação obtida pelo servidor PDBSum (LASKOWSKI, 2001) como sendo duas $\alpha$-hélice (H2 F84-E90 e H3 Q94T107) unidas por um pequeno loop composto por N91-S93, entretanto, os softwares PyMol (DELANO et al., 2002) e Chimera (GODDARD et al., 2005) exibem apenas uma $\alpha$-hélice para essa região que compreende os aminoácidos L85-K108. Para essa análise, foi considerada apenas a composição dos elementos secundários apresentados nos resultados obtidos pelo servidor PDBSum (LASKOWSKI, 2001). Entretanto, a análise visual feita com os softwares PyMol (DELANO et al., 2002) e Chimera (GODDARD et al., 2005) não exibiu fragmentação da $\alpha$-hélice ou variação da quantidade de $\alpha$-hélices para essa região quando analisadas as mesmas estruturas de hDectin-1 nos tempos 0, 50 e $100 \mathrm{~ns}$. Isso ocorre porque os softwares PyMol (DELANO et al., 2002) e Chimera (GODDARD et al., 2005) consideram uma maior distância para as ligações de hidrogênio entre os átomos que formam as estruturas secundárias.

De maneira similar a simulação 1, em geral, houve apenas pequenas variações dos elementos secundários na simulação 2 e 3 realizadas para hDectin-1 na membrana celular (figura 32B e figura 32C). Nenhuma variação grande o suficiente foi observada para que se pudesse atribuir a existência de alterações conformacionais importantes e/ou desenovelamento da estrutura tridimensional.

Figura 32 - Comportamento dos elementos secundários analisado ao longo do tempo da triplicata de simulação de DM da estrutura completa de hDectin-1. Estrutura inicial (0 ns), 50 ns e $100 \mathrm{~ns}$. 

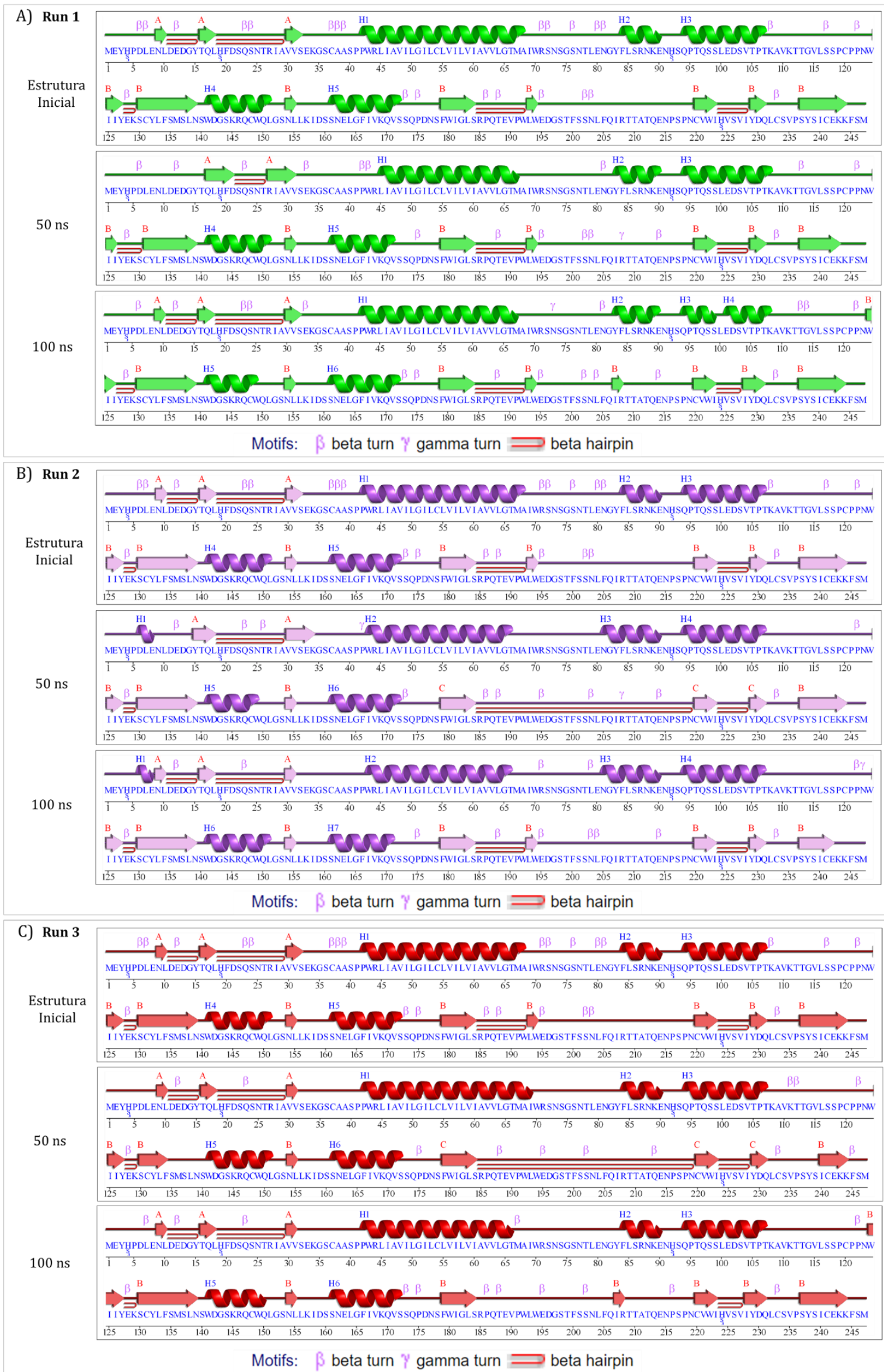

A) Simulação 1. B) Simulação 2. C) Simulação 3. Fonte: Arquivo pessoal. 
Proteínas integrais de membrana desempenham funções biológicas essenciais como transportadoras, receptoras e enzimas, estando envolvidas em funções críticas como adesão celular, resposta imune e sinalização celular (PRYOR; WIENER, 2014; GODING, 1996). Representam, aproximadamente, $15 \%$ a $30 \%$ das proteínas codificadas pelos genomas em geral e, para o genoma humano, a estimativa é de 30\% (KOEHLER et al., 2015).

Devido a estarem intimamente ligadas e relacionadas a membrana celular, a obtenção de estruturas transmembranares por meio de métodos experimentais tem se mostrado difícil (DE BREVERN, 2010; FLEISHMAN et al., 2006) e o número de proteínas transmembranares disponíveis no PDB ainda é limitado, $1 \%$ a $2 \%$ do total de estruturas depositadas na última década (KOEHLER et al., 2015). Esses dados mostram que a determinação de modelos estruturais in silico torna-se um importante eixo de pesquisa. Atualmente, mais da metade dos medicamentos comercializados têm como alvo proteínas transmembranares (KOEHLER et al., 2015; DE BREVERN, 2010). No entanto, o conhecimento de como essas drogas atuam em nível molecular permanece limitado, principalmente devido à falta de informações estruturais sobre a interação das drogas com suas proteínas alvo (KOEHLER et al., 2015).

O deslocamento estrutural superior a $20 \AA$ observado nos gráficos de RMSD e RMSF da estrutura completa de hDectin-1, quando comparados aos gráficos de RMSD e RMSF do CTLD de hDectin-1 com valores inferiores a $3 \AA$ vistos na triplicata de 100 ns (figura 33A), deixa evidente a contribuição das regiões com desordem intrínseca para os altos valores de RMSD e RMSF de hDectin-1 completa. Apesar dos domínios se mostrarem individualmente estáveis quando alinhados nos tempos inicial e final da simulação de DM (figura 33B, 33C, 33D e 33E), as regiões de desordem intrínseca localizadas, predominantemente, nas regiões de loop conferem a estrutura grande flexibilidade para movimentar-se. Essa característica pode ser fundamental em seu processo de reconhecimento de $\beta$-glucanos e dimerização cooperativa descrito por Dulal e Colaboradores (2018) e perfil de sinalização celular desencadeada pelo domínio intracelular divergente em diferentes espécies como descrito por TAKANO e colaboradores (2017).

Figura 33 - Comparativo dos resultados das simulações de DM do CTDL de hDectin-1 e sua estrutura completa. Alinhamento das estruturas inicial e final de hDectin-1 completa. 

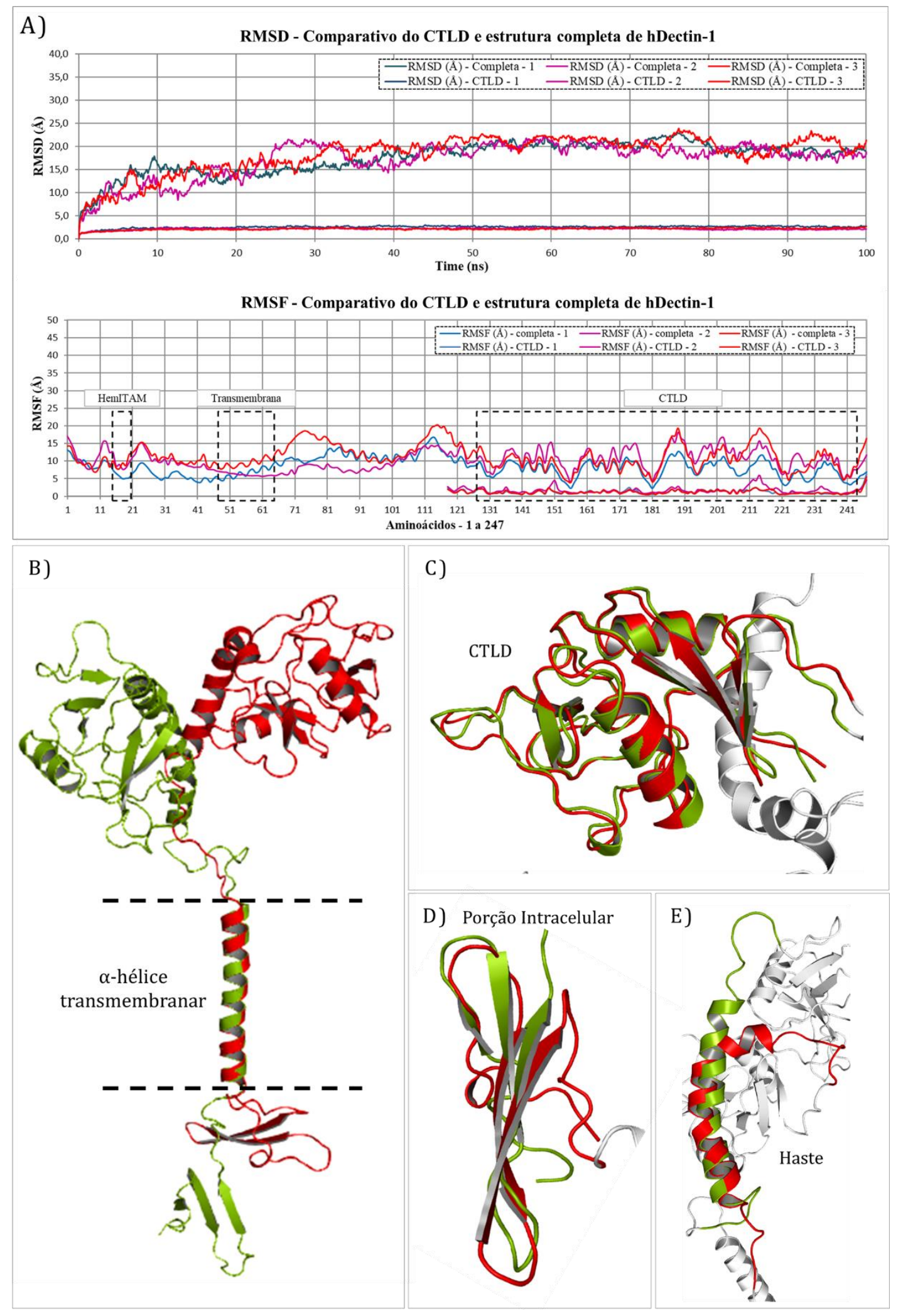

A) Comparativos dos RMSDs e RMSFs obtidos nas simulações de DM para o CTDL de hDcetin-1 e sua estrutura completa. B) Alinhamento dos domínios transmembranar inicial (verde) e final (vermelho) da estrutura completa de hDectin-1 simulada por $100 \mathrm{~ns}$ na membrana celular. C) Alinhamento das estruturas dos CTLD inicial (verde) e final (vermelho) da estrutura completa de hDectin-1 simulada por 100 ns na membrana celular. D) Alinhamento das estruturas da porção intracelular inicial (verde) e final (vermelho) da estrutura completa de hDectin-1 simulada por $100 \mathrm{~ns}$ na membrana celular. E) Alinhamento das estruturas do domínio Stalk (conecta o domínio transmembranar ao CTLD) inicial (verde) e final (vermelho) da estrutura completa de hDectin-1 simulada por 100 ns na membrana celular. Fonte: Arquivo pessoal. 
A partir da combinação de diferentes metodologias in silico foi possível determinar um modelo viável para a estrutura completa de hDectin-1 que, até o momento, era totalmente desconhecida. A simulação de DM da estrutura completa inserida na membrana celular demostrou que os domínios modelados apresentam estabilidade estrutural, possibilitando que que fossem empregados em estudos estruturais.

Visto que existem diferenças na função de Dectin-1 nas espécies estudadas (TAKANO et al., 2017) e, na maioria das vezes, não é possível trabalhar com uma estrutura obtida por métodos experimentais, os modelos teóricos de estruturas tridimensionais de proteínas são importantes nos campos de pesquisa para a compreensão de mecanismos de interações biológicas e design de fármacos (KOEHLER et al., 2015; DE BREVERN, 2010; WEIL; RENNER, 2008). Assim, o modelo completo de hDectin-1 obtido no presente estudo, permitiu realizar análises de comportamento estrutural e interação proteína-ligante e proteína-proteína.

\subsection{Dimerização de hDectin-1}

\subsubsection{Simulação de DM para análise da estabilidade do dímero de mDectin-1}

A principal referência para a dimerização de hDectin-1 é o dímero de mDectin-1 em complexo com o $\beta$-glucano laminarin depositado no PDB com ID 2CL8 (BROWN et al., 2007).

Brown e Colaboradores (2007) obtiveram a conformação desse dímero para o domínio CTLD de mDectin-1 por cristalografia com difração de raio-X (PDB ID 2CL8), porém, até aquele momento, o dímero foi descrito como inviável in vivo por não haver outros estudos que descrevessem a possibilidade da ocorrência dessa conformação dimérica para Dectin-1. Como não haviam sido realizados estudos in silico que avaliassem a viabilidade estrutural do dímero PDB ID: 2CL8 de mDectin-1 em relação a estabilidade de sua conformação dimérica, foram realizadas simulações de DM para verificar a estabilidade estrutural dessa conformação dimérica afim de verificar se as informações estruturais desse dímero poderiam ser usadas como referência para a dimerização de hDectin-1.

Antes da construção do sistema proteína/solvente para a simulação de DM do dímero de mDectin-1 PDB ID: 2CL8, foram excluídos do arquivo de coordenadas da estrutura as moléculas de água, íons e a molécula de laminarin, ficando apenas os dois monômeros correspondentes aos CTLD de mDectin-1.

As simulações de DM foram realizadas por meio do software GROMACS versão 2019.3 (ABRAHAM et al., 2015) que implementou o campo de força CHARMM36m 
(HUANG et al., 2017). O sistema proteína/solvente para a simulação de DM foi construído com moléculas de água e íons ( $\mathrm{Na}+$ e Cl-). A concentração de íons $\mathrm{Na}+$ e Cl- usada no sistema foi $0.15 \mathrm{M} \mathrm{KCl}$, estando essa concentração próxima da concentração fisiológica de íons (JO et al., 2008; JO et al., 2007). O sistema é do tipo cúbico, com dimensões de 79 Å nos eixos x, y e z, sendo composto pelo dímero (chain A e B), moléculas de água (TIP3) e íons, caracterizando o ambiente celular.

Foi feita triplicata de simulações de DM de 100 ns para o dímero de mDectin-1. Cada simulação de DM do sistema proteína-solvente foi realizada em condições físico-químicas controladas, com temperatura de $310 \mathrm{~K}$ e pressão constante de $1 \mathrm{~atm}$.

O comportamento molecular das estruturas ao longo do tempo foi analisado por meio do RMSD, RMSF e alinhamento das estruturas nos tempos inicial e final de simulação de DM.

O alinhamento das estruturas nos tempos inicial e final da simulação de DM mostrou que houve pouca movimentação dos monômeros em relação a posição inicial (figura 34A).

A análise do RMSD (figura 34B) mostrou que, ao longo das três simulações de DM, as três trajetórias do dímero de mDectin-1 foram similares, com RMSD constante após os primeiros $10 \mathrm{~ns}$ e permanecendo sem variações consideráveis até o final da simulação. No gráfico observa-se que o RMSD se eleva gradativamente até, aproximadamente, 8 ns, após esse tempo de simulação a estrutura se estabiliza e se mantem até o final dos 100 ns.

O RMSF da triplicata (figura 34B) apresenta consistência entre as variações por resíduo nas três simulações. São notadas apenas duas regiões menos consistentes: Aminoácidos 117 a 121, localizados na porção de transição entre o CTLD e domínio Stalk (ausente na estrutura); e aminoácidos 208 a 218 que compõem uma região longa de loop. 
Figura 34 - Trajetória da simulação de DM do dímero de mDectin-1 (PDB ID: 2CL8) e alinhamento das estruturas inicial e final.

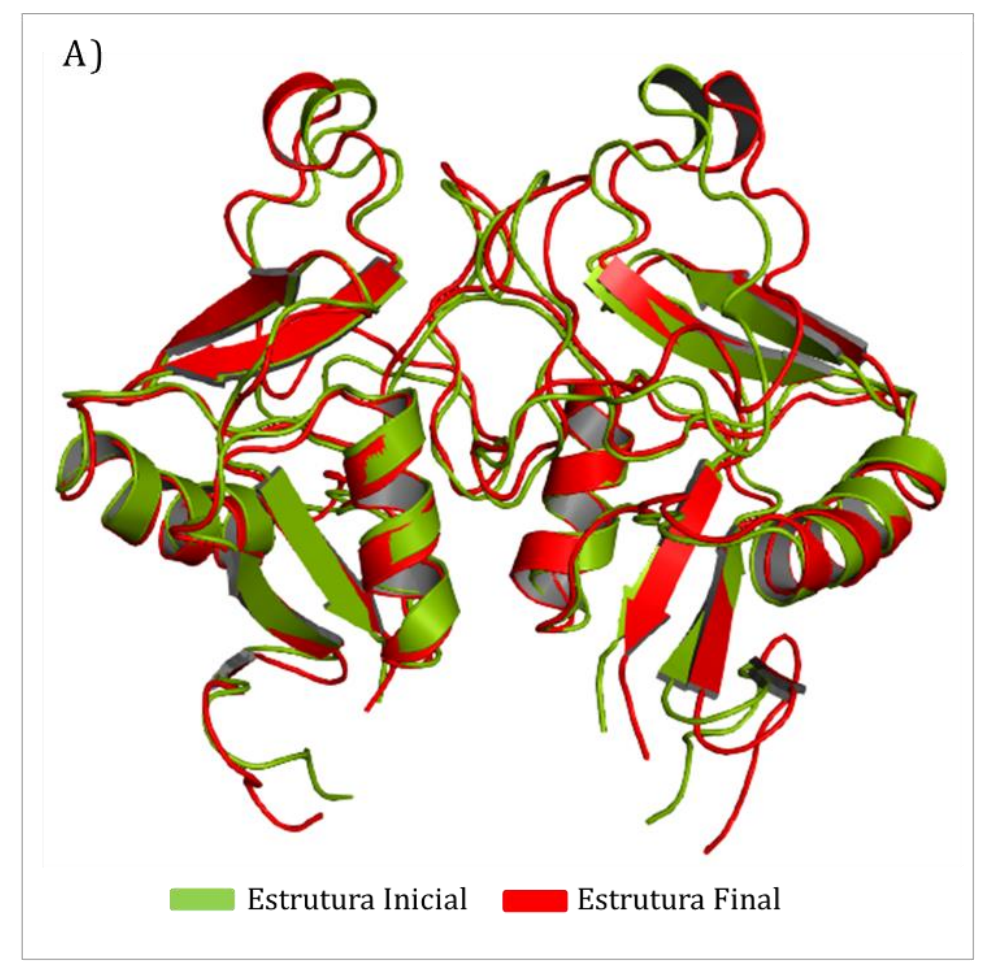

B)

RMSD - Dímero CTLD de mDectin-1 (PDB ID 2CL8)

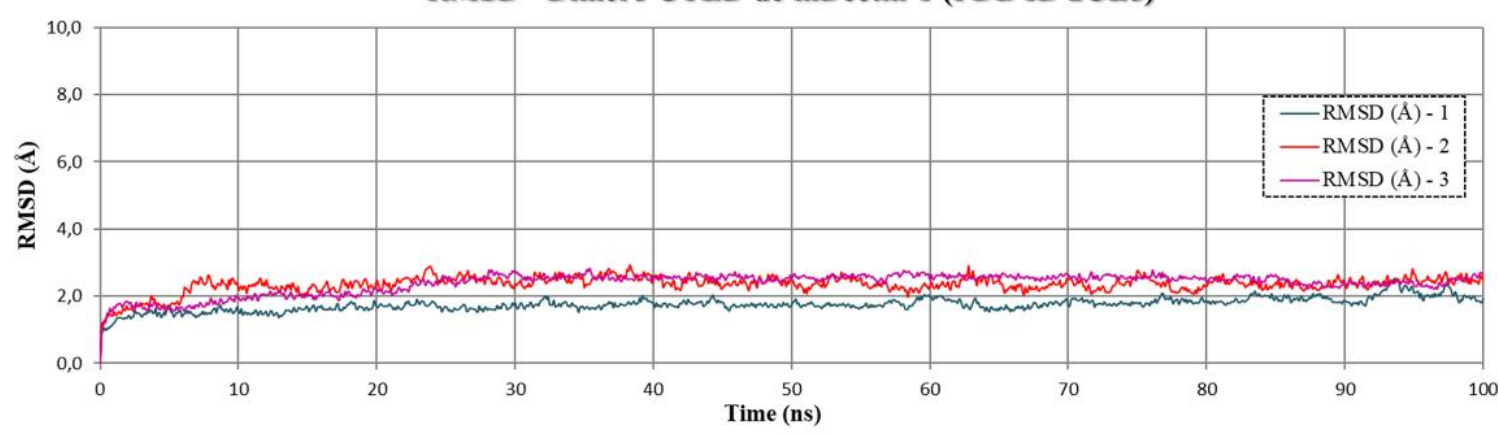

RMSF - Dímero CTLD de mDectin-1 (PDB ID 2CL8)

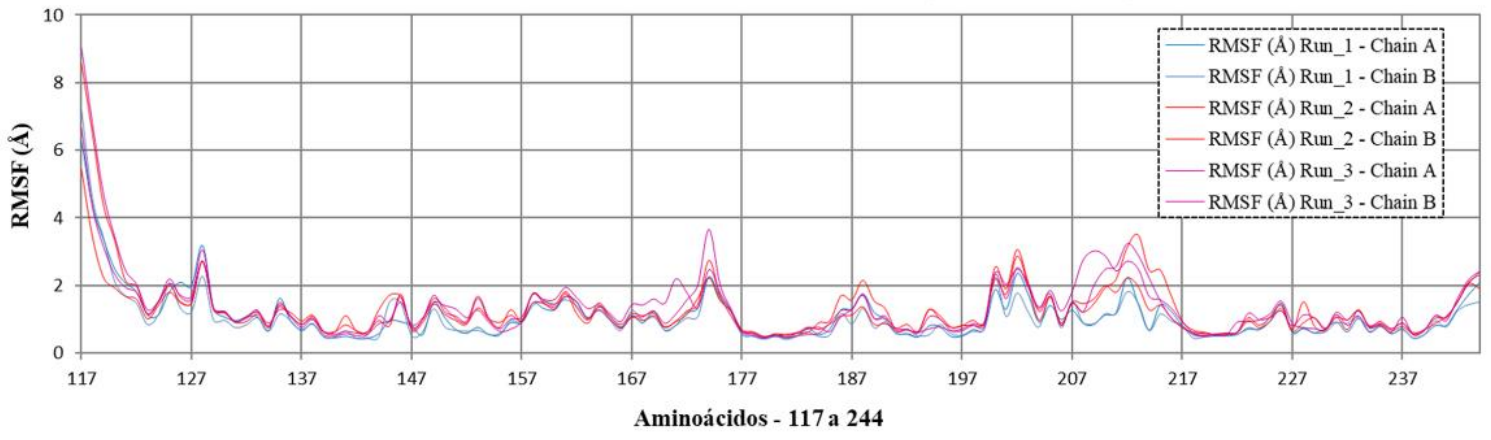

A) Alinhamento das estruturas inicial em $0 \mathrm{~ns}$ (verde) e final em $100 \mathrm{~ns}$ (vermelho) da simulação de DM. B) Valores de RMSD das coordenadas dos átomos $\mathrm{C} \alpha$ em função do intervalo de tempo de simulação em triplicata de 100 ns e comparativo da variação estrutural por aminoácido das três simulações expressos no gráfico de RMSF em relação à estrutura inicial. Fonte: Arquivo pessoal. 
O dímero de CTLD de mDectin-1 descrito por Brown e Colaboradores (2007) se mostrou estável ao longo das três simulações de DM, deste modo, pode ser considerado uma referência para a dimerização de hDectin-1.

\subsubsection{Dimerização de hDectin-1 completa por meio de Docking proteína- proteína}

O docking direcionado para a obtenção do dímero de hDectin-1 foi realizado por meio do servidor HADDOCK 2.2 (VAN ZUNDERT et al., 2016). Os resíduos ativos (diretamente envolvidos na interação proteína-proteína) indicados para o direcionamento do docking foram os aminoácidos W141, D142, K145, D146, W149, K157, S184, R185, P186, Q187, T188, P191, L193, E195, D196, G197, S198, T199, S217, N219, C220, L232, C233 e S234 de hDectin-1 correspondem aos resíduos W140, Y141, K144, R145, 148S, K156, S183, R184, N185, Q186, S187, P190, F192, E194, D195, G196, S197, A198, L216, N218, C219, I231, C232 e N233 que compõe a interface de interação proteína-proteína do dímero de mDectin-1 PDB ID: 2CL8 (figura 35) descrito por Brown e Colaboradores (2007), que se mostrou estável durante as simulações de DM (resultado anterior). Esses aminoácidos foram identificados por meio do script InterfaceResidues.py executado no software PyMOL (DELANO et al., 2002). O script InterfaceResidues.py permite localizar resíduos de formam a interface entre duas ou mais cadeias em um complexo. Os resíduos passivos (aminoácidos que estão na superfície da proteína em regiões circundantes aos resíduos indicados como ativos) não foram indicados, mas foi permitido que o software HADDOCK (VAN ZUNDERT et al., 2016) definisse automaticamente esses resíduos. 
Figura 35 - Interface de interação entre os monômeros do Dímero de mDectin-1.

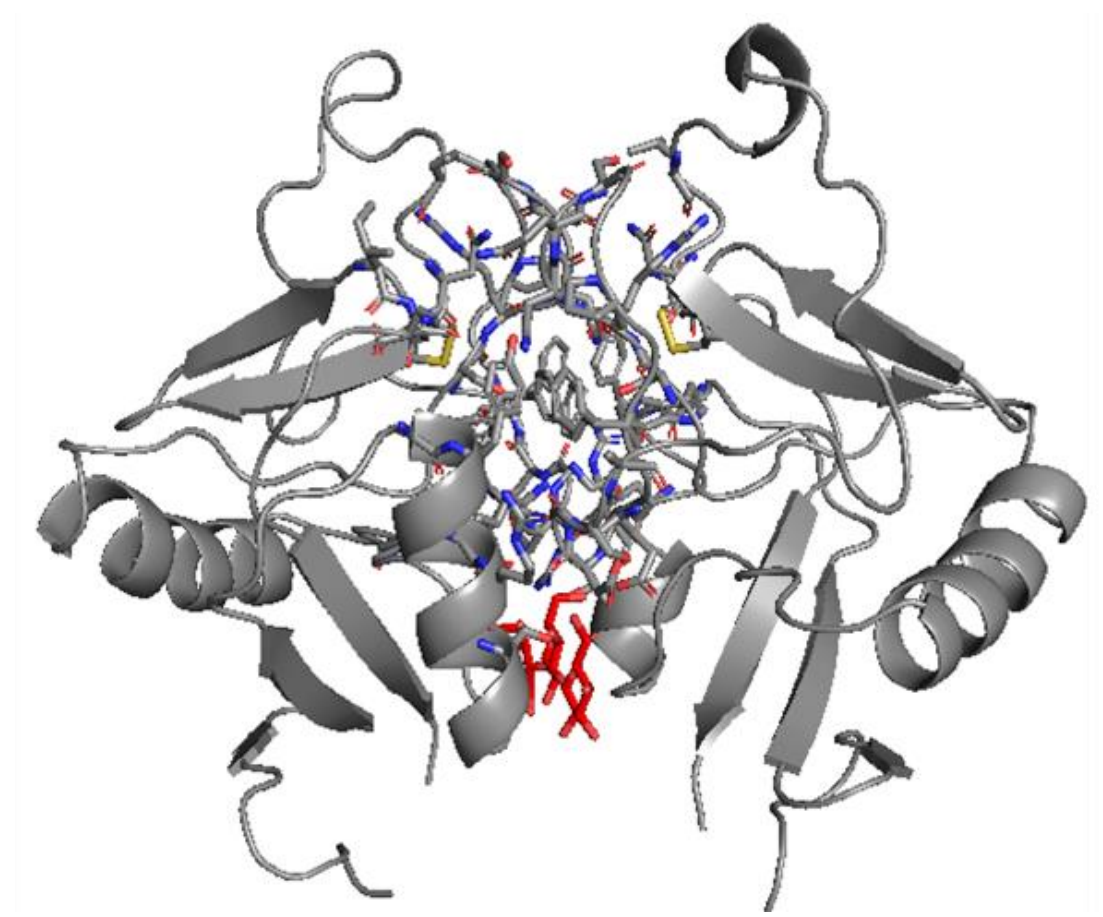

Dímero de mDectin-1 PDB ID: 2CL8 (cinza) e interface de interação entre os CTDL de mDectin-1 (azul). Fonte: Arquivo pessoal.

O servidor HADDOCK 2.2 (VAN ZUNDERT et al., 2016) forneceu como resultado do docking proteína-proteína quatro clusters, cada um com as quatros melhores conformações para o dímero de hDectin-1 de acordo com o HADDOCK score. Dois critérios foram empregados na escolha do dímero: 1) a conformação com resultado mais confiável de acordo com o HADDOCK score e; 2) a inspeção visual para verificar o posicionamento dos domínios transmembranares e dos $\mathrm{N}$-terminais para que o dímero pudesse ser adequadamente inserido na membrana celular.

O melhor cluster foi o cluster-1, com HADDOCK score -138.7 (figura 36A) e a conformação dimérica mais favorável para a inserção na membrana celular foi também a conformação vista no cluster-1. Como cada cluster é composto por quatro dímeros, todos foram analisados visualmente e como nenhuma diferença significante foi observada, o dímero 1 do cluster-1 foi escolhido para representar a conformação dimérica de hDectin-1 (figura 36B). 
Figura 36 - Dímero de hDectin-1.

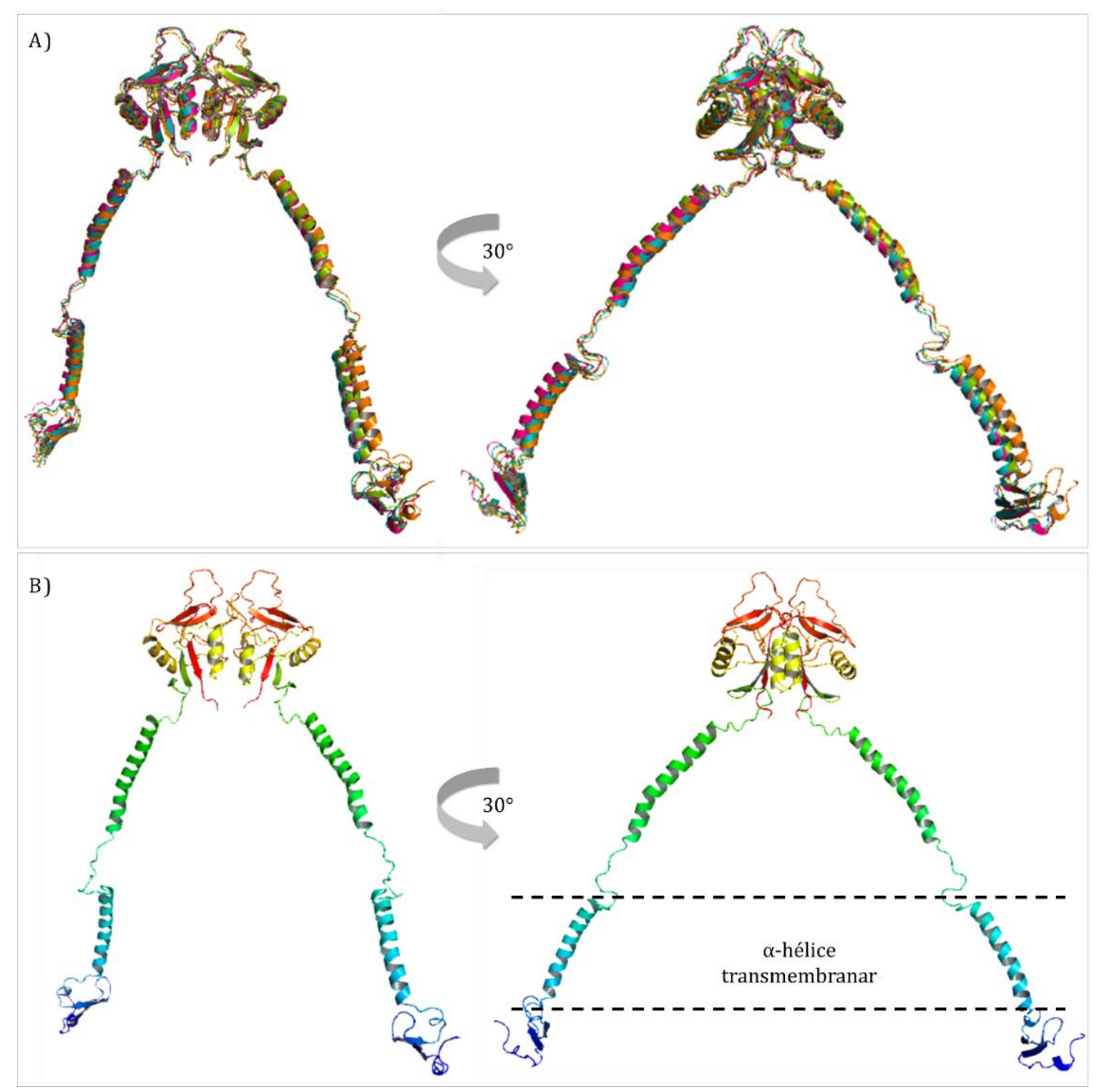

A) Alinhamento dos quatro dímeros presentes no cluster com melhor HADDOCK score e conformação dimérica mais favorável para a inserção na membrana celular. B) Dímero 1 do cluster-1 escolhido para representar a conformação dimérica de hDectin-1. Fonte: Arquivo pessoal.

\subsubsection{Simulação de DM do dímero de hDectin-1 na membrana celular}

A construção do sistema dímero/membrana celular para a simulação de DM do dímero foi realizada seguindo os mesmos critérios já descritos anteriormente na etapa de simulação de DM de hDectin-1 completa na membrana. O sistema obtido por meio do servidor CHARMM-GUI (JO et al., 2008) é do tipo paralelepipédico, com dimensões de $220.07 \AA$ no eixo x, $220.07 \AA ̊$ A no eixo y e $241.5 \AA$ Å no eixo z, composto pelo dímero (cadeias A e B idênticas 
da proteína hDectin-1) inserida em uma bicamada fosfolipídica, com moléculas de água (TIP3) e íons que caracterizam o ambiente intracelular e extracelular.

Após essa etapa, o sistema dímero/membrana foi submetido a simulação de DM para que fosse analisado seu comportamento na membrana ao longo do tempo. O sistema completo e pronto para simulação de DM está exposto na figura 37.

Figura 37 - Sistema dímero/membrana gerado pelo servidor CHARMM-GUI para simulação de dinâmica molecular.

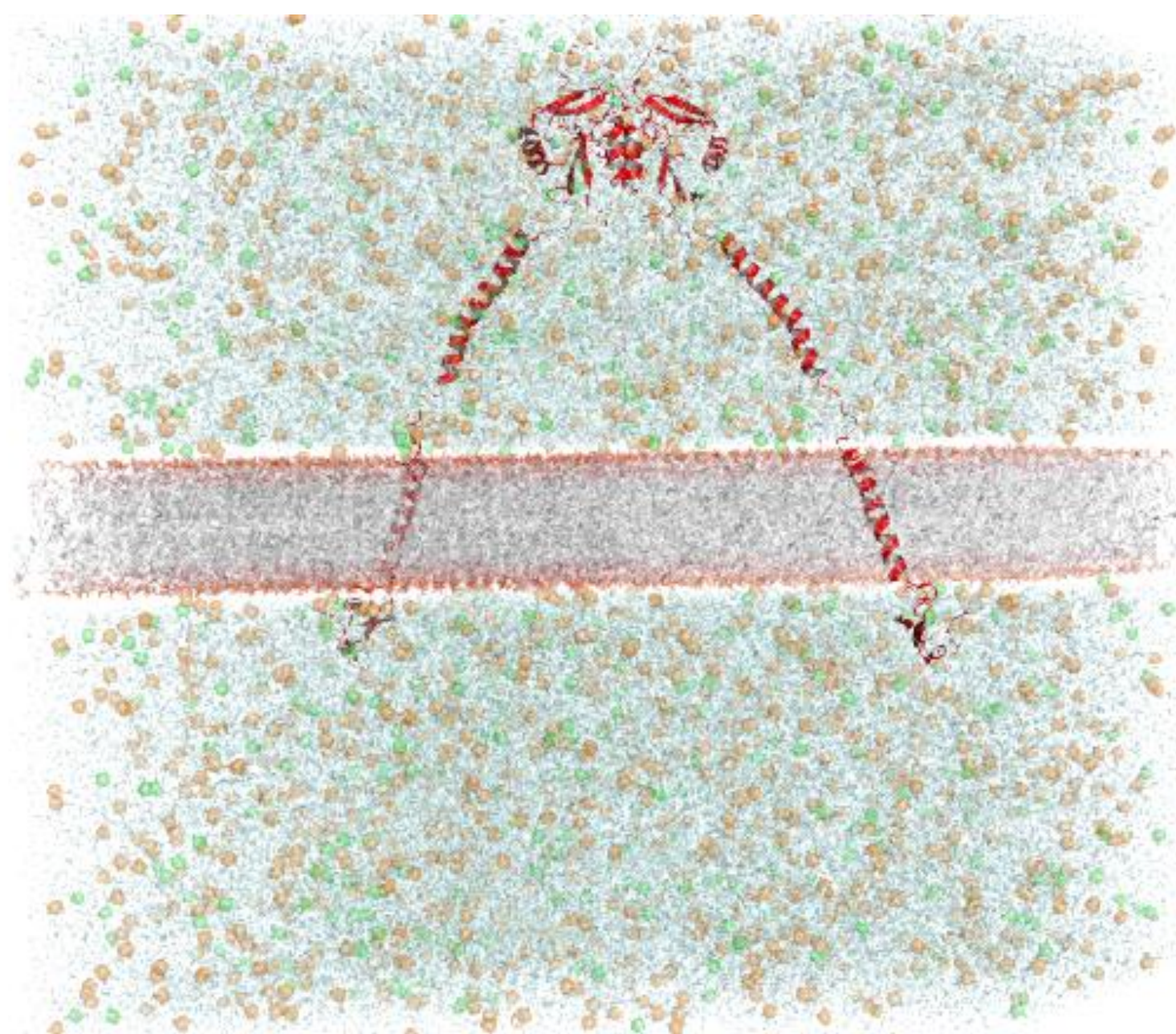

Sistema dímero/membrana contendo água (azul), íons $\mathrm{Na}+$ e Cl- (esferas verdes e laranja), dímero da proteína hDectin-1 completa (vermelho) e membrana celular composta de bicamada de fosfolipídios DLPA (cinza e vermelho). Fonte: Arquivo pessoal.

Foi feita a triplicata de simulações de DM de 50 ns para o dímero de hDectin-1 na membrana celular. Cada simulação de DM do sistema dímero/membrana foi realizada em condições físico-químicas controladas, com temperatura de $310 \mathrm{~K}$ e pressão constante de $1 \mathrm{~atm}$.

O comportamento molecular do dímero ao longo do tempo foi analisado por meio do alinhamento das estruturas nos tempos inicial e final de simulação de DM e RMSF. A figura 
38A apresenta as estruturas nos tempos inicial e final (50 ns) de simulação de DM, o alinhamento das estruturas foi feito usando como referência o CTLD da cadeia A de cada dímero para cada uma das três simulações (figura 38B e 38C).

$\mathrm{O}$ alinhamento das estruturas mostrou que, nas três simulações, a interação entre as superfícies das cadeias A e B que ocorre na região dos CTLD formando o dímero, permaneceu estável ao longo dos 50 ns. A flutuação por resíduo vista no gráfico de RMSF apresentou similaridade entre as cadeias A e B dos dímeros nas três simulações de DM, principalmente na região correspondentes aos CTLD (figura 38D).

Figura 38 - Analises da simulação de DM do dímero de hDectin-1 na membrana celular. 


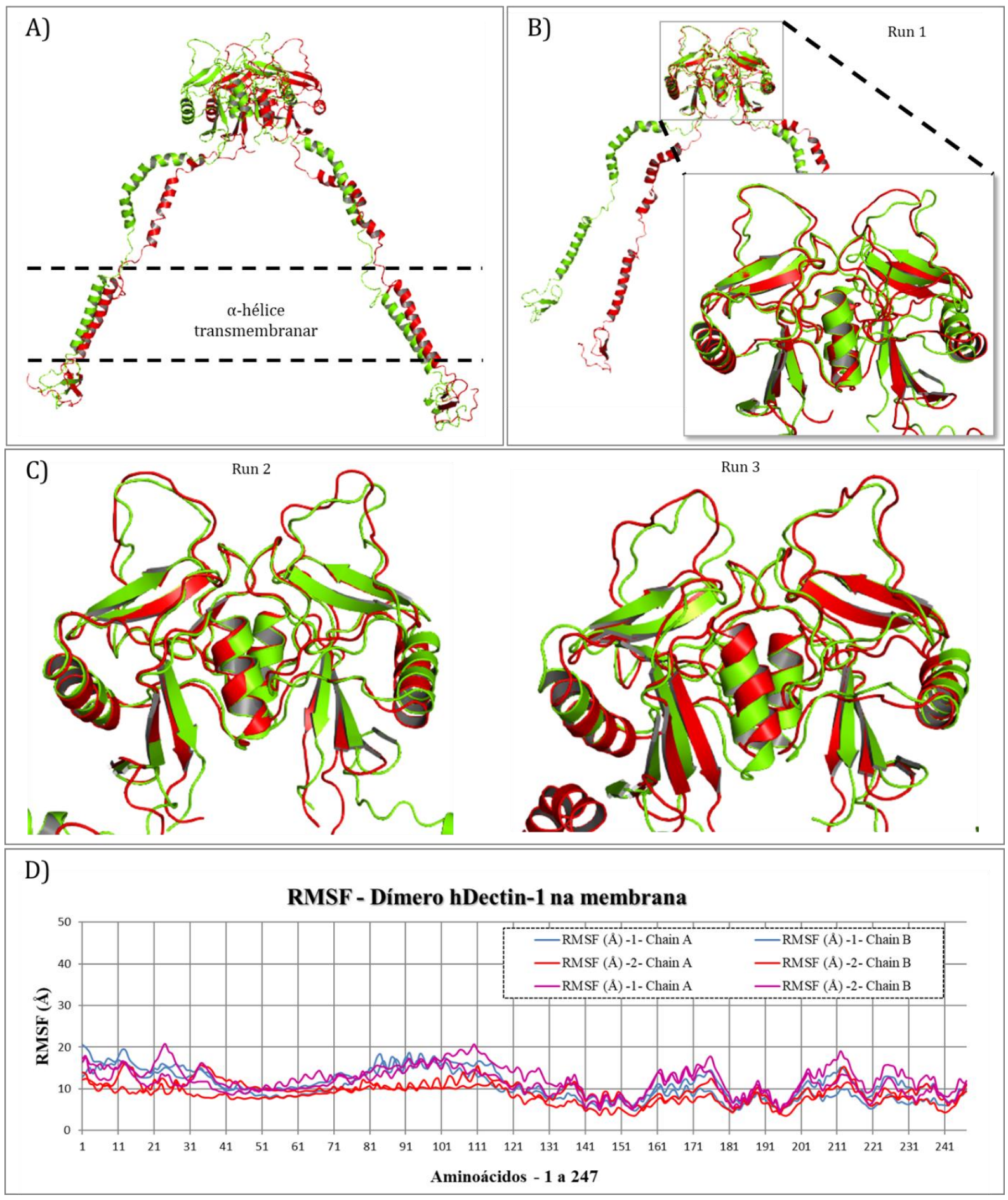

A) Dímero da estrutura completa de hDectin-1. Estrutura inicial em verde e final (50 ns) em vermelho. B) Alinhamento dos dímeros usando como referência a estrutura do CTLD da cadeia A na simulação de DM 1. C) Alinhamento dos dímeros usando como referência a estrutura do CTLD da cadeia A na simulação de DM 2 (esquerda) e 3 (direita). D) Comparativo da variação estrutural por aminoácido das três simulações expressos no gráfico de RMSF em relação à estrutura inicial. Fonte: Arquivo pessoal.

Por se tratar de um sistema composto por uma grande quantidade de átomos, não foi possível realizar simulações mais longas com, pelo menos, 100 ns em tempo hábil do dímero com as estruturas completas de hDectin-1 na membrana celular. Para que o comportamento do 
dímero formado pelos CTLD de hDectin-1 e estabilidade das ligações entre as cadeias A e B pudessem ser analisados em simulações de DM mais longas, foram realizadas outras simulações de DM do dímero apenas com os CTLD de hDectin-1.

\subsubsection{Simulação de DM do dímero de hDectin-1 formado pelos CTLD}

A interface de interação proteína/proteína que forma o dímero de hDectin-1 se encontra apenas na porção extracelular que corresponde ao CTLD, sendo essa uma conclusão baseada nos resultados obtido na etapa de docking e corroborada por Dulal e Colaboradores (2018) em análises de formação de oligômeros pelo CTLD de mDectin-1. Deste modo, para que fosse possível avaliar por mais tempo a estabilidade da interação entre as superfícies das cadeias A e B que formam o dímero, foram realizadas simulações de DM com o dímero composto pelos CTLD de hDectin-1 para verificar a estabilidade e viabilidade da conformação dimérica obtida por docking.

Antes da construção do sistema proteína/solvente para a simulação de DM do dímero composto pelos CTLD de hDectin-1, foram excluídos do arquivo de coordenadas da estrutura os átomos correspondentes aos aminoácidos 1 a 116, ficando apenas os dois monômeros correspondentes aos CTLD de hDectin-1.

As simulações de DM foram realizadas por meio do software GROMACS versão 2019.3 (ABRAHAM et al., 2015) que implementou o campo de força CHARMM36m (HUANG et al., 2017). O sistema proteína/solvente para a simulação de DM foi construído com moléculas de água e íons ( $\mathrm{Na}+$ e Cl-). A concentração de íons $\mathrm{Na}+$ e $\mathrm{Cl}$ - usada no sistema foi $0.15 \mathrm{M} \mathrm{KCl}$, estando essa concentração próxima da concentração fisiológica de íons (JO et al., 2008; JO et al., 2007). O sistema é do tipo cúbico, com dimensões de $80 \AA$ Ånos eixos x, y e z, sendo composto pelo dímero (chain A e B), moléculas de água (TIP3) e íons, caracterizando o ambiente celular.

Foi feita a triplicata de simulações de DM de 100 ns para o dímero dos CTLD de hDectin-1 (CTLD-hD). Cada simulação de DM do sistema proteína-solvente foi realizada em condições físico-químicas controladas, com temperatura de $310 \mathrm{~K}$ e pressão constante de $1 \mathrm{~atm}$.

O comportamento molecular das estruturas ao longo do tempo foi analisado por meio do RMSD, RMSF, $b$-factor e alinhamento das estruturas nos tempos inicial e final de simulação de DM. A figura 39A apresenta o alinhamento das estruturas nos tempos inicial e final de simulação de DM do dímero CTLD-hD. 
A análise do RMSD mostrou que, ao longo das três simulações de DM, as três trajetórias dímero de CTLD-hD foram similares, com RMSD constante após os primeiros 10 ns e permanecendo sem variações consideráveis até o final da simulação. No gráfico observase que o RMSD se eleva gradativamente até, aproximadamente, $10 \mathrm{~ns}$, após esse tempo de simulação a estrutura se estabiliza e se mantem até o final dos 100 ns nas três simulações (figura 39C).

O RMSF da triplicata apresenta consistência entre as variações por resíduo nas três simulações. São notadas apenas três regiões menos consistentes: Aminoácidos 117 a 122 , localizados na porção de transição entre o CTLD e domínio Stalk (ausente na estrutura); aminoácidos 210 a 217 que compõem uma região longa de loop, e últimos três aminoácidos da região C-terminal (245-247) (figura 39C).

A análise do $b$-factor confirma a localização das regiões com maior variação estrutural por resíduos observadas no gráfico de RMSF que correspondem, ao N e C terminal e uma longa região de loop (figura 39B). 
Figura 39 - Trajetória da simulação de DM do dímero de hDectin-1 (apenas CTLD) e alinhamento das estruturas inicial e final.

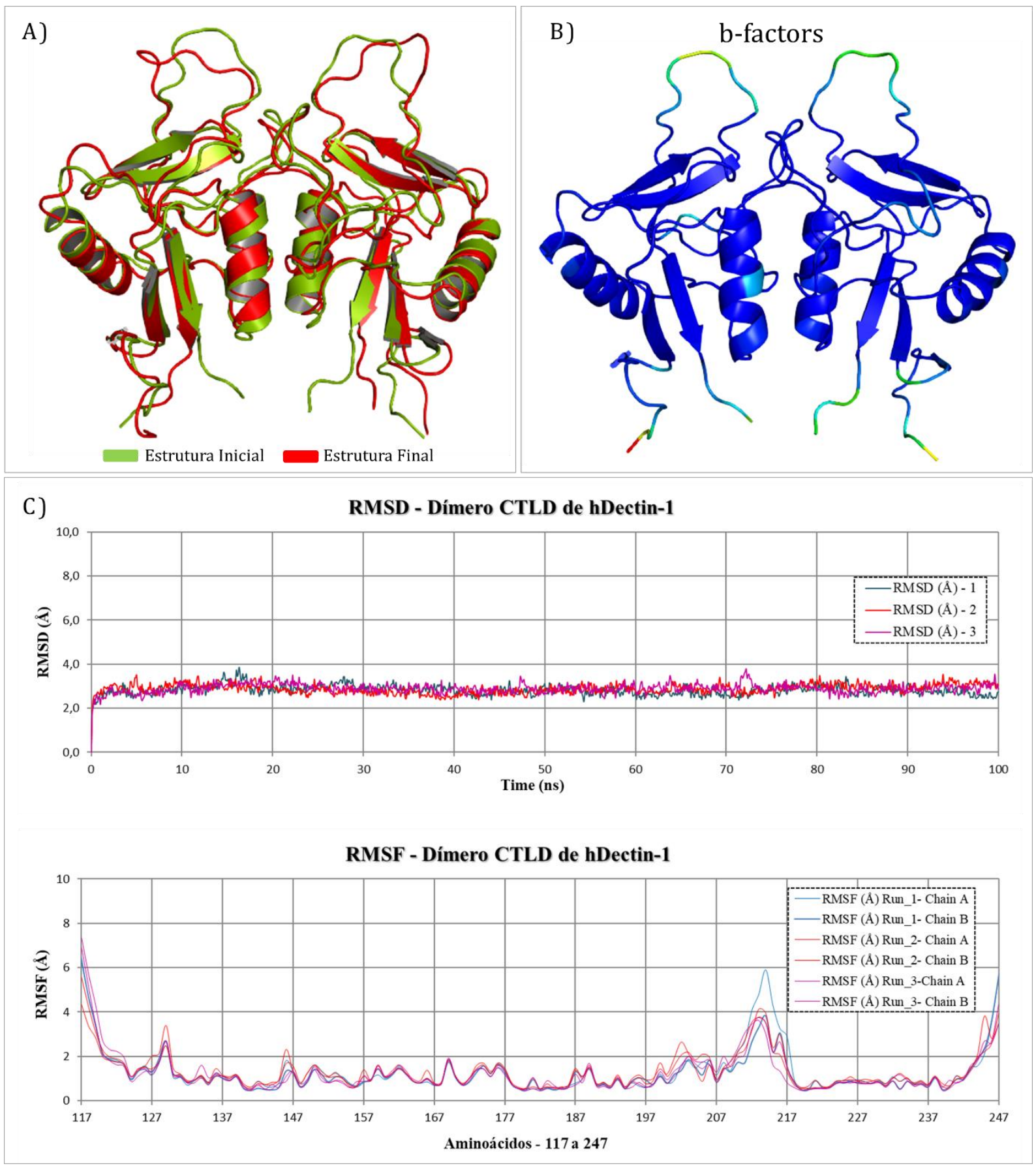

A) Alinhamento das estruturas inicial em $0 \mathrm{~ns}$ (verde) e final em $100 \mathrm{~ns}$ (vermelho) da simulação de DM. B) Representação gráfica do $b$-factor obtido para a estrutura final do dímero CTLD-hD em relação a estrutura inicial. O espectro de coloração vai do azul (regiões com baixo descolamento) até o vermelho (regiões com alto deslocamento). C) Valores de RMSD das coordenadas dos átomos $\mathrm{C} \alpha$ em função do intervalo de tempo de simulação em triplicata de $100 \mathrm{~ns}$ e comparativo da variação estrutural por aminoácido das três simulações expressos no gráfico de RMSF em relação à estrutura inicial. Fonte: Arquivo pessoal. 
Os resultados obtidos na triplicata de simulação de DM para o dímero CTLD-hD foi muito similar aos resultados obtidos para o dímero de mDectin-1 PDB ID: 2CL8. Deste modo, pode-se considerar que o dímero CTLD-hD apresenta uma conformação estável em relação a superfície de interação entre os monômeros.

Para a melhor compreensão da interação que ocorreu entre a interface de contato dos monômeros, foi realizada a análise dessa interação por meio do servidor PDBSum (LASKOWSKI, 2001). Foi verificado o estado de interação entre os monômeros do dímero CTLD-hD em três momentos diferentes: Inicial (0ns), $50 \mathrm{~ns}$ e final (100 ns).

A análise de interação mostrou que o dímero inicial apresentava 7 ligações de hidrogênio e 73 contatos não ligados na superfície de interação entre os monômeros, após 50 ns foram identificadas 5 ligações de hidrogênio e 94 contatos não ligados e, ao final dos 100 ns, o dímero apresentava 7 ligações de hidrogênio e 73 contatos não ligados. A área total de contato entre os dois monômeros variou entre $1764 \AA^{2}$ (chain-A $864 \AA^{2}$ e chain-B $900 \AA^{2}$ ) na estrutura inicial, $1886 \AA^{2}$ (chain-A $952 \AA^{2}$ e chain-B $934 \AA^{2}$ ) aos 50 ns e $1725 \AA^{2}$ (chain-A 862 $\AA^{2}$ e chain-B $899 \AA^{2}$ ) aos 100 ns (figura 40).

Os aminoácidos que fizeram parte da interface de interação dos monômeros ao longo da simulação de DM foram:

- $\quad 0$ ns: Chain-A 142, 145, 146, 149, 154, 185, 186, 187, 190, 191, 193, 198, 199 , 216, 217, 219, 220, 232 e 233. Chain-B 141, 142, 149, 185, 186, 187, 190, 192, 193, 194, 195 , 196, 197, 198, 217, 219, 220 e 233;

- $\quad 50$ ns: Chain-A 142, 145, 146, 149, 186, 187, 190, 193, 195, 196, 197, 198, 199 , 217, 219, 220, 232, 233 e 234. Chain-B 142, 145, 146, 149, 185, 186, 187, 190, 192, 193, 194, 197, 199, 217, 219, 220, 232 e 233;

- 100 ns: Chain-A 142, 145, 146, 149, 154, 185, 186, 187, 190, 191, 193, 198, 199, 216, 217, 219, 220, 232 e 233. Chain-B 141, 145, 146, 149, 185, 186, 187, 190, 192, 193, 194, 195, 196, 197, 199, 217, 219, 220, 232 e 233.

Nota-se que houve conservação dos aminoácidos que interagiram entre os monômeros ao logo de toda simulação, observadas apenas pequenas variações (figura 40). Esse resultado pode inferir que esses aminoácidos são importantes na dimerização de hDectin-1, pois o dímero com esta conformação se mostrou consideravelmente estável nas três simulações de DM realizadas. 
Figura 40 - Diagrama das interações entre os monômeros de CTLD de hDectin-1 que compõem o dímero nos tempos inicial (0 ns), 50 ns e aos 100 ns.

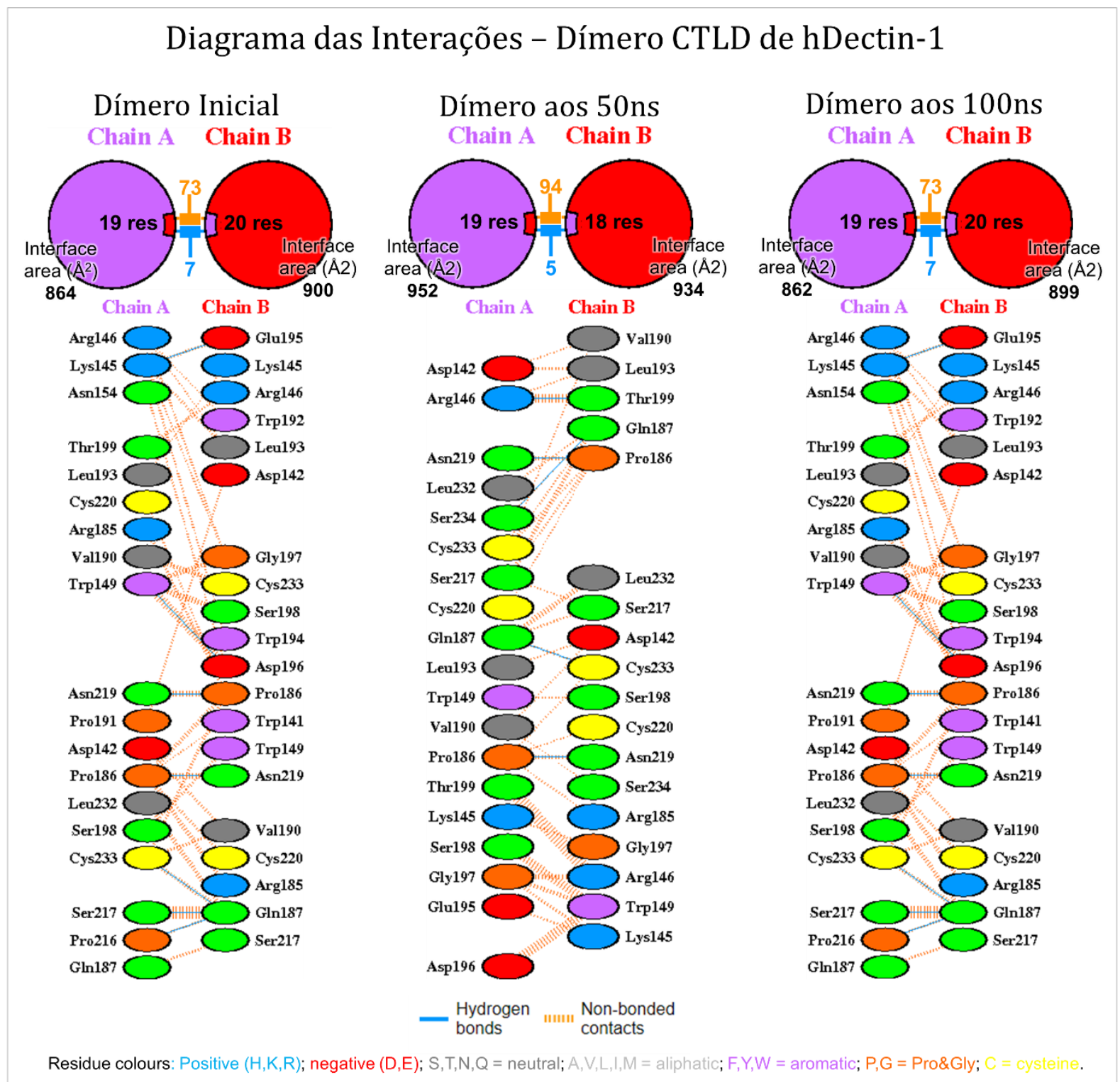

Fonte: Arquivo pessoal.

A análise de interação entre os monômeros que compõem o dímero CTLD-hD feita por meio do script InterfaceResidues.py também mostrou a conservação dos aminoácidos presentes na interface de interação ao longo da simulação de DM (figura 41). Na figura 41A é exibido o alinhamento das três conformações do dímero CTLD-hD analisadas ao longo da simulação de DM e pode-se considerar a ocorrência de baixa variação na interface de interação na conformação inicial, aos 50 ns e ao final dos 100 ns (figuras 41B, 41C e 41D). A participação dos aminoácido W141, D142, K145, R146, W149, N154, S184, R185, P186, Q187, T188, V190, P191, L193, W194, E195, D196, G197, S198, T199, P216, S217, N2219, C220, L232, 
C233, S234 e pequenas variações na interface de interação do dímero CTLD-hD ao longo do tempo de simulação é apresentada na figura 41E.

Figura 41 - Alinhamento das conformações do dímero CTLD-hD ao longo da simulação de DM, interface de interação e diagrama das interações entre os monômeros que compõem o dímero formado pelos CTLD de hDectin-1.
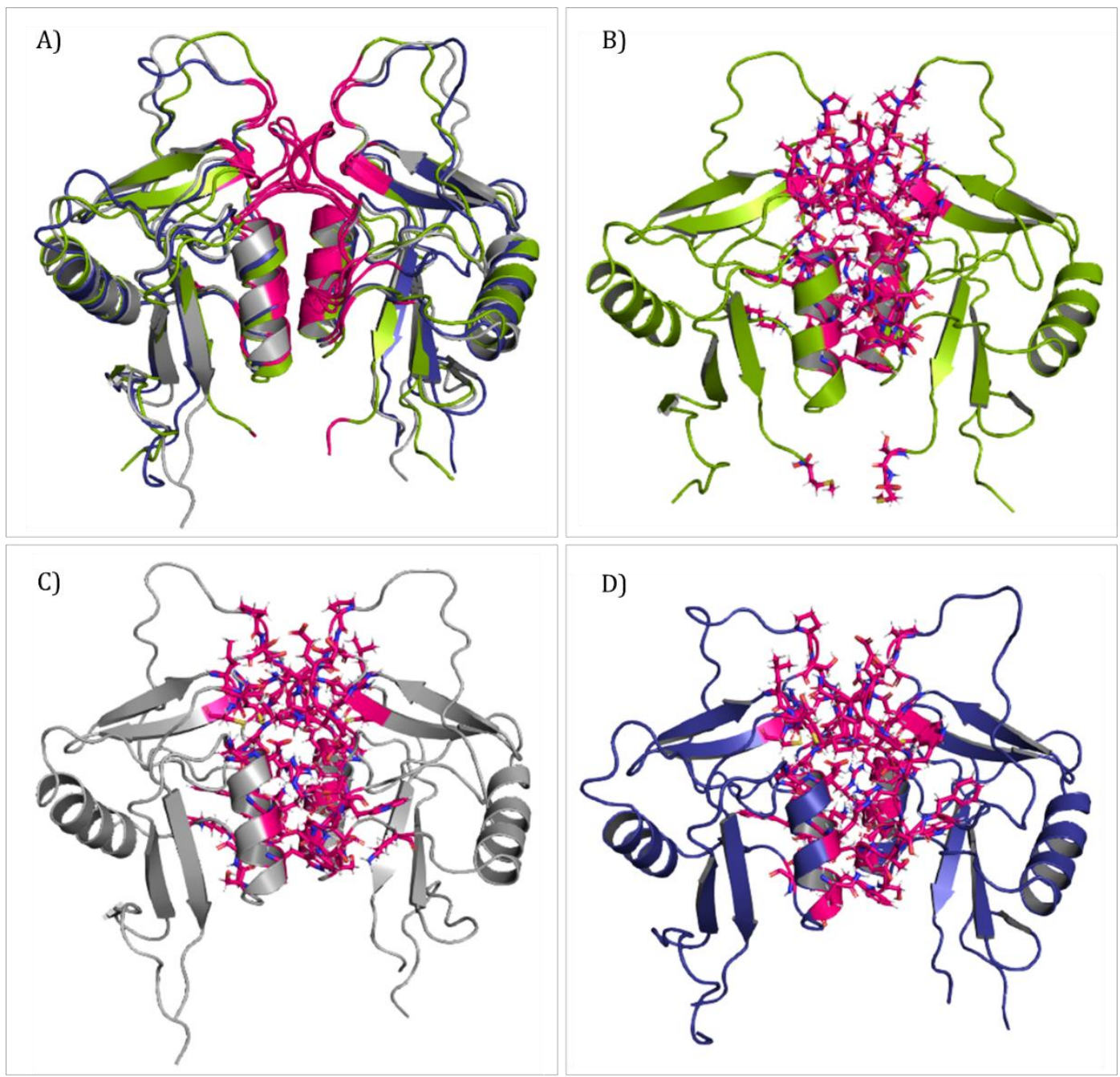

E)

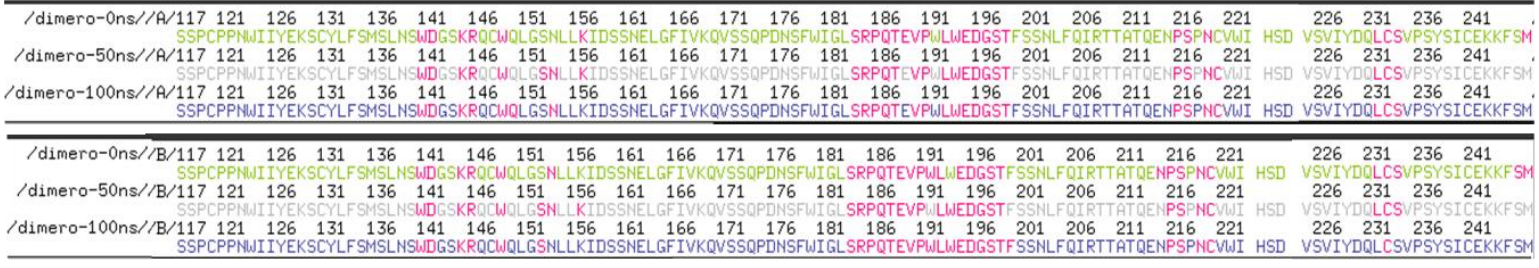

A) Alinhamento das três conformações do dímero CTLD-hD ao longo da simulação de DM (0 ns verde, $50 \mathrm{~ns}$ cinza e $100 \mathrm{~ns}$ azul). B) Conformação inicial (0 ns) em verde com a interface de interação entre os monômeros destacada em rosa. C) Conformação aos $50 \mathrm{~ns}$ em cinza com a interface de interação entre os monômeros destacada em rosa. D) Conformação final aos $100 \mathrm{~ns}$ em azul com a interface de interação entre os monômeros destacada em rosa. E) Diagrama das interações entre os monômeros de CTLD de hDectin-1 que compõem o dímero nos tempos inicial (0 ns), $50 \mathrm{~ns}$ e aos $100 \mathrm{~ns}$. Os resíduos que compõe a interface de interação entre os monômeros são mostrados em rosa. Fonte: Arquivo pessoal. 
Proteínas com CTLD são uma família muito conservada de receptores transmembranares. Esses CTLD se associam por meio de várias superfícies diferentes para formar oligômeros, a partir dos quais os sítios de ligação se projetam em uma variedade de orientações diferentes (DRICKAMER, 1999), entretanto, Dulal e colaboradores (2018) descrevem que a formação de oligômeros cooperativos pelo CTLD de mDectin-1 induzidos pelo $\beta$-glucano laminarin é fisiologicamente relevante na detecção de $\beta$-glucanos exógenos e no desencadeamento da sinalização intracelular.

Os resíduos Y141, R145 e E243 de mDectin-1 se mostraram muito importantes nesse processo de oligomerização induzida por laminarin (DULAL et al., 2018), sendo os resíduos D142, R146 e K244 correspondentes em hDectin-1. Os resultados obtidos no presente estudo mostram que os resíduos D142 e R146 de hDectin-1 fizeram parte da interface de interação do dímero ao longo das três simulações de DM. Assim, a conformação dimérica obtida no presente estudo pode ser uma das conformações que a proteína hDectin-1 assume no processo de reconhecimento de $\beta$-glucanos e oligomerização cooperativa.

\subsection{Análise da interação molecular entre hDectin-1 e seus alvos moleculares por meio de docking molecular com $\beta$-glucanos e proteína Syk}

\subsubsection{Docking molecular de $\beta$-glucanos com o CTLD de hDectin-1}

O estudo de Brown e colaboradores (2007) e Dulal e colaboradores (2018), caracterizou a interação entre mDectin-1 e laminarin (in vitro), descrevendo os principais aminoácidos do CTLD que compõem o sítio de ligação para reconhecimento de $\beta$-glucanos. Os estudos mostraram que os aminoácidos W221, H223 e Y228 de mDectin-1 são importantes para a formação do sítio em formato de sulco com características hidrofóbicas localizado na superfície da proteína responsável pelo reconhecimento do $\beta$-glucano laminarin (DULAL et al., 2018).

A análise do alinhamento entre as sequências de mDectin-1 e hDectin-1 mostrou que a região do sítio de reconhecimento de $\beta$-glucanos descrita por Brown e colaboradores (2007) e Dulal e colaboradores (2018) para mDectin-1 é conservada em hDectin-1. A região correspondente aos aminoácidos W221, H223 e Y228 de mDectin-1 é W222, H224 e Y229 em hDectin-1 (Figura 42). 
Figura 42 - Alinhamento das sequencias primarias de mDectin-1 e hDectin-1 para destacar a correspondências dos aminoácidos $\mathrm{W}, \mathrm{H}$ e Y que compõe o sítio de reconhecimento de $\beta$ glucanos.

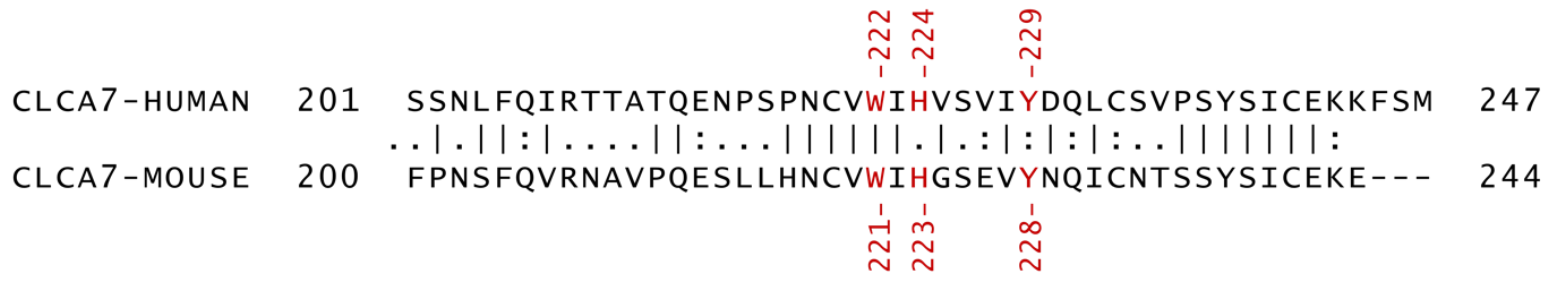

Localização dos aminoácidos que compõe o sítio de reconhecimento de $\beta$-glucanos destacada em vermelho no alinhamento. Fonte: Arquivo pessoal.

Inicialmente foi feita a identificação de possíveis sítios de ligação no CTLD de hDectin-1 por meio do software FTSite (NGAN et al., 2011). A predição de sítios detectou três sítios no CTLD (figura 43).

Figura 43 - Resultado da predição dos sítios de ligação realizada por meio do software FTSite.

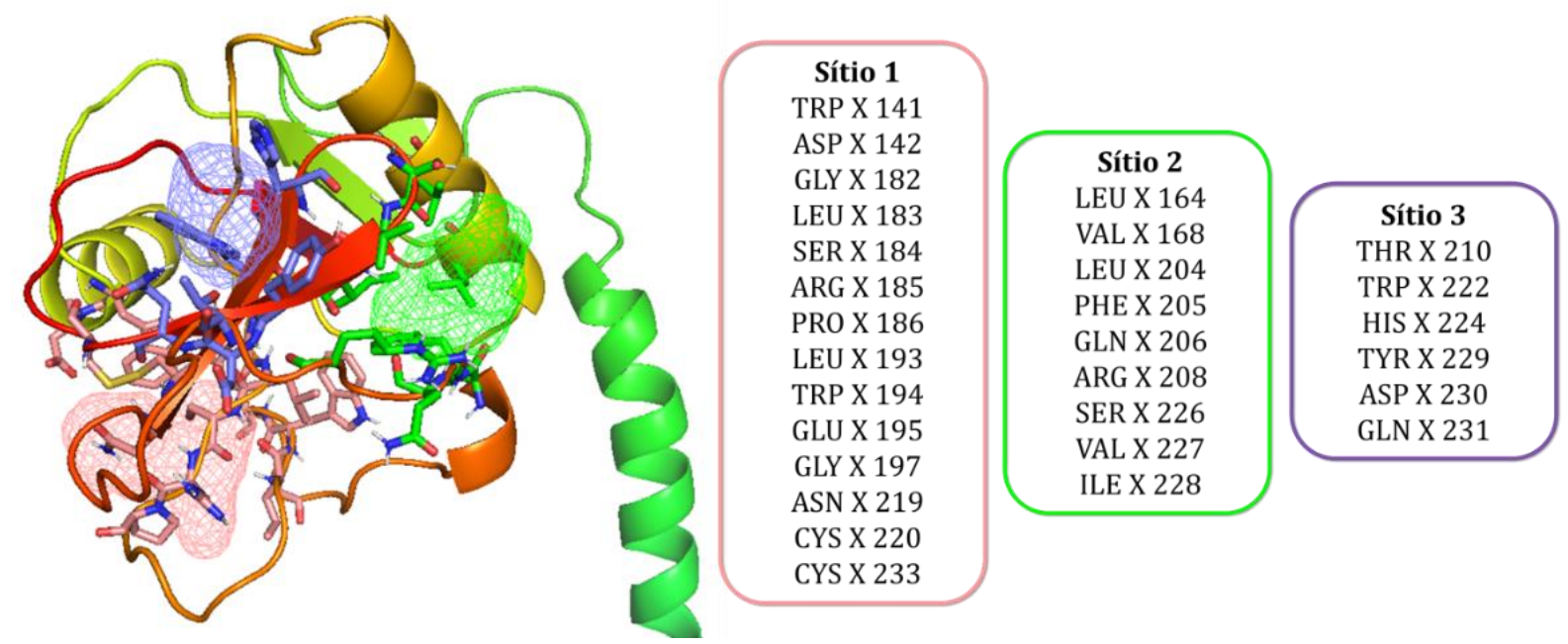

Os três possíveis sítios preditos estão destacados na estrutura do CTLD de hDectin-1 pela malha rosa (sítio 1), verde (sítio 2) e roxo (sítio 3). Os quadrados com bordas rosa, verde e roxo apresentam os aminoácidos que compõe cada sítio predito. Fonte: Arquivo pessoal.

Os resíduos W222, H224 e Y229 de hDectin-1 correspondentes aos resíduos W221, H223 e Y228 de mDectin-1, importantes no reconhecimento de $\beta$-glucanos (DULAL et al., 2018; BROWN et al., 2007), foram localizados no sítio 3. Esse sítio predito é composto pelos aminoácidos Thr210, Trp222, His224, Tyr229, Asp230 e Gln231 (figura 44). 
Figura 44 - Sítio 3 predito por meio do software FTSite.

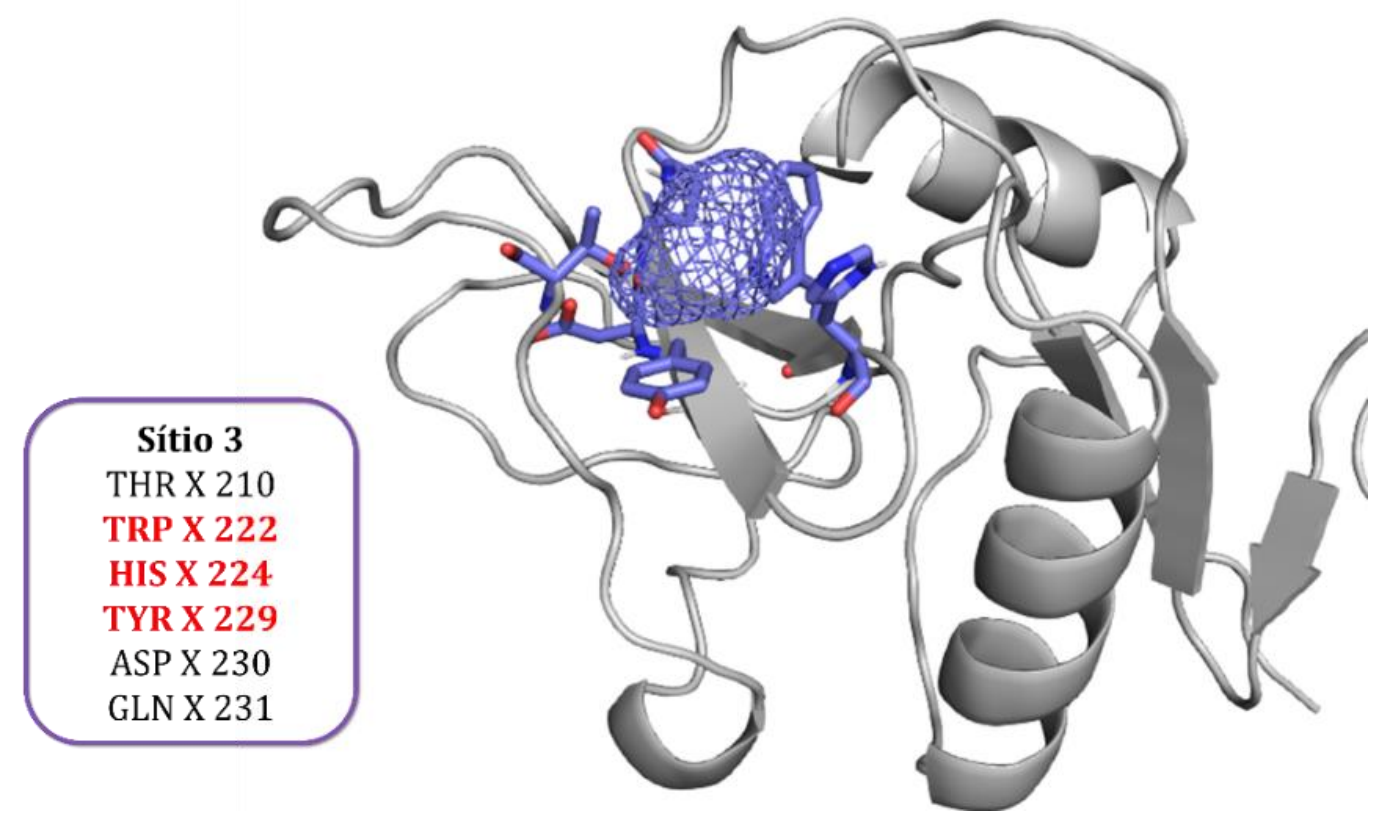

Aminoácidos que compõem o sítio 3 estão apresentados no retângulo roxo e os aminoácidos descritos na literatura como parte importante do sítio estão destacados em vermelho. Fonte: Arquivo pessoal.

O perfil de hidrofobicidade e potencial eletrostático da superfície do CTLD da estrutura de mDectin-1 descritos por Brown e colaboradores (2007) e Dulal e Colaboradores (2018), mostrou haver um sulco que se estende entre os aminoácidos W221, H223 e Y228 com características hidrofóbicas favoráveis à interação com $\beta$-glucanos. A análise do perfil de hidrofobicidade e potencial eletrostático da superfície do CTLD da estrutura de hDectin-1 realizada por meio do software PyMol (DELANO, 2002), mostrou que, na região formada pelos aminoácidos W222, H224 e Y229 de hDectin-1, o sulco também apresenta características predominantemente hidrofóbicas (figura 45A) com potencial eletrostático predominantemente negativo (figura 45B), favorecendo a interação com $\beta$-glucanos como descrito por Dulal e Colaboradores (2018). 
Figura 45 - Perfil de hidrofobicidade e potencial eletrostático da superfície do CTLD da estrutura de hDectin-1.
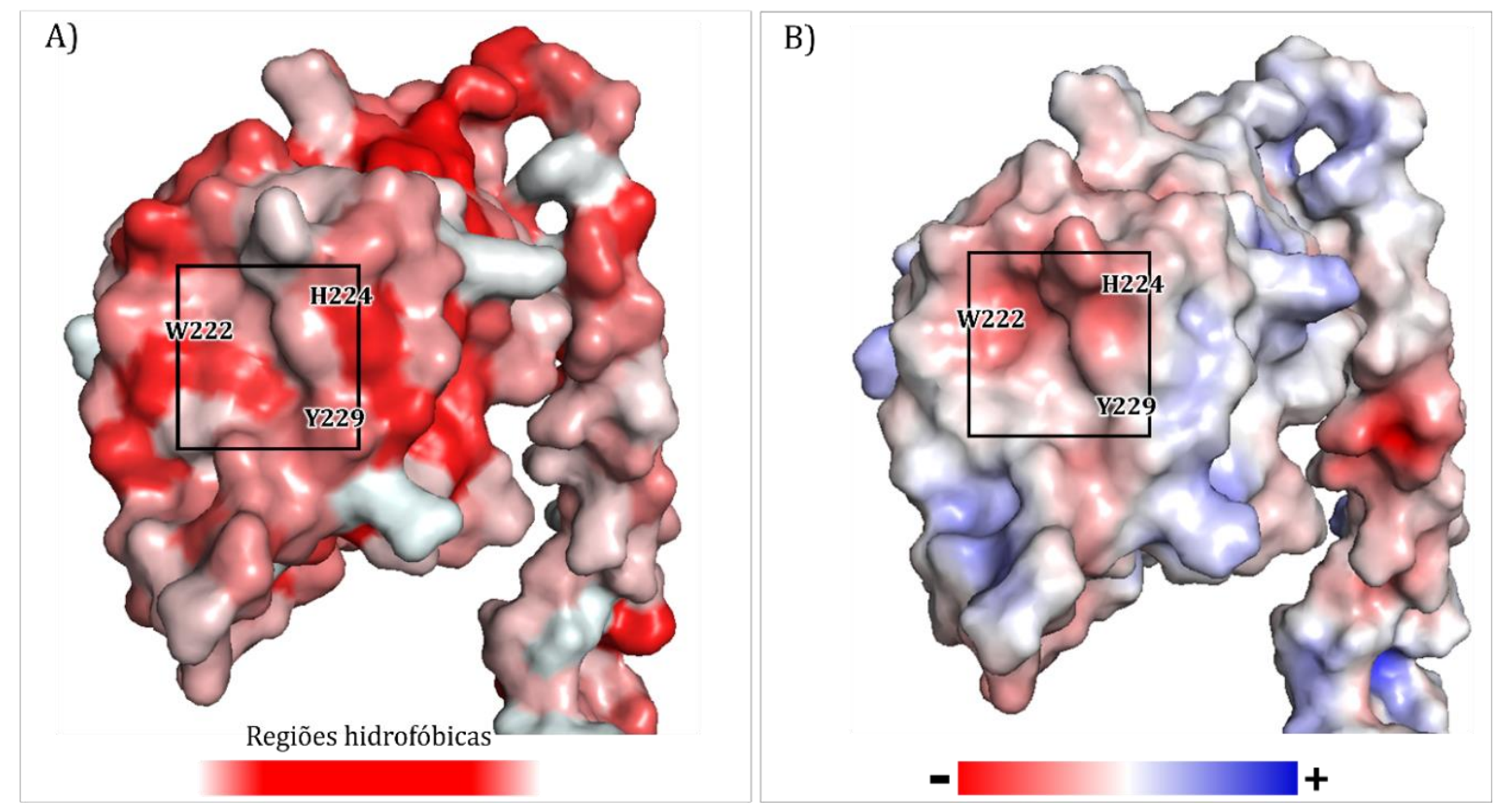

A) Região dos aminoácidos W222, H224 e Y229 com predomínio de regiões de superfície hidrofóbicas destacada pelo quadrado com contorno preto. As regiões hidrofóbicas são apresentas em vermelho e as regiões hidrofílicas são apresentadas em branco. B) Região dos aminoácidos W222, H224 e Y229 com predomínio de regiões com potencial de superfície eletrostático negativo apresentado pelo quadrado com contorno preto. As regiões eletrostáticas negativas são apresentas em vermelho, regiões neutras são apresentadas em branco e regiões positivas são apresentadas em azul. Fonte: Arquivo pessoal.

Os resultados obtidos na predição de sítios de ligação, análise do perfil de hidrofobicidade e potencial eletrostático da superfície e a descrição encontrada nos trabalhos de Dulal e colaboradores (2018) e de Brown e colaboradores (2007), justificam a escolha dos resíduos Thr210, Trp222, His224, Tyr229, Asp230 e Gln231 (T210, W222, H224, Y229, D230 e Q231) de hDectin-1 para direcionamento do docking com $\beta$-glucanos (figura 46). 
Figura 46 - Região correspondente aos aminoácidos T210, W222, H224, Y229, D230 e Q231 do CTLD de hDectin-1 que foram usados o para direcionamento do docking com $\beta$-glucanos.

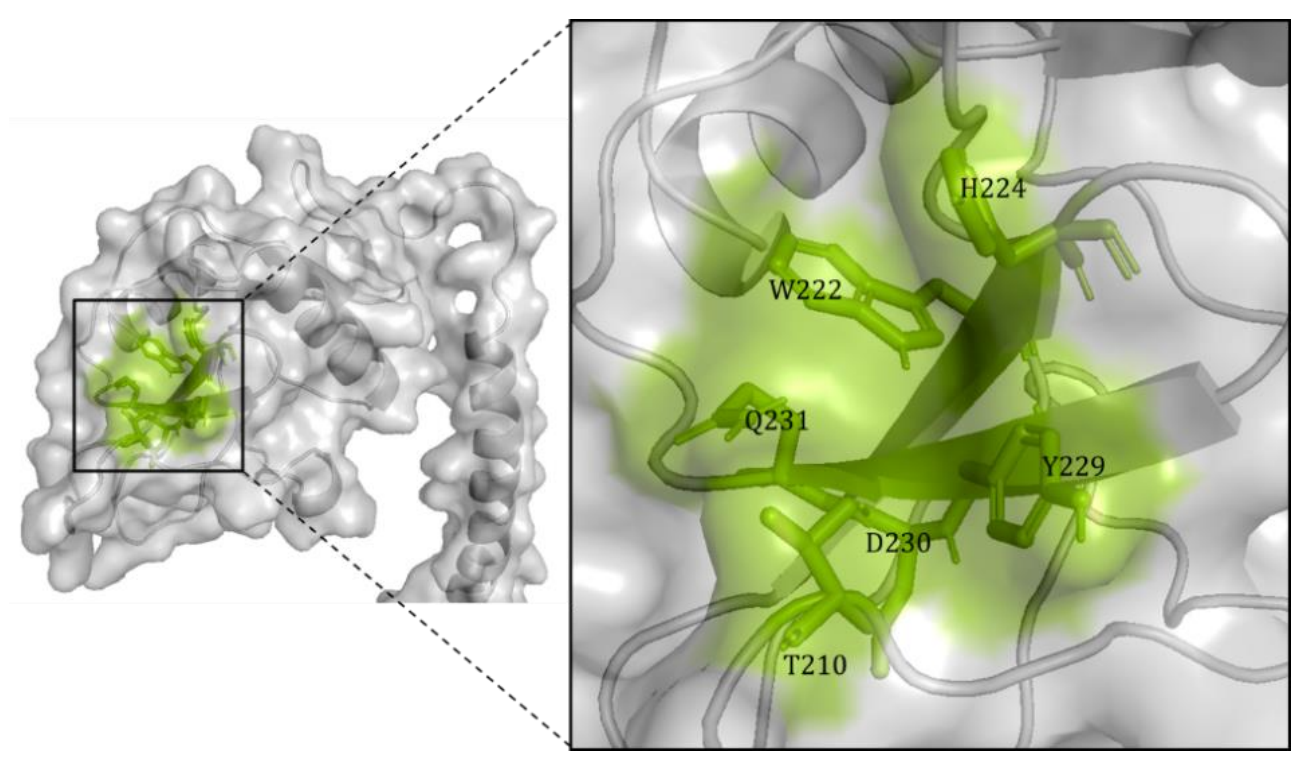

Fonte: Arquivo pessoal.

Dentre os $\beta$-glucanos bem caracterizados experimentalmente por interagirem com Dectin-1 estão o Laminarin, relatado como agonista e antagonista de Dectin-1 (SMITH et al., 2018; BROWN et al., 2007; PALMA et al., 2006); Zymosan, agonista de Dectin-1 (KUMAR et al., 2015; BROWN et al., 2007; PALMA et al., 2006), Scleroglucan, agonista de Dectin-1 (ZHAO et al., 2016) e Sizofiran ou Schizophyllan, agonista de Dectin-1 (GOODRIDGE et al., 2009; ADACHI et al., 2004) (figura 47).

Figura 47 - Estruturas 2D dos $\beta$-glucanos Laminarin, Zymosan, Scleroglucan e Sizofiran.

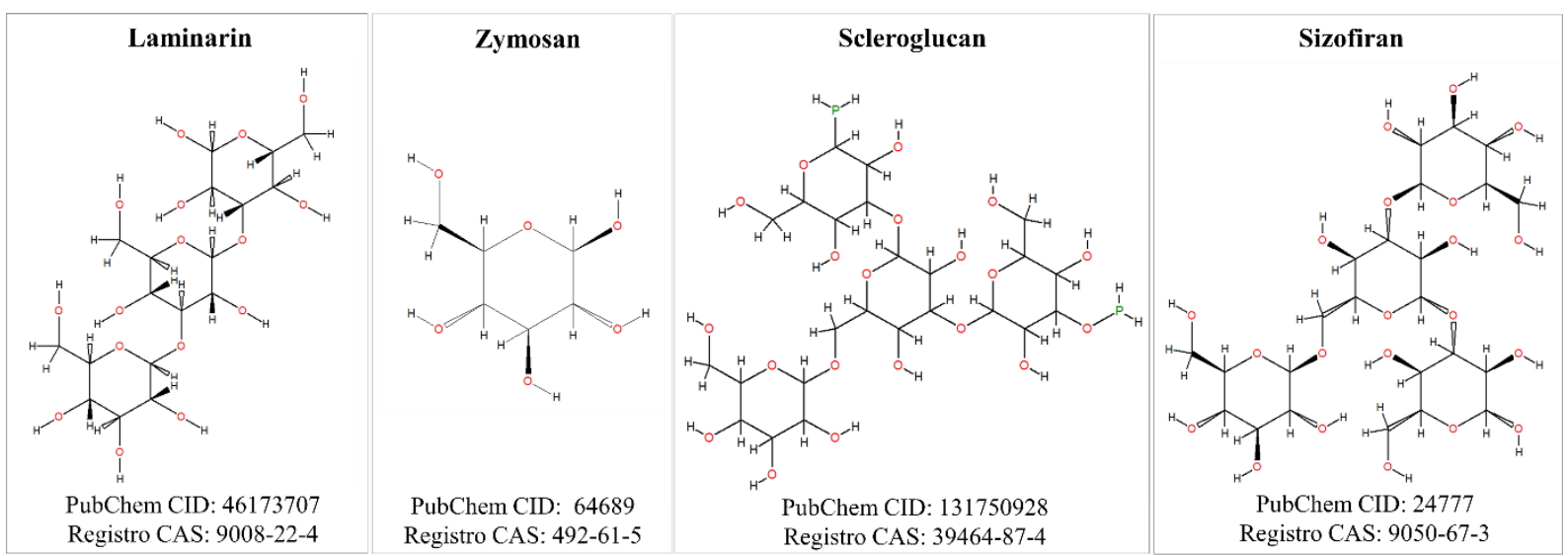

Fonte: Estruturas 2D obtidas no banco de dados PubChem do National Institutes of Health (KIM et al., 2019). Imagens geradas com o software ChemFileBrowser 0.2.9.3 (disponível em http://www.hyleos.net/). Fonte: Arquivo pessoal. 
Foram escolhidos quatro tipos diferentes de $\beta$-glucanos para realizar o docking com hDectin-1. A escolha dos $\beta$-glucanos foi feita com base na relevância experimental encontrada na literatura, onde os $\beta$-glucanos Laminarin, Zymosan, Scleroglucan e Sizofiran são ligantes com afinidade comprovada para Dectin-1 (BAO et al., 2017; ZHAO et al., 2016; KUMAR et al., 2015; BATBAYAR et al., 2012; GOODRIDGE et al., 2009; BROWN et al., 2007; PALMA et al., 2006; ADACHI et al., 2004). Para a escolha dos $\beta$-glucanos também foi levado em consideração a variabilidade estrutural e configuração das unidades de D-glicose, posição e distribuição das ligações glicosídicas, tamanho molecular, tipo e grau de ramificação afim de verificar se essa variabilidade influenciaria as características do docking em hDectin-1. A tabela 4 exibe as principais informações sobre os $\beta$-glucanos que foram usados no docking.

Tabela 4 - Identificadores dos $\beta$-glucanos selecionados para o docking com hDectin-1.

\begin{tabular}{|c|c|c|c|c|}
\hline$\beta$-glucanos & $\begin{array}{l}\text { PubChem } \\
\text { CID }\end{array}$ & $\begin{array}{l}\text { Registro } \\
\text { CAS }\end{array}$ & $\begin{array}{l}\text { International Union of Pure and } \\
\text { Applied Chemistry (IUPAC) }\end{array}$ & $\begin{array}{l}\text { Quantidade de } \\
\text { unidades de D- } \\
\text { glicose }\end{array}$ \\
\hline Laminarin & 46173707 & $9008-22-4$ & $\begin{array}{c}\text { (2S,3R,4S,5R,6R)-4-[(2S,3R,4S,5R,6R)- } \\
\text { 3,5-dihydroxy-6-(hydroxymethyl)-4- } \\
\text { [(2S,3R,4S,5S,6R)-3,4,5-trihydroxy-6- } \\
\text { (hydroxymethyl)oxan-2-yl]oxyoxan-2- } \\
\text { yl]oxy-6-(hydroxymethyl)oxane-2,3,5- } \\
\text { triol }\end{array}$ & 3 \\
\hline Zymosan & 64689 & $492-61-5$ & $\begin{array}{l}(2 \mathrm{R}, 3 \mathrm{R}, 4 \mathrm{~S}, 5 \mathrm{~S}, 6 \mathrm{R})-6- \\
\text { (hydroxymethyl)oxane-2,3,4,5-tetrol }\end{array}$ & 1 \\
\hline Sizofiran & 24777 & $9050-67-3$ & $\begin{array}{c}\text { (2R,3R,4S,5R,6R)-4-[(2S,3R,4S,5R,6R)- } \\
\text { 3,5-dihydroxy-4-[(2R,3R,4S,5S,6R)- } \\
\text { 3,4,5-trihydroxy-6- } \\
\text { (hydroxymethyl)oxan-2-yl]oxy-6- } \\
\text { [[(2R,3R,4S,5S,6R)-3,4,5-trihydroxy-6- } \\
\text { (hydroxymethyl)oxan-2- } \\
\text { yl]oxymethyl]oxan-2-yl]oxy-6- } \\
\text { (hydroxymethyl)oxane-2,3,5-triol }\end{array}$ & 4 \\
\hline Scleroglucan & 131750928 & 39464-87-4 & $\begin{array}{c}\text { 2-[[6-[3,5-dihydroxy-2- } \\
\text { (hydroxymethyl)-6-phosphanyloxan-4- } \\
\text { yl]oxy-4-[3,5-dihydroxy-6- } \\
\text { (hydroxymethyl)-4-phosphanyloxyoxan- } \\
\text { 2-yl]oxy-3,5-dihydroxyoxan-2- } \\
\text { yl]methoxy]-6-(hydroxymethyl)oxane- } \\
\text { 3,4,5-triol }\end{array}$ & 4 \\
\hline
\end{tabular}


Para o docking entre o CTLD de hDectin-1 e os $\beta$-glucanos Laminarin, Zymosan, Scleroglucan e Sizofiran, foi usado o software AutoDock Tools (HUEY; MORRIS, 2008) especificamente para determinar o tamanho e as coordenadas do espaço de busca para o docking dos $\beta$-glucanos em hDectin-1 e gerar os arquivos de entrada no formato PDBQT que foram usados no docking realizado pelo software AutoDock Vina (TROTT; OLSON, 2010).

O espaço de busca para o docking das moléculas de $\beta$-glucanos no CTLD foi delimitado usando como referência a localização dos aminoácidos T210, W222, H224, Y229, D230 e Q231 presentes no CTLD de hDectin-1. Para que o algoritmo de docking pudesse explorar exatamente o local composto pelos aminoácidos de interesse, foi especificado o menor espaço de busca possível que apresentou as dimensões de $16 \AA$, $14 \AA$ e $18 \AA$, respetivamente, nos eixos $\mathrm{X}, \mathrm{Y}$ e $\mathrm{Z}$. As coordenadas do centro da caixa que delimitaram o espaço de busca

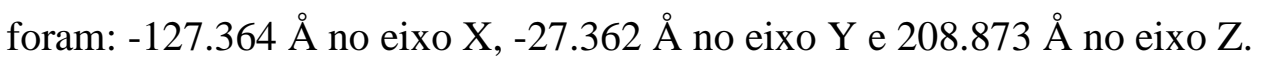

$\mathrm{O}$ docking gerou dez estruturas em diferentes posicionamentos (poses) ranqueadas pelo score de energia das ligações em kcal/mol. Foi escolhida a pose com melhor score de energia (figura 48).

O score de energia das ligações em kcal/mol para as melhores poses do docking entre o CTLD de hDectin-1 e Laminarin, Zymosan, Scleroglucan e Sizofiran foram, respectivamente, $-5.4,-3.7,-5.1$ e $-5.8 \mathrm{kcal} / \mathrm{mol}$.

Figura 48 - Resultado do docking entre o CTDL de hDectin-1 e $\beta$-glucanos. 

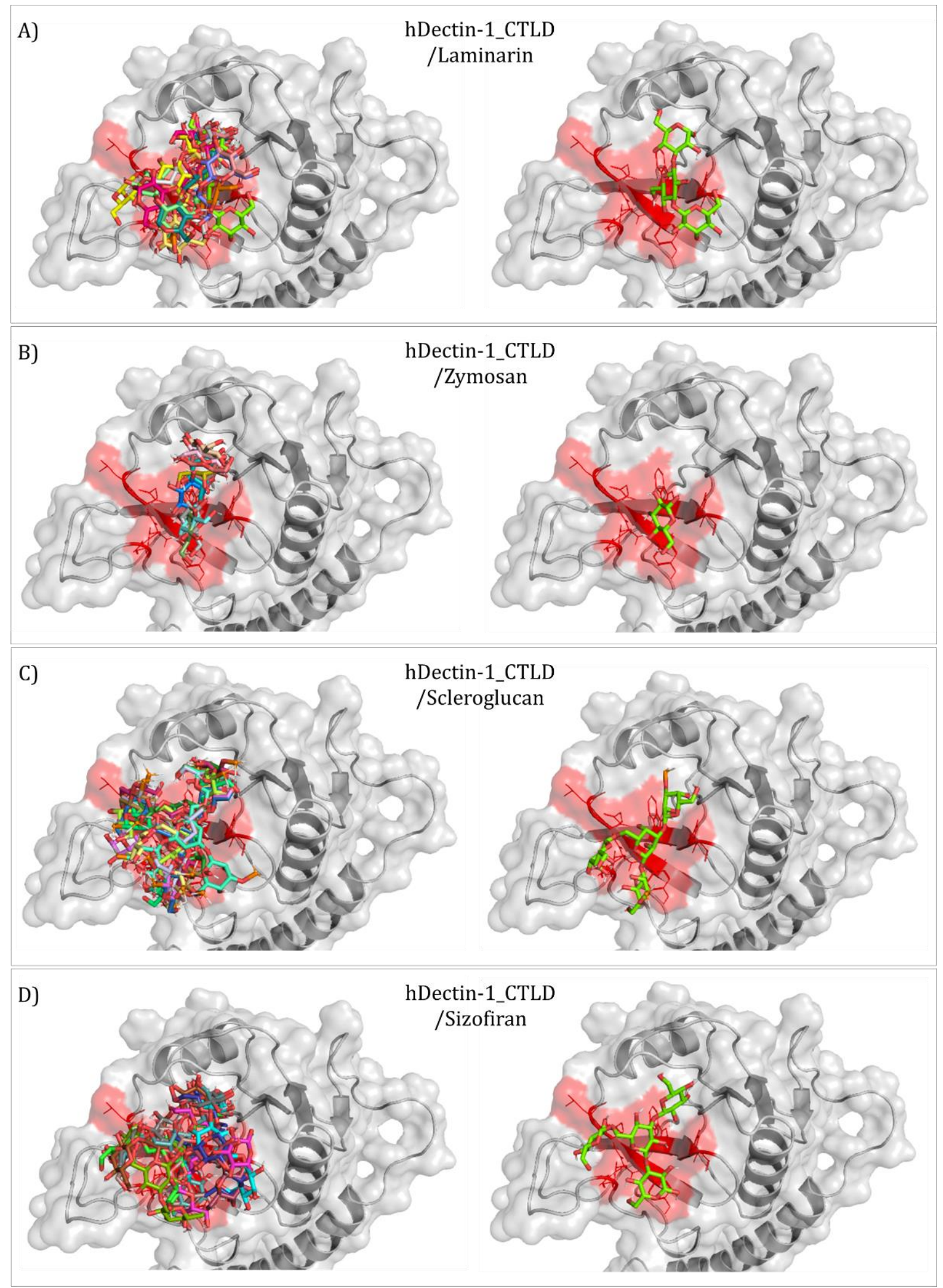

As imagens a esquerda mostram o CTLD com as 10 poses do docking para cada $\beta$-glucano e as imagens a direita mostram o CTLD com as melhores poses de cada $\beta$-glucano segundo o score de energia das ligações em $\mathrm{kcal} / \mathrm{mol}$. A região correspondente ao sítio no CTLD é mostrada em vermelho e os $\beta$-glucanos com melhor score em verde. A) Resultado do docking entre o CTLD e Laminarin. B) Resultado do docking entre o CTLD e Zymosan. C) Resultado do docking entre o CTLD e Scleroglucan. A) Resultado do docking entre o CTLD e Sizofiran. Fonte: Arquivo pessoal. 


\subsubsection{Simulação de DM dos complexos CTLD/ß-glucanos e análise de interação proteína/ligante}

Com objetivo de otimizar o tempo de execução das simulações de DM, tendo em vista a grande quantidade de simulações que foram realizadas, para a simulação de DM dos complexos hDectin-1/ $\beta$-glucanos (CTLD/ $\beta$-glucano) foi considerada apenas a estrutura do CTLD de hDectin-1, pois é especificamente neste domínio que ocorre o reconhecimento dos $\beta$ glucanos (DULAL et al., 2018; BROWN et al., 2007). Os aminoácidos 1 a 115, que fazem parte dos domínios intracelular, transmembranar e Stalk, foram removidos dos arquivos de coordenadas dos complexos CTLD/ $\beta$-glucano.

Para a construção dos sistemas CTLD/ $\beta$-glucanos foi o usado o servidor CHARMMGUI que disponibiliza o protocolo Glycan Reader \& Modeler (PARK et al., 2019; JO e KIM, 2007). Foi obtido um sistema para cada complexo CTLD/ $\beta$-glucano por meio do servidor CHARMM-GUI (JO et al., 2008). Os sistemas são do tipo cúbico, com dimensões de, aproximadamente, 75,5 $\AA$ nos eixos x, y e z, sendo compostos pelos complexos CTLD/ $\beta$ glucano, moléculas de água (TIP3) e íons que caracterizam o ambiente intracelular e extracelular.

Após essa etapa, o sistema CTLD/ $\beta$-glucano foi submetido a simulação de DM por meio do software GROMACS (HESS et al., 2008) que implementou o campo de força CHARMM36m (HUANG et al., 2017). Foram feitas triplicatas de 25 ns para cada complexo com o objetivo de verificar a estabilidade do complexo CTLD/ $\beta$-glucano gerado por docking.

Cada simulação de DM do sistema complexo-solvente foi realizada em condições físico-químicas controladas, com temperatura máxima de $310 \mathrm{~K}$ e pressão constante de 1 atm.

O comportamento estrutural do complexo CTLD/ $\beta$-glucano ao longo do tempo foi analisado por meio do RMSF, $b$-factor e alinhamento das estruturas ao longo do tempo de simulação de DM.

O alinhamento das estruturas inicial ( $0 \mathrm{~ns})$ e final ( $25 \mathrm{~ns})$ mostrou que nenhum dos $\beta$ glucanos permaneceram no sítio do CTLD ao longo dos $25 \mathrm{~ns}$ de simulação de DM. Isso foi observado nas triplicatas realizadas para cada complexo. Deste modo, foram extraídos arquivos de coordenadas dos complexos CTLD/ $\beta$-glucano a cada $1 \mathrm{~ns}$ da simulação de DM para verificar em que momento cada $\beta$-glucano deixou de interagir com o sítio onde inicialmente foi docado.

O alinhamento das estruturas do complexo CTLD/Zymosan mostrou que o $\beta$-glucano Zymosan permaneceu por, aproximadamente, $1 \mathrm{~ns}$ de simulação interagindo com o sítio do CTLD de hDectin-1 (figura 49A). A análise do b-factor (figura 49B) e RMSF (figura 49C) 
mostrou ter ocorrido maior movimentação dos aminoácidos 210 a 217, comparados aos demais aminoácidos adjacentes a eles. Esses aminoácidos estão localizados em um grande loop que compõe o sulco com características hidrofóbicas composto pelos aminoácidos T210, W222, H224, Y229, D230 e Q231 usados como referência para o docking.

Figura 49 - Complexo CTLD/Zymosan.

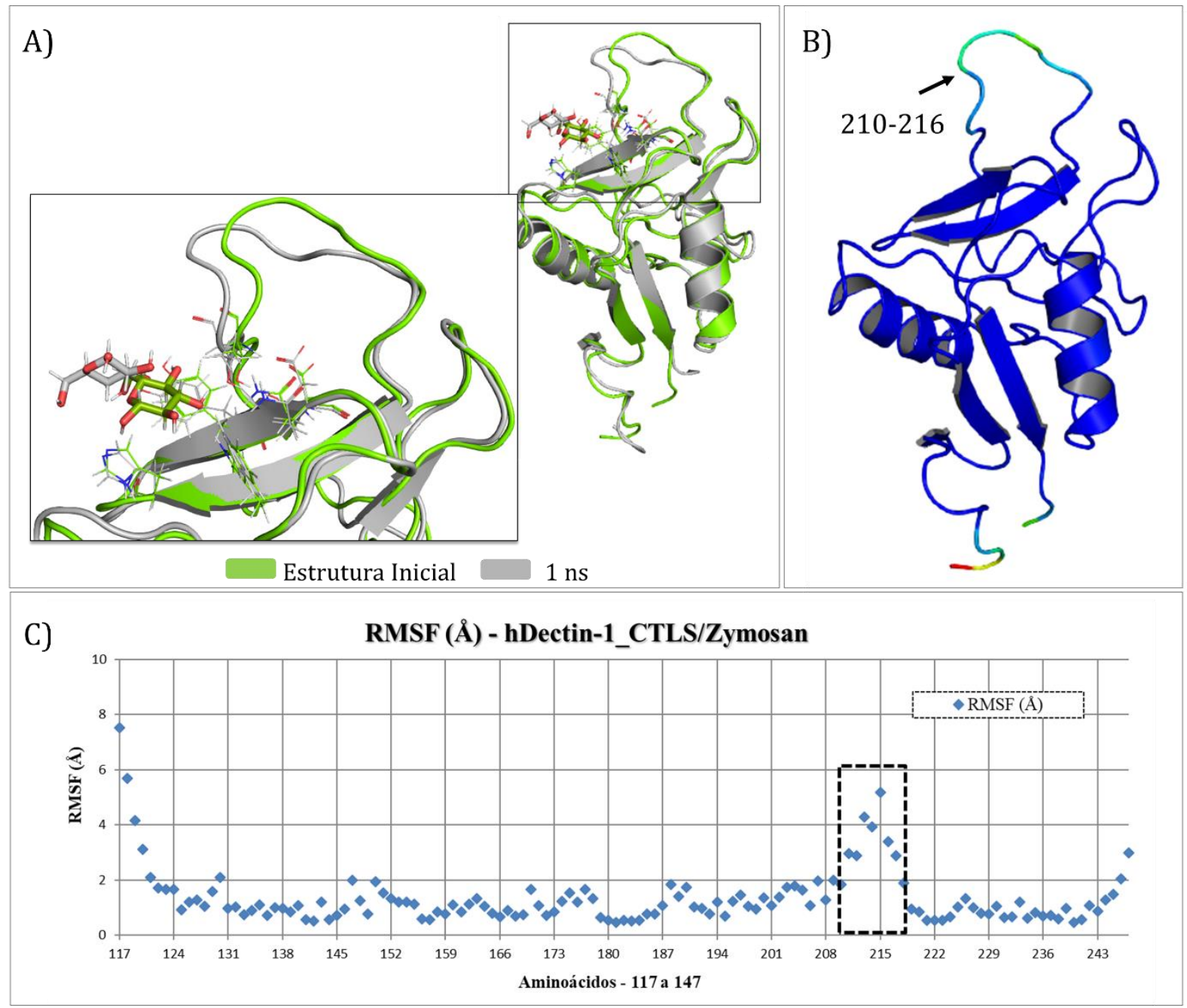

A) Alinhamento das estruturas dos complexos nos tempos inicial (verde) e 1 ns (cinza). A estrutura do complexo no tempo de 1 ns mostra o limite do tempo de interação entre Zymosan e o sítio do CTLD de hDectin-1 onde foi inicialmente docado. B) Representação gráfica do b-factor obtido para a estrutura do complexo CTLD/Zymosan em relação a estrutura inicial. O espectro de coloração vai do azul (regiões com baixo descolamento) até o vermelho (regiões com alto deslocamento). C) Valores de RMSF das coordenadas dos átomos C $\alpha$ em relação à estrutura inicial. Os retângulos pontilhados em preto destacam a região dos aminoácidos 210 a 217 que apresentaram maior movimentação estrutural. Fonte: Arquivo pessoal.

$\mathrm{Na}$ análise do complexo CTLD/Laminarin, o alinhamento das estruturas do complexo mostrou que Laminarin permaneceu menos de 1 ns de simulação interagindo com o sítio do CTLD de hDectin-1 (figura 50A). A análise do b-factor (figura 50B) e RMSF (figura 
50C), assim como na análise do complexo CTLD/Zymosan, mostrou que também ocorreu maior movimentação na região dos aminoácidos 210 a 217.

Figura 50 - Complexo CTLD/Laminarin.

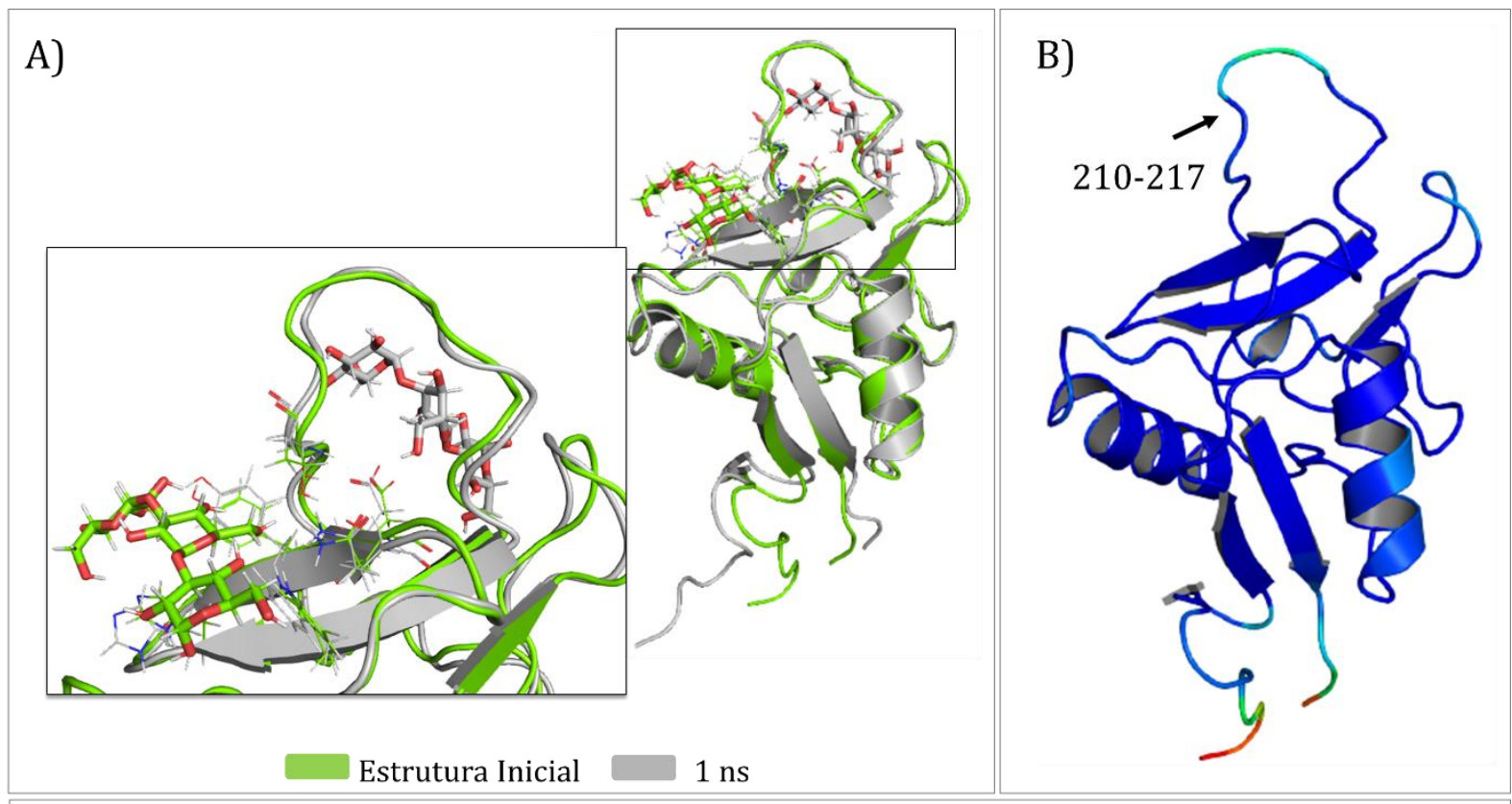

C)

RMSF ( $(\AA)$ - hDectin-1_CTLS/Laminarin

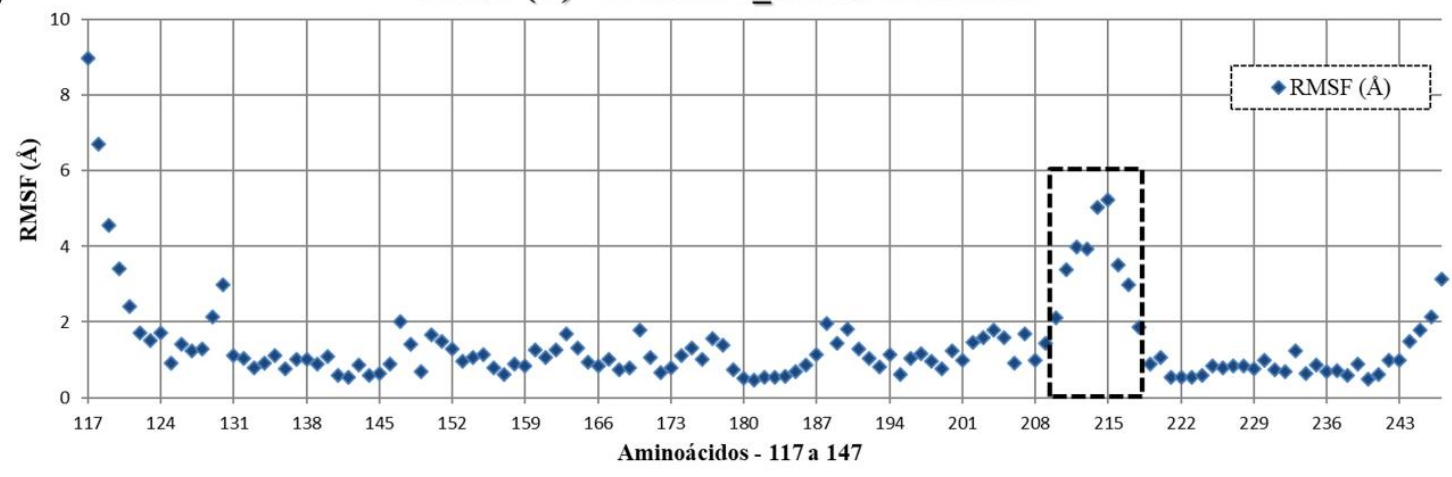

A) Alinhamento das estruturas dos complexos nos tempos inicial (verde) e $1 \mathrm{~ns}$ (cinza). A estrutura do complexo no tempo de $1 \mathrm{~ns}$ mostra que, nesse tempo, Laminarin não apresentava mais interação com o sítio do CTLD de hDectin-1 onde foi inicialmente docado. B) Representação gráfica do b-factor obtido para a estrutura do complexo CTLD/Laminarin em relação a estrutura inicial. O espectro de coloração vai do azul (regiões com baixo descolamento) até o vermelho (regiões com alto deslocamento). C) Valores de RMSF das coordenadas dos átomos $\mathrm{C} \alpha$ em relação à estrutura inicial. Os retângulos pontilhados em preto destacam a região dos aminoácidos 210 a 217 que apresentaram maior movimentação estrutural. Fonte: Arquivo pessoal.

O $\beta$-glucano Scleroglucan permaneceu, aproximadamente, 3 ns interagindo com o sítio do CTLD de hDectin-1 (figura 51A), o triplo do tempo da interação de Zymosan e Laminarin. A análise do b-factor (figura 51B) e RMSF (figura 51C) também mostrou que houve maior movimentação na região dos aminoácidos 212 a 216. 
Figura 51 - Complexo CTLD/Scleroglucan.

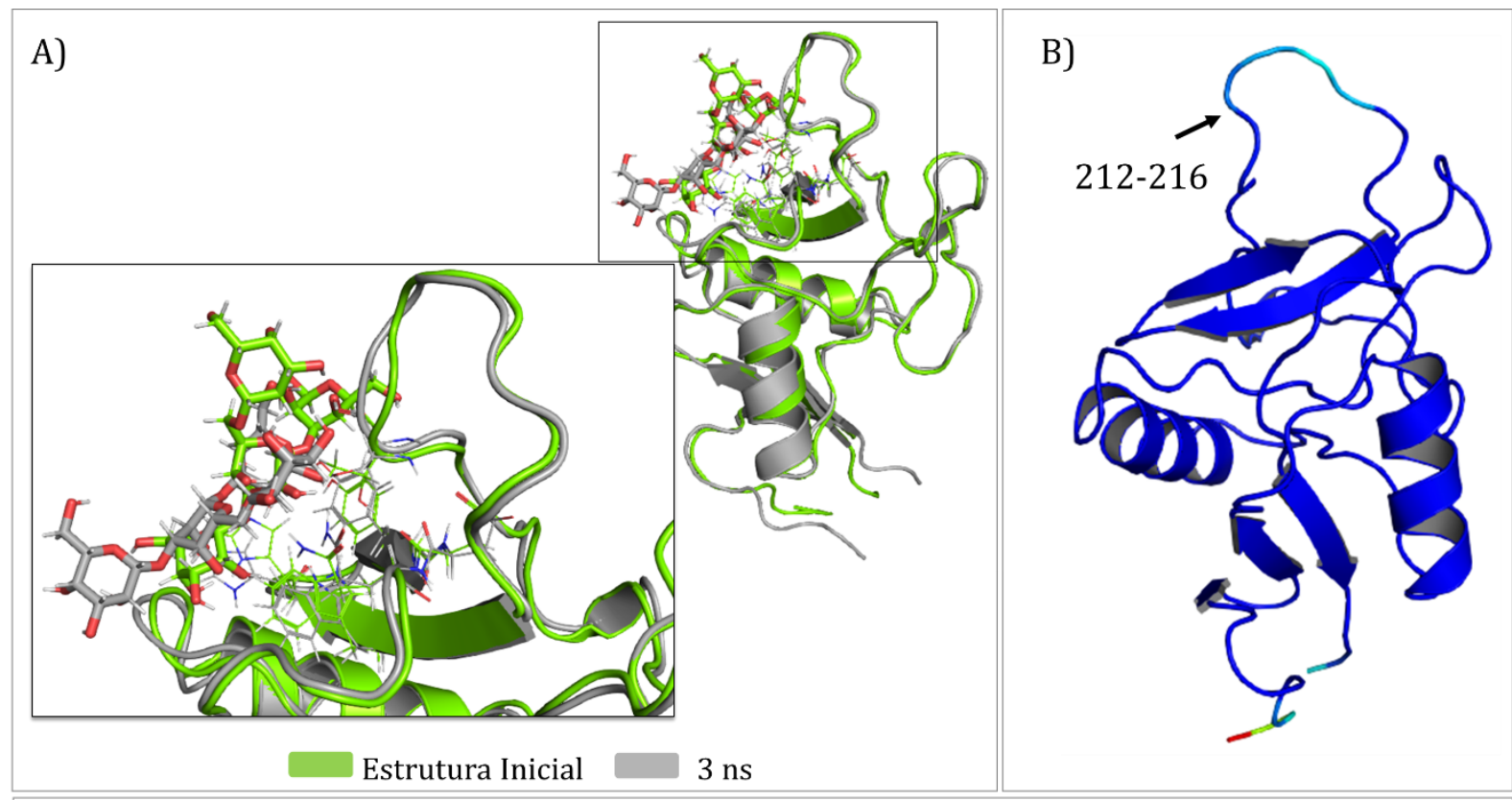

C)

RMSF ( $\AA$ ) - hDectin-1_CTLD/Scleroglucan

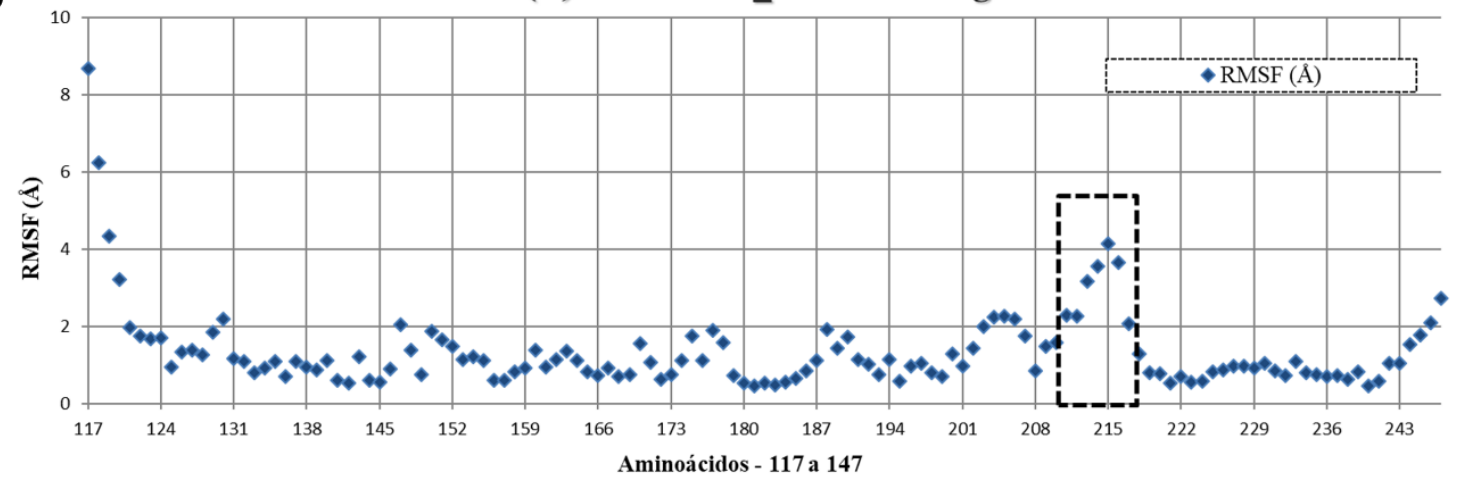

A) Alinhamento das estruturas dos complexos nos tempos inicial (verde) e 3 ns (cinza). A estrutura do complexo no tempo de 3 ns mostra o limite do tempo de interação entre Scleroglucan e o sítio do CTLD de hDectin-1 onde foi inicialmente docado. B) Representação gráfica do b-factor obtido para a estrutura do complexo CTLD/Scleroglucan em relação a estrutura inicial. O espectro de coloração vai do azul (regiões com baixo descolamento) até o vermelho (regiões com alto deslocamento). C) Valores de RMSF das coordenadas dos átomos $\mathrm{C} \alpha$ em relação à estrutura inicial. Os retângulos pontilhados em preto destacam a região dos aminoácidos 212 a 216 que apresentaram maior movimentação estrutural. Fonte: Arquivo pessoal.

Um pouco mais longa que as demais, a interação do $\beta$-glucano Sizofiran com o sítio do CTLD foi de, aproximadamente, $10 \mathrm{~ns}$ (figura 52A). Mas não diferente das análises anteriores, o b-factor (figura 52B) e RMSF (figura 52C) também mostraram um aumento da movimentação dos aminoácidos 211 a 217 presentes no loop que compõe o sítio de reconhecimento de $\beta$-glucano no CTLD de hDectin-1. 
Figura 52 - Complexo CTLD/Sizofiran.

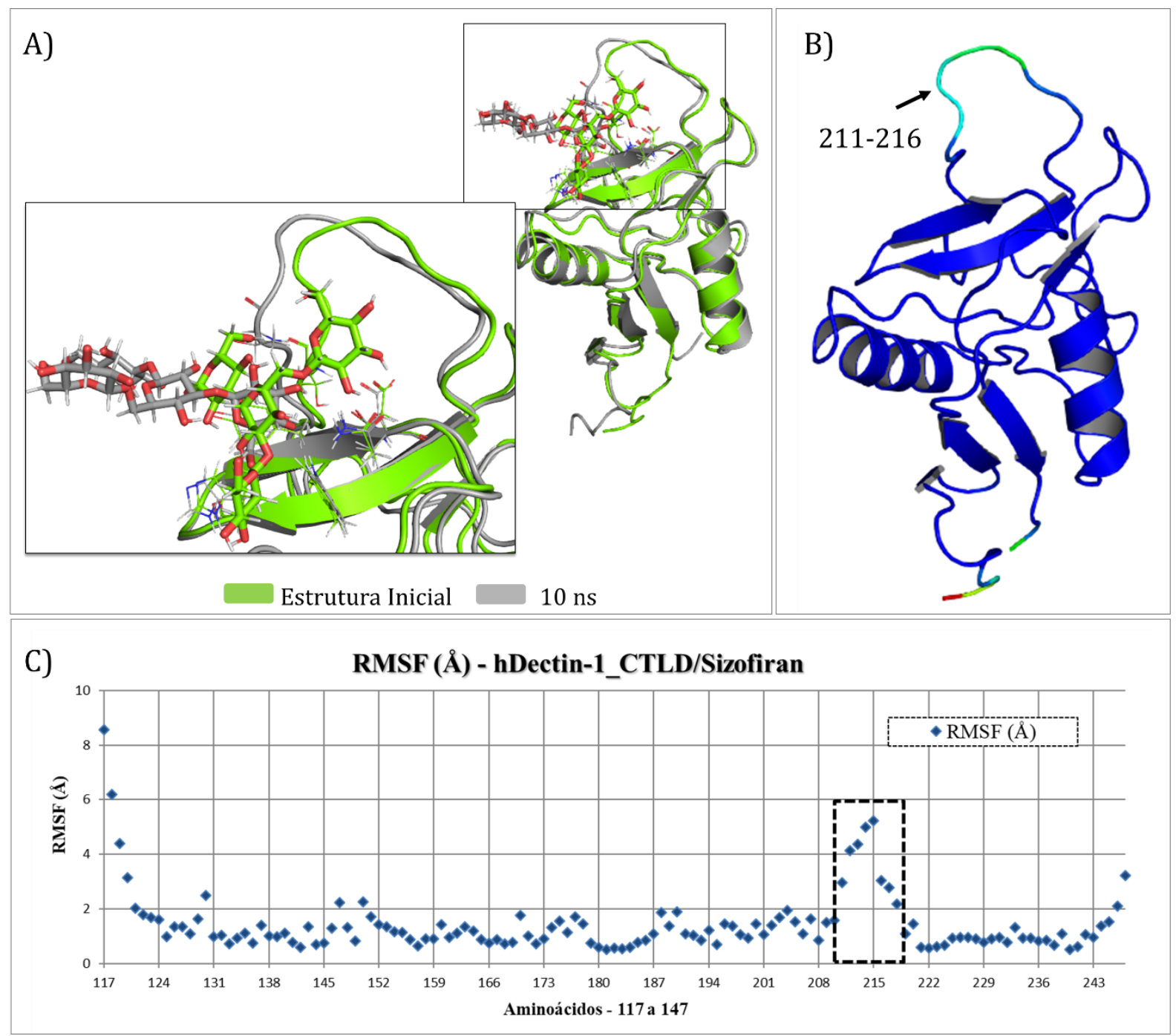

A) Alinhamento das estruturas dos complexos nos tempos inicial (verde) e $10 \mathrm{~ns}$ (cinza). A estrutura do complexo no tempo de 10 ns mostra o limite do tempo de interação entre Sizofiran e o sítio do CTLD de hDectin-1 onde foi inicialmente docado. B) Representação gráfica do $b$-factor obtido para a estrutura do complexo CTLD/Sizofiran em relação a estrutura inicial. O espectro de coloração vai do azul (regiões com baixo descolamento) até o vermelho (regiões com alto deslocamento). C) Valores de RMSF das coordenadas dos átomos C $\alpha$ em relação à estrutura inicial. Os retângulos pontilhados em preto destacam a região dos aminoácidos 210 a 216 que apresentaram maior movimentação estrutural. Fonte: Arquivo pessoal.

Os resultados de simulação de DM obtidos para os complexos CTLD/ $\beta$-glucano mostraram que houve pouco tempo de interação entre os $\beta$-glucanos com o CTLD de hDectin1. Esses resultados sozinhos não trazem muitas informações sobre a interação de $\beta$-glucanos com hDectin-1. Apenas é possível salientar que, com base nesses resultados, o tempo de interação entre o $\beta$-glucano e o CTLD pode estar relacionado ao tamanho dos $\beta$-glucanos e disposição das ramificações das unidades de D-glicose, sou seja, o tipo e local de interação com o CTLD de hDectin-1 pode estar diretamente relacionada a quantidade e arranjo das unidades de D-glicose que compõe o $\beta$-glucano. 
$\beta$-glucanos podem ser encontrados como polissacarídeos estruturais em cereais, algas ou exopolissacarídeos secretados nas superfícies de fungos e a sua estrutura depende significativamente de sua origem. Eles podem desencadear diferentes respostas imunes, podendo ser uma resposta fisiológica direcionada ao combate de patologias ou atuando como agentes imunoestimulantes eficientes. No entanto, os mecanismos associados a ambos os papéis ainda não são totalmente conhecidos (LEGENTIL et al., 2015).

Alguns $\beta$-glucanos devem interagir com dois CTLD de Dectin-1 na superfície celular para induzir a ativação intracelular de Syk e, então, a ativação da cascata de sinalização. Entretanto, as respostas imunológicas decorrentes do reconhecimento de $\beta$-glucanos por Dectin-1, com ou sem a assistência de TLRs, está fortemente ligado ao tipo de $\beta$-glucano usado nos estudos (ANAYA et al., 2020; LEGENTIL et al., 2015; MANSOUR el al., 2013). Assim, para complementar os resultados e obter mais informações sobre a interação de hDectin-1 com $\beta$-glucanos, foi feito o docking dos $\beta$-glucanos com o dímero dos CTLD de hDectin-1 obtido no presente estudo já descrito anteriormente nos resultados.

\subsubsection{Docking dos $\beta$-glucanos com o dímero CTLD-hD}

O docking entre o dímero do CTLD de hDectin-1 e os $\beta$-glucanos Laminarin, Zymosan, Scleroglucan e Sizofiran, foi realizado seguindo a mesma metodologia usada na etapa de docking entre o CTLD de hDectin-1 e os $\beta$-glucanos descrita anteriormente. O espaço de busca para o docking das moléculas de $\beta$-glucanos no sulco com características hidrofóbicas presente no CTLD também foi delimitado usando como referência a localização dos aminoácidos T210, W222, H224, Y229, D230 e Q231 na cadeia A do dímero. Foi especificado o espaço de busca com dimensões de $18 \AA$ nos eixos X, Y e Z. As coordenadas do centro da caixa que delimitaram o espaço de busca foram: $20.298 \AA$ no eixo X, $54.707 \AA$ no eixo Y e $39.859 \AA$ A no eixo Z.

O docking gerou dez estruturas em diferentes posicionamentos (poses) ranqueadas pelo score de energia das ligações em kcal/mol. Foi escolhida a pose com melhor score de energia (figura 53). O score de energia das ligações em kcal/mol para as melhores poses do docking entre o dímero dos CTLD de hDectin-1 e Laminarin, Zymosan, Scleroglucan e Sizofiran foi, respectivamente, -6.4, -4.9, -6.4 e -5.9 kcal/mol. 
Figura 53 - Resultado do docking entre o dímero dos CTDL de hDectin-1 e $\beta$-glucanos.

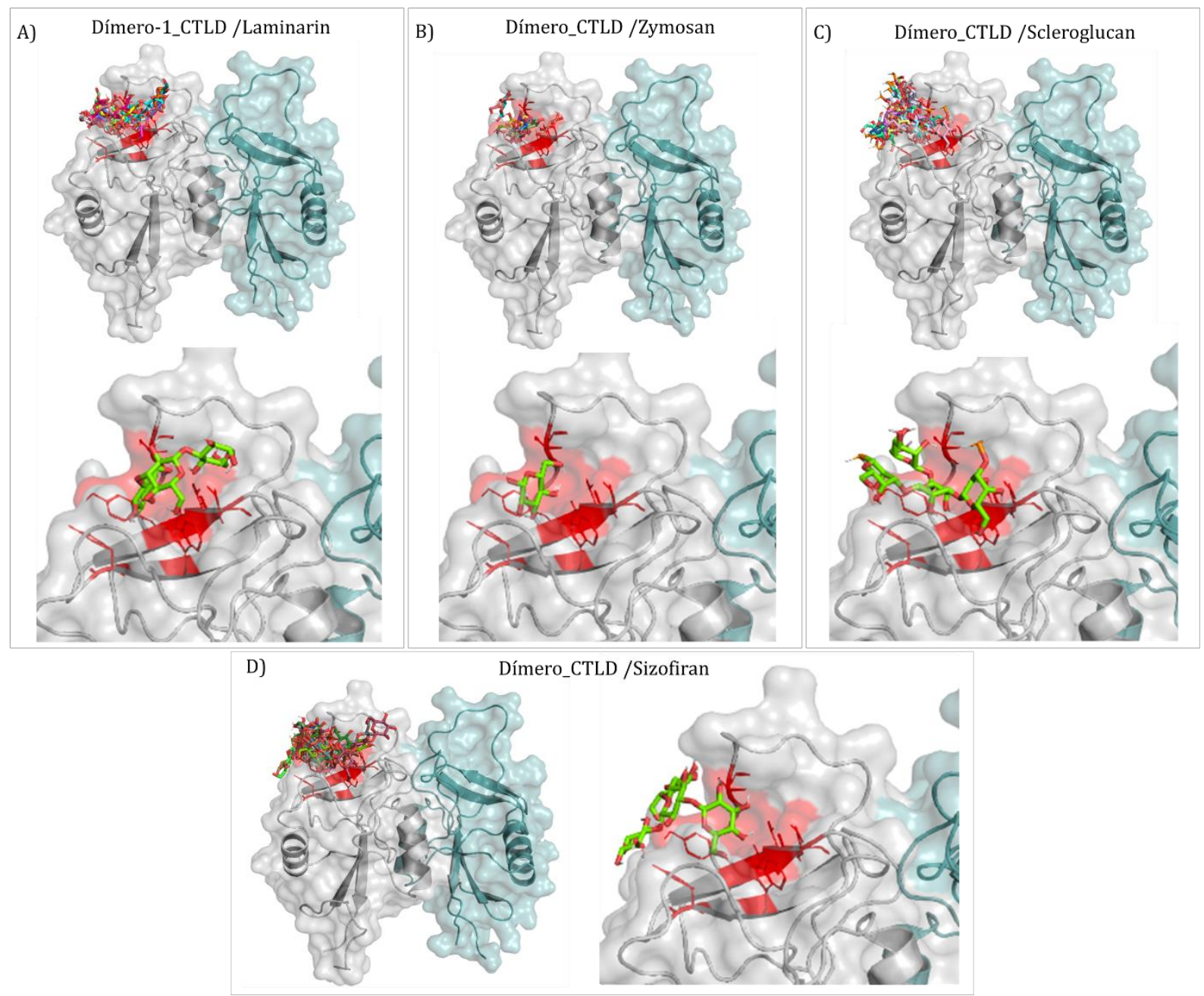

As imagens mostram o dímero (cadeia A em cinza e cadeia B em azul) com as 10 poses do docking para cada $\beta$ glucano e destacando o dímero com as melhores poses de cada $\beta$-glucano segundo o score de energia das ligações em kcal $/ \mathrm{mol}$. A região correspondente ao sítio na cadeia A do dímero é mostrada em vermelho e os $\beta$-glucanos com melhor score em verde. A) Resultado do docking entre o dímero e Laminarin. B) Resultado do docking entre o dímero e Zymosan. C) Resultado do docking entre o dímero e Scleroglucan. A) Resultado do docking entre o dímero e Sizofiran. Fonte: Arquivo pessoal.

\subsubsection{Simulação de DM dos dímeros CTLD-hD e $\beta$-glucanos e análise de interação proteína/ligante}

Para a construção dos sistemas com os dímeros de CTLD e $\beta$-glucanos (Dímero/ $\beta$ glucano) foi o usado o servidor CHARMM-GUI que disponibiliza o protocolo Glycan Reader \& Modeler (PARK et al., 2019; JO e KIM, 2007). Para cada complexo foi obtido um sistema por meio do servidor CHARMM-GUI (JO et al., 2008). Os sistemas são do tipo cubico, com dimensões de $84 \AA$ nos eixos x, y e z, sendo compostos pelo complexo Dímero/ $\beta$-glucano, moléculas de água (TIP3) e íons que caracterizam o ambiente intracelular e extracelular. 
Após essa etapa, o sistema Dímero/ $\beta$-glucano foi submetido a simulação de DM por meio do software GROMACS (HESS et al., 2008) que implementou o campo de força CHARMM36m (HUANG et al., 2017). Foram feitas simulações de 100 ns para cada complexo com o objetivo de verificar a estabilidade do complexo Dímero/ $\beta$-glucano gerado por docking.

Cada simulação de DM do sistema complexo-solvente foi realizada em condições físico-químicas controladas, com temperatura máxima de $310 \mathrm{~K}$ e pressão constante de $1 \mathrm{~atm}$.

O comportamento estrutural do complexo CTLD/ $\beta$-glucano ao longo do tempo foi analisado por meio do RMSF, $b$-factor e alinhamento das estruturas ao longo do tempo de simulação de DM.

Assim como no resultado obtido para os complexos CTLD/ $\beta$-glucanos, o alinhamento das estruturas inicial ( $0 \mathrm{~ns})$ e final (100 ns) mostrou que nenhum dos $\beta$-glucanos permaneceram no sítio do CTLD do dímero pelo tempo total de 100 ns de simulação de DM. Entretanto, resultados diferentes foram observados. Foram extraídos arquivos de coordenadas dos complexos CTLD/ $\beta$-glucano a cada 1 ns da simulação de DM para verificar em que momento cada $\beta$-glucano deixou de interagir com o sítio onde inicialmente foi docado.

O alinhamento das estruturas do complexo Dímero/Zymosan mostrou que o $\beta$-glucano Zymosan permaneceu menos de 3 ns de simulação interagindo com o sítio do CTLD de hDectin-1 (figura 54A). Nas análises do b-factor (figura 54B) e RMSF (figura 54C) foi observado que, assim como na análise de simulação de DM do monômero CTLD/Zymosan, ocorreu uma maior movimentação dos aminoácidos localizados na região entre 210 a 216, comparados aos demais aminoácidos adjacentes a eles. 
Figura 54 - Complexo Dímero/Zymosan.

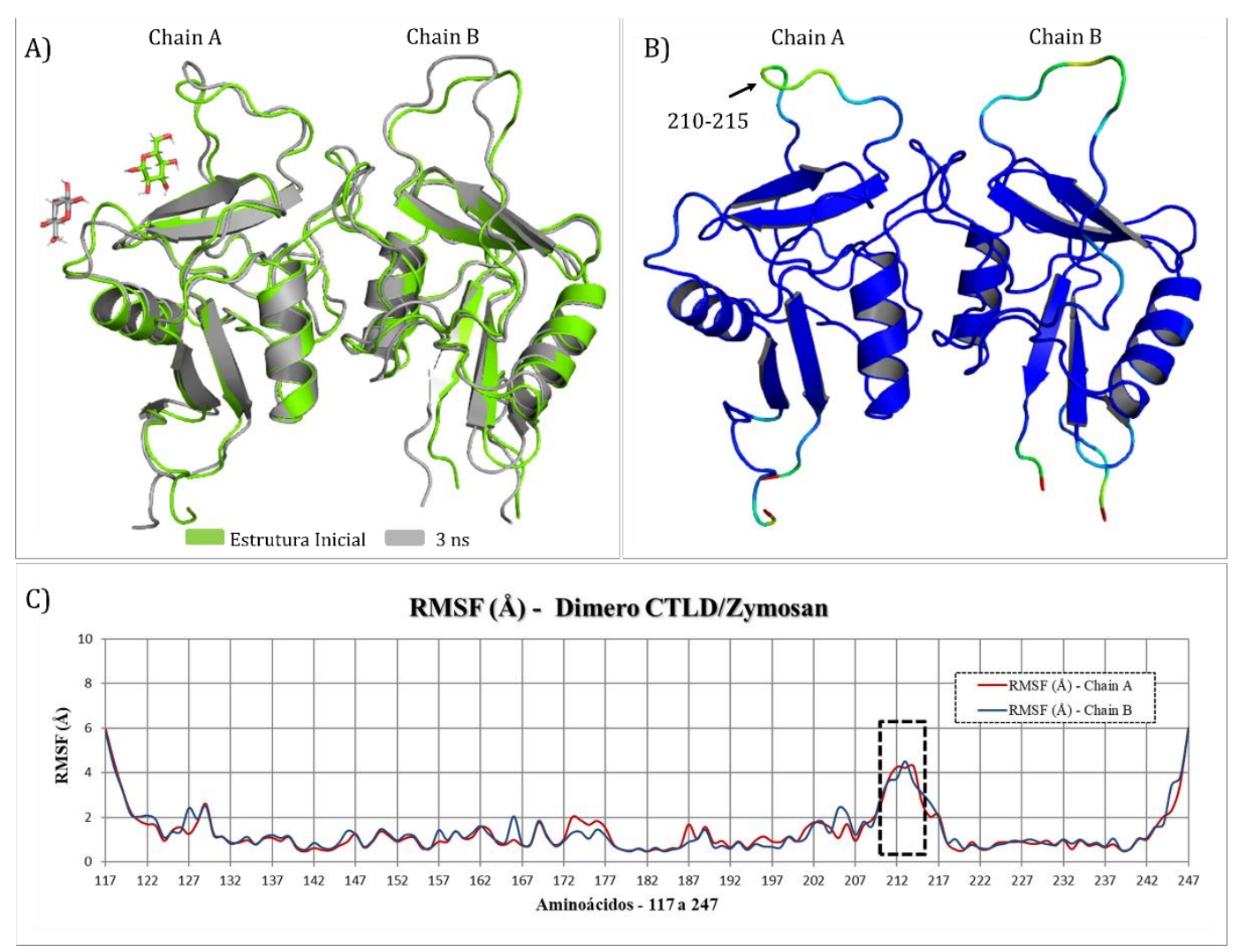

A) Alinhamento das estruturas dos complexos nos tempos inicial (verde) e 3 ns (cinza). A estrutura do complexo no tempo de 3 ns mostra que o tempo de interação entre Zymosan e o sítio do CTLD de hDectin-1 foi inferior a este tempo. B) Representação gráfica do b-factor obtido para a estrutura do complexo Dímero/Zymosan em relação a estrutura inicial. O espectro de coloração vai do azul (regiões com baixo descolamento) até o vermelho (regiões com alto deslocamento). C) Valores de RMSF das coordenadas dos átomos $\mathrm{C} \alpha$ em relação à estrutura inicial. Os retângulos pontilhados em preto destacam a região dos aminoácidos 210 a 216 que apresentaram maior movimentação estrutural. Fonte: Arquivo pessoal.

$\mathrm{Na}$ análise do complexo Dímero/Laminarin, o alinhamento das estruturas do complexo mostrou que Laminarin permaneceu, aproximadamente, $25 \mathrm{~ns}$ de simulação interagindo com o sítio do CTLD de hDectin-1 (figura 55A), tempo este muito superior ao $1 \mathrm{~ns}$ observado na simulação de DM do monômero CTLD/Laminarin. A análise do $b$-factor (figura 55B) e RMSF (figura 55C) mostrou haver maior movimentação na região dos aminoácidos 210 a 216 da cadeia A do dímero em relação a cabeia B. A região dos aminoácidos 210 a 216 da cadeia A é onde o $\beta$-glucano esteve interagindo, deste modo, é possível que essa diferença observada tenha sido induzida pelo $\beta$-glucano Laminarin. 
Figura 55 - Complexo Dímero/Laminarin.
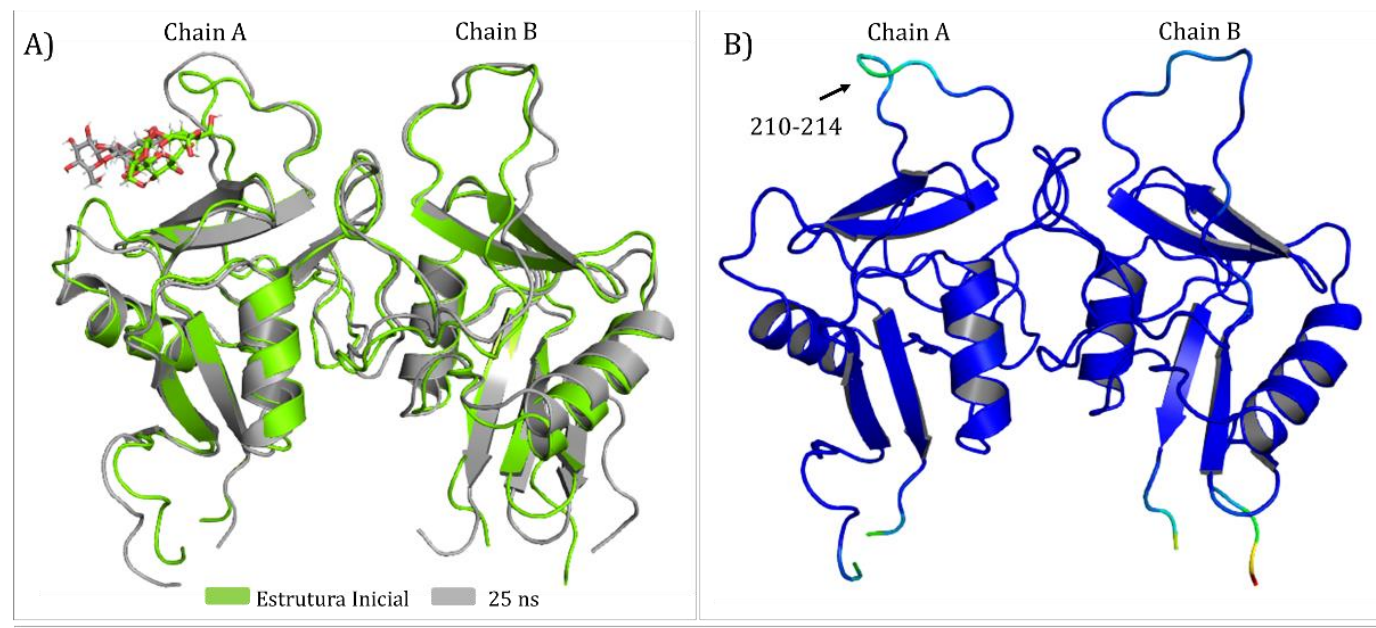

C)

RMSF (Å) - Dimero CTLD/Laminarin

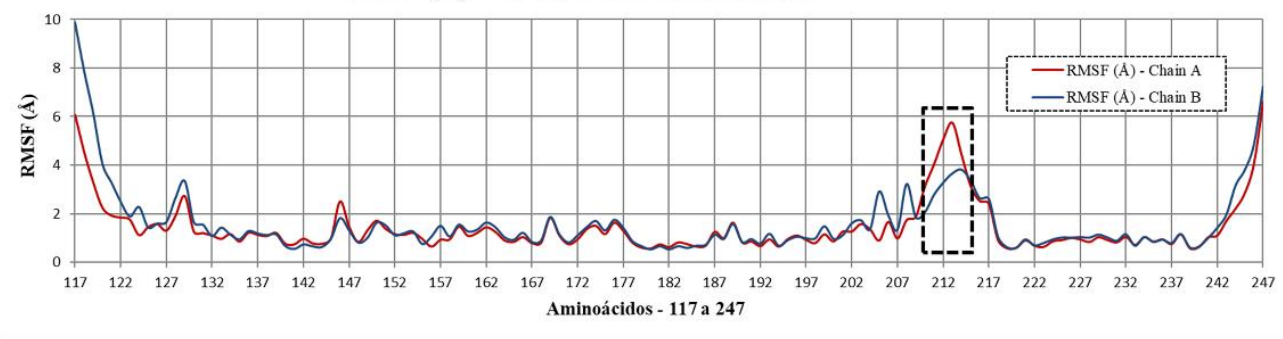

A) Alinhamento das estruturas dos complexos nos tempos inicial (verde) e 25 ns (cinza). A estrutura do complexo no tempo de 25 ns mostra o limite do tempo de interação entre Laminarin e o sítio do CTLD de hDectin-1 onde foi inicialmente docado. B) Representação gráfica do b-factor obtido para a estrutura do complexo Dímero/Laminarin em relação a estrutura inicial. O espectro de coloração vai do azul (regiões com baixo descolamento) até o vermelho (regiões com alto deslocamento). C) Valores de RMSF das coordenadas dos átomos $\mathrm{C} \alpha$ em relação à estrutura inicial. Os retângulos pontilhados em preto destacam a região dos aminoácidos $210 \mathrm{a}$ 216 que apresentaram maior movimentação estrutural, principalmente na cadeia A. Fonte: Arquivo pessoal.

O $\beta$-glucano Scleroglucan permaneceu, aproximadamente, $10 \mathrm{~ns}$ interagindo com o sítio do CTLD de hDectin-1 (figura 56A), tempo também superior ao observado na simulação de DM do monômero CTLD/Scleroglucan. Apesar de ser mais que o dobro do tempo da interação com o monômero (3 ns), foi bem inferior ao tempo observado na simulação de DM do dímero com Laminarin. A análise do b-factor (figura 56B) e RMSF (figura 56C) também mostrou haver maior movimentação na região dos aminoácidos 210 a 216 da cadeia $\mathrm{A}$ do dímero em relação a cabeia B. A região dos aminoácidos 210 a 216 da cadeia A é onde o $\beta$ glucano Scleroglucan esteve interagindo, deste modo, é possível que essa diferença observada tenha sido induzida por ele. 
Figura 56 - Complexo Dímero/Scleroglucan.
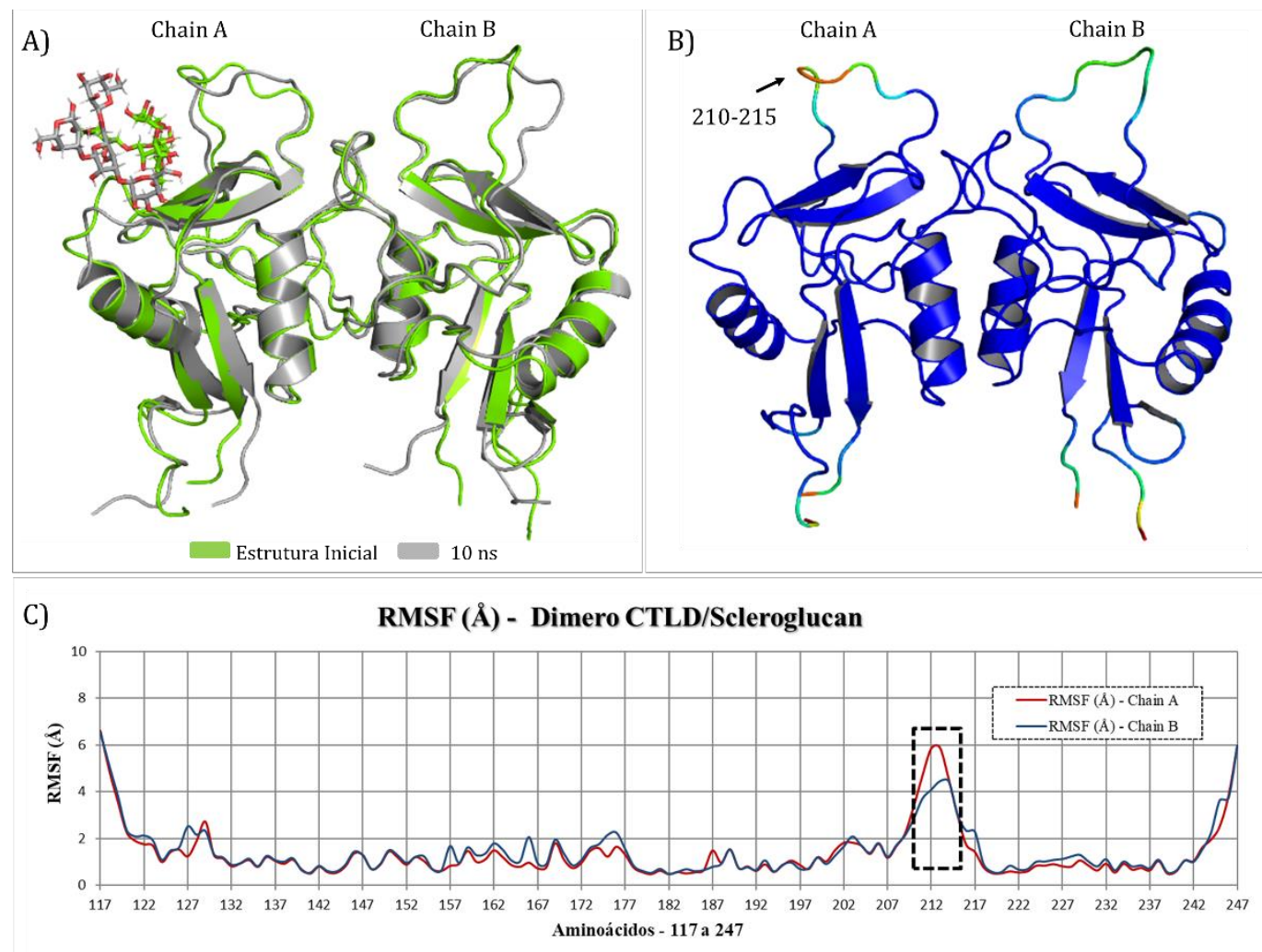

A) Alinhamento das estruturas dos complexos nos tempos inicial (verde) e $10 \mathrm{~ns}$ (cinza). A estrutura do complexo no tempo de 10 ns mostra o limite do tempo de interação entre Scleroglucan e o sítio do CTLD de hDectin-1 onde foi inicialmente docado. B) Representação gráfica do b-factor obtido para a estrutura do complexo Dímero/Scleroglucan em relação a estrutura inicial. O espectro de coloração vai do azul (regiões com baixo descolamento) até o vermelho (regiões com alto deslocamento). C) Valores de RMSF das coordenadas dos átomos $\mathrm{C} \alpha$ em relação à estrutura inicial. Os retângulos pontilhados em preto destacam a região dos aminoácidos 210 a 216 que apresentaram maior movimentação estrutural, principalmente na cadeia A. Fonte: Arquivo pessoal.

O resultado anterior da simulação de DM do monômero de CTLD com Sizofiran mostrou que a interação com o CTLD foi de, aproximadamente, 10 ns. Já a simulação de DM do Dímero/Sizofiran mostrou que a interação do $\beta$-glucano com o sítio do CTLD foi de, aproximadamente, $40 \mathrm{~ns}$ (figura 57A). Esse foi o maior tempo de interação observado, tanto nas simulações de DM dos $\beta$-glucanos com o monômero quanto com o dímero. Mas o mesmo padrão de variação local foi observado nos resultados do b-factor (figura 57B) e RMSF (figura 57C), onde também foi notado o aumento da movimentação dos aminoácidos na região de 210 a 216 de ambos os monômeros. 
Figura 57 - Complexo Dímero/Sizofiran.
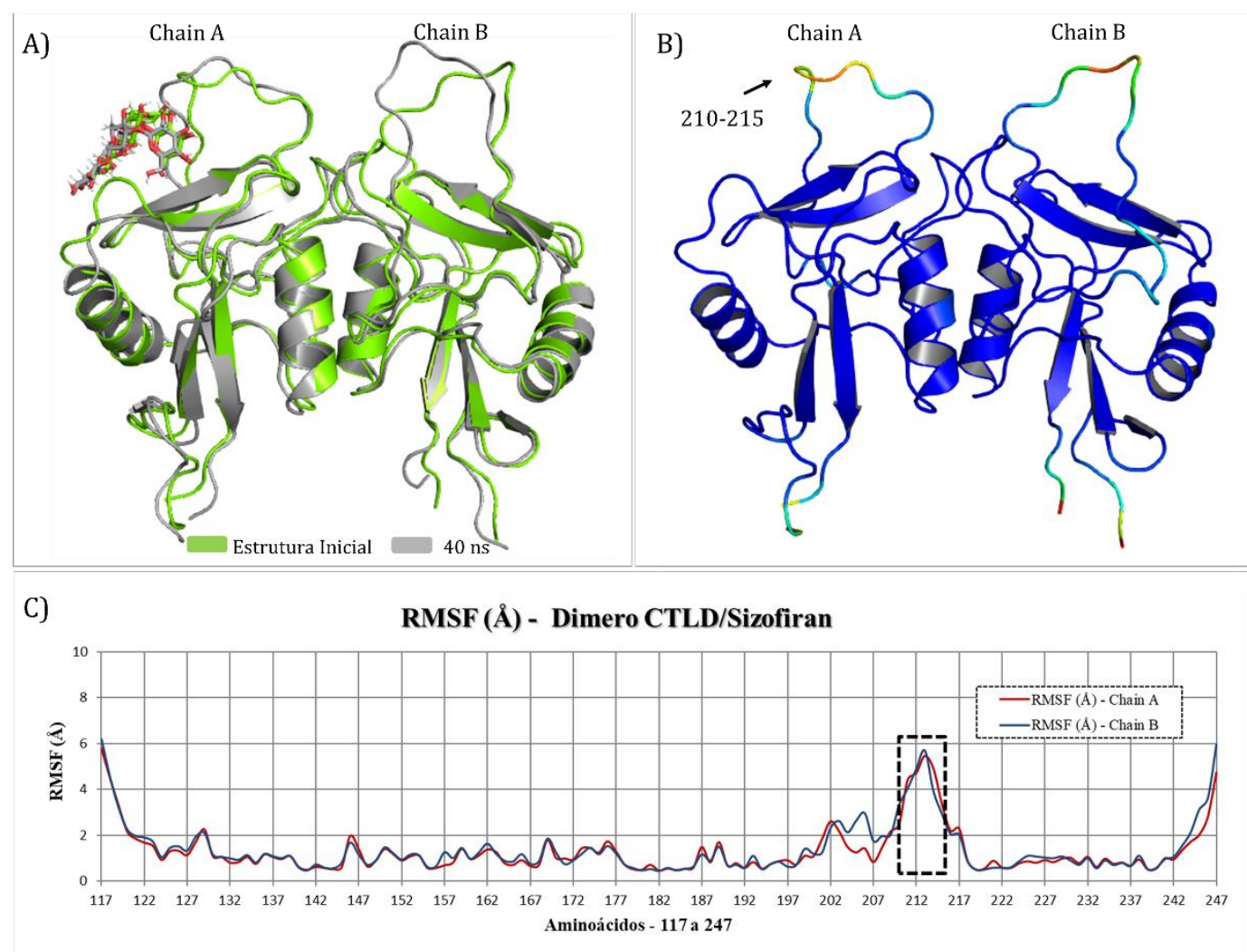

A) Alinhamento das estruturas dos complexos nos tempos inicial (verde) e $40 \mathrm{~ns}$ (cinza). A estrutura do complexo no tempo de 40 ns mostra o limite do tempo de interação entre Sizofiran e o sítio do CTLD de hDectin-1 onde foi inicialmente docado. B) Representação gráfica do b-factor obtido para a estrutura do complexo Dímero/Sizofiran em relação a estrutura inicial. O espectro de coloração vai do azul (regiões com baixo descolamento) até o vermelho (regiões com alto deslocamento). C) Valores de RMSF das coordenadas dos átomos C $\alpha$ em relação à estrutura inicial. Os retângulos pontilhados em preto destacam a região dos aminoácidos 210 a 216 que apresentaram maior movimentação estrutural. Fonte: Arquivo pessoal.

Inicialmente, após analisar os resultados da interação entre os $\beta$-glucanos e o monômero de CTLD de hDectin-1, pode-se inferir que, a movimentação observada no RMSF e b-factor da região dos aminoácidos 210 a 216, localizados no loop que compõe o sulco hidrofóbico que forma o sítio de reconhecimento de $\beta$-glucanos, pode ter sido fator determinante no tempo em que cada $\beta$-glucano interagiu com o sítio onde foram inicialmente docados.

Foi observado nos dímeros Dímero/Laminarin e Dímero/Scleroglucan que essa região apresentou maior movimentação na cadeia A do dímero em relação ao mesmo local da cadeia B. Isso pode ser o indicativo de que essa movimentação esteja relacionada ao tipo de $\beta$-glucano com o qual esteja interagindo. Entretanto, a análise dos resultados da interação entre o dímero de CTLD de hDectin-1 e $\beta$-glucanos, evidenciou que, o aumento da movimentação observada nos aminoácidos da região 210 a 216, pode ser algo vantajoso para a estabilidade de alguns $\beta$ - 
glucanos no sítio de reconhecimento do CTLD em conformação dimérica. Diferente dos resultados observados nas simulações de DM do monômero do CTLD de hDectin-1, onde, aparentemente, a movimentação dessa região parecia ser desfavorável para a interação com os $\beta$-glucanos, na conformação dimérica esse fator pode ser algo importante no processo de reconhecimento de $\beta$-glucanos específicos, como Laminarin e Scleroglucan, por hDectin-1.

A tabela 5 mostra a diferença no tempo de interação dos $\beta$-glucanos com o sítio de reconhecimento presente no CTLD de hDectin-1 no monômero e no dímero. É possível observar que, todas as simulações de DM do complexo Dímero/ $\beta$-glucanos, apresentaram maior tempo de interação dos $\beta$-glucanos com o sítio se comparadas as simulações dos complexos CTLD/ $\beta$-glucanos.

Tabela 5 - Tempo de interação dos $\beta$-glucanos com o sítio de reconhecimento presente no CTLD de hDectin-1 no monômero e no dímero e quantidade de interações entre os $\beta$-glucanos e sítio nos complexos obtidos por docking.

\begin{tabular}{|c|c|c|c|c|c|c|c|}
\hline $\begin{array}{l}\text { Monômero/ } \\
\beta \text {-glucano }\end{array}$ & $\begin{array}{c}N^{o} \\
\text { hydrogen } \\
\text { bonds }\end{array}$ & $\begin{array}{l}N^{\circ} \text { non- } \\
\text { bonded } \\
\text { contacts }\end{array}$ & $\begin{array}{l}\text { Tempo } \\
\text { no sítio }\end{array}$ & $\begin{array}{l}\text { Dímero/ } \beta \text { - } \\
\text { glucano }\end{array}$ & $\begin{array}{c}N^{o} \\
\text { hydrogen } \\
\text { bonds }\end{array}$ & $\begin{array}{l}N^{\circ} \text { non- } \\
\text { bonded } \\
\text { contacts }\end{array}$ & $\begin{array}{l}\text { Tempo } \\
\text { no sítio }\end{array}$ \\
\hline $\begin{array}{c}\text { CTLD/ } \\
\text { Zymosan }\end{array}$ & 3 & 26 & $1 \mathrm{~ns}$ & $\begin{array}{c}\text { CTLD/ } \\
\text { Zymosan }\end{array}$ & 6 & 17 & $5 \mathrm{~ns}$ \\
\hline $\begin{array}{c}\text { CTLD/ } \\
\text { Laminarin }\end{array}$ & 4 & 34 & $1 \mathrm{~ns}$ & $\begin{array}{c}\text { CTLD/ } \\
\text { Laminarin }\end{array}$ & 4 & 42 & $25 \mathrm{~ns}$ \\
\hline $\begin{array}{c}\text { CTLD/ } \\
\text { Scleroglucan }\end{array}$ & 5 & 51 & $3 \mathrm{~ns}$ & $\begin{array}{c}\text { CTLD/ } \\
\text { Scleroglucan }\end{array}$ & 9 & 58 & $10 \mathrm{~ns}$ \\
\hline $\begin{array}{l}\text { CTLD/ } \\
\text { Sizofiran }\end{array}$ & 5 & 54 & $10 \mathrm{~ns}$ & $\begin{array}{l}\text { CTLD/ } \\
\text { Sizofiran }\end{array}$ & 13 & 54 & $40 \mathrm{~ns}$ \\
\hline
\end{tabular}

Fonte: Arquivo pessoal.

A análise das interações entre os $\beta$-glucanos com o sítio de reconhecimento presente no CTLD expos diferenças na quantidade de ligações de hidrogênio e contatos entre átomos não ligados nos complexos CTLD/ $\beta$-glucanos e Dímero/ $\beta$-glucanos, sendo os resultados obtidos para os complexos Dímero/ $\beta$-glucanos, possivelmente, mais favoráveis à interação entre os $\beta$-glucanos e o sítio de reconhecimento devido a maior quantidade de interações átomoátomo presentes. Outra diferença observada entre as duas etapas de docking está presente no score de energia das ligações em kcal/mol para as melhores poses do docking entre o monômero e dímero. Para o monômero, o score de energia das ligações foi, respectivamente, -5.4, -3.7, 5.1 e $-5.8 \mathrm{kcal} / \mathrm{mol}$ para Laminarin, Zymosan, Scleroglucan e Sizofiran, para o dímero, o score 
foi, respectivamente, -6.4, -4.9, -6.4 e -5.9 kcal/mol para Laminarin, Zymosan, Scleroglucan e Sizofiran.

Apesar dos ligantes ( $\beta$-glucanos) e alvo (aminoácidos T210, W222, H224, Y229, D230 e Q231 do CTLD) serem os mesmo, o algoritmo do software AutoDock Vina não é determinístico, deste modo, é esperado que ocorram variações nos resultados obtidos em diferentes execuções, mesmo que os dados de entrada sejam os mesmos (TROTT; OLSON, 2010).

Para excluir possíveis conflitos nos resultados ocasionados pela diferença na quantidade de interações atômicas e score de energia das ligações observadas nos resultados de docking no monômero e dímero, foi feita a simulação de DM dos monômeros de CTLD de hDectin-1 com $\beta$-glucanos obtidos na mesma etapa de docking do dímero de CTLD com $\beta$ glucanos. Apenas foi excluída a cadeia B dos dímeros no processo de construção do sistema complexo/solvente pelo servidor CHARMMGUI (JO et al., 2008). Os sistemas obtidos por meio do servidor CHARMM-GUI (JO et al., 2008) para os complexos CTLD/ $\beta$-glucanos são do tipo cubico, com dimensões de $73 \AA ̊$ nos eixos x, y e z, sendo compostos pelo complexo CTLD/ $\beta$-glucano, moléculas de água (TIP3) e íons que caracterizam o ambiente intracelular e extracelular.

Após essa etapa, o sistema CTLD/ $\beta$-glucano foi submetido a simulação de DM por meio do software GROMACS (HESS et al., 2008) que implementou o campo de força CHARMM36m (HUANG et al., 2017). Foram feitas simulações de 50 ns para cada complexo com o objetivo de verificar a estabilidade do complexo CTLD/ $\beta$-glucano gerado por docking.

Cada simulação de DM do sistema complexo-solvente foi realizada em condições físico-químicas controladas, com temperatura máxima de $310 \mathrm{~K}$ e pressão constante de $1 \mathrm{~atm}$.

O comportamento estrutural do complexo CTLD/ $\beta$-glucano ao longo do tempo foi analisado por meio do RMSF, $b$-factor e alinhamento das estruturas ao longo do tempo de simulação de DM.

$\mathrm{O}$ alinhamento das estruturas inicial e final, mais uma vez, mostrou que nenhum $\beta$ glucano permaneceu no sítio de ligação ao longo dos 50 ns de simulação. Os $\beta$-glucanos Laminarin e Zymosan mantiveram-se no sítio por, aproximadamente, 1 ns (figura 58A e Figura 58B). O $\beta$-glucano Scleroglucan permaneceu no sítio por 3 ns (figura 58C) e o Sizofiran permaneceu por $17 \mathrm{~ns}$ (figura 58D), sendo este o maior tempo de interação observado de um $\beta$ glucano com o monômero de CTLD de hDectin-1.

Os resultados obtidos para o RMSF e b-factor mostraram haver o mesmo comportamento estrutural observado nos resultados descritos anteriormente, tanto para o 
monômero quanto para o dímero, onde a região entre os aminoácidos 210 e 216 apresentou uma maior movimentação em relação a posição da estrutura inicial (figura 58A, 58B, 58C e 58D).

Apesar de haver diferenças na quantidade de interações átomo-átomo e score de energia de ligação entre os resultados obtidos nas duas etapas de docking para os $\beta$-glucanos no monômero de CTLD de hDectin-1, os resultados obtidos na simulação de DM foram semelhantes. Ambas as simulações de DM mostraram que o tempo de interação entre $\beta$ glucanos com o monômero de CTLD é inferior ao tempo de interação com o dímero (tabela 6).

Tabela 6 - Comparativo do tempo de interação dos $\beta$-glucanos com o sítio de reconhecimento presente no CTLD de hDectin-1 na primeira e na segunda etapa de docking com o monômero e com o dímero.

\begin{tabular}{|c|c|c|c|}
\hline $\begin{array}{c}1^{\text {a }} \text { etapa: Monômero/ } \beta \text { - } \\
\text { glucano }\end{array}$ & $\begin{array}{c}N^{\circ} \text { hydrogen } \\
\text { bonds }\end{array}$ & $N^{o}$ non-bonded contacts & Tempo no sítio \\
\hline CTLD/ Zymosan & 3 & 26 & $1 \mathrm{~ns}$ \\
\hline CTLD/ Laminarin & 4 & 34 & $1 \mathrm{~ns}$ \\
\hline CTLD/ Scleroglucan & 5 & 51 & $3 \mathrm{~ns}$ \\
\hline CTLD/ Sizofiran & 5 & 54 & $10 \mathrm{~ns}$ \\
\hline Dímero/ $\beta$-glucano & $\begin{array}{c}N^{o} \text { hydrogen } \\
\text { bonds }\end{array}$ & $N^{o}$ non-bonded contacts & Tempo no sítio \\
\hline CTLD/ Zymosan & 6 & 17 & $5 \mathrm{~ns}$ \\
\hline CTLD/ Laminarin & 4 & 42 & $25 \mathrm{~ns}$ \\
\hline CTLD/ Scleroglucan & 9 & 58 & $10 \mathrm{~ns}$ \\
\hline CTLD/ Sizofiran & 13 & 54 & $40 \mathrm{~ns}$ \\
\hline $\begin{array}{c}2^{\mathrm{a}} \text { etapa Monômero/ } \beta \text { - } \\
\text { glucano }\end{array}$ & $\begin{array}{c}N^{o} \text { hydrogen } \\
\text { bonds }\end{array}$ & $N^{o}$ non-bonded contacts & Tempo no sítio \\
\hline CTLD/ Zymosan & 6 & 17 & $1 \mathrm{~ns}$ \\
\hline CTLD/ Laminarin & 4 & 42 & $1 \mathrm{~ns}$ \\
\hline CTLD/ Scleroglucan & 9 & 58 & $3 \mathrm{~ns}$ \\
\hline CTLD/ Sizofiran & 13 & 54 & $17 \mathrm{~ns}$ \\
\hline
\end{tabular}

Fonte: Arquivo pessoal.

Figura 58 - Complexo monômero/b-glucano. 

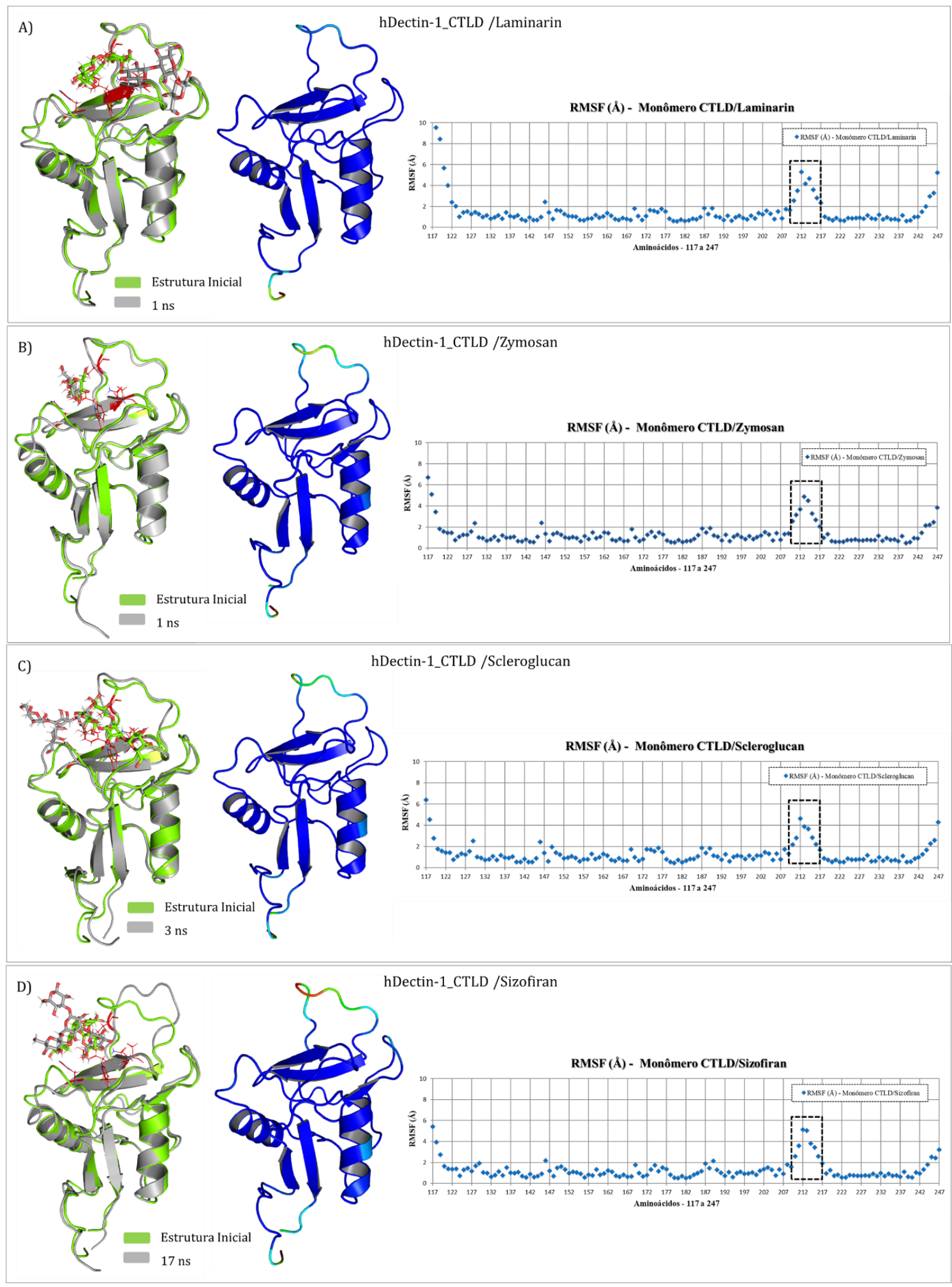

À esquerda das imagens é apresentado o alinhamento das estruturas inicial (0 ns) e final da interação do b-glucano com o CTLD. No centro é apresentada a representação gráfica do $b$-factor obtido para a estrutura do monômero de CTLD em relação a estrutura inicial. O espectro de coloração vai do azul escuro (regiões com baixo descolamento) até o vermelho (regiões com alto deslocamento). À direita são apresentados os valores de RMSF das coordenadas dos átomos $\mathrm{C} \alpha$ em relação à estrutura inicial. Os retângulos pontilhados em preto destacam a região dos aminoácidos 210 a 217 que apresentaram maior movimentação estrutural. A) Complexo CTLD/Laminarin. Alinhamento inicial e a $1 \mathrm{ns,} b$-factor e gráfico de RMSF. B) Complexo CTLD/Zymosan. Alinhamento inicial e a $1 \mathrm{~ns}, b$-factor e gráfico de RMSF. C) Complexo CTLD/Scleroglucan. Alinhamento inicial e aos $3 \mathrm{~ns}, b$-factor e gráfico de RMSF. D) Complexo CTLD/Sizofiran. Alinhamento inicial e aos $17 \mathrm{~ns}, b$-factor e gráfico de RMSF. Fonte: Arquivo pessoal. 
Os estudos de Brown e colaboradores (2007) e Dulal e Colaboradores (2018) mostraram que os aminoácidos W221, H223 e Y228 presentes no CTLD de mDectin-1 compõem o principal sítio de reconhecimento do $\beta$-glucano Laminarin. No presente estudo foi demostrado que os aminoácidos W222, H224 e Y229 presentes no CTLD de hDectin-1 apresentam as mesmas características físico-químicas e possível papel fundamental para o reconhecimento de alguns $\beta$-glucanos. Além dos aminoácidos W222, H224 e Y229, os resultados obtidos por meio das simulações de DM do CTLD de hDectin-1 em complexo com $\beta$-glucanos mostrou que, os aminoácidos T210, A211, T212, Q213, E214, N215 e P216 localizados em um grande loop do CTLD se mostraram importantes componentes do sítio de reconhecimento de $\beta$-glucanos. O loop composto por esses aminoácidos mostrou maior flexibilidade durante as simulações de DM quando comparado as demais regiões que compõe o CTLD de hDectin-1, sugerindo que esse possa ser um importante fator no processo de interação com $\beta$-glucanos.

Dulal e Colaboradores (2018) descreveram a observação do evento de oligomerização do CTLD de mDectin-1 in vitro (cromatografia com exclusão por tamanho). A pesquisa mostrou que a interação do CTLD com o $\beta$-glucano laminarin induziu a formação de tetrâmeros de CTLD, estando os quatro monômeros de CTLD interagindo com as moléculas de laminarin. No mesmo estudo foi feita a mutagênese dirigida aos resíduos Y141, R145 e E243 de mDectin1, que exibiu formação reduzida de oligômeros, entretanto, neste caso foi sugerindo pelos autores que esses aminoácidos participam nas interações proteína-proteína guiadas por laminarin.

Os resíduos Y141, R145 e E243 de mDectin-1 fazem parte da interface de interação entre os monômeros do dímero mDectin-1 (PDB ID: 2CL8), descrito por Brown e Colaboradores (2007) considerado na época, possivelmente, inviável in vivo. Entretanto, após considerar os resultados obtidos por Dulal e Colaboradores (2018) e os resultados obtidos no presente estudo, onde foi verificada a estabilidade conformacional desse dímero por simulação de DM, podemos avaliar a possibilidade de que essa conformação deva ser melhor explorada para confirmar sua existência in vivo, assim como é vista sua ocorrência in vitro (DULAL et al., 2018; BROWN et al., 2007) e observada sua estabilidade in silico.

A conformação dimérica para hDectin-1 obtida por docking proteína-proteína e avaliada por meio de simulação de DM se mostrou viável, sendo um fator importante no processo de interação do CTLD de hDectin-1 com $\beta$-glucanos identificado no presente estudo. Os resultados obtidos por meio das simulações de DM mostraram que a interação do CTLD em conformação dimérica se mostrou mais favorável para a interação e possível reconhecimento 
de $\beta$-glucanos. Os mesmos resultados sugerem que, cada tipo de $\beta$-glucano, pode ter um local especifico para seu reconhecimento no CTLD de hDectin-1, sendo possível que o sítio usado como referência no presente estudo seja mais especializado em reconhecer os $\beta$-glucanos Laminarin e Sizofiran, pois estes permaneceram mais tempo interagindo com o sítio de reconhecimento do CTLD em conformação dimérica quando comparados ao Zymosan e Scleroglucan.

Esse resultado corrobora as informações presentes na pesquisa realizada por Drickamer (1999), onde é descrito que receptores com CTLD compõem uma família muito conservada, onde esses CTLD interagem por meio de várias superfícies diferentes, projetando seus sítios em diferentes orientações para melhorar a eficiência de reconhecimento de alvos moleculares específicos e também corrobora os resultados obtidos por Anaya e colaboradores (2020), onde demostraram que a oligomerização de Dectin-1 ocorre de maneira dependente do tipo e quantidade de $\beta$-glucanos disponíveis na superfície celular.

Além da resposta inflamatória desencadeada pelo reconhecimento de $\beta$-glucanos provenientes de patógenos fúngicos, Dectin-1 se liga à linfócitos $\mathrm{T}$ e aumenta sua resposta mitogênica (ARIIZUMI et al., 2000). O domínio de ligação presente nas moléculas de Dectin1 para ativação das células $\mathrm{T}$ ainda não foi definido, embora já tenha sido confirmado por Willment e colaboradores (2001) que a ligação com $\beta$-glucanos não interfere nas interações com as células $\mathrm{T}$.

Recentemente Anaya e Colaboradores (2020), por meio de microscopia de fluorescência, observaram a ocorrência da oligomerização de Dectin-1 induzida por $\beta$-glucanos in vitro. A formação dos dímeros e oligômeros de Dectin-1 estiveram diretamente correlacionadas ao tamanho da estrutura e quantidade de moléculas de $\beta$-glucanos ao qual as proteínas Dectin-1 foram expostas. Também foi descrito pelos autores que, nas células em repouso, Dectin-1 foi encontrado, predominantemente, em estado monomérico.

Os CTLD e domínios hemITAM de Dectin-1 são conservados nos mamíferos, sugerindo a importância dessa proteína em promover respostas imunes adquiridas em uma ampla variedade de espécies (TAKANO et al., 2017; ARIIZUMI et al., 2000). Portanto, os agonistas da Dectin-1 possuem potencial como adjuvantes de vacinas que podem facilitar respostas imunes protetoras contra patógenos ou câncer. Os resultados obtidos por Takano e colaboradores (2017) mostraram que, existem diferenças importantes na sinalização de Dectin1 mediada por $\beta$-glucanos em camundongos e humanos que sugerem que, além de cada espécie responder de forma diferente ao mesmo $\beta$-glucano, o domínio intracelular, e não o CTLD de Dectin-1, determina o perfil de resposta específico para $\beta$-glucanos em cada espécie. Dado esse 
potencial, é importante caracterizar em detalhes a função da hDectin-1 e comparar com as evidências acumuladas para a mDectin-1 que é amplamente mais estudada.

Os $\beta$-glucanos representam um grupo heterogêneo de polissacarídeos de ocorrência natural e os efeitos promotores de saúde mediados por eles são milenarmente conhecidos. Alguns $\beta$-glucanos tem sua atividade imunomoduladora e antitumoral já comprovada (DEL CORNÒ et al., 2020; CHIFFOLEAU, 2018; ZHAO et al., 2016; SYNYTSYA; NOVAK, 2013). Outros efeitos terapêuticos como, por exemplo, regeneração axonal (BALDWIN et al., 2015) e antidepressivo (BAO et al., 2017) também foram atribuídos ao uso terapêutico de $\beta$-glucanos. Deste modo, a compreensão a nível estrutural dos mecanismos de interação de hDectin-1 no reconhecimento de $\beta$-glucanos se faz necessária para a total compreensão de como esses eventos ocorrem.

\subsubsection{Docking molecular do motivo hemITAM com Syk}

Para melhor compreensão da interação entre o motivo hemITAM de hDectin-1 e os domínios SH2 de Syk, foram analisadas visualmente conformações tridimensionais de motivos ITAM de outras proteínas depositadas no PDB.

A busca por estruturas tridimensionais que contivessem motivos hemITAMs realizada no PDB retornou cinco modelos com motivos ITAM: Três estruturas de CD3Z e duas de CD3E, mas nenhuma estrutura com um motivo hemITAM foi encontrada. A análise visual dessas estruturas tridimensionais mostrou que todas são muito diferentes da conformação da estrutura da porção intracelular de hDectin-1 obtida no presente estudo, assim como suas sequências primárias (figura 59).

Figura 59 - Sequências primarias das estruturas de motivos ITAM depositadas no PDB.

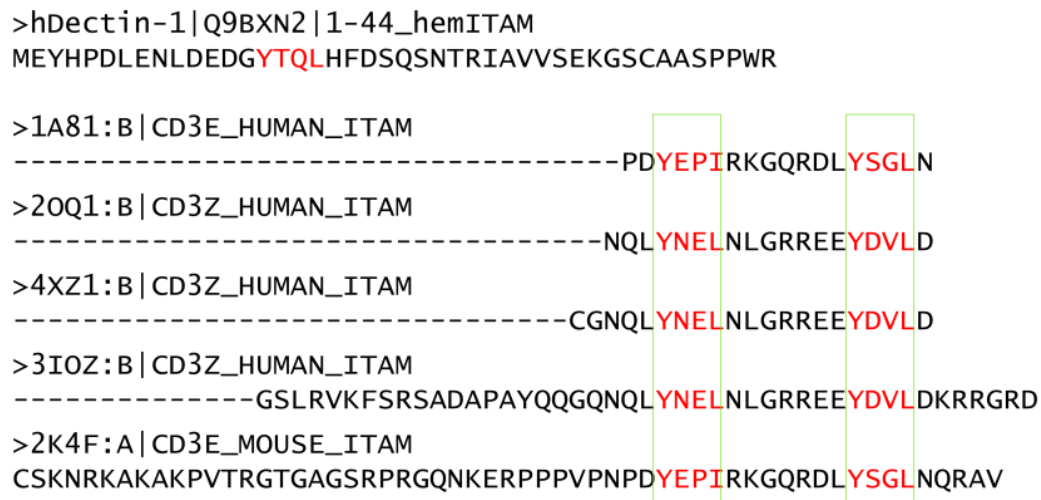

Em vermelho são destacados os aminoácidos correspondentes a motivos ITAM. Fonte: Arquivo pessoal. 
Apesar da sequência primária da porção intracelular de hDectin-1 (onde o domínio hemITAM está localizado) ser muito conservada na proteína Dectin-1 de outras espécies, não existe nenhuma estrutura tridimensional depositada no PDB que corresponda a esta sequência ou, pelo menos, parte dela. A estrutura tridimensional da porção intracelular de hDectin-1 onde se localiza o motivo hemITAM foi determinada pelo método ab initio no presente estudo justamente por carecer de estruturas moldes.

Sequências ITAM tradicionais consistem de uma repetição em tandem de sequências $\operatorname{Yxx}(\mathrm{I} / \mathrm{L})$. Após a interação do ligante com o receptor, ocorre a fosforilação da tirosina do motivo ITAM pela proteína Src (KIMURA et al, 2014). Em contraste a isso, a proteína Dectin-1 tem um único motivo ITAM denominado hemITAM, e a fosforilação desta sequência de hemITAM é suficiente para mediar a interação com Syk (que normalmente requer duas fosfotirosinas para a ligação) através de um mecanismo ainda desconhecido (KIMURA et al, 2014; BROWN, 2006; UNDERHILL et al., 2005).

Modificações pós-traducionais, como a fosforilação do aminoácido tirosina, são alterações químicas que ocorrem após a síntese proteica e constituem um aspecto importante da biologia de proteínas (LIU et al., 2016). Deste modo, antecedendo a etapa de docking do motivo hemITAM de hDecin-1 com Syk, foi realizada a adição de um grupo fosfato na tirosina localizada na posição 15 presente no motivo hemITAM de hDectin-1. A adição do grupo fosfato $\left(\mathrm{PO}_{4}{ }^{3-}\right)$ na cadeia lateral polar de Y15 foi realizada por meio do software PyMol (WARNECKE et al., 2014; DELANO et al., 2002) (figura 60).

Figura 60 - Adição de um grupo fosfato $\mathrm{PO}_{4}{ }^{3-}$ na tirosina presente no motivo hemITAM de hDectin-1.

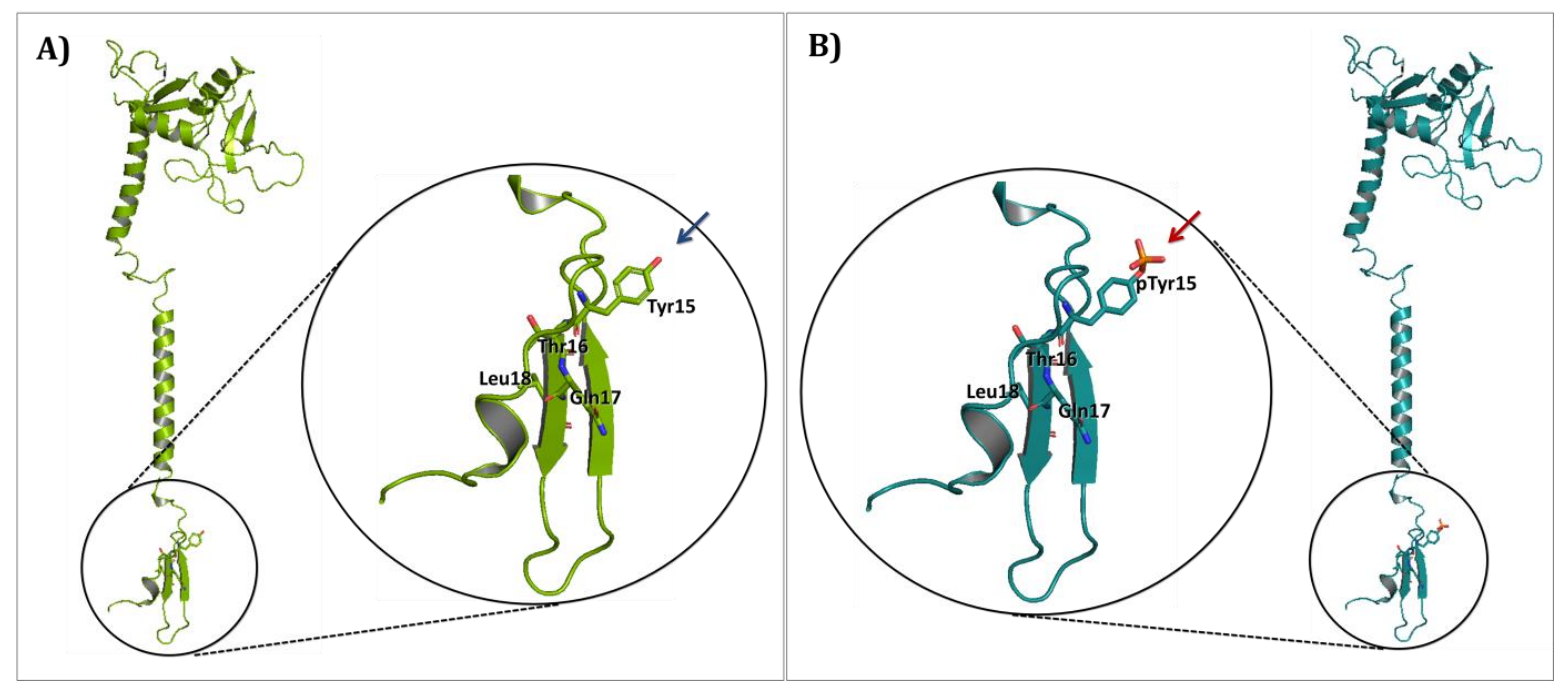

A) Tyr15 que compõe o motivo hemITAM indicada pela seta azul. B) Motivo hemITAM com a Try15 fosforilada (pTyr15) indicada pela seta vermelha. Fonte: Arquivo pessoal. 
A proteína Syk contém dois domínios $\mathrm{SH} 2$ em tandem e um domínio de tirosina cinase do terminal C. O domínio SH2 1 é composto pelos aminoácidos 15 a 107 e o domínio SH2 2 pelos aminoácidos 168 a 259. Os domínios SH2 estão ligados por uma região especifica da proteína Syk, denominada Interdominío A, composta pelos aminoácidos 108 a 167 (figura 61) (MÓCSAI et al., 2010).

Figura 61 - Domínio SH2 1, domínio SH2 2 e interdominío A de Syk.

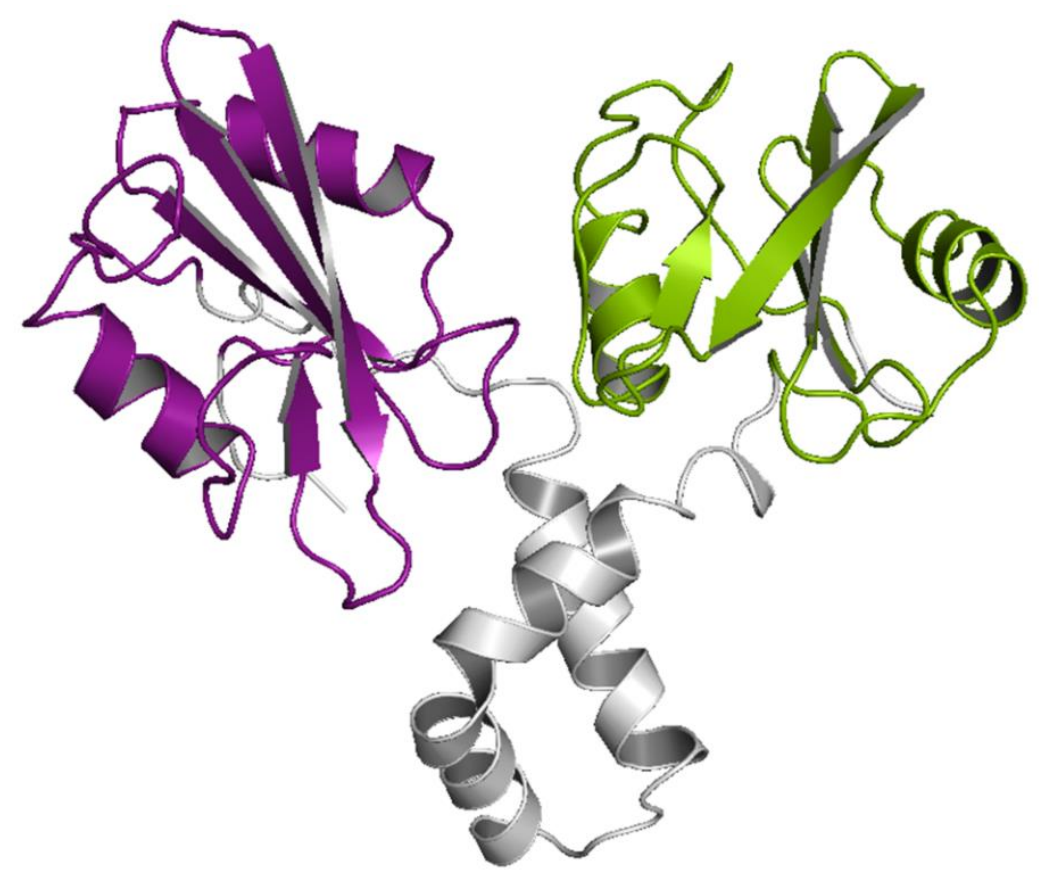

Domínio SH2 1 exibido em roxo e o domínio SH2 2 em verde, o interdominío A é exibido em cinza claro. Fonte: Arquivo pessoal.

Os domínios SH2 (do inglês Src Homology 2) são estruturas conservadas compostas por, aproximadamente, 100 aminoácidos e ligam-se a motivos contendo fosfotirosina. Desempenham papéis importantes na transdução de sinal intracelular e representam potenciais alvos para a intervenção farmacológica (TONG et al., 1996).

Partindo da sequência primária dos domínios SH2 da proteína Syk humana obtida no UniProt com ID P43405, foi realizada uma busca no PDB para encontrar uma estrutura tridimensional dos domínios SH2 da proteína Syk humana para que esta pudesse ser usada na predição de sítios de ligação para reconhecimento de motivos ITAM e, posteriormente, no docking proteína-proteína com hDectin-1.

O melhor resultado obtido para estrutura tridimensional dos domínios SH2 1 e SH2 2 de Syk humana é a estrutura com PDB ID 1A81. Essa estrutura foi determinada por 
cristalografia com difração de raios-X com resolução de $3 \AA$ por Fütterer e colaboradores (1998). Foram depositados seis complexos formados por domínios SH2 (Chain A, Chain C, Chain E, Chain G, Chain I, Chain K) e motivos ITAM provenientes de proteínas CD3E (Chain B, Chain D, Chain F, Chain H, Chain J, Chain L).

A predição dos sítios de ligação de Syk foi feita por meio do software FTSite (NGAN et al., 2011). Foi usada a cadeia A da estrutura 1A81 que corresponde aos domínios SH2-1 e SH2-1 de Syk humana interligados pela região Interdominío A.

A predição detectou 3 possíveis sítios nos domínios SH2 (figura 62). Os aminoácidos que compõem os sítios S1, S2 e S3 são: S1 - N19, Q43, S44, R45, Y47, L48, G49, G50, F120, E121, K124, W238, Q239 e E242; S2 - P119, F120, L123, M166, W168, L237, W238, Q239, V241, E242 e S245; S3 - A10, Q43, S44, G49, G50 e F51 (figura 62). Entretanto, os aminoácidos F120, E121, K124 do S1 e P119, F120, L123, M166 do S2 não fazem parte dos domínios SH2-1 ou SH2-2 e sim do Interdominío A, assim, foram desconsiderados.

Figura 62 - Resultado da predição de sítios de ligação do software FTSite.

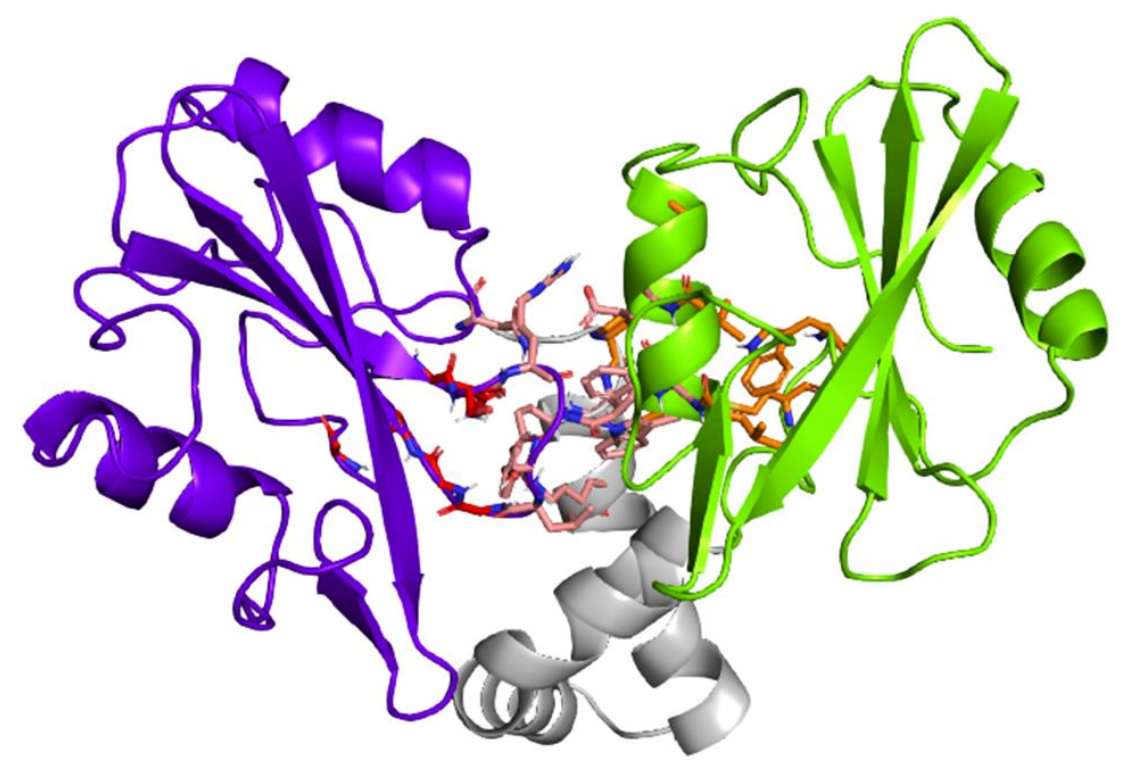

Domínio SH2 1 exibido em roxo, SH2 2 em verde e o interdominío A em cinza. Aminoácidos que compõe S1 exibido em rosa, S2 em laranja e S3 em vermelho. Fonte: Arquivo pessoal.

Para refinar a identificação de possíveis resíduos ativos presentes no sítio de reconhecimento de Syk para motivos ITAM, foi realizada a análise de interação proteínaproteína com a estrutura tridimensional dos seis complexos formados por domínios SH2 e motivos ITAM (PDB ID 1A81). Para identificar os resíduos ativos na interação entre os 
domínios SH2 e motivo ITAM da estrutura PDB ID 1A81 foi usado o script InterfaceResidues.py executado no software PyMol (DELANO et al., 2002).

Todas as estruturas dos domínios SH2 presentes no arquivo de coordenadas da estrutura com PDB ID 1A81 apresentaram a mesma quantidade e tipo de aminoácidos, havendo apenas variação do posicionamento das cadeias laterais dos aminoácidos entre as estruturas. Os motivos ITAMs também não apresentaram variação entre a quantidade e tipo de aminoácidos.

Para cada um dos seis complexos SH2/ITAM encontrados no arquivo de coordenadas PDB ID 1A81 foi feita a análise de interação proteína/proteína para a identificação dos resíduos ativos. Assim, foi analisada a interação entre os complexos Chain A/Chain B, Chain C/Chain D, Chain E/Chain F, Chain G/Chain H e Chain I/Chain J (figura 63).

Figura 63 - Interface de interação entre o Chain A (domínios SH2) e Chain B (motivo ITAM de CD3E) do complexo PDB ID: 1A81.

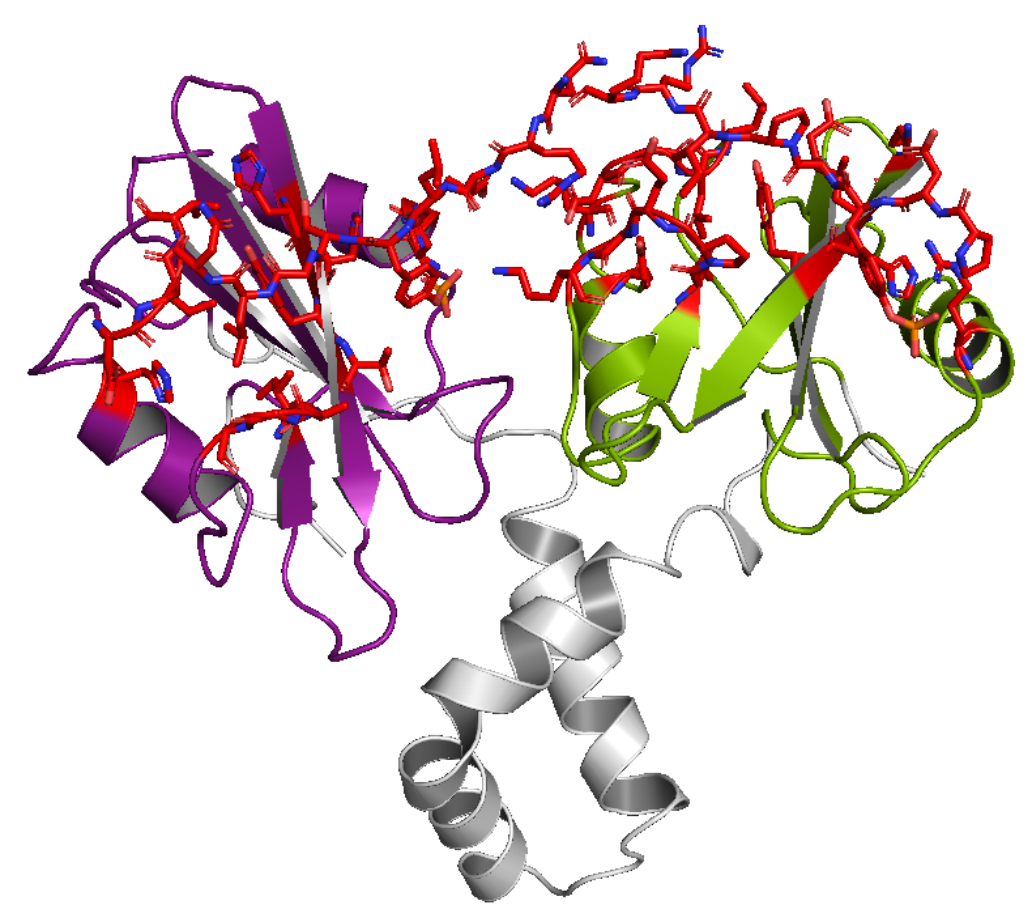

Os aminoácidos que compõem a região dos domínios SH2 que interagem com o motivo ITAM são exibidos em vermelho. Fonte: Arquivo pessoal.

Na tabela 7 estão dispostos os resíduos ativos de cada estrutura dos domínios SH2 em relação aos seus respectivos motivos ITAMs. 
Tabela 7 - Resíduos ativos na interação entre os domínios SH2 e motivo ITAM da estrutura PDB ID: 1A81. Em vermelho estão os resíduos que interagem diretamente (distância de até $3 \AA ̊$ ) com a fosfotirosina (pTyr) do motino ITAM YxxL.

\begin{tabular}{|c|c|c|c|c|c|}
\hline \multicolumn{6}{|c|}{ Resíduos ativos dos domínios SH2 de Syk (PDB ID 1A81) } \\
\hline Chain A & Chain $\mathrm{C}$ & Chain E & Chain $\mathrm{G}$ & Chain I & Chain $\mathrm{K}$ \\
\hline $\mathrm{R} 22$ & $\mathrm{R} 22$ & $\mathrm{R} 22$ & $\mathrm{R} 22$ & $\mathrm{R} 22$ & $\mathrm{R} 22$ \\
\hline E23 & E23 & E23 & E23 & E23 & E23 \\
\hline & & & A61 & & A61 \\
\hline H62 & H62 & H62 & H62 & H62 & H62 \\
\hline H63 & H63 & $\mathrm{H} 63$ & $\mathrm{H} 63$ & H63 & H63 \\
\hline Y64 & Y64 & Y64 & Y64 & Y64 & Y64 \\
\hline T65 & T65 & T65 & T65 & T65 & T65 \\
\hline I76 & I76 & $\mathrm{I} 76$ & I76 & I76 & I76 \\
\hline A77 & A77 & A77 & A77 & A77 & A77 \\
\hline G78 & G78 & G78 & G78 & G78 & G78 \\
\hline G79 & G79 & G79 & G79 & G79 & G79 \\
\hline H92 & H92 & H92 & H92 & H92 & H92 \\
\hline D97 & D97 & D97 & D97 & D97 & D97 \\
\hline G98 & G98 & G98 & G98 & G98 & G98 \\
\hline L99 & L99 & L99 & L99 & L99 & L99 \\
\hline V100 & V100 & & & & V100 \\
\hline R175 & R175 & R175 & $\mathrm{R} 175$ & R175 & R175 \\
\hline K212 & K212 & K212 & & K212 & K212 \\
\hline L214 & L214 & L214 & L214 & L214 & L214 \\
\hline $\mathrm{H} 215$ & $\mathrm{H} 215$ & $\mathrm{H} 215$ & $\mathrm{H} 215$ & H 215 & $\mathrm{H} 215$ \\
\hline Y216 & Y216 & Y216 & Y216 & Y216 & Y216 \\
\hline & $\mathrm{R} 217$ & R217 & $\mathrm{R} 217$ & & R217 \\
\hline I228 & I228 & I228 & I228 & $\mathrm{I} 228$ & I 228 \\
\hline P229 & P229 & P229 & P229 & P229 & P229 \\
\hline E230 & E230 & E230 & E230 & E230 & E230 \\
\hline G231 & G231 & G231 & G231 & G231 & G231 \\
\hline K232 & K232 & K232 & K232 & K232 & K232 \\
\hline Y244 & Y244 & Y244 & Y244 & & Y244 \\
\hline K247 & K247 & K247 & K247 & K247 & K247 \\
\hline D249 & D249 & D249 & D249 & D249 & D249 \\
\hline $\mathrm{G} 250$ & G250 & $\mathrm{G} 250$ & $\mathrm{G} 250$ & $\mathrm{G} 250$ & G250 \\
\hline L251 & L251 & L251 & $\mathrm{L} 251$ & L251 & L251 \\
\hline L252 & L252 & L252 & L252 & L252 & L252 \\
\hline
\end{tabular}

Fonte: Arquivo pessoal. 
A análise de interação entre os domínios SH2 e motivos ITAM mostrou haver boa conservação entre os resíduos ativos, sendo apenas observado que os resíduos A61, V100, R217 e Y244 não estão interagindo em todos os complexos SH2/ITAM. Foi observado também que o resíduo R22 interage por contato polar com a fosfotirosina (pTyr) do motino ITAM YxxL em todos os seis complexos.

Os resíduos ativos R22, E23, H62, H63, Y64, T65, I76, A77, G78, G79, H92, D97, G98, L99, V100, R175, K212, L214, H215, Y216, I228, P229, E230, G231, K232, Y244, K247, D249, G250, L251 e L252 identificados por meio do script InterfaceResidues.py na interação dos domínios SH2 com ITAMs do complexo PDB ID 1A81 e resíduos A10, N19, Q43, S44, R45, Y47, L48, G49, G50, F51, W168, L237, W238, Q239, V241, E242 e S245 preditos pelo software FTSite (NGAN et al., 2011) foram usados para direcionar o docking entre hDectin-1 e Syk.

O docking direcionado foi realizado por meio do servidor HADDOCK 2.2 (VAN ZUNDERT et al., 2016). Os resíduos ativos (diretamente envolvidos na interação proteínaproteína) indicados para o direcionamento do docking foram os aminoácidos que compõem o motivo hemITAM de hDectin-1 15Y, 16T, 17Q e 18L e aminoácidos R22, E23, H62, H63, Y64, T65, I76, A77, G78, G79, H92, D97, G98, L99, V100, R175, K212, L214, H215, Y216, I228, P229, E230, G231, K232, Y244, K247, D249, G250, L251, L252, A10, N19, Q43, S44, R45, Y47, L48, G49, G50, F51, W168, L237, W238, Q239, V241, E242 e S245 presentes nos domínios SH2 de Syk. Os resíduos passivos (aminoácidos que estão na superfície da proteína em regiões circundantes aos resíduos indicados como ativos) não foram indicados, mas foi permitido que o servidor HADDOCK definisse automaticamente esses resíduos.

O cluster mais confiável foi escolhido de acordo com o HADDOCK score (VAN ZUNDERT et al., 2016) e inspeção visual. O melhor cluster foi o cluster-7, com HADDOCK score -153.8, composto por 4 complexos sem diferenças relevantes entre eles (figura 64A), deste modo foi escolhido o complexo 1 do cluster-7 (figura 64B). A inspeção visual também mostrou que o cluster 7 apresenta o melhor posicionamento das estruturas para posterior construção do sistema com o complexo hDectin-1/Syk na membrana celular para simulação de DM (figura 64B). 
Figura 64 - Complexo proteína-proteína formado pela estrutura completa de hDectin-1 e domínios SH2-1, SH2-2 e Interdominío A de Syk.

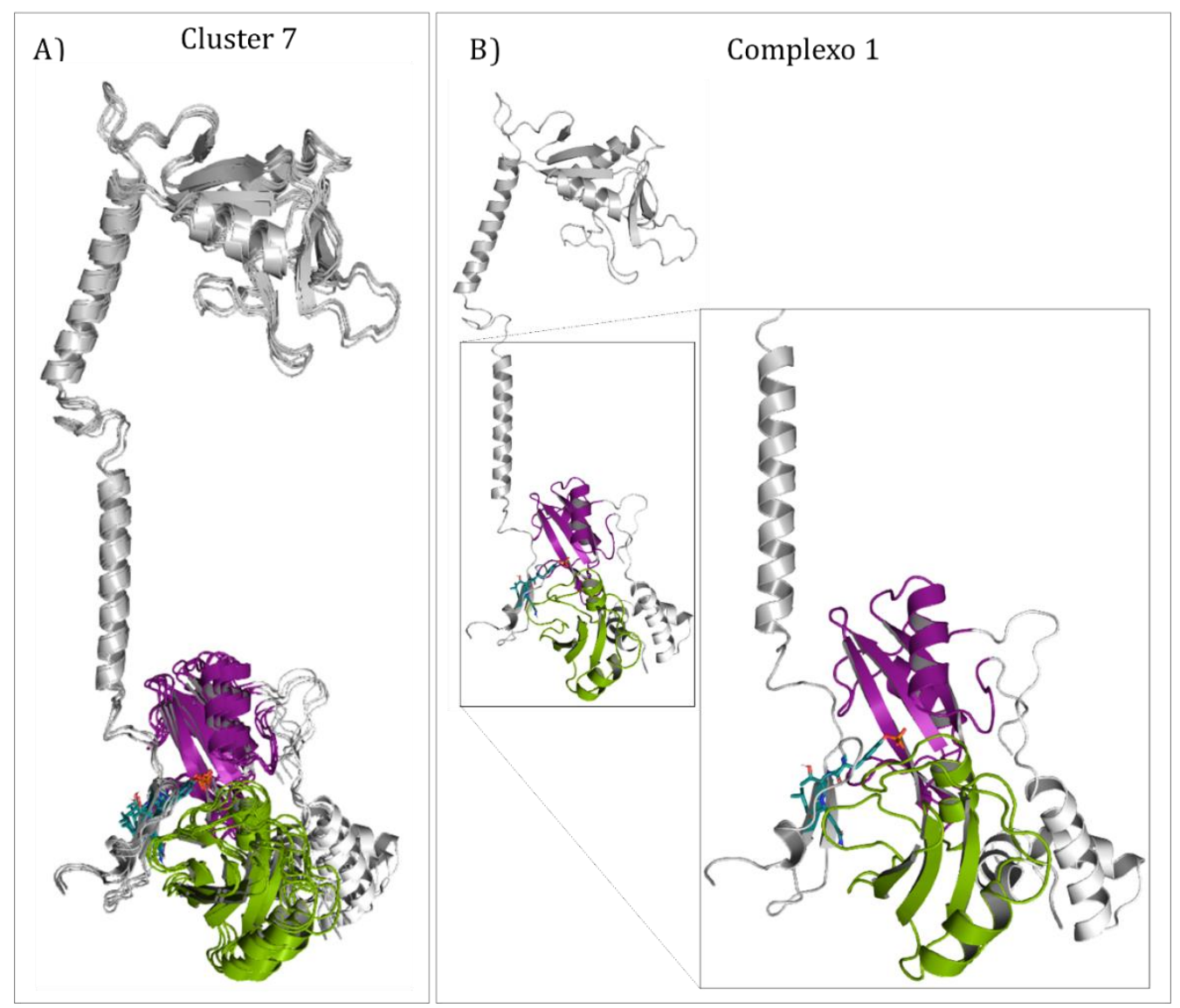

Complexo proteína-proteína formado pela estrutura completa de hDectin-1 (cinza) e domínios SH2-1 (roxo), SH22 (verde) e Interdominío A (branco) de Syk (Chain A de PDB ID: 1A81). A) Cluster 7 composto por quatro complexos (estruturalmente alinhados) obtido por docking direcionado pelo servidor HADDOCK (VAN ZUNDERT et al., 2016). B) Complexo 1 do cluste- 7, com domínio hemITAM de hDectin-1 destacado em azul, docado entre os domínios SH2-1 (roxo) e SH2-2 (verde) de Syk. Fonte: Arquivo pessoal.

A estrutura do domínio transmembranar e porção intracelular de hDectin-1 onde está localizado o motivo hemITAM em complexo com os domínios SH2 de Syk serão denominados hemITAM/SH2 a partir deste ponto para facilitar a compreensão durante a descrição dos resultados.

\subsubsection{Simulação de DM do complexo hDectin-1/Syk e análise de interação proteína/proteína}

Apesar do docking molecular entre hDectin-1 e domínios SH2 de Syk ter sido realizado com a estrutura completa de hDectin-1, os aminoácidos correspondentes a porção extracelular foram excluídos do arquivo de coordenadas para que as simulações de DM levassem menos tempo de execução, possibilitando a realização de simulações mais longas. $\mathrm{O}$ 
complexo hemITAM/SH2 que foi simulado é composto pela porção intracelular, domínio transmembranar e mais 10 aminoácidos da porção extracelular localizados logo após o termino do domínio transmembranar de hDectin-1 e estrutura dos domínios SH2 e Interdomínio A de Syk.

A construção do sistema com o complexo hemITAM/SH2 na membrana celular para a simulação de DM foi realizada seguindo os mesmos critérios já descritos anteriormente nas etapas de simulação de DM de hDectin-1 completa na membrana e dímero de hDectin-1 completo na membrana. O sistema obtido por meio do servidor CHARMM-GUI (JO et al., 2008) é do tipo paralelepipédico, com dimensões de $120,1 \AA$ Å no eixo x, 120,1 $\AA$ no eixo y e $156,3 \AA$ no eixo $\mathrm{z}$, sendo composto pelo complexo hemITAM/SH2 (cadeias A e B respectivamente) com o domínio transmembranar de hDectin-1 inserido em uma bicamada fosfolipídica, moléculas de água (TIP3) e íons que caracterizam o ambiente intracelular e extracelular. Após essa etapa, o sistema hemITAM/SH2/membrana foi submetido a simulação de DM para verificar a estabilidade do complexo hemITAM/SH2 gerado por docking. O sistema completo e pronto para simulação de DM está exposto na figura 65.

Figura 65 - Sistema com o complexo hemITAM/SH2 na membrana celular gerado pelo servidor CHARMM-GUI para simulação de dinâmica molecular.

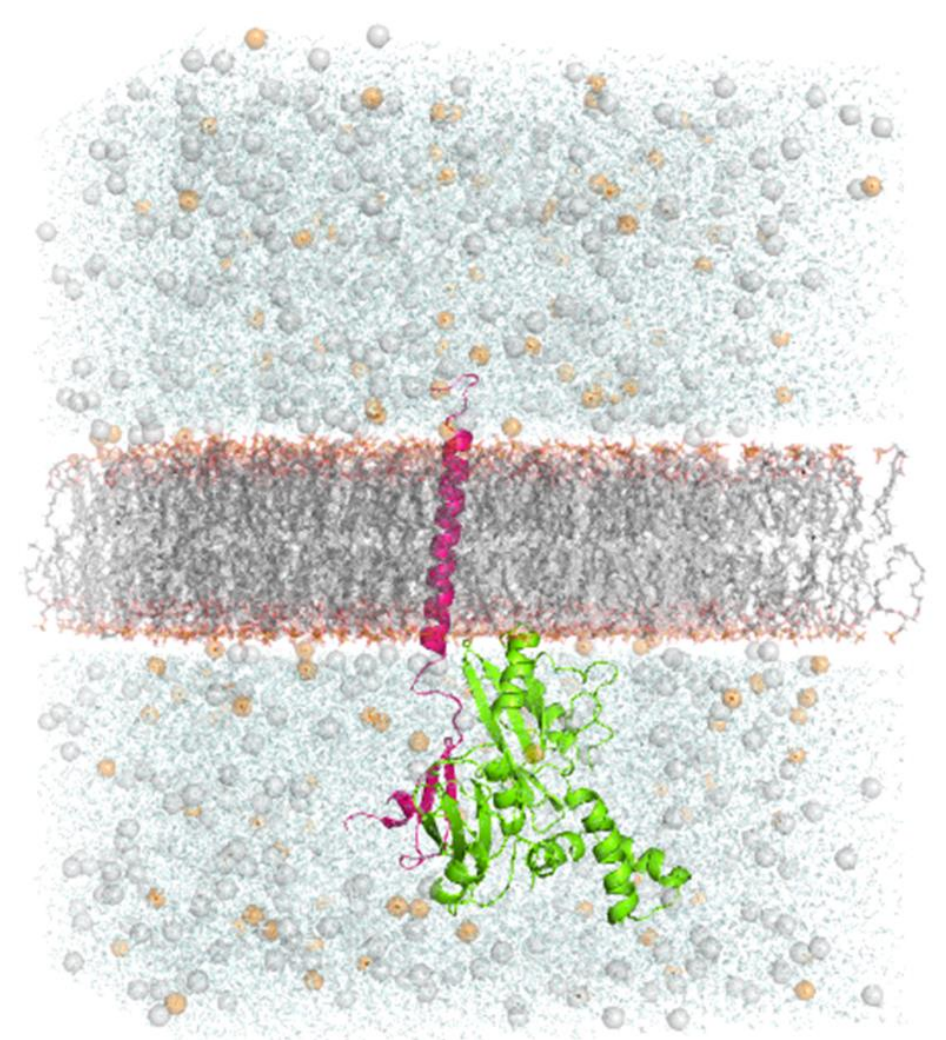

Sistema hemITAM/SH2/membrana contendo água (azul), íons $\mathrm{Na}+$ e Cl- (esferas cinza e laranja), proteína hDectin-1 (rosa), proteína Syk (verde) e membrana celular composta por fosfolipídios DLPA (cinza e vermelho). Fonte: Arquivo pessoal. 
Foi feita triplicata de simulações de DM de 200 ns para o complexo hemITAM/SH2 na membrana celular. Cada simulação de DM do sistema complexo-solvente foi realizada em condições físico-químicas controladas, com temperatura máxima de $310 \mathrm{~K}$ e pressão constante de $1 \mathrm{~atm}$.

O comportamento estrutural do complexo hemITAM/SH2 ao longo do tempo foi analisado por meio do RMSD, RMSF e alinhamento das estruturas nos tempos inicial e final de simulação de DM.

A análise do gráfico de RMSD (figura 66A) da triplicata de 200 ns realizada, mostra que, apesar do complexo obtido por meio de docking molecular ser composto por domínios específicos de duas proteínas diferentes, as estruturas alcançam um bom estado de estabilidade conformacional ao longo da simulação de DM. Após os primeiros 40 ns, é possível observar uma variação próxima de $5 \AA$ ao longo do tempo. Nenhuma variação brusca ou superior a $10 \AA$ foi observada ao longo de toda simulação.

Foram gerados dois gráficos de RMSF para uma melhor visualização da variação estrutural dos aminoácidos que compõe o complexo hemITAM/SH2. O gráfico do RMSF correspondente a parte da proteína hDectin-1 mostra que uma das regiões com menor variação é a região correspondente ao motivo hemITAM (figura 66B).

Apesar de Fütterer e colaboradores (1998) destacarem que os dois domínios SH2 de Syk exibem uma notável flexibilidade estrutural, sugerindo que Syk pode adaptar-se ao reconhecimento de uma grande variedade de estruturas contendo motivos ITAM com sequências de aminoácidos entre eles de tamanhos variados, a análise do RMSF da estrutura dos domínios SH2 de Syk em complexo com o motivo hemITAM de hDectin-1 (figura 66B) mostrou que o deslocamento por resíduo foi inferior ao observado para a porção intracelular de hDectin-1. Assim, é possível inferir que o motivo hemITAM pode conferir estabilidade aos domínios SH2, tomando o complexo proteína/proteína estável para a posterior ativação de outras proteínas da cascata de sinalização. 
Figura 66 - Trajetória da simulação de DM do complexo hemITAM/SH2.

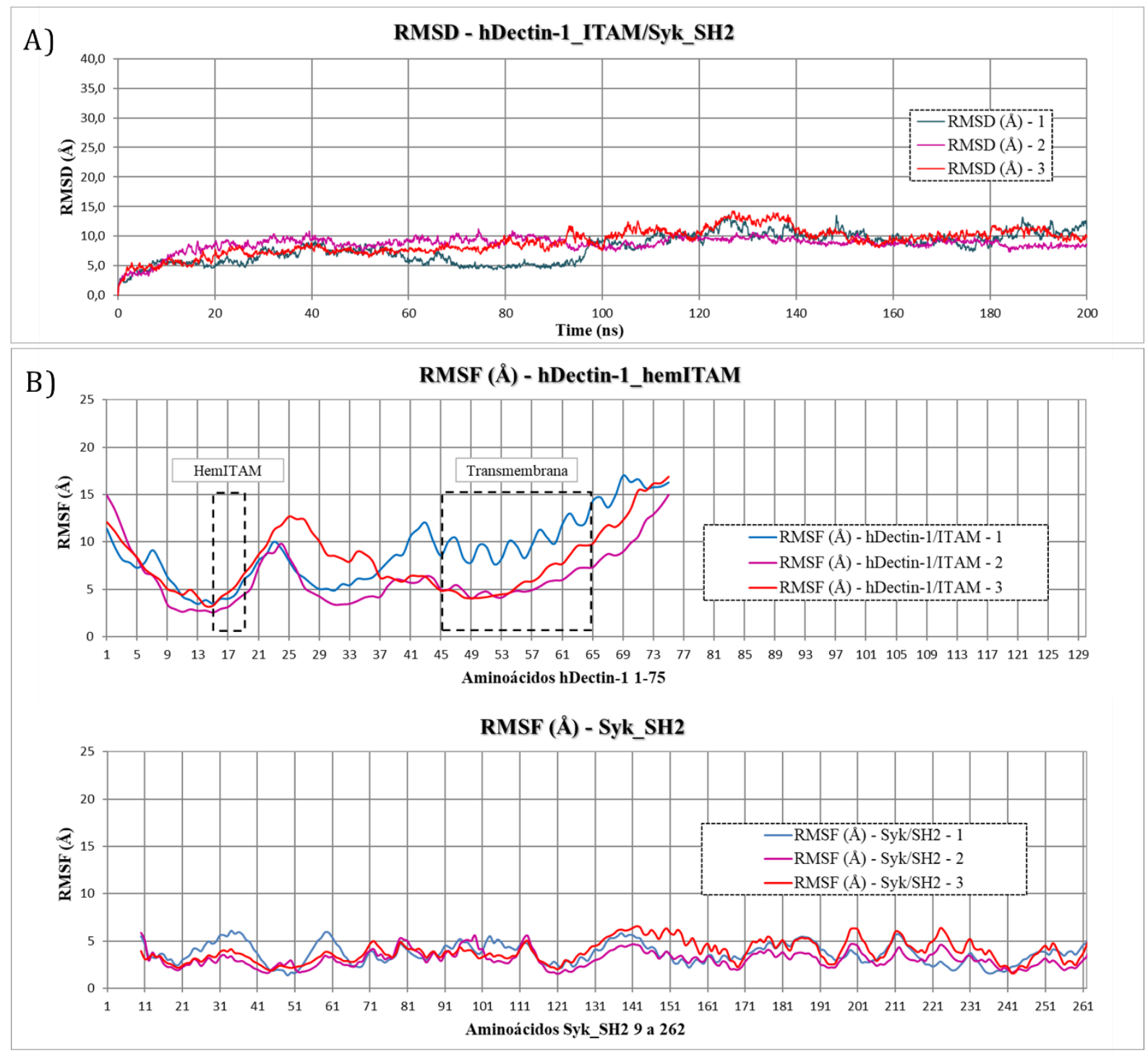

A) Trajetória de DM do complexo hemITAM/SH2. Valores de RMSD das coordenadas dos átomos C $\alpha$ em função do intervalo de tempo de simulação em triplicata de $200 \mathrm{~ns}$. B) Comparativo da variação estrutural por aminoácido das três simulações. Valores de RMSF das coordenadas dos átomos $\mathrm{C} \alpha$ em relação à estrutura inicial de parte da estrutura de hDectin-1 e Syk. Os retângulos pontilhados em preto destacam as regiões correspondentes ao motivo hemITAM e domínio transmembranar de hDectin-1. Fonte: Arquivo pessoal.

Para complementar as análises de comportamento estrutural ao longo do tempo e análise das interações moleculares entre as interfaces de contato das proteínas, foi feita a verificação do estado conformacional do complexo hemITAM/SH2 em três momentos diferentes da simulação de DM: Estrutura inicial (0 ns), 100 ns e 200 ns.

A primeira análise foi feita por meio da inspeção visual das estruturas do complexo hemITAM/SH2 nos tempos 0 ns, 100 ns e 200 ns. Com base no posicionamento das estruturas é possível verificar que o complexo se manteve estável em relação ao posicionamento do motivo hemITAM nos domínios SH2 (figura 67A). 
Como o RMSF dos resíduos que compõe a porção intracelular de hDectin-1 ficou acima do RMSF observado para os resíduos dos domínios SH2 de Syk, foi verificado se houve variação dos elementos secundários nos tempos 100 ns e 200 ns em relação a estrutura inicial. Essa análise foi realizada por meio do servidor PDBSum (LASKOWSKI, 2001) e os resultados mostraram que: Partindo do N-terminal, a estrutura inicial era composta por uma pequena $\alpha$ hélice H1 (D6-E8), seguida de três folhas- $\beta$ antiparalelas A1, A2 e A3 compostas, respectivamente, por N9-L10, T16-L18 e V30-S32, finalizada com a $\alpha$-hélice transmembranar H2 (R44-G65). Aos 100 ns a estrutura apresentou a ausência de H1, conservação de A1, aumento de três aminoácidos na composição de A2 (T16-S22), aumento também de três aminoácidos em A3 (T26-V31) e aumento de quatro aminoácidos na composição da $\alpha$-hélice transmembranar (W43-A68). Aos 200 ns de simulação de DM, a estrutura apresentou ausência de A1, mantendo A2 e A3 antiparalelas. Nessa estrutura o motivo hemITAM é todo abrangido pela folha- $\beta$ A2 (Y15-S22) antiparalela a A3 (T26-E33). A $\alpha$-hélice transmembranar apresentou uma pequena variação em relação aos 100 ns, onde antes era composta por W43-A68, agora é composta por W43-T66 (figura 67B). 
Figura 67 - Comportamento estrutural ao longo do tempo da simulação de DM do complexo hemITAM/SH2.

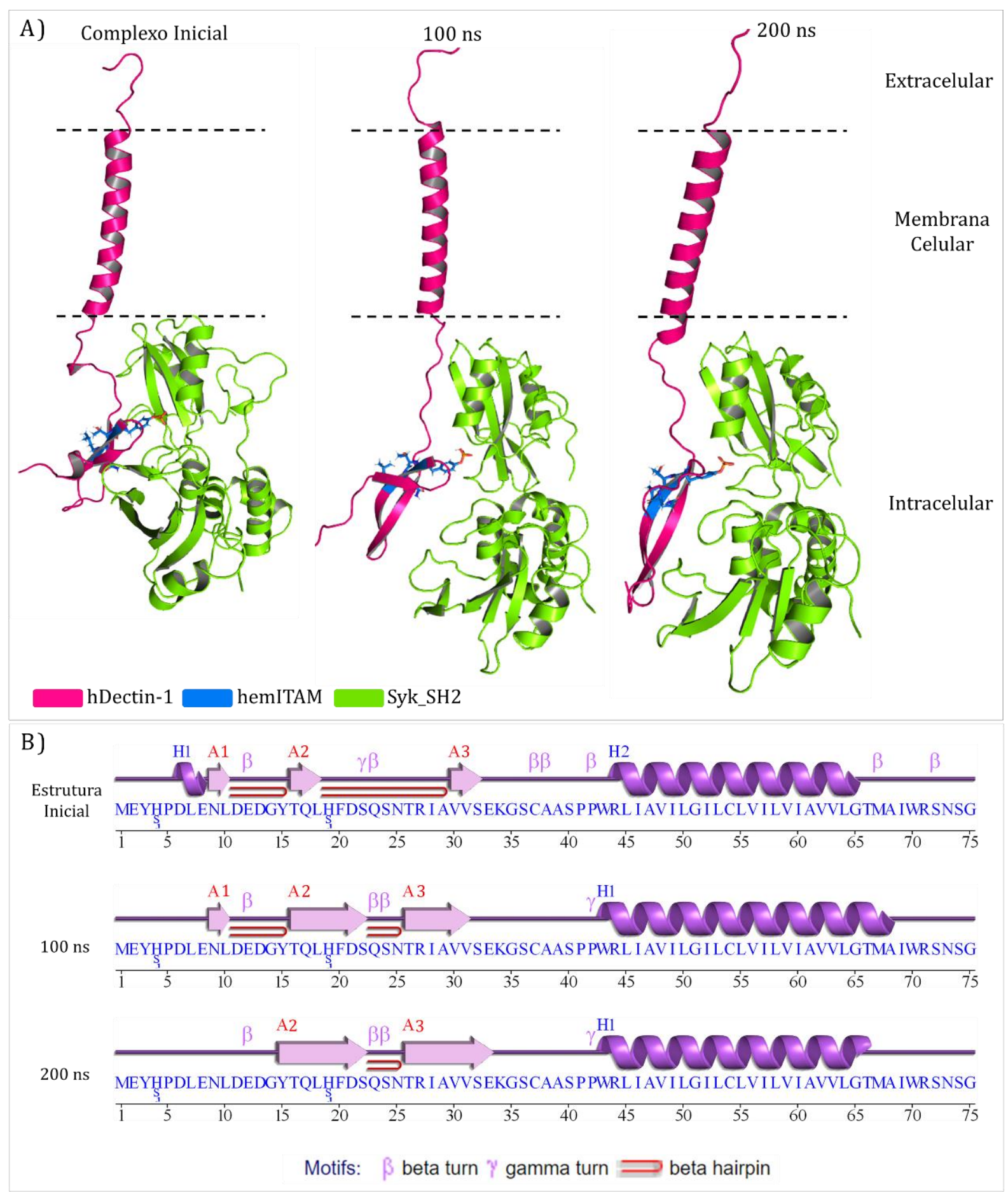

A) Complexo hemITAM/SH2. Estrutura de hDectin-1 em rosa, motivo hemITAM em azul e domínios SH2 em verde. Estrutura inicial (à esquerda), 100 ns (no centro) e 200 ns (à direita). B) Elementos secundários da estrutura de hDectin-1 ao longo do tempo da simulação de DM. Fonte: Arquivo pessoal. 
A análise de interação entre o motivo hemITAM e domínios SH2 realizada por meio do servidor PDBSum (LASKOWSKI, 2001) mostrou que a fosfotirosina pTyr15 manteve-se em interação com os domínios SH2-1 de Syk ao longo dos 200 ns de simulação de DM. Inicialmente, após o docking, pTyr15 interagia com Y64 e T65 do domínio SH2-1 por meio apenas de interações entre átomos não ligados. Após verificar as interações aos $100 \mathrm{~ns}$ de simulação de DM, notou-se que pTyr15 passou a interagir com R45 e N46 também do domínio SH2-1 de Syk. A interação com R45 ocorreu por meio de interação entre átomos não ligados e a interação com N46 ocorreu por meio de interação entre átomos não ligados e ligação de hidrogênio.

Para verificar se a interação entre pTyr15 (hemITAM-hDectin-1) com R45 e N46 (SH2-Syk) se manteria por mais tempo ou se ocorreriam outras variações na interação como visto durante os primeiros $100 \mathrm{~ns}$, a simulação de DM do complexo (que incialmente teria apenas $100 \mathrm{~ns}$ ) foi estendida até $200 \mathrm{~ns}$ e, após sua conclusão, verificou-se que a interação de pTyr15 com R45 e N46 permaneceu estável e com as mesmas características observadas aos 100ns (Figura 68).

A área de interface entre as estruturas também mostrou que o complexo apresentou estabilidade durante a simulação de DM. Inicialmente, a interface de hDectin- 1 era de $1028 \AA 2$ e Syk $946 \AA 2$, aos 100 ns hDectin-1 diminuiu para $733 \AA 2$ e Syk $623 \AA 2$, ao final dos 200 ns a área de interface aumentou novamente, hDectin-1 foi para $831 \AA 2$ e Syk $810 \AA 2$ (figura 68). 
Figura 68 - Diagrama das interações entre o motivo hemITAM e domínio SH2-1 com a estrutura inicial do complexo hemITAM/SH2, aos $100 \mathrm{~ns}$ e aos $200 \mathrm{~ns}$.

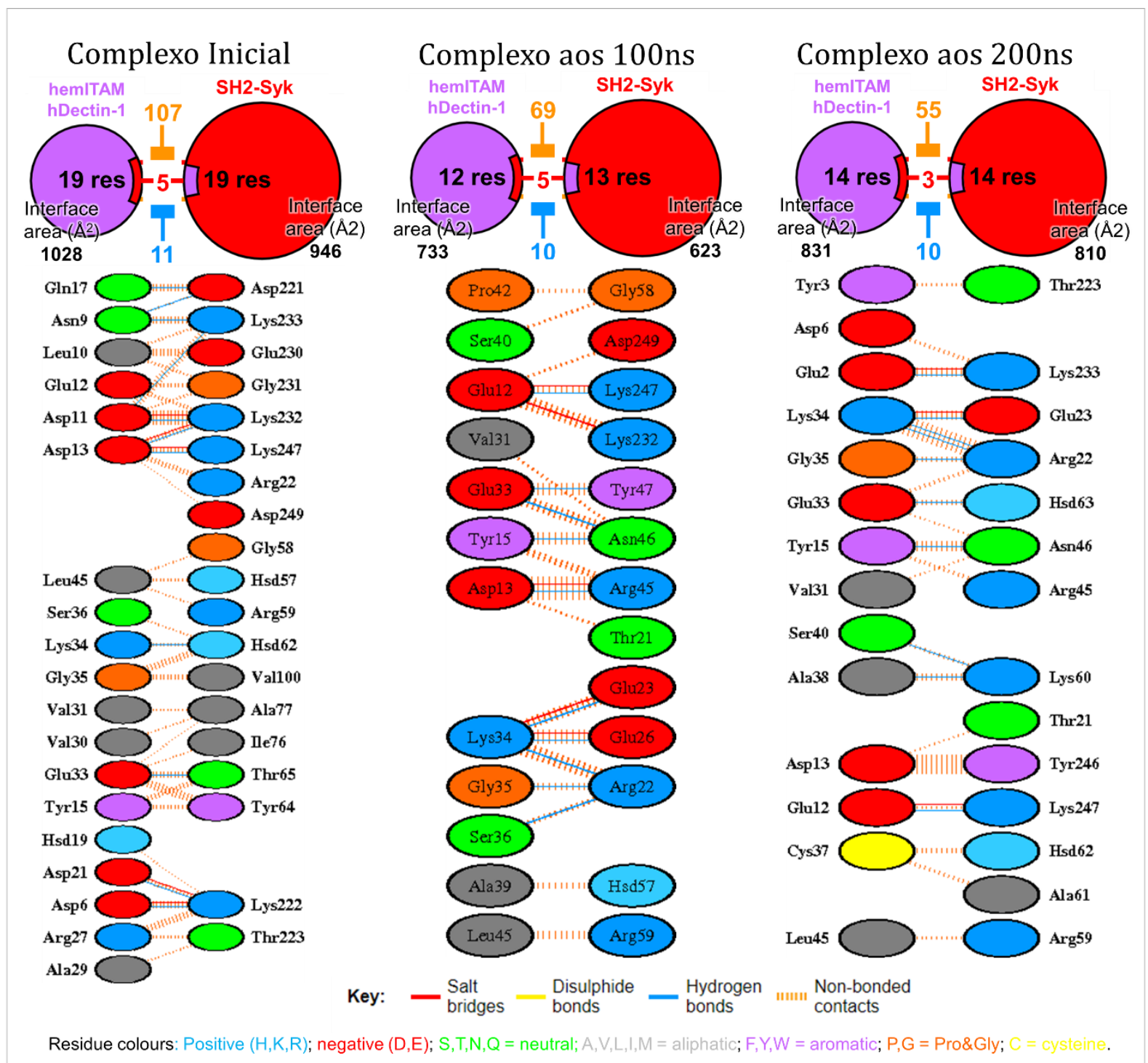

Fonte: Arquivo pessoal.

A análise de interação entre o motivo hemITAM de hDectin-1 e domínios SH2 de Syk por meio de docking e simulações de DM mostrou que pTyr15 de hDectin-1 e os aminoácidos R45 e N46 do motivo SH2-1 de Syk podem ser fundamentais para essa interação molecular e consequente sinalização celular. Esse resultado destaca a importância da interação entre esses aminoácidos do motivo hemITAM de hDectin-1 e SH2-1 de Syk e fornece informações importantes quanto ao mecanismo de sinalização celular para início de resposta imune iniciada por hDectin-1 e desencadeada por Syk. Os resíduos identificados na interação de hDectin-1 com Syk aqui descritos, poderão ser usados como alvo molecular para amplificar ou inibir essa resposta, representando potenciais alvos para o desenvolvimento de estratégias terapêuticas mediadas por intervenções farmacológicas. 
Há algumas décadas se pensava que dois resíduos de tirosina fosforilados eram necessários na composição de uma única cadeia peptídica (como em um motivo ITAM clássico) para que houvesse o recrutamento e ativação de Syk. Entretanto, uma nova família de lectinas do tipo C, incluindo os receptores Dectin-1 e CLEC2, tem se mostrado capazes de ativar Syk, embora esses receptores tenham apenas um único motivo YxxL (hemITAM) em sua porção intracelular (TAKANO et al., 2017; ROGERS et al., 2005).

Fütterer e colaboradores (1998) observaram em seus experimentos que, o sítio de ligação de Syk nos domínios SH2 N-terminal (SH2-1) poderia ser autossuficiente na interação com um motivo ITAM duplamente fosforilado, sugerindo que os domínios SH2 N e C-terminal (SH2-1 e SH2-2) poderiam funcionar de forma independente.

A oligomerização cooperativa do CTLD de Dectin-1 induzida por $\beta$-glucanos provavelmente antecede o agrupamento desses receptores para formar regiões de alta densidade de hemITAMs na superfície celular interna, facilitando a posterior ligação com a proteína Syk. Faltam informações estruturais desses eventos, mas, oligômeros de domínios extracelulares de moléculas de Dectin-1 na superfície celular podem aumentar a chance de atividades de ligação à quinase Syk, mais do que o alcançado por apenas monômeros receptores (DULAL et al., 2018).

Os resultados obtidos no presente estudo mostraram que é possível hDectin-1 formar um complexo estável com Syk apenas pela interação do motivo hemITAM fosforilado com o domínio SH2-1, deixando o domínio SH2-2 livre para interagir com outro motivo hemITAM, facilitando essa interação com a proteína Syk como sugerido por Dulal e colaboradores (2018) e sendo auto suficiente como sugerido por Fütterer e colaboradores (1998).

Diferente das estruturas tridimensionais dos motivos ITAM encontrados nos complexos SH2/ITAM determinados experimentalmente por cristalografia com difração de raios-X (VISPERAS et al., 2015; KIM et al., 2010; XU et al., 2008; FÜTTERER et al., 1998; HATADA et a., 1995), onde a estrutura dos motivos ITAM tem sua estrutura tridimensional formada predominantemente por loops, o motivo hemITAM presente em hDectin-1 determinado in silico por meio de método ab initio, está localizado em uma folhas- $\beta$ antiparalela a outra de tamanho similar.

A análise da estabilidade e comportamento estrutural realizada ao longo do tempo por meio de simulação de DM mostrou que, as folhas- $\beta$ antiparalelas onde está localizado o motivo hemITAM de hDectin-1, se mantiveram estáveis ao longo de $200 \mathrm{~ns}$ de simulação de DM em triplicata. Isso pode ser um indicativo de que, a capacidade de hDectin-1 em sinalizar Syk com 
apenas um motivo hemITAM (uma fosfotirosina) em um único domínio SH2, pode ocorrer eficientemente devido a conformação estrutural estável dos elementos secundários da região.

A capacidade de hDectin-1 sinalizar Syk também se deve ao fato de que Syk pode fosforilar os próprios resíduos de tirosina presentes nos motivos ITAM (MÓCSAI et al., 2010). Este evento associado a estrutura estável de motivos hemITAM, pode garantir uma maior eficiência nos eventos de interação proteína-proteína na interação de motivos hemITAM por Syk.

A proteína transmembranar Dectin-1, além de ser um componente fundamental para a habilidade do sistema imune inato em sinalizar infecções fúngicas (DALEY et al., 2017; GOODRIDGE et al., 2011), ter um importante papel nas respostas imunes antitumorais (CHIBA et al., 2014), estar correlacionada à resistência à insulina, obesidade e contribuir para o desenvolvimento de aterosclerose (CASTOLDI et al. 2017; THIAGARAJAN et al., 2013; ELSORI et al., 2011), atuar de forma importante em doenças que causam processos inflamatórios crônicos (CASTOLDI et al., 2017) e, em determinadas situações, desencadear o surgimento de doenças autoimunes (GOODRIDGE et al., 2011; BROWN, 2008), este importante receptor tem se mostrado um excelente alvo para o desenvolvimento de vacinas e imunoterapia (DALEY et al., 2017; CHEN et al., 2016; ZHAO et al., 2016; BRYANT et al., 2015; CHIBA et al., 2014).

Estruturalmente, devido à importância biológica e farmacêutica das proteínas integrais de membrana, esforços experimentais e computacionais consideráveis têm sido feitos para melhor entender a estrutura e função dessas proteínas em ambientes de membrana (ALSAADI; JONES, 2019). Como resultado dos avanços tecnológicos em vários campos, novas estruturas de proteínas de membrana se tornaram disponíveis, embora esse número ainda seja muito menor que o das proteínas globulares (ALSAADI; JONES, 2019; PRYOR; WIENER, 2014; DE ARAÚJO et al., 2013; JO et al., 2007).

Até o momento, a estrutura de hDectin-1 completa ou parte dela não foi resolvida experimentalmente. O presente estudo obteve, por meio de métodos in silico, o primeiro modelo para a estrutura completa de hDectin-1 e o empregou em análises de interação molecular com os principais alvos moleculares descritos, $\beta$-glucanos e Syk. Os resultados obtidos trouxeram muitos pontos relevantes sobre características estruturais de hDectin-1 em relação a sua estrutura e função.

O processo de oligomerização de Dectin-1 foi observado e descrito em três estudos diferentes ao longo dos últimos quinze anos. Brown e Colaboradores (2007) obtiveram uma conformação dimérica para mDectin-1 por meio de cristalografia com difração de raio-X, mas 
essa conformação foi considerada pelos autores possivelmente inviável in vivo na época. Em 2018 Dulal e Colaboradores descreveram novamente a observação do evento de oligomerização do CTLD de mDectin-1 in vitro, nesse estudo foi observada a formação de tetrâmeros. Recentemente, Anaya e Colaboradores (2020), observaram a ocorrência da oligomerização de Dectin-1 induzida por $\beta$-glucanos também in vitro e foi descrito pelos autores que, nas células em repouso, Dectin-1 foi encontrada, predominantemente, em estado monomérico.

O fenômeno em comum na descrição desses eventos de oligomerização são os aminoácidos que compõem a interface de interação entre os monômeros. Apesar de serem estudos não relacionados, realizados com metodologias diferentes, as hipóteses e conclusões são similares. Deste modo, o presente estudo analisou a possibilidade da conformação dimérica descrita por Brown e Colaboradores (2007) e reforçada por Dulal e Colaboradores (2018) e Anaya e Colaboradores (2020) ser estável in silico. Tanto o dímero de mDectin-1 obtido experimentalmente por Brown e Colaboradores (2007), quanto o dímero de hDectin-1 obtido in silico por meio de docking proteína-proteína no presente estudo, se mostraram estáveis em relação a conformação. Esse resultado possibilitou que fossem feitas análises de interação entre os $\beta$-glucanos e o dímero do CTLD de hDectin-1 a fim de verificar se haveriam diferenças de interação dos $\beta$-glucanos com o monômero e dímero.

Os resultados obtidos das análises de interação dos complexos CTLD/ $\beta$-glucano mostraram heterogeneidade entre o tempo de interação dos $\beta$-glucanos com o sítio de reconhecimento localizado no CTLD de hDectin-1. No monômero e dímero, as simulações de DM com os mesmos $\beta$-glucanos no mesmo sítio de reconhecimento apresentaram tempos diferentes para a interação. Laminarin, $\beta$-glucano amplamente utilizado nos estudos experimentais (DULAL et al., 2018), composto por três unidades de D-glicose, foi o que apresentou maior discrepância no tempo de interação com o CTDL de hDectin-1. Enquanto a interação com o monômero durou menos de 1 ns, no dímero Laminarin permaneceu em interação com o sítio, aproximadamente, 25 ns. Já os $\beta$-glucanos Zymosan (uma unidade de Dglicose) e Scleroglucan (quatro unidades de D-glicose) apresentaram resultados proporcionalmente semelhantes, respectivamente, $1 \mathrm{~ns}$ em interação no sítio do monômero e 3 ns com o dímero e 3 ns em interação no sítio do monômero e 10 ns com o dímero. Já o $\beta$ glucano Sizofiran foi o que permaneceu maior tempo em interação com o sitio, 17 ns com o monômero e $40 \mathrm{~ns}$ com o dímero, entretanto é composto por quatro unidades de D-glicose assim como Scleroglucan, mas a conformação estrutural deles é diferente.

O sítio de reconhecimento para $\beta$-glucanos usado como referência foi descrito por Brown e colaboradores (2007) e Dulal e colaboradores (2018), entretanto, ambos utilizaram 
Laminarin em seus experimentos. Outros estudos com diferentes $\beta$-glucanos sugerem que o processo de reconhecimento desses ligantes ocorrem de maneira dependente do tipo, tamanho e conformação da estrutura dos $\beta$-glucanos (ANAYA et al., 2020; DRICKAMER, 1999). Além de diferentes processos de reconhecimento, a natureza do ligante pode determinar qual tipo de resposta mediada por Dectin-1 ocorrerá das células T (BRYANT et al., 2015). Os resultados obtidos no presente estudo mostraram que, a conformação dimérica do CTLD de hDectin-1 pareceu mais favorável para a interação e possível reconhecimento de $\beta$-glucanos quando comparada com o monômero e o tempo de interação entre os $\beta$-glucanos e o sítio de reconhecimento sugeriu que, possivelmente, cada tipo de $\beta$-glucano pode ter um local especifico para seu reconhecimento no CTLD de hDectin-1.

Esses resultados são corroborados por Anaya e Colaboradores (2020) que afirmam ter observado que, nas células em repouso, Dectin-1 se encontra, predominantemente, em estado monomérico, ou seja, sem a disponibilidade de $\beta$-glucanos não ocorre a oligomerização. Assim, outras conformações diméricas e outros sítios de reconhecimento para $\beta$-glucanos precisam ser explorados afim de expandir o conhecimento sobre esse importante evento que, até o momento, apresenta informações quase exclusivamente relacionadas à um único sítio vinculado a Laminarin.

Ampliando o conhecimento sobre as características do possível sítio de reconhecimento para $\beta$-glucanos presente no CTLD de hDectin-1, destaca-se uma característica importante observada nos resultados da análise de interação entre $\beta$-glucanos e CTLD, que foi a maior movimentação observada na região dos aminoácidos 210 a 217 (em relação aos aminoácidos circundantes). Esses aminoácidos estão localizados no loop que compõe o sulco hidrofóbico que forma o sítio de reconhecimento de $\beta$-glucanos. A maior movimentação desses aminoácidos foi observada com homogeneidade nas simulações de DM do monômero e do dímero. Esse comportamento estrutural pareceu ser um fator importante no processo de reconhecimento dos $\beta$-glucanos por hDectin-1, entretanto, mais estudos com diferentes $\beta$ glucanos são necessários para comprovar que essa flexibilidade local está relacionada ao processo de interação do CTLD com $\beta$-glucanos.

Ariizumi e colaboradores (2000), descreveram que Dectin-1 se liga à linfócitos T e promovem o aumento da sua resposta mitogênica e, Willment e colaboradores (2001), mostraram que, apesar do local de ligação presente nas moléculas de Dectin-1 para ativação das células T ainda não ser conhecido, foi confirmado que a ligação com $\beta$-glucanos não interfere nas interações com as células T. Takano e colaboradores (2017) ressaltaram a importância de caracterizar em detalhes a função de hDectin-1 e comparar com as evidências acumuladas para 
mDectin-1, pois, foi observado pelos autores que, existem diferenças importantes na sinalização de Dectin-1 mediada por $\beta$-glucanos em camundongos e humanos. O modelo para a estrutura completa de hDectin-1 permitirá a ampliação dessas análises comparativas, assim como também possibilitará a realização de estudos para ampliar o conhecimento sobre a ativação de linfócitos T por hDectin-1.

Os resultados provenientes das simulações de DM de hDectin-1 na membrana celular obtidos no presente estudo, evidenciaram locais específicos que conferem à estrutura a capacidade de grande deslocamento de seus domínios funcionais. Grande flexibilidade estrutural foi observada em duas regiões, sendo uma na porção intracelular, próxima ao motivo hemITAM, e outra no domínio Stalk, que liga o CTLD ao domínio transmembranar. A alta movimentação observada direcionou a busca por regiões com desordem intrínseca em hDectin1 e, a análise realizada por meio da sequência primária, retornou como resultado a existência de duas regiões intrinsecamente desordenadas em hDectin-1 e também em Dectin-1 de outros mamíferos.

Os locais com desordem intrínseca descritos aqui para hDectin-1 correspondem às regiões que apresentaram maior flexibilidade estrutural observada nas análises das simulações de DM, e, como descrito por Xue e colaboradores (2009), é esperado que uma estrutura dinâmica, derivada de um segmento intrinsecamente desordenado em solução, seja caracterizado pela sua alta mobilidade em diferentes escalas de tempo. Esses segmentos em hDectin-1 compõem loops que ligam domínios funcionais de reconhecimento e sinalização, assim, é possível que essa alta flexibilidade contribua para a eficiência do reconhecimento de $\beta$-glucanos e sinalização de Syk.

Takano e colaboradores (2017) demostraram que, diferente do que se imaginava inicialmente, o domínio intracelular, e não o CTLD de Dectin-1, determina o perfil de resposta relacionado a cada tipo específico de $\beta$-glucano em cada espécie, sendo também diferentes as respostas ao mesmo $\beta$-glucano em espécies distintas. No presente estudo foram observadas variações do tamanho do segmento com desordem intrínseca na região correspondente à porção intracelular nas diferentes espécies analisadas. A diferença observada na quantidade de aminoácidos desordenados entre hDectin-1 e mDectin-1, sendo maior em mDectin-1, pode estar diretamente relacionada aos resultados encontrados por Takano e colaboradores (2017). Essa propriedade estrutural pode ser a responsável pelas diferenças encontradas nas respostas de Dectin-1 ao mesmo $\beta$-glucano em diferentes espécies.

Comparado ao CTLD de Dectin-1, os demais domínios da estrutura foram pouco estudados até o momento, especialmente o domínio Stalk. Os resultados obtidos no presente 
estudo apresentaram características especificas e possivelmente importantes em relação a funções do domínio Stalk. A alta movimentação estrutural observada nas análises dos resultados de simulação de DM em hDectin-1 associada a desordem intrínseca presente nessa região que também é conservada em outras espécies analisadas, pode indicar que, além de ser um segmento flexível de ligação entre os domínios transmembranar e CTLD, como descrito por Sattler e colaboradores (2012), existam funções especificas relacionadas a esse domínio que ainda não foram descobertas.

O evento de splicing alternativo da origem a uma isoforma menor de Dectin-1 onde o domínio Stalk está ausente. Diferenças subjacentes à expressão e função específica dessa isoforma ainda não são totalmente compreendidas em humanos, embora existam evidências de funções específicas relacionadas à essa isoforma de Dectin-1 em camundongos (DRUMMOND; BROWN, 2011; VIRIYAKOSOL et al., 2008). A suscetibilidade às infecções fúngicas foi observada em camundongos com maior expressão da isoforma de Dectin-1 onde o domínio Stalk está ausente. Esse estudo realizado por Viriyakosol e colaboradores (2008) com mDectin-1, mostrou que o domínio Stalk pode participar da interação proteína-proteína ou proteína-ligante e estar indiretamente relacionado à sinalização celular e decorrente produção de citocinas pró-inflamatórias. Heinsbroek e colaboradores (2006) observaram em seu estudo que, na isoforma de mDectin-1 e hDectin-1 onde o domínio Stalk está ausente, ocorreu diminuição da capacidade de reconhecimento do $\beta$-glucano Zymosan e consequente diminuição da produção de citocinas. Agora, com o conhecimento do modelo para a estrutura completa de hDectin-1 poderão ser realizados estudos para gerar conhecimento sobre a função do domínio Stalk no processo de reconhecimento de patógenos fúngicos.

As regiões intrinsecamente desordenadas são sequências peculiares de aminoácidos que apresentam poucas conformações estáveis em solução. A desordem intrínseca de proteínas é definida pela presença de, pelo menos, uma longa região desordenada associada a vários processos celulares, incluindo sinalização celular, ligação ao DNA e carcinogênese (BÜRGI et al., 2016). No caso de Dectin-1, sua função no processo de sinalização celular é amplamente relatado e pesquisado (CASTOLDI et al., 2017; DAMBUZA; BROWNCHIBA et al., 2015; CHIBA et al., 2014; DEL FRESNO et al., 2013; BLANCO-MENÉNDEZ et al., 2015; ELSORI et al., 2011; BROWN et al., 2007; BROWN, 2006; GANTNER et al., 2003; HERNANZFALCON et al., 2003), entretanto, nenhum estudo de predição ou sobre o papel da desordem intrínseca em Dectin-1 foi publicado até o momento. Como observado nos resultados obtidos, a presença de desordem intrínseca em hDectin-1 ocorre principalmente na porção intracelular, responsável por ativar Syk no processo de sinalização celular (BROWN, 2006). 
Cerca de $50 \%$ das proteínas transmembranares têm pelo menos um segmento de desordem intrínseca (BÜRGI et al., 2016; PRYOR; WIENER, 2014; YANG et al., 2008) com, aproximadamente, 30 aminoácidos ou mais (BÜRGI et al., 2016). Curiosamente, esses segmentos desordenados costumam localizam-se do lado intracelular, sobretudo em proteínas transmembranares com múltiplas passagens pela membrana. Também é frequente a presença de locais de fosforilação nesses segmentos desordenados em proteínas transmembranares (BÜRGI et al., 2016; BAH eu al., 2015; XUE et al., 2009). Partindo dessas informações, não é peculiar a presença de desordem intrínseca na porção intracelular de hDectin-1, uma vez que essa proteína tem muitas características predisponentes, como seu local de fosforilação em Y15 na porção intracelular e o fato dela ser uma peça fundamental no início da transdução de sinal. Essa característica, relatada aqui pela primeira vez, necessita ser incluída nas análises estruturais que envolvam o domínio intracelular de hDectin-1, pois, a desordem intrínseca por si só, já infere características funcionais marcantes como, por exemplo, a sinalização e regulação celular (BÜRGI et al., 2016; BAH et al., 2015; XUE et al., 2009). Deste modo, é interessante que mais estudos sejam feitos para verificar o papel dos segmentos desordenados em hDectin-1.

Os resultados obtidos no presente estudo ampliaram o conhecimento estrutural de hDectin-1. Até o momento, nenhum estudo determinou experimentalmente a estrutura de hDectin-1, assim, o modelo teórico aqui apresentado é de grande valia para o desenvolvimento de estudos para expandir o conhecimento acerca da função de hDectin-1 no reconhecimento de $\beta$-glucanos, modulação das respostas imunológicas para doenças infecciosas e ativação de células $\mathrm{T}$. 


\section{CONCLUSÕES}

Foi possível determinar a estrutura completa de hDectin-1 por meio da combinação de diferentes métodos in silico.

A análise do comportamento estrutural de hDectin-1 na membrana, realizado por meio de simulações de DM, evidenciou a existência de dois segmentos com alta flexibilidade estrutural. Uma análise complementar identificou regiões com desordem intrínseca correspondentes aos segmentos com alta flexibilidade exibidos nas simulações de DM. Essa característica estrutural pode estar diretamente relacionada a capacidade de hDectin-1 em reconhecer $\beta$-glucanos, se oligomerizar e sinalizar Syk.

O domínio Stalk, porção que liga o domínio transmembranar ao CTLD, mostrou características estruturais importantes que podem estar relacionadas a alguma função ainda não compreendida estruturalmente atribuída à proteína hDectin-1. Há necessidade desse domínio ser melhor estudado, pois, existem apenas menções sobre ele, nenhuma análise funcional foi realizada até o momento.

Uma conformação dimérica estável de hDectin-1 foi obtida por meio de docking proteína-proteína e isto possibilitou ampliar as análises de interação de $\beta$-glucanos com o CTLD de hDectin-1.

A interação dos $\beta$-glucanos com o CTLD de hDectin-1 se mostrou mais favorável quando o CTLD está em conformação dimérica. É plausível que o CTLD apresente mais de um sítio de reconhecimento para $\beta$-glucanos e isto esteja vinculado ao tamanho e conformação estrutural do $\beta$-glucano.

A análise das características e do comportamento estrutural do motivo hemITAM, presente no domínio intracelular de hDectin-1, indicou que a presença de desordem intrínseca nessa região e flexibilidade estrutural conferida por ela contribuem para a interação do hemITAM com o domínio SH2-1 de Syk, sendo necessária a interação do hemITAM com apenas um domínio SH2 para manter a estabilidade da interação.

Assim, pode-se concluir que, além de poder ser usada como molde para a determinação estrutural de outras proteínas da família das lectinas, a estrutura de hDectin-1 poderá ser usada para ampliar o conhecimento acerca de sua função nos diversos processos de sinalização celular. 
A caracterização estrutural de hDectin-1 também permitirá que este importante receptor tenha seus domínios explorados como alvos em estudos para o desenvolvimento de fármacos com potencial ativador ou inibidor de suas funções, podendo promover a terapêutica em patologias inflamatórias relacionadas à obesidade em humanos, buscando terapias mais efetivas para aumentar a imunidade protetora contra patógenos fúngicos, encontrar meios para inibir o desencadeamento de doenças autoimunes, desenvolver tratamento para processos inflamatórios crônicos e que também seja empegado como alvo para o desenvolvimento de vacinas e imunoterapia. 


\section{REFERÊNCIAS BIBLIOGRÁFICAS}

ABRAHAM, Mark James et al. GROMACS: High performance molecular simulations through multi-level parallelism from laptops to supercomputers. SoftwareX, v. 1, p. 19-25, 2015.

ADACHI, Yoshiyuki et al. Characterization of $\beta$-glucan recognition site on C-type lectin, dectin 1. Infection and immunity, v. 72, n. 7, p. 4159-4171, 2004.

ALI, Shabana Kouser et al. Molecular dynamics-based analyses of the structural instability and secondary structure of the fibrinogen gamma chain protein with the D356V mutation. Journal of Biomolecular Structure and Dynamics, v. 35, n. 12, p. 2714-2724, 2017.

ALSAADI, Entedar AJ.; JONES, Ian M. Membrane binding proteins of coronaviruses. Future Virology, v. 14, n. 4, p. 275-286, 2019.

ANAYA, Eduardo U. et al. Dectin-1 Molecular Aggregation and Signaling is Sensitive to $\beta$ Glucan Structure and Glucan Exposure on Candida albicans Cell Walls. bioRxiv, p. 824995, 2020.

ARIIZUMI, Kiyoshi et al. Identification of a novel, dendritic cell-associated molecule, dectin1, by subtractive cDNA cloning. Journal of Biological Chemistry, v. 275, n. 26, p. 2015720167, 2000.

ARNOLD, Konstantin et al. The SWISS-MODEL workspace: a web-based environment for protein structure homology modelling. Bioinformatics, v. 22, n. 2, p. 195-201, 2006.

BAGNÉRIS, Claire et al. Role of the C-terminal domain in the structure and function of tetrameric sodium channels. Nature communications, v. 4, p. 2465, 2013.

BAH, Alaji et al. Folding of an intrinsically disordered protein by phosphorylation as a regulatory switch. Nature, v. 519, n. 7541, p. 106-109, 2015.

BAKER, David; SALI, Andrej. Protein structure prediction and structural genomics. Science, v. 294, n. 5540, p. 93-96, 2001.

BALDWIN, Katherine T. et al. Neuroinflammation triggered by $\beta$-glucan/dectin- 1 signaling enables CNS axon regeneration. Proceedings of the National Academy of Sciences, v. 112, n. 8, p. 2581-2586, 2015.

BAO, Hongkun et al. Lentinan produces a robust antidepressant-like effect via enhancing the prefrontal Dectin-1/AMPA receptor signaling pathway. Behavioural brain research, v. 317, p. 263-271, 2017.

BATBAYAR, Sainkhuu; LEE, Dong Hee; KIM, Ha Won. Immunomodulation of fungal $\beta$ glucan in host defense signaling by dectin-1. Biomolecules \& Therapeutics, v. 20, n. 5, p. 433, 2012.

BAUER, Björn; STEINLE, Alexander. HemITAM: A single tyrosine motif that packs a punch. Sci. Signal., v. 10, n. 508, p. eaan3676, 2017. 
BENKERT, Pascal; BIASINI, Marco; SCHWEDE, Torsten. Toward the estimation of the absolute quality of individual protein structure models. Bioinformatics, v. 27, n. 3, p. 343-350, 2010.

BENKERT, Pascal; TOSATTO, Silvio CE; SCHOMBURG, Dietmar. QMEAN: A comprehensive scoring function for model quality assessment. Proteins: Structure, Function, and Bioinformatics, v. 71, n. 1, p. 261-277, 2008.

BIASINI, Marco et al. SWISS-MODEL: modelling protein tertiary and quaternary structure using evolutionary information. Nucleic acids research, v. 42, n. W1, p. W252-W258, 2014.

BLANCO-MENÉNDEZ, Noelia et al. SHIP-1 couples to the dectin-1 hemITAM and selectively modulates reactive oxygen species production in dendritic cells in response to Candida albicans. The Journal of Immunology, v. 195, n. 9, p. 4466-4478, 2015.

BOWIE, James U.; LUTHY, Roland; EISENBERG, David. A method to identify protein sequences that fold into a known three-dimensional structure. Science, v. 253, n. 5016, p. 164$170,1991$.

BRADLEY, P.; MISURA, K. M. S.; BAKER, D. Toward high-resolution de novo structure prediction for small 18 proteins. Science (New York, N.Y.), v. 309, n. 5742, p. 1868-1871, 2005.

BROWN, Gordon D. Dectin-1: a signalling non-TLR pattern-recognition receptor. Nature reviews. Immunology, v. 6, n. 1, p. 33, 2006.

BROWN, Gordon D. Innate antifungal immunity: the key role of phagocytes. Annual review of immunology, v. 29, p. 1-21, 2011.

BROWN, Gordon D.; GORDON, Siamon. A new receptor for $\beta$-glucans. Nature, v. 413, n. 6851, p. 36-37, 2001.

BROWN, James et al. Structure of the fungal $\beta$-glucan-binding immune receptor dectin-1: Implications for function. Protein Science, v. 16, n. 6, p. 1042-1052, 2007.

BRYANT, Clare E. et al. International union of basic and clinical pharmacology. XCVI. Pattern recognition receptors in health and disease. Pharmacological Reviews, v. 67, n. 2, p. 462-504, 2015.

BÜRGI, Jérôme et al. Intrinsic disorder in transmembrane proteins: roles in signaling and topology prediction. PLoS One, v. 11, n. 7, p. e0158594, 2016.

CANUTESCU, Adrian A.; DUNBRACK, Roland L. Cyclic coordinate descent: A robotics algorithm for protein loop closure. Protein science, v. 12, n. 5, p. 963-972, 2003.

CASTOLDI, Angela et al. Dectin-1 Activation Exacerbates Obesity and Insulin Resistance in the Absence of MyD88. Cell Reports, v. 19, n. 11, p. 2272-2288, 2017.

CHAVENT, Matthieu; DUNCAN, Anna L.; SANSOM, Mark SP. Molecular dynamics simulations of membrane proteins and their interactions: from nanoscale to mesoscale. Current 
opinion in structural biology, v. 40, p. 8-16, 2016.

CHEN, Jintong et al. Dectin-1-activated dendritic cells: A potent Th9 cell inducer for tumor immunotherapy. Oncoimmunology, v. 5, n. 11, p. e1238558, 2016.

CHEN, Kangkang et al. Enhancement of Streptomyces transglutaminase activity and propeptide cleavage efficiency by introducing linker peptide in the C-terminus of the propeptide. Journal of industrial microbiology \& biotechnology, v. 40, n. 3-4, p. 317-325, 2013. (b)

CHEN, Xiaoying; ZARO, Jennica L.; SHEN, Wei-Chiang. Fusion protein linkers: property, design and functionality. Advanced drug delivery reviews, v. 65, n. 10, p. 1357-1369, 2013. (a)

CHIBA, Shiho et al. Recognition of tumor cells by Dectin-1 orchestrates innate immune cells for anti-tumor responses. Elife, v. 3, p. e04177, 2014.

CHIFFOLEAU, Elise. C-type lectin-like receptors as emerging orchestrators of sterile inflammation represent potential therapeutic targets. Frontiers in Immunology, v. 9, p. 227, 2018.

COLOVOS, Chris; YEATES, Todd O. Verification of protein structures: patterns of nonbonded atomic interactions. Protein science, v. 2, n. 9, p. 1511-1519, 1993.

DALEY, Donnele et al. Dectin 1 activation on macrophages by galectin 9 promotes pancreatic carcinoma and peritumoral immune tolerance. Nature Medicine, v. 23, n. 5, p. 556-567, 2017.

DAMBUZA, Ivy M.; BROWN, Gordon D. C-type lectins in immunity: recent developments. Current opinion in immunology, v. 32, p. 21-27, 2015.

DAS, Rhiju; BAKER, David. Macromolecular modeling with rosetta. Annu. Rev. Biochem., v. 77, p. 363-382, 2008.

DE ARAÚJO, Maria Elisa Melo Branco et al. Enzymatic de-glycosylation of rutin improves its antioxidant and antiproliferative activities. Food chemistry, v. 141, n. 1, p. 266-273, 2013.

DE BREVERN, Alexandre G. 3D structural models of transmembrane proteins. In: Membrane Protein Structure Determination. Humana Press, Totowa, NJ, 2010. p. 387-401.

DEL CORNÒ, Manuela; GESSANI, Sandra; CONTI, Lucia. Shaping the innate immune response by dietary glucans: any role in the control of cancer?. Cancers, v. 12, n. 1, p. 155, 2020.

DEL FRESNO, Carlos et al. Interferon- $\beta$ production via Dectin-1-Syk-IRF5 signaling in dendritic cells is crucial for immunity to C. albicans. Immunity, v. 38, n. 6, p. 1176-1186, 2013.

DOMINGUEZ, Cyril; BOELENS, Rolf; BONVIN, Alexandre MJJ. HADDOCK: a proteinprotein docking approach based on biochemical or biophysical information. Journal of the American Chemical Society, v. 125, n. 7, p. 1731-1737, 2003. 
DRICKAMER, Kurt. C-type lectin-like domains. Current opinion in structural biology, v. 9, n. 5, p. 585-590, 1999.

DRUMMOND, Rebecca A.; BROWN, Gordon D. Signalling C-type lectins in antimicrobial immunity. PLoS pathogens, v. 9, n. 7, p. e1003417, 2013.

DRUMMOND, Rebecca A.; BROWN, Gordon D. The role of Dectin-1 in the host defence against fungal infections. Current opinion in microbiology, v. 14, n. 4, p. 392-399, 2011.

DULAL, Hari P. et al. $\beta$-Glucan-induced cooperative oligomerization of Dectin-1 C-type lectin-like domain. Glycobiology, v. 28, n. 8, p. 612-623, 2018.

DURRANT, Jacob D.; MC CAMMON, J. Andrew. Moleculardynamics simulations and drug discovery. BMC biology, v. 9, n. 1, p. 1, 2011.

DWYER, Donard S. Electronic properties of the amino acid side chains contribute to the structural preferences in protein folding. Journal of Biomolecular Structure and Dynamics, v. 18, n. 6, p. 881-892, 2001.

DYER, Mark R.; HERRLING, Paul L. Progress and potential for gene-based medicines. Molecular Therapy, v. 1, n. 3, p. 213-224, 2000.

ELSORI, Deena $\mathrm{H}$. et al. Protein kinase $\mathrm{C} \delta$ is a critical component of Dectin-1 signaling in primary human monocytes. Journal of leukocyte biology, v. 90, n. 3, p. 599-611, 2011.

FERREIRA, Leonardo et al. Molecular docking and structure-based drug design strategies. Molecules, v. 20, n. 7, p. 13384-13421, 2015.

FERWERDA, Bart et al. Human dectin-1 deficiency and mucocutaneous fungal infections. New England Journal of medicine, v. 361, n. 18, p. 1760-1767, 2009.

FISER, András et al. Modeling of loops in protein structures. Protein science, v. 9, n. 9, p. 1753-1773, 2000.

FLEISHMAN, Sarel J.; UNGER, Vinzenz M.; BEN-TAL, Nir. Transmembrane protein structures without X-rays. Trends in biochemical sciences, v. 31, n. 2, p. 106-113, 2006.

FLOUDAS, C. A. et al. Advances in protein structure prediction and de novo protein design: A review. Chemical Engineering Science, v. 61, n. 3, p. 966-988, 2006.

FRIEDMAN, Ran; NACHLIEL, Esther; GUTMAN, Menachem. Molecular dynamics of a protein surface: ion-residues interactions. Biophysical journal, v. 89, n. 2, p. 768-781, 2005.

FULLER, Gemma LJ et al. The C-type lectin receptors CLEC-2 and Dectin-1, but not DCSIGN, signal via a novel YXXL-dependent signaling cascade. Journal of Biological Chemistry, v. 282, n. 17, p. 12397-12409, 2007.

FÜTTERER, Klaus et al. Structural basis for Syk tyrosine kinase ubiquity in signal transduction pathways revealed by the crystal structure of its regulatory $\mathrm{SH} 2$ domains bound to a dually phosphorylated ITAM peptide. Journal of molecular biology, v. 281, n. 3, p. 523-537, 1998. 
GANTNER, Benjamin N. et al. Collaborative induction of inflammatory responses by dectin1 and Toll-like receptor 2. Journal of Experimental medicine, v. 197, n. 9, p. 1107-1117, 2003.

GEIJTENBEEK, Teunis BH; GRINGHUIS, Sonja I. C-type lectin receptors in the control of T helper cell differentiation. Nature Reviews Immunology, v. 16, n. 7, p. 433, 2016.

GODDARD, Thomas D.; HUANG, Conrad C.; FERRIN, Thomas E. Software extensions to UCSF chimera for interactive visualization of large molecular assemblies. Structure, v. 13, n. 3, p. 473-482, 2005.

GODING, James W. Monoclonal antibodies: principles and practice. Elsevier, 1996.

GOGUET, Matthieu et al. In silico analysis of Glanzmann variants of Calf-1 domain of $\alpha$ IIb $\beta$ 3 integrin revealed dynamic allosteric effect. Scientific reports, v. 7, n. 1, p. 1-13, 2017.

GOODRIDGE, Helen S. et al. Activation of the innate immune receptor Dectin-1 upon formation of a "phagocytic synapse". Nature, v. 472, n. 7344, p. 471, 2011.

GOODRIDGE, Helen S.; WOLF, Andrea J.; UNDERHILL, David M. $\beta$-glucan recognition by the innate immune system. Immunological reviews, v. 230, n. 1, p. 38-50, 2009.

GRAHAM, Lisa M. et al. Soluble Dectin-1 as a tool to detect $\beta$-glucans. Journal of immunological methods, v. 314, n. 1-2, p. 164-169, 2006.

GRINGHUIS, Sonja I. et al. Dectin-1 directs $\mathrm{T}$ helper cell differentiation by controlling noncanonical NF- $\kappa$ B activation through Raf-1 and Syk. Nature immunology, v. 10, n. 2, p. 203, 2009.

GRINGHUIS, Sonja I. et al. Selective C-Rel activation via Malt1 controls anti-fungal TH-17 immunity by dectin-1 and dectin-2. PLoS pathogens, v. 7, n. 1, p. e1001259, 2011.

GRUBB, Jeffrey H. et al. Infused Fc-tagged $\beta$-glucuronidase crosses the placenta and produces clearance of storage in utero in mucopolysaccharidosis VII mice. Proceedings of the National Academy of Sciences, v. 105, n. 24, p. 8375-8380, 2008.

GRÜNEBACH, Frank et al. Molecular and functional characterization of human Dectin1. Experimental hematology, v. 30, n. 11, p. 1309-1315, 2002.

HARDISON, Sarah E.; BROWN, Gordon D. C-type lectin receptors orchestrate antifungal immunity. Nature immunology, v. 13, n. 9, p. 817-822, 2012.

HATADA, Marcos H. et al. Molecular basis for interaction of the protein tyrosine kinase ZAP70 with the T-cell receptor. Nature, v. 377, n. 6544, p. 32-38, 1995.

HEINSBROEK, Sigrid EM et al. Expression of functionally different dectin-1 isoforms by murine macrophages. The Journal of Immunology, v. 176, n. 9, p. 5513-5518, 2006.

HERNANZ-FALCON, P. et al. Cloning of human DECTIN-1, a novel C-type lectin-like 
receptor gene expressed on dendritic cells. Immunogenetics, v. 53, n. 4, p. 288-295, 2001.

HESS, Berk et al. GROMACS 4: algorithms for highly efficient, load-balanced, and scalable molecular simulation. Journal of chemical theory and computation, v. 4, n. 3, p. 435-447, 2008 .

HOLEC, P. V.; HACKEL, B. J. PyMOL360: Multi-user gamepad control of molecular visualization software. Journal of Computational Chemistry, v. 37, n. 30, p. 2667-2669, 2016.

HOLLMIG, S. Tyler; ARIIZUMI, Kiyoshi; CRUZ JR, Ponciano D. Recognition of non-selfpolysaccharides by C-type lectin receptors dectin-1 and dectin-2. Glycobiology, v. 19, n. 6, p. 568-575, 2009.

HUANG, Jing et al. CHARMM36m: an improved force field for folded and intrinsically disordered proteins. Nature methods, v. 14, n. 1, p. 71-73, 2017.

HUANG, Jing; MACKERELL JR, Alexander D. CHARMM36 all-atom additive protein force field: Validation based on comparison to NMR data. Journal of computational chemistry, $v$. 34, n. 25, p. 2135-2145, 2013.

HUANG, Sheng-You; ZOU, Xiaoqin. Advances and challenges in protein-ligand docking. International journal of molecular sciences, v. 11, n. 8, p. 3016-3034, 2010.

HUANG, Sheng-You; ZOU, Xiaoqin. Ensemble docking of multiple protein structures: considering protein structural variations in molecular docking. Proteins: Structure, Function, and Bioinformatics, v. 66, n. 2, p. 399-421, 2007.

HUEY, Ruth; MORRIS, Garrett M. Using AutoDock 4 with AutoDocktools: a tutorial. The Scripps Research Institute, USA, p. 54-56, 2008.

HUMPHREY, William; DALKE, Andrew; SCHULTEN, Klaus. VMD: visual molecular dynamics. Journal of molecular graphics, v. 14, n. 1, p. 33-38, 1996.

HUTCHINSON, E. Gail; THORNTON, Janet M. PROMOTIF-a program to identify and analyze structural motifs in proteins. Protein Science, v. 5, n. 2, p. 212-220, 1996.

JO, Sunhwan et al. CHARMM-GUI Membrane Builder for mixed bilayers and its application to yeast membranes. Biophysical journal, v. 97, n. 1, p. 50-58, 2009.

JO, Sunhwan et al. CHARMM-GUI: a web-based graphical user interface for CHARMM. Journal of computational chemistry, v. 29, n. 11, p. 1859-1865, 2008.

JO, Sunhwan; KIM, Taehoon; IM, Wonpil. Automated builder and database of protein/membrane complexes for molecular dynamics simulations. PloS one, v. 2, n. 9, p. e880, 2007.

JONES, David T. Protein secondary structure prediction based on position-specific scoring matrices1. Journal of molecular biology, v. 292, n. 2, p. 195-202, 1999. 
KABSCH, Wolfgang; SANDER, Christian. Dictionary of protein secondary structure: pattern recognition of hydrogen-bonded and geometrical features. Biopolymers, v. 22, n. 12, p. 2577 2637, 1983.

KÄLL, Lukas; KROGH, Anders; SONNHAMMER, Erik LL. An HMM posterior decoder for sequence feature prediction that includes homology information. Bioinformatics, v. 21, n. suppl_1, p. i251-i257, 2005.

KARPLUS, Martin; KURIYAN, John. Molecular dynamics and protein function. Proceedings of the National Academy of Sciences, v. 102, n. 19, p. 6679-6685, 2005.

KARPLUS, Martin; MCCAMMON, J. Andrew. Molecular dynamics simulations of biomolecules. Nature structural biology, v. 9, n. 9, p. 646-652, 2002.

KERRIGAN, Ann M.; BROWN, Gordon D. C-type lectins and phagocytosis. Immunobiology, v. 214, n. 7, p. 562-575, 2009.

KERRIGAN, Ann M.; BROWN, Gordon D. Syk-coupled C-type lectin receptors that mediate cellular activation via single tyrosine based activation motifs. Immunological reviews, v. 234, n. 1, p. 335-352, 2010.

KERRIGAN, Ann M.; BROWN, Gordon D. Syk-coupled C-type lectins in immunity. Trends in immunology, v. 32, n. 4, p. 151-156, 2011.

KHAN, Faez Iqbal et al. Current updates on computer aided protein modeling and designing. International journal of biological macromolecules, v. 85, p. 48-62, 2016.

KIM, David E.; CHIVIAN, Dylan; BAKER, David. Protein structure prediction and analysis using the Robetta server. Nucleic acids research, v. 32, n. suppl_2, p. W526-W531, 2004.

KIM, Walter M.; SIGALOV, Alexander B.; STERN, Lawrence J. Pseudo-merohedral twinning and noncrystallographic symmetry in orthorhombic crystals of SIVmac239 Nef core domain bound to different-length TCR $\zeta$ fragments. Acta Crystallographica Section D: Biological Crystallography, v. 66, n. 2, p. 163-175, 2010.

KIMBERG, Matti; BROWN, Gordon D. Dectin-1 and its role in antifungal immunity. Medical mycology, v. 46, n. 7, p. 631-636, 2008.

KIMURA, Yukihiro et al. Dectin-1-mediated signaling leads to characteristic gene expressions and cytokine secretion via spleen tyrosine kinase (Syk) in rat mast cells. Journal of Biological Chemistry, v. 289, n. 45, p. 31565-31575, 2014.

KJAERGAARD, Magnus; KRAGELUND, Birthe B. Functions of intrinsic disorder in transmembrane proteins. Cellular and Molecular Life Sciences, v. 74, n. 17, p. 3205-3224, 2017.

KLOTZ, I. M.; LANGEBMAN, N. R.; DAHNALL, D. W. Quaternary structure of proteins. Annual review of biochemistry, v. 39, n. 1, p. 25-62, 1970.

KOEHLER LEMAN, Julia; ULMSCHNEIDER, Martin B.; GRAY, Jeffrey J. Computational 
modeling of membrane proteins. Proteins: Structure, Function, and Bioinformatics, v. 83, n. 1 , p. 1-24, 2015.

KOZAKOV, Dima et al. The ClusPro web server for protein-protein docking. nature protocols, v. 12, n. 2, p. 255-278, 2017.

KOZAKOV, Dima et al. The FTMap family of web servers for determining and characterizing ligand-binding hot spots of proteins. Nature protocols, v. 10, n. 5, p. 733, 2015.

KRAUSGRUBER, Thomas et al. IRF5 promotes inflammatory macrophage polarization and T H 1-T H 17 responses. Nature immunology, v. 12, n. 3, p. 231, 2011.

KROGH, Anders et al. Predicting transmembrane protein topology with a hidden markov model: application to complete genomes1. Journal of molecular biology, v. 305, n. 3, p. 567580, 2001.

KRYSHTAFOVYCH, Andriy; FIDELIS, Krzysztof. Protein structure prediction and model quality assessment. Drug discovery today, v. 14, n. 7, p. 386-393, 2009.

KUMAR, Deepak Kumar Vijaya; EIMER, William A.; RAMAKRISHNAN, Sreejith. Specificity of Toll-like receptor 2 and Dectin-1 signaling in CNS macrophages. Journal of Neuroscience, v. 35, n. 49, p. 16015-16017, 2015.

KUKOL, A. Molecular modeling of proteins. 1a edição. Hatfield, Hertfordshire, UK. Humana Press, 2008. 383 páginas.

KYTE, Jack. Structure in protein chemistry. Garland Science, 2006.

LASKOWSKI RA, MACARTHUR MW, MOSS DS, THORNTON JM. PROCHECK: a program to check the stereochemical quality of protein structures. J. Appl. Cryst. 1993. 26, 283-291

LASKOWSKI, Roman A. et al. PROCHECK: a program to check the stereochemical quality of protein structures. Journal of applied crystallography, v. 26, n. 2, p. 283-291, 1993.

LASKOWSKI, Roman A. PDBsum: summaries and analyses of PDB structures. Nucleic acids research, v. 29, n. 1, p. 221-222, 2001.

LAU et al. The structure of the integrin $\alpha \operatorname{IIb} \beta 3$ transmembrane complex explains integrin transmembrane signalling. The EMBO journal, v. 28, n. 9, p. 1351-1361, 2009.

LE QUELLEC, Sandra et al. Potential limits of AAV-based gene therapy with the use of new transgenes expressing factor IX fusion proteins. Haemophilia, v. 25, n. 1, p. e11-e18, 2019.

LEE, J.; WU, S.; ZHANG, Y. Ab initio protein structure prediction. From Protein Structure to Function with Bioinformatics. Editora Springer-London, 2009. Capítulo 1, p 126.

LEE, Jumin et al. CHARMM-GUI input generator for NAMD, GROMACS, AMBER, OpenMM, and CHARMM/OpenMM simulations using the CHARMM36 additive force 
field. Journal of chemical theory and computation, v. 12, n. 1, p. 405-413, 2015.

LEGENTIL, Laurent et al. Molecular interactions of $\beta-(1 \rightarrow 3)$-glucans with their receptors. Molecules, v. 20, n. 6, p. 9745-9766, 2015.

LESK, Arthur. Introduction to bioinformatics. Oxford university press, 2019.

LI, Weizhong et al. The EMBL-EBI bioinformatics web and programmatic tools framework. Nucleic acids research, v. 43, n. W1, p. W580-W584, 2015.

LIU, Juan; QIAN, Cheng; CAO, Xuetao. Post-translational modification control of innate immunity. Immunity, v. 45, n. 1, p. 15-30, 2016.

LIU, Siyu; LIU, Chuyao; DENG, Lei. Machine Learning Approaches for Protein-Protein Interaction Hot Spot Prediction: Progress and Comparative Assessment. Molecules, v. 23, n. 10, p. 2535, 2018.

LIWO, Adam et al. Computational techniques for efficient conformational sampling of proteins. Current opinion in structural biology, v. 18, n. 2, p. 134-139, 2008.

LODISH, Harvey et al. Molecular cell biology. 4th. New York: WH Freeman, v. 33, n. 973, p. 79, 2000.

LU, Xinyao et al. Enhanced thermal stability and specific activity of Pseudomonas aeruginosa lipoxygenase by fusing with self-assembling amphipathic peptides. Applied microbiology and biotechnology, v. 97, n. 21, p. 9419-9427, 2013.

LUTHY R, BOWIE JU, EISENBERG D. Assessment of protein models with three-dimentional profiles. Nature. 356: 83-85, 1992.

LÜTHY, Roland; BOWIE, James U.; EISENBERG, David. Assessment of protein models with three-dimensional profiles. Nature, v. 356, n. 6364, p. 83, 1992.)

MACKERELL JR, Alex D. et al. All-atom empirical potential for molecular modeling and dynamics studies of proteins. The journal of physical chemistry B, v. 102, n. 18, p. 3586-3616, 1998.

MACKERELL JR, Alexander D.; FEIG, Michael; BROOKS III, Charles L. Extending the treatment of backbone energetics in protein force fields: limitations of gas-phase quantum mechanics in reproducing protein conformational distributions in molecular dynamics simulations. Journal of computational chemistry, v. 25, n. 11, p. 1400-1415, 2004.

MARAKALALA, Mohlopheni J.; KERRIGAN, Ann M.; BROWN, Gordon D. Dectin-1: a role in antifungal defense and consequences of genetic polymorphisms in humans. Mammalian Genome, v. 22, n. 1-2, p. 55-65, 2011.

MCGUFFIN, L. J.; BUENAVISTA, M. T.; ROCHE, D. B. The ModFOLD4 server for the quality assessment of 3D protein models. Nucleic Acids Research, v. 41, n. Web Server issue, p. W368-372, 2013. 
MISURA, Kira MS et al. Physically realistic homology models built with ROSETTA can be more accurate than their templates. Proceedings of the National Academy of Sciences, v. 103, n. 14, p. 5361-5366, 2006.

MÓCSAI, Attila; RULAND, Jürgen; TYBULEWICZ, Victor LJ. The SYK tyrosine kinase: a crucial player in diverse biological functions. Nature Reviews Immunology, v. 10, n. 6, p. $387,2010$.

MONTEIRO, João T.; LEPENIES, Bernd. Myeloid C-Type Lectin Receptors in Viral Recognition and Antiviral Immunity. Viruses, v. 9, n. 3, p. 59, 2017.

MORRIS, Garrett M. et al. AutoDock4 and AutoDockTools4: Automated docking with selective receptor flexibility. Journal of computational chemistry, v. 30, n. 16, p. 2785-2791, 2009.

NADEAU, Vincent G.; DEBER, Charles M. Loop sequence dictates the secondary structure of a human membrane protein hairpin. Biochemistry, v. 52, n. 14, p. 2419-2426, 2013.

NGAN, Chi-Ho et al. FTSite: high accuracy detection of ligand binding sites on unbound protein structures. Bioinformatics, v. 28, n. 2, p. 286-287, 2011.

OSGUTHORPE, David J. Ab initio protein folding. Current Opinion in Structural Biology, v. 10, n. 2, p. 146-152, 2000.

OSTROP, Jenny; LANG, Roland. Contact, Collaboration, and Conflict: Signal Integration of Syk-Coupled C-Type Lectin Receptors. The Journal of Immunology, v. 198, n. 4, p. 14031414, 2017.

OVCHINNIKOV, Sergey et al. Improved de novo structure prediction in CASP11 by incorporating coevolution information into Rosetta. Proteins: Structure, Function, and Bioinformatics, v. 84, n. S1, p. 67-75, 2016.

PALMA, Angelina S. et al. Ligands for the $\beta$-glucan receptor, Dectin-1, assigned using "designer" microarrays of oligosaccharide probes (neoglycolipids) generated from glucan polysaccharides. Journal of Biological Chemistry, v. 281, n. 9, p. 5771-5779, 2006.

PARK, Sang-Jun et al. CHARMM-GUI glycan modeler for modeling and simulation of carbohydrates and glycoconjugates. Glycobiology, v. 29, n. 4, p. 320-331, 2019.

PARK, Sang-Jun et al. Glycan Reader is improved to recognize most sugar types and chemical modifications in the Protein Data Bank. Bioinformatics, v. 33, n. 19, p. 3051-3057, 2017.

PETREY, Donald et al. Template-based prediction of protein function. Current opinion in structural biology, v. 32, p. 33-38, 2015.

PETREY, Donald; HONIG, Barry. Structural bioinformatics of the interactome. Annual review of biophysics, v. 43, p.193, 2014.

PETTERSEN EF, GODDARD TD, HUANG CC, COUCH GS, GREENBLATT DM, MENG EC, FERRIN TE. UCSF Chimera-- a visualization system for exploratory research and analysis. 
J Comput Chem. 2004 Oct;25(13):1605-12.

PIROVANO, Walter; HERINGA, Jaap. Protein secondary structure prediction. In: Data Mining Techniques for the Life Sciences. Humana Press, 2010. p. 327-348.

PLUMMER, Emily M. et al. Interaction of cowpea mosaic virus nanoparticles with surface vimentin and inflammatory cells in atherosclerotic lesions. Nanomedicine, v. 7, n. 6, p. 877888, 2012.

PRYOR JR, Edward E.; WIENER, Michael C. A critical evaluation of in silico methods for detection of membrane protein intrinsic disorder. Biophysical journal, v. 106, n. 8, p. 16381649, 2014.

RADIVOJAC, Predrag et al. Protein flexibility and intrinsic disorder. Protein Science, v. 13, n. 1, p. 71-80, 2004.

REDELINGHUYS, Pierre; BROWN, Gordon D. Inhibitory C-type lectin receptors in myeloid cells. Immunology letters, v. 136, n. 1, p. 1-12, 2011.

REID, Delyth M.; GOW, Neil AR; BROWN, Gordon D. Pattern recognition: recent insights from Dectin-1. Current opinion in immunology, v. 21, n. 1, p. 30-37, 2009.

ROGERS, Neil C. et al. Syk-dependent cytokine induction by Dectin-1 reveals a novel pattern recognition pathway for $\mathrm{C}$ type lectins. Immunity, v. 22, n. 4, p. 507-517, 2005.

ROY, Ambrish; KUCUKURAL, Alper; ZHANG, Yang. I-TASSER: a unified platform for automated protein structure and function prediction. Nature protocols, v. 5, n. 4, p. 725, 2010.

RUBINSTEIN, Rotem et al. Functional classification of immune regulatory proteins. Structure, v. 21, n. 5, p. 766-776, 2013.

RUTHES, Andrea Caroline; SMIDERLE, Fhernanda Ribeiro; IACOMINI, Marcello. DGlucans from edible mushrooms: A review on the extraction, purification and chemical characterization approaches. Carbohydrate polymers, v. 117, p. 753-761, 2015.

SAIJO, Shinobu; IWAKURA, Yoichiro. Dectin-1 and Dectin-2 in innate immunity against fungi. International immunology, v. 23, n. 8, p. 467-472, 2011.

SALI A, BLUNDELL T L. Comparative protein modeling by satisfaction of spatial restraints. Journal of Molecular Biology. v. 234, p. 779-815, 1993.

SANCHEZ, Roberto; ŠALI, Andrej. Advances in comparative protein-structure modelling. Current opinion in structural biology, v. 7, n. 2, p. 206-214, 1997.

SANCHO, David; REIS E SOUSA, Caetano. Signaling by myeloid C-type lectin receptors in immunity and homeostasis. Annual review of immunology, v. 30, p. 491-529, 2012.

SAPAY, Nicolas; TIELEMAN, D. Peter. Combination of the CHARMM27 force field with united-atom lipid force fields. Journal of computational chemistry, v. 32, n. 7, p. 1400-1410, 2011. 
SATTLER, Susanne; GHADIALLY, Hormas; HOFER, Erhard. Evolution of the C-type lectinlike receptor genes of the DECTIN-1 cluster in the NK gene complex. The Scientific World Journal, v. 2012, 2012.

SAYERS EW et al. Database resources of the National Center for Biotechnology Information. Nucleic Acids Research. 2011;39 (Database issue):D38-D51.

SCHMIDT, Stefan R. (Ed.). Fusion protein technologies for biopharmaceuticals: applications and challenges. John Wiley \& Sons, 2013.

SHAKIL, Shazi et al. Molecular interaction of the antineoplastic drug, methotrexate with human brain acetylcholinesterase: a docking study. CNS \& Neurological Disorders-Drug Targets (Formerly Current Drug Targets-CNS \& Neurological Disorders), v. 11, n. 2, p. 142-147, 2012.

SIEVERS, Fabian; HIGGINS, Desmond G. Clustal Omega, accurate alignment of very large numbers of sequences. In: Multiple sequence alignment methods. Humana Press, Totowa, NJ, 2014. p. 105-116.

SIMOSSIS, Victor A.; HERINGA, Jaap. PRALINE: a multiple sequence alignment toolbox that integrates homology-extended and secondary structure information. Nucleic acids research, v. 33, n. suppl_2, p. W289-W294, 2005.

SMITH, Alyson J. et al. Immunoregulatory activity of the natural product laminarin varies widely as a result of its physical properties. The Journal of Immunology, v. 200, n. 2, p. 788799, 2018.

SOBANOV, Yuri et al. A novel cluster of lectin-like receptor genes expressed in monocytic, dendritic and endothelial cells maps close to the NK receptor genes in the human NK gene complex. European journal of immunology, v. 31, n. 12, p. 3493-3503, 2001.

STUDER, Gabriel; BIASINI, Marco; SCHWEDE, Torsten. Assessing the local structural quality of transmembrane protein models using statistical potentials (QMEANBrane). Bioinformatics, v. 30, n. 17, p. i505-i511, 2014.

SUBRAMANI, A.; FLOUDAS, C. A. Structure prediction of loops with fixed and flexible stems. The Journal of Physical Chemistry B, v. 116, n. 23, p. 6670-6682, 2012.

SUGAWARA, Tomoko et al. Refinement of the structures of cell-wall glucans of Schizosaccharomyces pombe by chemical modification and NMR spectroscopy. Carbohydrate Research, v. 339, n. 13, p. 2255-2265, 2004.

SUN, Zhoutong et al. Utility of B-factors in protein science: interpreting rigidity, flexibility, and internal motion and engineering thermostability. Chemical reviews, v. 119, n. 3, p. 16261665, 2019.

SYNYTSYA, Andriy; NOVAK, Miroslav. Structural analysis of glucans. Annals of translational medicine, v. 2, n. 2, 2014. 
SYNYTSYA, Andriy; NOVÁK, Miroslav. Structural diversity of fungal glucans. Carbohydrate polymers, v. 92, n. 1, p. 792-809, 2013.

TAKANO, Tomotsugu et al. Dectin-1 intracellular domain determines species-specific ligand spectrum by modulating receptor sensitivity. Journal of Biological Chemistry, v. 292, n. 41, p. 16933-16941, 2017.

TAYLOR, Philip R. et al. The $\beta$-glucan receptor, dectin- 1 , is predominantly expressed on the surface of cells of the monocyte/macrophage and neutrophil lineages. The Journal of immunology, v. 169, n. 7, p. 3876-3882, 2002.

THIAGARAJAN, Praveena S. et al. Vimentin is an endogenous ligand for the pattern recognition receptor Dectin-1. Cardiovascular research, v. 99, n. 3, p. 494-504, 2013.

TONG, Liang et al. Crystal structures of the human p56lckSH2 domain in complex with two short phosphotyrosyl peptides at $1.0 \AA$ and $1.8 \AA$ resolution. Journal of molecular biology, v. 256, n. 3, p. 601-610, 1996.

TROTT, Oleg; OLSON, Arthur J. AutoDock Vina: improving the speed and accuracy of docking with a new scoring function, efficient optimization, and multithreading. Journal of computational chemistry, v. 31, n. 2, p. 455-461, 2010.

TSONI, S. Vicky; BROWN, Gordon D. $\beta$-Glucans and Dectin-1. Annals of the New York Academy of Sciences, v. 1143, n. 1, p. 45-60, 2008.

TURNER, Martin et al. Tyrosine kinase SYK: essential functions for immunoreceptor signalling. Immunology today, v. 21, n. 3, p. 148-154, 2000.

TUSNADY, Gabor E.; SIMON, Istvan. The HMMTOP transmembrane topology prediction server. Bioinformatics, v. 17, n. 9, p. 849-850, 2001.

UNDERHILL, David M. et al. Dectin-1 activates Syk tyrosine kinase in a dynamic subset of macrophages for reactive oxygen production. Blood, v. 106, n. 7, p. 2543-2550, 2005.

UNIPROT CONSORTIUM et al. Reorganizing the protein space at the Universal Protein Resource (UniProt). Nucleic acids research, p. gkr981, 2011.

VAKSER, Ilya A. Protein-protein docking: From interaction to interactome. Biophysical journal, v. 107, n. 8, p. 1785-1793, 2014.

VAN GUNSTEREN, Wilfred F.; DOLENC, Jožica; MARK, Alan E. Molecular simulation as an aid to experimentalists. Current opinion in structural biology, v. 18, n. 2, p. 149$153,2008$.

VAN ZUNDERT, G. C. P. et al. The HADDOCK2. 2 web server: user-friendly integrative modeling of biomolecular complexes. Journal of molecular biology, v. 428, n. 4, p. 720-725, 2016.

VIRIYAKOSOL, S. et al. Susceptibility to Coccidioides species in C57BL/6 mice is associated with expression of a truncated splice variant of Dectin-1 (Clec7a). Genes and immunity, v. 9, 
n. 4, p. 338, 2008.

VIRIYAKOSOL, S. et al. Susceptibility to Coccidioides species in C57BL/6 mice is associated with expression of a truncated splice variant of Dectin-1 (Clec7a). Genes and immunity, v. 9, n. 4, p. 338, 2008.

VISPERAS, Patrick R. et al. Modification by covalent reaction or oxidation of cysteine residues in the tandem-SH2 domains of ZAP-70 and Syk can block phosphopeptide binding. Biochemical Journal, v. 465, n. 1, p. 149-161, 2015.

WAGENER, Matthew et al. Dectin-1-Syk-CARD9 signaling pathway in TB immunity. Frontiers in immunology, v. 9, p. 225, 2018.

WALLACE, Andrew C.; LASKOWSKI, Roman A.; THORNTON, Janet M. LIGPLOT: a program to generate schematic diagrams of protein-ligand interactions. Protein engineering, design and selection, v. 8, n. 2, p. 127-134, 1995.

WANG, Chu; BRADLEY, Philip; BAKER, David. Protein-protein docking with backbone flexibility. Journal of molecular biology, v. 373, n. 2, p. 503-519, 2007.

WARNECKE, Andreas et al. PyTMs: a useful PyMOL plugin for modeling common posttranslational modifications. BMC bioinformatics, v. 15, n. 1, p. 370, 2014.

WATERHOUSE, Andrew et al. SWISS-MODEL: homology modelling of protein structures and complexes. Nucleic acids research, v. 46, n. W1, p. W296-W303, 2018.

WEBB, Benjamin; SALI, Andrej. Comparative protein structure modeling using MODELLER. Current protocols in bioinformatics, v. 54, n. 1, p. 5.6. 1-5.6. 32, 2016.

WEBB, Benjamin; SALI, Andrej. Protein structure modeling with MODELLER. In: Protein Structure Prediction. Humana Press, New York, NY, 2014. p. 1-15.

WEIL, Tanja; RENNER, Steffen. Homology model-based virtual screening for GPCR ligands using docking and target-biased scoring. Journal of chemical information and modeling, $\mathrm{v}$. 48, n. 5, p. 1104-1117, 2008.

WIEDERSTEIN, Markus; SIPPL, Manfred J. ProSA-web: interactive web service for the recognition of errors in three-dimensional structures of proteins. Nucleic acids research, v. 35, n. suppl_2, p. W407-W410, 2007.

WILLMENT, Janet A. et al. The human $\beta$-glucan receptor is widely expressed and functionally equivalent to murine Dectin-1 on primary cells. European journal of immunology, v. 35, n. 5, p. 1539-1547, 2005.

WILLMENT, Janet A.; BROWN, Gordon D. C-type lectin receptors in antifungal immunity. Trends in microbiology, v. 16, n. 1, p. 27-32, 2008.

WILLMENT, Janet A.; GORDON, Siamon; BROWN, Gordon D. Characterization of the human $\beta$-glucan receptor and its alternatively spliced isoforms. Journal of Biological Chemistry, v. 276, n. 47, p. 43818-43823, 2001. 
WU, Emilia L. et al. CHARMM-GUI Membrane Builder toward realistic biological membrane simulations. Journal of computational chemistry, v. 35, n. 27, p. 1997-2004, 2014.

WÜTHRICH, Marcel; DEEPE JR, George S.; KLEIN, Bruce. Adaptive immunity to fungi. Annual review of immunology, v. 30, p. 115-148, 2012.

XIE, Jianhui et al. Human Dectin-1 isoform E is a cytoplasmic protein and interacts with RanBPM. Biochemical and biophysical research communications, v. 347, n. 4, p. 10671073, 2006.

$\mathrm{XU}$, Chenqi et al. Regulation of $\mathrm{T}$ cell receptor activation by dynamic membrane binding of the CD3e cytoplasmic tyrosine-based motif. Cell, v. 135, n. 4, p. 702-713, 2008.

XU, Dong; ZHANG, Yang. Ab initio protein structure assembly using continuous structure fragments and optimized knowledge-based force field. Proteins: Structure, Function, and Bioinformatics, v. 80, n. 7, p. 1715-1735, 2012.

XU, Dong; ZHANG, Yang. Toward optimal fragment generations for ab initio protein structure assembly. Proteins: Structure, Function, and Bioinformatics, v. 81, n. 2, p. 229-239, 2013.

XU, Jinbo; JIAO, Feng; BERGER, Bonnie. A tree-decomposition approach to protein structure prediction. In: 2005 IEEE Computational Systems Bioinformatics Conference (CSB'05). IEEE, 2005. p. 247-256.

$\mathrm{XU}$, Shengli et al. Activated dectin-1 localizes to lipid raft microdomains for signaling and activation of phagocytosis and cytokine production in dendritic cells. Journal of Biological Chemistry, v. 284, n. 33, p. 22005-22011, 2009.

XUE, Bin et al. Analysis of structured and intrinsically disordered regions of transmembrane proteins. Molecular bioSystems, v. 5, n. 12, p. 1688-1702, 2009.

YADAV, Mahesh; SCHOREY, Jeffrey S. The $\beta$-glucan receptor dectin-1 functions together with TLR2 to mediate macrophage activation by mycobacteria. Blood, v. 108, n. 9, p. 31683175, 2006.

YANG, Haiquan et al. Fusion of an oligopeptide to the $\mathrm{N}$ terminus of an alkaline $\alpha$-amylase from Alkalimonas amylolytica simultaneously improves the enzyme's catalytic efficiency, thermal stability, and resistance to oxidation. Applied and environmental microbiology, v. 79, n. 9, p. 3049-3058, 2013.

YANG, Jack Y. et al. Investigation of transmembrane proteins using a computational approach. BMC genomics, v. 9, n. S1, p. S7, 2008.

YANG, Jianyi et al. The I-TASSER Suite: protein structure and function prediction. Nature methods, v. 12, n. 1, p. 7, 2015.

YOKOTA, Koichi et al. Identification of a human homologue of the dendritic cell-associated C-type lectin-1, dectin-1. Gene, v. 272, n. 1-2, p. 51-60, 2001. 
YU, Haoran et al. Two strategies to engineer flexible loops for improved enzyme thermostability. Scientific reports, v. 7, p. 41212, 2017.

ZHANG, C. H. I.; LIU, Song; ZHOU, Yaoqi. Accurate and efficient loop selections by the DFIRE-based all-atom statistical potential. Protein science, v. 13, n. 2, p. 391-399, 2004.

ZHANG, Yang. Protein structure prediction: when is it useful?. Current opinion in structural biology, v. 19, n. 2, p. 145-155, 2009.

ZHAO, Gui-Qiu et al. The role of Dectin-1/Raf-1 signal cascade in innate immune of human corneal epithelial cells against Aspergillus fumigatus infection. International Journal of Ophthalmology, v. 9, n. 10, p. 1371, 2016.

ZHAO, Yinghua et al. Dectin-1-activated dendritic cells trigger potent antitumour immunity through the induction of Th9 cells. Nature communications, v. 7, n. 1, p. 1-12, 2016.

ZHENG, Wei et al. I-TASSER gateway: A protein structure and function prediction server powered by XSEDE. Future Generation Computer Systems, v. 99, p. 73-85, 2019.

ZHOU, Hongyi; ZHOU, Yaoqi. Distance-scaled, finite ideal-gas reference state improves structure-derived potentials of mean force for structure selection and stability prediction. Protein science, v. 11, n. 11, p. 2714-2726, 2002. 


\title{
ANEXO A - Manuscrito
}

Title

\section{Structural characterization of human Dectin-1 and analysis of interaction with the molecular targets $\beta$-glucans and Syk}

\author{
Elvira Regina Tamarozzi ${ }^{1}$ e Silvana Giuliatti ${ }^{1}$ \\ ${ }^{1}$ Department of Genetics, School of Medicine of Ribeirão Preto, University of São Paulo.
}

Avenida Bandeirantes, 3900, Ribeirão Preto, SP, Brazil, zip code: 14049-900

E-mail: elvira.tamarozzi@gmail.com

\begin{abstract}
The human Dectin-1 protein is a transmembrane receptor expressed in most cells that act on innate immunity. Dectin-1 features a single C-type lectin-like domain (CTLD) in the extracellular portion and a hemi-immunoreceptor tyrosine-based activation motif (hemITAM) in the intracellular portion. The hemITAM motif acts as a mediator of cell signaling induced by the recognition of $\beta$-glucans and initiates the response that leads to the production of several immunomodulators. Dectin-1, in addition to being a fundamental component in the signaling of fungal infections, also plays an important role in anti-tumor immune responses, is correlated with insulin resistance and obesity, participates in the process of developing atherosclerosis, plays an important role in diseases that cause chronic inflammatory processes and, in specific situations, can trigger the appearance of autoimmune diseases. This study aimed to determine the complete three-dimensional structure of human Dectin-1 and to analyze the interaction of its functional domains with the described molecular targets, $\beta$-glucans and Syk protein. Through in silico methods it was possible to determine the model for the complete structure of Dectin-1 and use the functional domains in analysis of interaction with the targets $\beta$-glucans and Syk. A stable dimeric conformation of Dectin-1 was obtained through protein-protein docking, enabling the expansion of the analysis of interaction of Dectin- 1 with $\beta$-glucans. The analysis of interaction between CTLD and $\beta$-glucans showed that the dimeric conformation is possibly more favorable for the interaction and recognition of $\beta$-glucans when compared to the monomeric state. The time of interaction of $\beta$-glucans with the recognition site suggested that, possibly, the structural organization and size of $\beta$-glucan may influence the Dectin-1 oligomerization process and the location of the CTLD recognition site. Interaction analyzes between the hemITAM motif and the Syk protein showed that it is possible for Dectin-1 to form a stable complex with Syk by the interaction of the phosphorylated hemITAM motif with only the SH2-1 domain, leaving the SH2-2 domain free to interact with another hemITAM, optimizing the interaction with the Syk protein. Thus, it can be concluded that the theoretical model described here for human Dectin-1 will allow more studies to be developed, either to expand knowledge about its function or in the development of therapies that use Dectin-1 as a target.
\end{abstract}

Keywords: Dectin-1, transmembrane receptor, cell signaling, structural analysis. 


\section{Introduction}

The human transmembrane protein Dectin-1 (hDectin-1), in addition to being a fundamental component for the ability of the innate immune system to signal fungal infections (DALEY et al., 2017; GOODRIDGE et al., 2011), has an important role in antitumor immune responses (CHIBA et al., 2014), be correlated with insulin resistance, obesity, development of atherosclerosis (CASTOLDI et al. 2017; THIAGARAJAN et al., 2013; ELSORI et al., 2011), acts in an important way in diseases that cause chronic inflammatory processes (CASTOLDI et al., 2017) and, in specific situations, trigger the emergence of autoimmune diseases (GOODRIDGE et al., 2011; BROWN, 2006), this important receptor has proved to be an excellent target for the development of drug therapies, vaccines and immunotherapy (DALEY et al., 2017; CHEN et al., 2016; ZHAO et al., 2016; BRYANT et al., 2015; CHIBA et al., 2014).

hDectin-1 is a type II transmembrane protein, classified as a Group V non-classical Ctype lectin (REDELINGHUYS; BROWN, 2011; HOLLMIG et al., 2009). It consists of 247 residues, has an $\mathrm{N}$-terminal cytoplasmic portion composed of the first 44 residues, followed by a transmembrane domain (residues 45 to 65 ) and an extracellular C-terminal portion that is divided into two portions, the first portion being the domain Stalk that starts at residues 66 (KIMURA et al., 2014; TSONI; BROWN, 2008) and the second portion is the type C lectin domain (CTLD) that comprises residues 127 to 242 (YOKOTA et al., 2001 ; HOLLMIG et al., 2009).

Unlike many C-type lectin receptors, hDectin-1 has a single CTLD in the extracellular portion and a immunoreceptor tyrosine-based activation motif (ITAM) in the intracellular domain (REDELINGHUYS; BROWN, 2011; KERRIGAN; BROWN, 2009).

The interaction of hDectin- 1 with $\beta$-glucans occurs at CTLD. After the recognition of a particulate $\beta$-glucan, the ITAM motif is phosphorylated and ready to interact with Syk. This transmembrane signaling can induce the production of various cytokines and chemokines, it can also induce respiratory burst and uptake of ligands by phagocytosis and possibly endocytosis (LEGENTIL et al., 2015; BROWN, 2006).

Glucans are the most common polysaccharides found in nature. Most play the role of structural components of the cell wall in different organisms, others are used as an energy source for metabolism (RUTHES et al., 2015; SYNYTSYA; NOVAK, 2014). Some $\beta$-glucans are known to have immunomodulatory and anti-tumor activities (CHIFFOLEAU, 2018; ZHAO et al., 2016; SYNYTSYA; NOVAK, 2013). Several studies have used Dectin-1 agonist $\beta$ glucans to induce anti-tumor immune responses in various types of cancer (CHIFFOLEAU, 2018). Other studies, such as Baldwin et al. (2015), showed that the intraocular administration of particulate $\beta$-glucans induced axonal regeneration through interaction with Dectin-1, displaying immune cells in the retina. Bao et al. (2017) reported having obtained a potent effect similar to the use of antidepressants mediated by Dectin- 1 after administration of the lentinan $\beta$-glucan. Thus, understanding the mechanisms of interaction between Dectin- 1 and $\beta$-glucans is of great therapeutic importance.

The recognition of $\beta$-glucans and immunogenic substances from a pathogen by antigen presenting cells, such as dendritic cells (DCs) and macrophages, can increase the activation of pathogen-specific T cells. Thus, Dectin-1 can modulate several immune responses to infectious 
diseases, not only by activating innate immunity, but also by the acquired antigen-specific immunity (ADACHI et al., 2004).

The modulation of immune responses is directly linked to protein-protein interactions, and structural knowledge of the protein and its functional domains is important to increase the understanding of the immune responses associated with them. The $\beta$-glucans agonists of hDectin-1 showed potential as vaccine adjuvants that can facilitate protective immune responses against pathogens or cancer in model murine and human patients. Given this potential, it is important to characterize in detail the function of hDectin- 1 in comparison with the accumulated evidence for the most studied murine Dectin-1 (mDectin-1) (TAKANO et al., 2017).

The ITAM motif of hDectin-1 is denominated hemITAM because it is formed by a single YxxL sequence in its N-terminal cytoplasmic portion. Signaling via Dectin-1 depends on its cytoplasmic hemITAM motif, which resembles sequences found in other signaling proteins (MONTEIRO; LEPENIES, 2017). Cell signaling initiated by hDectin-1 occurs through the recruitment of Syk, which interacts with the phosphorylated hemITAM hDectin-1 motif through its $\mathrm{SH} 2$ domains. Signal transduction occurs after recognition of $\beta$-glucans by CTLD and subsequent interaction of the phosphorylated hemITAM motif with Syk (KIMURA et al, 2014; BATBAYAR et al., 2012; BROWN, 2006; ROGERS et al., 2005).

The exact way in which the interaction between Syk and Dectin-1 occurs is not fully understood (MARAKALALA et al., 2011), the development of studies for the structural analysis of the interaction between Dectin-1 and Syk can bring more information about the mechanisms of interaction between these two proteins.

The CTDL present in the conserved family of lectin proteins can interact through several different surfaces to form dimers and trimers, from which the binding sites project in a variety of different orientations (DRICKAMER, 1999).

Observation of the Dectin-1 oligomerization event in the $\beta$-glucan recognition process has been described in some studies over the past two decades (ANAYA et al., 2020; DULAL et al. 2018; BROWN et al., 2007). Of these studies, two used only $\beta$-glucan laminarin and observed the induction of cooperative oligomerization triggered by this $\beta$-glucan (DULAL et al. 2018; BROWN et al., 2007). In 2007, Brown et al. described the structure of a dimer for mDectin-1 which, at that time, was considered possibly unfeasible in vivo due to the lack of information to support the possibility of that conformation occurring naturally. In 2018, Dulal et al. described the observation of the formation of mDectin- 1 tetramers induced by $\beta$-glucan laminarin and reported not having observed the presence of dimers or trimers. In 2020, Anaya et al. also described the observation of Dectin-1 oligomerization, however, the way this event occurred was linked to the type, size and quantity of $\beta$-glucans available on the cell surface. Thus, there is still no consensus on how Dectin-1 oligomerization occurs, whether or not it is linked to the type and / or bioavailability of these $\beta$-glucans.

Structurally, due to the biological and pharmaceutical importance of integral membrane proteins, considerable experimental and computational efforts have been made to better understand the structure and function of these proteins in membrane environments (ALSAADI; JONES, 2019). As a result of technological advances in various sectors, new structures of membrane proteins have become available, although this number is still much 
lower than that of globular proteins (ALSAADI; JONES, 2019; PRYOR; WIENER, 2014; DE ARAÚJO et al., 2013; JO et al., 2007).

Knowing that, to better understand the function of a protein and how it interacts with molecular targets, it is important to know and analyze its complete three-dimensional structure (PETREY et al., 2015), the importance of structural protein determination studies is highlighted. In silico methods offer a viable solution to expand the structural knowledge of macromolecules (PETREY et al., 2015; PETREY; HONIG, 2014). Thus, this study aimed to determine the complete three-dimensional structure of Dectin-1 and to analyze the interaction of its functional domains with the described molecular targets, $\beta$-glucans and Syk protein.

Using different in silico methods, it was possible to determine a viable model for the complete structure of hDectin-1 which, until now, was unknown. The molecular dynamics simulation of the complete structure inserted in the cell membrane showed that the modeled domains were of sufficient quality to be used in structural studies.

\section{Methods}

Structural determination

The primary sequences of hDectin- 1 and mDectin-1 were obtained from the public repositories NCBI and UniProt, the identifiers are: hDectin-1 AY026769.2 (GenBank) and Q9BXN2 (UniProt); mDectin-1 AF262985.1 (GenBank) and Q6QLQ4 (UniProt). All threedimensional structures used as molds were obtained from Protein Data Bank (PDB).

Homology modeling of hDectin-1 CTLD was performed using the structure's chain-A with PDB ID 2BPD (2BPD_A) as a template. Structure 2BPD_A contains 127 amino acids (117-243) of the 174 (72-244) that make up the extracellular portion of mDectin-1 and has a divergence of three amino acids, P118S, T209A and A210V in relation to the mDectin-1 sequence (ID UniProt: Q6QLQ4) (BROWN et al., 2007). The MODELLER 9.19 software (WEBB; SALI, 2016; WEBB; SALI, 2014) was used and ten models were generated for CTLD. All models were also evaluated by the ERRAT software (COLOVOS; YEATES, 1993), ProSAWeb software (WIEDERSTEIN; SIPPL, 2007), PROCHECK software (LASKOWSKI et al., 1993) and QMEAN software (BENKERT et al., 2008). The model chosen was the one that presented the best result in most of the software used in the evaluation.

The Stalk domain of hDectin-1 is formed by amino acids 66-117 and, for its modeling, the threading method implemented by the server I-Tasser (ROY et al., 2010) was used. Five models were obtained and the best was chosen based on the C-score provided by I-Tasser (ROY et al., 2010) and results from the PROCHECK software (LASKOWSKI et al., 1993), QMEAN (BENKERT et al., 2010), ERRAT (COLOVOS; YEATES, 1993) and ProSA-Web (WIEDERSTEIN; SIPPL, 2007).

The transmembrane domain of hDectin-1, formed by residues $45-65$, was modeled by homology using two molds, the structures PDB ID: 2M3E and PDB ID: 3ZJZ, both structures corresponding to transmembrane domains. Modeling with multiple molds was performed using the MODELLER 9.19 software (WEBB and SALI, 2014) and ten models were generated. The models were also evaluated by the QMEAN software (BENKERT et al., 2010), PROCHECK 
software (LASKOWSKI et al., 1993) and QMEANBrane software (STUDER et a., 2014) being chosen the model that presented the best result in the three software used in evaluation.

The modeling of the intracellular portion of hDectin-1, formed by the first 44 amino acids of the N-terminal, was performed by the ab initio method through the QUARK server (XU; ZHANG, 2013; XU; ZHANG, 2012). Five thousand models were generated for the target sequence and the five best models ranked by the QUARK server TM-score were made available (XU; ZHANG, 2012; ZHANG et al., 2004). The five models were also evaluated using the PROCHECK software (LASKOWSKI et al., 1993), QMEAN software (BENKERT et al., 2010), ERRAT software (COLOVOS; YEATES, 1993) and ProSA-Web software (WIEDERSTEIN; SIPPL, 2007) and the model chosen was the one that presented the best result in most of the software used in the evaluation.

The models obtained for each segment of the hDectin-1 structure were joined using homology modeling using the structures obtained from the previous steps as templates. The MODELLER 9.19 software (WEBB; SALI, 2014) was used for this modeling using multiple molds. Ten models were generated and all were equally evaluated using the PROCHECK software (LASKOWSKI et al., 1993), QMEAN software (BENKERT et al., 2010), ERRAT software (COLOVOS; YEATES, 1993) and ProSA-Web software (WIEDERSTEIN; SIPPL, 2007). The model chosen was the one that presented the best result in most software.

The last three residues of the C-terminal, 245F, 246S and 247M, had not yet been modeled, as these were left without mold cover. Then, modeling was done by the ab initio method, using the Rosetta software (OVCHINNIKOV et al., 2016). Initially, a fragment library was generated through Robetta server (KIM et al., 2004) and then the construction of the models by ab initio was done by the Rosetta software (OVCHINNIKOV et al., 2016). A thousand models were generated for the complete hDectin-1 structure and all were first evaluated using the ModFOLD 4.0 software (MCGUFFIN et al., 2013). The 100 best models according to the ModFOLD global quality score were reevaluated by the QMEAN software (BENKERT et al., 2010) so that the best was chosen. The best model chosen for the complete hDectin-1 structure was also evaluated by the ERRAT software (COLOVOS; YEATES, 1993) and PROCHECK software (LASKOWSKI et al., 1993).

The refinement of loops of the complete hDectin-1 structure was done using the Modeller 9.19 software (WEBB; SALI, 2014) using the loop model protocol, which allows defining the specific region of the loop to be refined in the protein structure (FISER et al., 2000).

Construction of the protein-cell membrane system

The CHARMM-GUI server was used to build the protein-cell membrane system, which provides the Membrane Builder protocol (LEE et al., 2015, WU et al., 2014).

Protein-protein docking

Protein-protein docking for hDectin-1 dimerization and protein-protein docking between the hemITAM motif present in the intracellular domain of hDectin-1 with the SH2 domains of the Syk protein were performed using the HADDOCK 2.2 server (VAN ZUNDERT et al., 2016). 


\section{Protein- $\beta$-glucans docking}

The dockings between the CTLD of hDectin- 1 and $\beta$-glucans were performed using the AutoDock Vina software (TROTT; OLSON, 2010) and the AutoDock Tolls package (HUEY; MORRIS, 2008).

Construction of the protein- $\beta$-glucan system

For the construction of the protein- $\beta$-glucan system that was subsequently subjected to DM simulation, the CHARMM-GUI server that provides the Glycan Reader \& Modeler protocol (PARK et al., 2019; PARK et al, 2017) was used.

\section{Molecular dynamics simulations}

The molecular dynamics (DM) simulations were performed using the GROMACS software (HESS et al., 2008), which implemented the CHARMM27 (SAPAY; TIELEMAN, 2011) and CHARMM36m (HUANG et al., 2017) force fields. All systems submitted to DM simulation went through a previous energy minimization stage and, after minimization, they went through equilibration stages through the GROMACS software (HESS et al., 2008).

For each DM simulation, the values of Root Mean Square Deviation (RMSD) and Root Mean Square Fluctuation (RMSF) were calculated using as reference the carbons $\alpha(\mathrm{C} \alpha)$ of the initial structure. For some DM simulations, the b-factor was also calculated using the total protein as a reference. These calculations were performed using the GROMACS software (HESS et al., 2008).

Structural visualization and analysis

The three-dimensional structures were visualized and inspected using the UCSF Chimera software (PETTERSEN et al., 2004) and PyMOL software (HOLEC; HACKEL, 2016).

The results from protein-protein docking were analyzed using the PyMOL software (HOLEC et al., 2016), which allowed to identify and describe the molecular interaction between the surface of proteins using the InterfaceResidues.py script.

To identify and quantify the hydrogen bonds and non-bonded contacts in the proteinprotein and protein-ligand interactions, the LIGPLOT software (WALLACE et al., 1995) was used.

\section{Results and discussion}

Modeling the hDectin-1 structure and molecular dynamics simulation

The complete structure of hDectin-1 was obtained through several stages of modeling and combining the use of different in silico methods. 
The CTLD region (residues 118-244) of hDectin-1 was modeled by homology, the Stalk domain (residues 66-117) was modeled by threading, the transmembrane domain (residues 45-65) was modeled by homology and the portion intracellular (residues 1-44) was modeled by ab initio. The portions modeled in different stages were joined by homology modeling, each structural fragment previously modeled was used as a mold and the last three residues of the C-terminal region (245, 246 and 247) were modeled in the last modeling step by ab initio.

The global refinement of the complete hDectin-1 structure was carried out by means of energy minimization steps and optimization of the conformations of the side chains and refinement of the loops. The evaluation of the model chosen to represent the three-dimensional conformation of the complete structure of hDectin-1 performed using the QMEAN software (BENKERT et al., 2010), ERRAT software (COLOVOS; YEATES, 1993) and PROCHECK software (LASKOWSKI et al., 1993) presented, respectively, the results Z-score -0.63, global quality factor $91.22 \%$ and $90.9 \%$ of amino acids in very favorable regions in the Ramachandran graph (LASKOWSKI et al., 1993). In general, the evaluation of the complete structure of hDectin-1 presented satisfactory results. Based on the results of the structural evaluation, the overall quality of the structure is compatible with experimentally predicted structures. The consensus of the results of the evaluation indicates that the complete structure of hDectin-1 (figure 1) determined in silico has good structural quality.

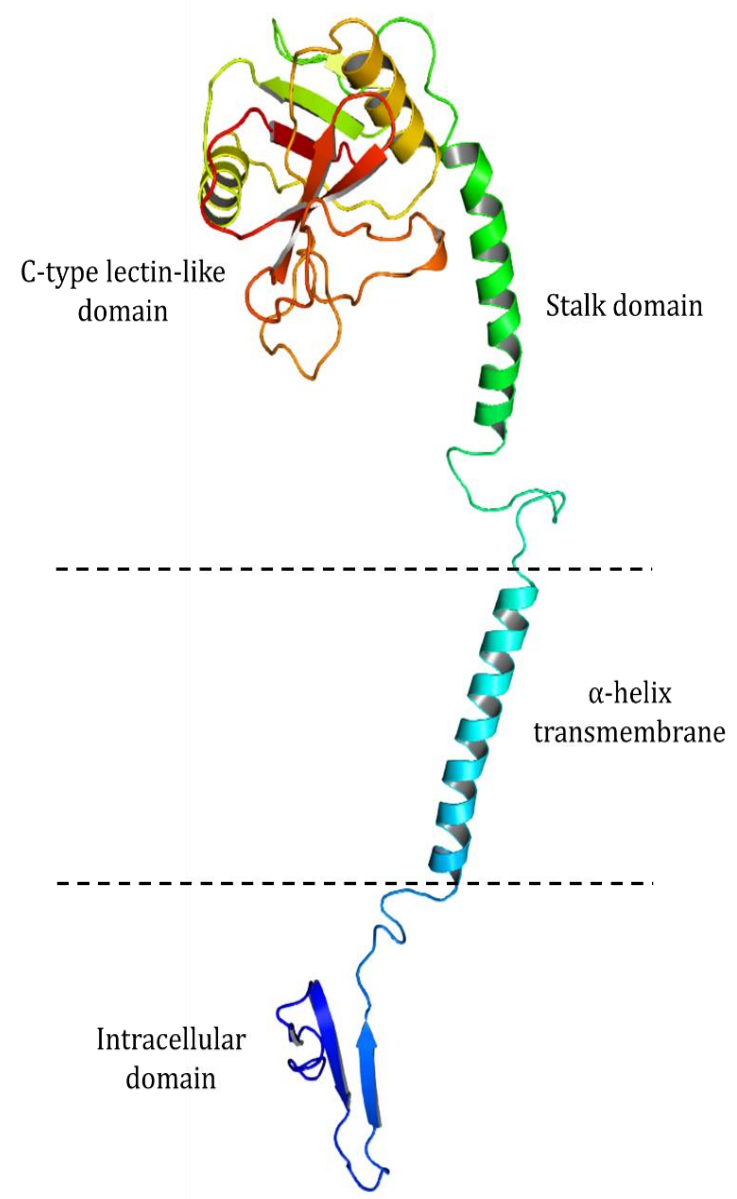

Figure 1: Complete structure of hDectin-1 modeled by combining different in silico methods. 
The protein-cell membrane system was constructed using the complete hDectin-1 structure obtained in the present study and this system was subjected to DM simulation to analyze the structural behavior of hDectin-1.

The analysis of the results of the DM simulation showed that the RMSD (figure 2A) over the three DM simulations of the complete hDectin-1 structure in the membrane were similar. The graph shows that the RMSD rises gradually during the first $45 \mathrm{~ns}$, after this simulation time the structure stabilizes considerably until the end of the $100 \mathrm{~ns}$. In the $43 \mathrm{~ns}$ to 100 ns time interval, the RMSD oscillates approximately $7 \AA$ within the range of $17 \AA$ to $23 \AA$ on the $y$ axis, without major variations.

In the RMSF graph (figure 2B) consistency in the structural variation by residues was observed in the three DM simulations; however, regions that exhibit an increase in the RMSF are observed, they are: 1-3, 11-14, 21-26, 72 -84, 99-125, 148-151, 172-177, 186-191, 200-204, 212-206 and 243-247. All of these regions correspond predominantly to loops. The region with the highest fluctuation by residues observed in the RMSF is part of the Stalk domain that connects the transmembrane domain to CTLD.

The alignment of the structures in the initial and final times of the DM simulation using the transmembrane domain as a reference showed that there was a large displacement of the extracellular and intracellular portion in relation to the position of the initial structure, justifying the high variation of the RMSF in the regions corresponding to loops and RMSD high. The structural alignment done by domains showed that, individually, the CTLD, Stalk domain, transmembrane domain and intracellular domain showed structural stability (figure 2C).

The b-factor analysis (figure 2D) confirms the location of the regions with high fluctuation by residues observed in the RMSF graph that correspond, predominantly, to loops. Regions with high fluctuations observed in the RMSF are often associated with loops because they are structures with the primary function of connecting the secondary elements and providing the necessary structural flexibility for the protein to perform its function (SUN et al., 2019; GOGUET et al., 2017; YU et al., 2017; SUBRAMANI; FLOUDAS, 2012).

Since there are differences in the function of Dectin-1 in the species studied (TAKANO et al., 2017) and, in most cases, it is not possible to work with a structure obtained by experimental methods, theoretical models of three-dimensional structures of proteins are important in several research areas to broaden the understanding of mechanisms of molecular interactions and studies for the design of structure-based drugs (KOEHLER et al., 2015; DE BREVERN, 2010; WEIL; RENNER, 2008).

From the combination of different in silico methodologies it was possible to determine a viable model for the complete structure of hDectin-1 which, until now, was unknown. The DM simulation of the complete structure inserted in the cell membrane showed that the modeled domains have structural stability, allowing them to be used in structural studies. 


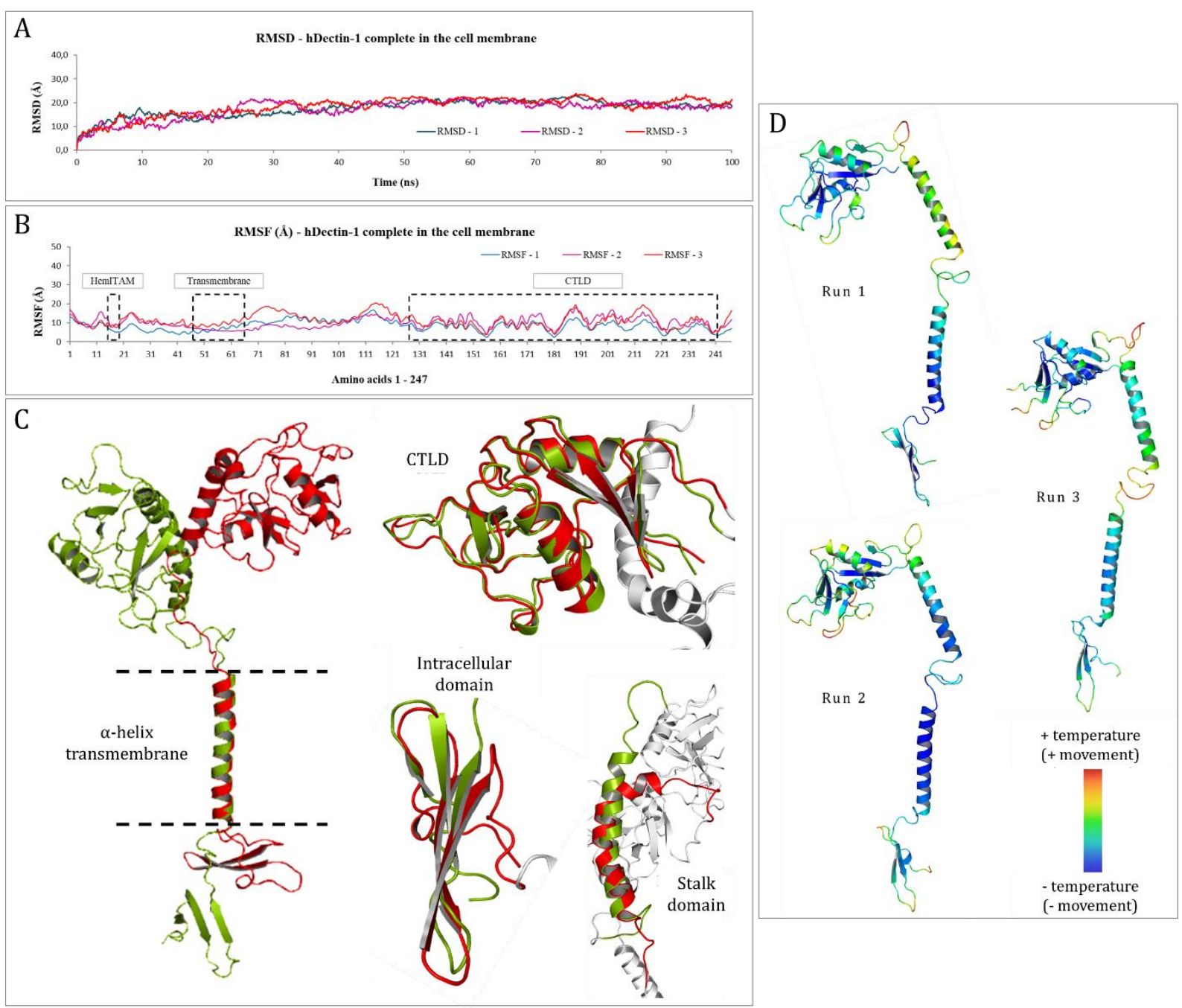

Figure 2: A) RMSD values of the coordinates of the $\mathrm{C} \alpha$ atoms as a function of the $100 \mathrm{~ns}$ triplicate simulation time interval. B) Comparison of the structural variation per amino acid of the three simulations. RMSF values of the coordinates of $\mathrm{C} \alpha$ atoms in relation to the initial structure. C) Alignment of the initial structures in $0 \mathrm{~ns}$ (green) and final in $100 \mathrm{~ns}$ (red) of the DM simulation. D) b-factors for each of the three DM simulations.

\section{Dimerization of hDectin-1}

The dimerization of hDectin- 1 was done through targeted docking. The active residues (directly involved in the protein-protein interaction) indicated to target the docking were the amino acids W141, D142, K145, D146, W149, K157, S184, R185, P186, Q187, T188, P191, L193, E195, D196, G197, S198, T199, S217, N219, C220, L232, C233 and S234 of hDectin1 corresponding to residues W140, Y141, K144, R145, 148S, K156, S183, R184, N185, Q186, S187, P190, F192, E194, D195, G196, S197, A198, L216, N218, C219, I231, C232 and N233 that make up the protein-protein interaction interface of the mDectin-1 dimer PDB ID: 2CL8 described by Brown et al. (2007).

The best dimeric conformation presented the HADDOCK score (VAN ZUNDERT et al., 2016) -138.7 and favorable conformation in relation to the positioning of the transmembrane and $\mathrm{N}$-terminal domains for insertion of the dimer in the cell membrane. 
A cell-membrane-dimer system was built and subjected to DM simulation. The alignment of the structures showed that, in the three simulations, the interaction between the surfaces of chains A and B present in the CTLD region, remained stable throughout the $50 \mathrm{~ns}$ in the three simulations. The fluctuation by residue observed in the RMSF graph showed similarity between the A and B chains of the dimers in the three DM simulations (figure 3).

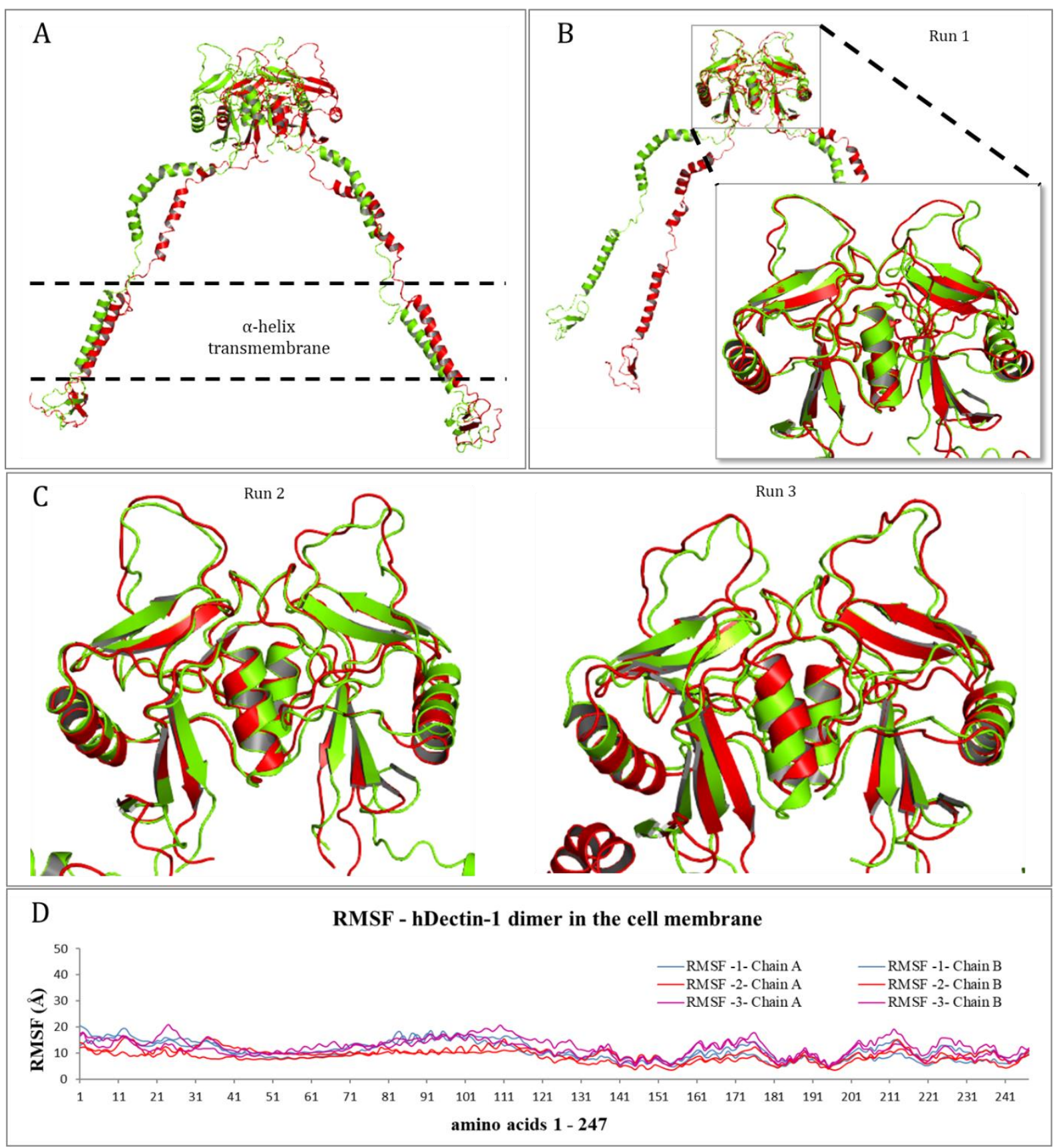

Figure 3: Dimer of the complete hDectin-1 structure. A) Alignment of the initial structure (0 ns) in green and the final structure (50 ns) in red. B) Alignment of the dimers using as reference the structure of CTLD of chain A in the simulation of DM 1. C) Alignment of dimers using as reference the structure of CTLD of chain A in simulation of DM 2 (left) and 3 (right). D) Comparison of the structural variation in relation to the initial structure per residue of the three DM simulations expressed in the RMSF graph.

The interaction analysis between the surfaces of chains A and B that form the dimer showed that residues W141, D142, K145, R146, W149, N154, S184, R185, P186, Q187, T188, 
V190, P191, L193, W194, E195, D196, G197, S198, T199, P216, S217, N2219, C220, L232, C233 and S234 composed the interaction interface between the two monomers over the DM simulation time.

The formation of cooperative oligomers by mDectin-1 CTLD induced by laminarin $\beta$ glucan is physiologically relevant in the detection of exogenous $\beta$-glucans and in the triggering of intracellular signaling (ANAYA et al., 2020; DULAL et al., 2018). Residues Y141, R145 and E243 proved to be very important in this process of oligomerization induced by laminarin (DULAL et al., 2018). Residues Y141, R145 and E243 of mDectin-1 correspond to residues D142, R146 and K244 of hDectin-1. The results obtained in the present study show that residues D142 and R146 of hDectin-1 were part of the interaction interface of the dimer throughout the three DM simulations. Thus, the dimeric conformation obtained in the present study may be one of the conformations that the hDectin- 1 protein assumes in the process of recognizing $\beta$ glucans during cooperative oligomerization.

\section{Molecular docking of $\beta$-glucans with the hDectin-1 CTLD}

Studies carried out with $\beta$-glucan laminarin showed that the amino acids W221, H223 and Y228 of mDectin-1 are important in the composition of the $\beta$-glucan recognition site that is located in a groove with hydrophobic characteristics on the protein surface (DULAL et al., 2018; BROWN et al., 2007). The analysis of the alignment made using the EMBOSS Needle software (LI et al., 2015) between the sequences of mDectin-1 and hDectin-1 showed that the region of the $\beta$-glucan recognition site described by Brown et al. (2007) and Dulal et al. (2018) for mDectin-1 is conserved in hDectin-1. The region corresponding to the amino acids W221, H223 and Y228 of mDectin-1 is W222, H224 and Y229 in hDectin-1.

The prediction of binding sites made using the FTSite software (NGAN et al., 2011) in hDectin-1 CTLD, pointed out residues T210, W222, H224, Y229, D230 and Q231 as potential active residues in a binding site, with W (221 L 222), H (223 ए 224) and Y (228 L 229) already described as active residues in laminarin recognition (BROWN et al., 2007; DULAL et al., 2018). Thus, the region of residues T210, W222, H224, Y229, D230 and Q231 of hDectin1 was used as a possible recognition site for $\beta$-glucans to perform docking with $\beta$-glucans in the hDectin-1 CTLD in monomeric and dimeric conformation.

The $\beta$-glucans experimentally characterized by interacting with Dectin- 1 chosen for docking are Laminarin, reported as agonist and antagonist (SMITH et al., 2018; BROWN et al., 2007; PALMA et al., 2006); Zymosan, agonist (KUMAR et al., 2015; BROWN et al., 2007; PALMA et al., 2006), Scleroglucan, agonist (ZHAO et al., 2016) and Sizofiran, agonist (GOODRIDGE et al., 2009; ADACHI et al., 2004).

The docking generated ten structures in different positions (pose) ranked by the energy score of the connections in $\mathrm{kcal} / \mathrm{mol}$. The pose with the best energy score was chosen between the CTLD of hDectin-1 and Laminarin, Zymosan, Scleroglucan and Sizofiran being, respectively, $-5.4,-3.7,-5.1$ and $-5.8 \mathrm{kcal} / \mathrm{mol}$.

DM simulations were performed for each complex formed by $\beta$-glucans and CTLD in dimeric and monomeric conformation. The alignment of the initial and final structures showed that each of the $\beta$-glucans interacted with the CTLD site for a certain time. Coordinate files were extracted from the CTLD / $\beta$-glucan complexes every $1 \mathrm{~ns}$ of the DM simulation to check 
when each $\beta$-glucan stopped interacting with the site where it was originally docked. Even both complexes (monomer- $\beta$-glucan and dimer- $\beta$-glucan) presenting the same amount of hydrogen bonds and non-bonded contacts, the DM simulations showed that the interaction time between the $\beta$-glucans and the CTLD monomer is less than the time of interaction with the dimer (table 1).

Table 1 - Time of interaction of $\beta$-glucans with the recognition site present in the CTLD of hDectin-1 in the monomer and in the dimer and amount of interactions between the $\beta$-glucans and site in the complexes obtained by docking.

\begin{tabular}{cccc}
\hline Monomer / $\beta$-glucano & $\begin{array}{c}\mathbf{N}^{\mathbf{0}} \text { hydrogen } \\
\text { bonds }\end{array}$ & $\begin{array}{c}\mathbf{N}^{\mathbf{0}} \text { non-bonded } \\
\text { contacts }\end{array}$ & Time on the site \\
\hline CTLD/ Zymosan & 6 & 17 & $1 \mathrm{~ns}$ \\
CTLD/ Laminarin & 4 & 42 & $1 \mathrm{~ns}$ \\
CTLD/ Scleroglucan & 9 & 58 & $3 \mathrm{~ns}$ \\
CTLD/ Sizofiran & 13 & 54 & $17 \mathrm{~ns}$ \\
\hline Dimer / $\beta$-glucano & $\mathbf{N}^{\mathbf{0}}$ hydrogen & $\mathbf{N}^{\mathbf{0}}$ non-bonded & Time on the site \\
\hline CTLD/ Zymosan & bonds & contacts & $5 \mathrm{~ns}$ \\
CTLD/ Laminarin & 6 & 17 & $25 \mathrm{~ns}$ \\
CTLD/ Scleroglucan & 4 & 42 & $10 \mathrm{~ns}$ \\
CTLD/ Sizofiran & 9 & 58 & $40 \mathrm{~ns}$ \\
\hline
\end{tabular}

The b-factor and RMSF analyses showed that there was a greater fluctuation of the residues located in the region between 210-217 in comparison to the adjacent amino acids. This event observed in region 210-217 occurred in all DM simulations of the CTLD- $\beta$-glucans and dimer- $\beta$-glucans complexes. These residues are located in a loop that forms part of the groove with hydrophobic characteristics that compose the $\beta$-glucan recognition site in the CTLD of hDectin-1 (figure 4).

The studies by Brown et al. (2007) and Dulal et al. (2018) showed that the amino acids W221, H223 and Y228 present in the CTLD of mDectin-1 make up the main recognition site for $\beta$-glucan laminarin. In the present study, it was shown that the amino acids W222, H224 and Y229 present in the hDectin-1 CTLD have the same physical-chemical characteristics and possible fundamental role for the recognition of some $\beta$-glucans. In addition to the amino acids W222, H224 and Y229, the results obtained through the MD simulations of the hDectin-1 CTLD in complex with $\beta$-glucans showed that, the amino acids T210, A211, T212, Q213, E214, N215, P216 and S217, located in the CTLD loop, proved to be important components of the $\beta$ glucan recognition site. The loop composed of these amino acids showed greater flexibility during the DM simulations when compared to the other regions that make up the hDectin-1 CTLD, suggesting that this may be an important factor in the process of interaction with $\beta$ glucans (figure 4). 


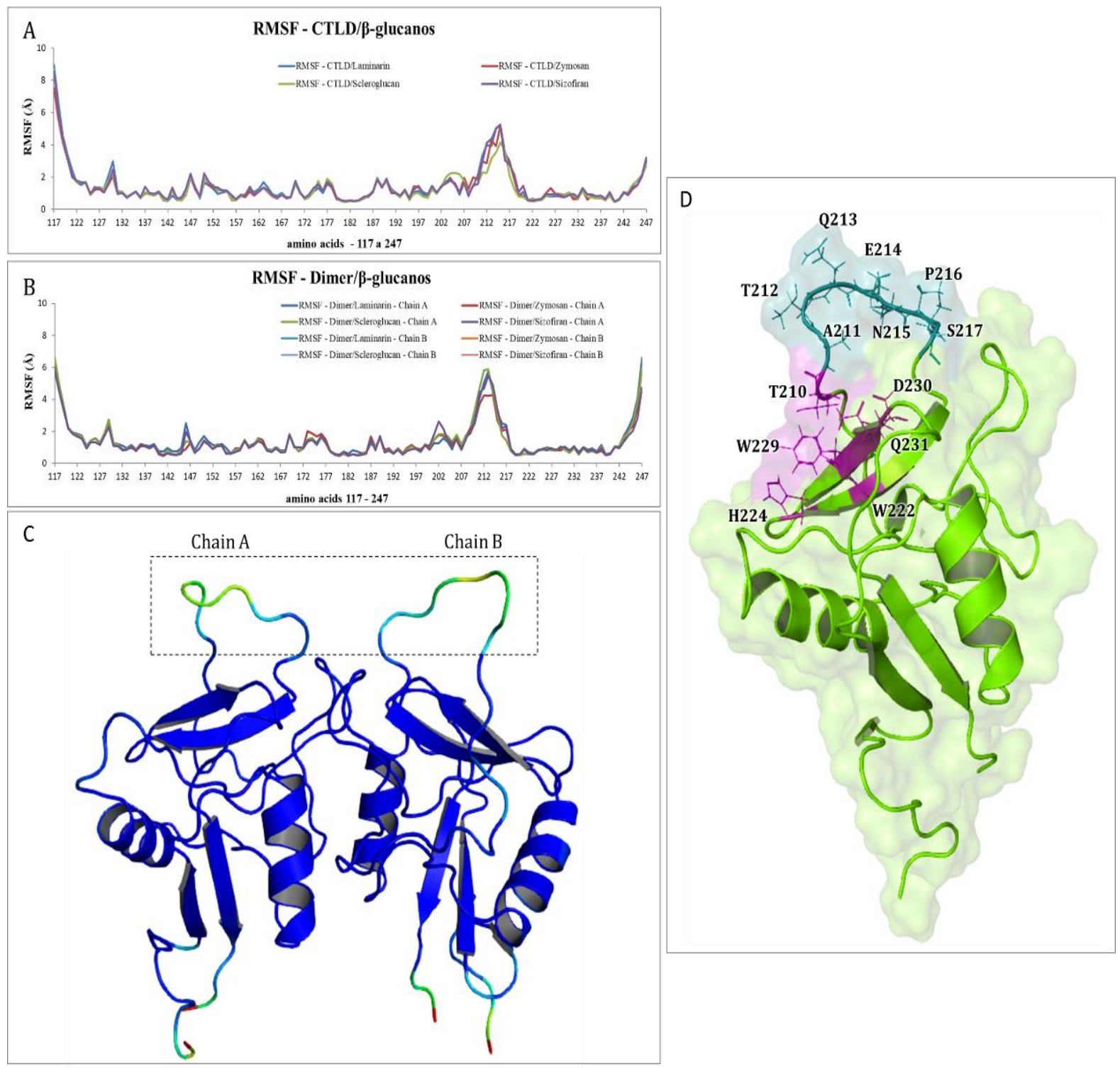

Figure 4: A) RMSF of the coordinates of the $\mathrm{C} \alpha$ atoms in relation to the initial structure of the CTLD in monomeric conformation during the simulation of DM in complex with $\beta$-glucans. Highlight for the region of residues 210 217 , which are located close to the $\beta$-glucan recognition site, which showed greater movement in relation to the other residues. B) RMSF of the coordinates of $\mathrm{C} \alpha$ atoms in relation to the initial structure of the CTLD in dimer conformation during the simulation of DM in complex with $\beta$-glucans. Highlight for the region of residues 210217 , which are located close to the $\beta$-glucan recognition site, which showed greater movement compared to other residues. C) Graphical representation of the b-factor obtained for the structure of the CTLD Dimer in complex with $\beta$-glucans in relation to the initial structure of the DM simulations. The color spectrum ranges from blue (regions with low movement) to red (regions with high movement). D) hDectin-1 CTLD monomer highlighting the residues that make up the $\beta$-glucan recognition site (purple) and the region of residues 210-217 that are located close to the site (blue).

The results obtained through the analysis of the DM simulations showed that the CTLD interaction in dimer conformation was possibly more favorable for the recognition of $\beta$ glucans. The same results suggest that each type of $\beta$-glucan may have a specific location for its recognition in the hDectin-1 CTLD and it is possible that the site used as a reference in the present study is more specialized in recognizing the $\beta$-glucans Laminarin and Sizofiran, as they remained longer interacting with the CTLD recognition site in dimer conformation when compared to Zymosan and Scleroglucan. 
This result corroborates the information described by Drickamer (1999), where it was observed that receptor proteins with CTLD make up a very conserved family, and these CTLDs interact through several different surfaces, exposing their sites in different orientations to improve the efficiency of recognition of specific molecular targets. It also corroborates the results obtained by Anaya et al. (2020), where it was demonstrated that Dectin-1 oligomerization possibly occurs depending on the type and quantity of $\beta$-glucans available on the cell surface. It was also described by the authors that, in resting cells, Dectin- 1 was found, predominantly, in a monomeric state.

\section{Molecular docking of the hemITAM motif with Syk}

Post-translational modifications, such as phosphorylation of the amino acid tyrosine, are chemical changes that occur after protein synthesis and constitute an important aspect of protein biology (LIU et al., 2016). Thus, preceding the docking stage of the hDectin-1 hemITAM motif with Syk, a phosphate group $\left(\mathrm{PO}_{4}{ }^{3-}\right)$ was added to the tyrosine located at position 15 (pTyr15) present in the hDectin-1 hemITAM motif using the PyMOL software (WARNECKE et al., 2014).

For docking with the hDectin-1 hemITAM motif, the three-dimensional structure of the human Syk SH2-1 and SH2-2 domains, which is deposited in the PDB with ID 1A81, was used. This structure, that comprises the SH2-1 domain, SH2-2 domain and Interdomain A, was determined by $3 \AA$ resolution X-ray diffraction crystallography by Fütterer et al. (1998). Six complexes formed by SH2 domains (Chain A, Chain C, Chain E, Chain G, Chain I, Chain K) and ITAM motifs from CD3E proteins (Chain B, Chain D, Chain F, Chain H, Chain J, Chain L).

The interaction analysis between Syk's SH2 domains and ITAM motifs present in the coordinate file with PDB ID: 1A81 of all six SH2-ITAM complexes identified the active residues in the formation of these complexes. These residues were used to direct the docking between the SH2 domains and the hemITAM motif of hDectin-1.

Active residues R22, E23, H62, H63, Y64, T65, I76, A77, G78, G79, H92, D97, G98, L99, V100, R175, K212, L214, H215, Y216, I228, P229, E230, G231, K232, Y244, K247, D249, G250, L251 and L252 identified in the interaction of SH2 domains with ITAMs of the PDB ID 1A81 complex and residues A10, N19, Q43, S44, R45, Y47, L48, G49, G50, F51, W168, L237, W238, Q239, V241, E242 and S245 predicted by the FTSite software (NGAN et al., 2011), all present in the SH2 domains of Syk were used to direct the docking with the pTyr15, 16T, 17Q and 18L residues present in the hemITAM motif of hDectin-1.

The hDectin-1-Syk complex chosen presented the HADDOCK score (VAN ZUNDERT et al., 2016) of -153.8, which is the best score obtained in docking. The hDectin-1Syk complex also presented a favorable conformation for insertion into the cell membrane.

A system was constructed with the $\mathrm{SH} 2$ domains of Syk in complex with the intracellular portion and transmembrane domain of hDectin-1 inserted in the cell membrane that was submitted to DM simulation.

The analysis of the RMSD graph (figure 5A) of the $200 \mathrm{~ns}$ triplicate performed shows that, although the complex obtained through molecular docking is composed of specific domains of two different proteins obtained by different methodologies, the structures reach a 
good state of stability conformational throughout the DM simulation. The RMSF graph corresponding to part of the hDectin-1 protein shows that one of the regions with the least fluctuation is the region corresponding to the hemITAM motif (figure 5B).

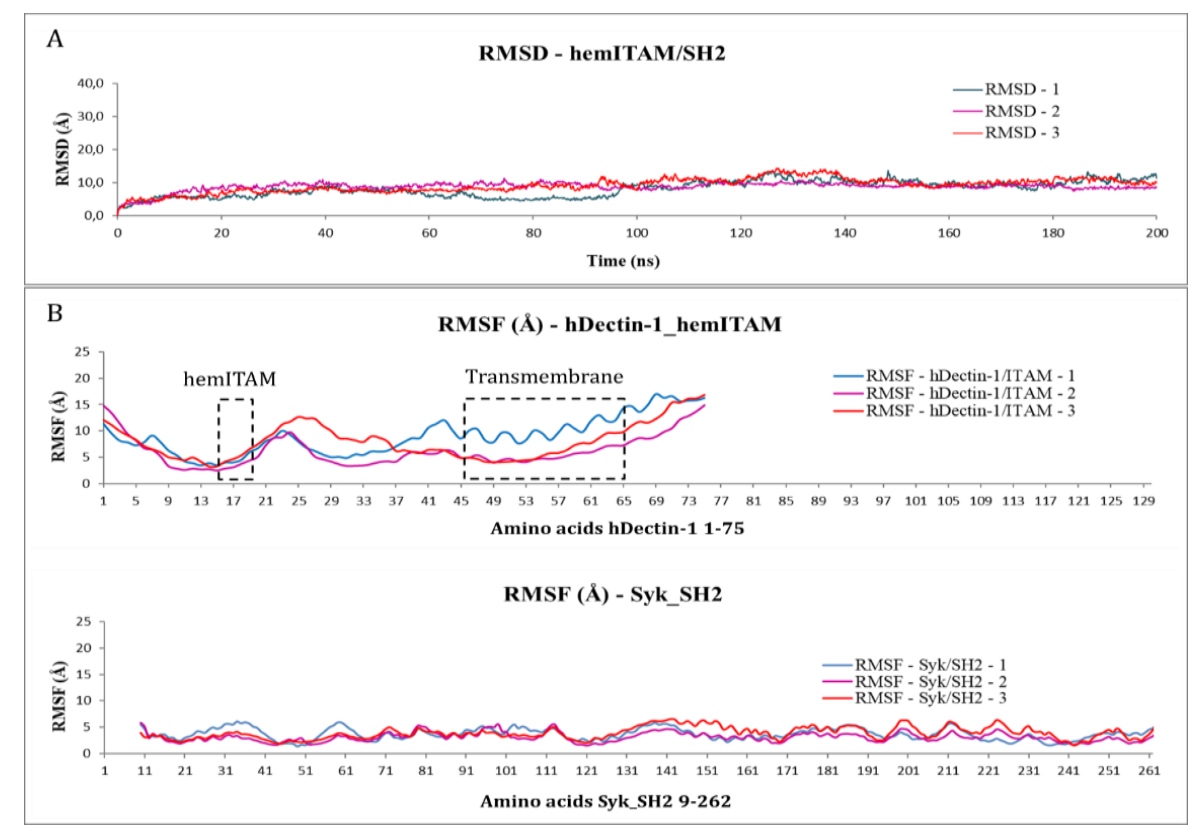

Figure 5: A) DM simulation trajectory of the hemITAM-SH2 complex. RMSD values of the coordinates of C $\alpha$ atoms as a function of the $200 \mathrm{~ns}$ triplicate simulation time interval. B) Comparison of the structural variation per amino acid of the three simulations. RMSF values of the coordinates of $\mathrm{C} \alpha$ atoms in relation to the initial structure of part of the structure of hDectin-1 and Syk. The black dotted rectangles highlight the regions corresponding to the hemITAM motif and transmembrane domain of hDectin-1.

Fütterer et al. (1998) point out that Syk's two SH2 domains exhibit remarkable structural flexibility, suggesting that Syk can adapt to the recognition of a wide variety of structures containing ITAM motifs with amino acid sequences of varying sizes. Analysis of the RMSF of the structure of the SH2 domains of Syk in complex with the hemITAM motif of hDectin-1 showed that the fluctuation per residue was lower than that observed for the intracellular portion of hDectin-1. Thus, it is possible to infer that, in complex with the hemITAM motif, the $\mathrm{SH} 2$ domains remain less flexible, making the protein-protein complex stable for the subsequent activation of other proteins in the signaling cascade.

The interface area between the structures also showed that the complex had stability during the DM simulation. Initially, the hDectin-1 interface was $1028 \AA^{2}$ and Syk $946 \AA^{2}$, at $100 \mathrm{~ns}$ hDectin-1 decreased to $733 \AA^{2}$ and Syk $623 \AA^{2}$, at the end of $200 \mathrm{~ns}$ the interface area increased again, hDectin-1 went to $831 \AA^{2}$ and Syk $810 \AA^{2}$. The number of interacting residues, hydrogen bonds, non-bonded contacts and salt bridges between the two proteins remained similar between the $100 \mathrm{~ns}$ and $200 \mathrm{~ns}$ of DM simulation, indicating that the atomic interactions between the two proteins stabilized after $100 \mathrm{~ns}$ (figure 6A).

The interaction analysis between the hDectin-1 hemITAM motif and Syk SH2 domains carried out using DM simulations showed that the pTyr15 residues of hDectin-1 and R45 and N46 of the Syk SH2-1 motif (Figure 6B) can be fundamental for this molecular interaction and subsequent cell signaling. The stable interaction observed in the results presented here of the hemITAM motif interacting only with the SH2-1 domain, leaving SH2-2 free, corroborates the hypothesis already raised in other studies, which suggest that Syk builds 
a bridge over two monophosphorylated molecules of Dectin -1 (BROWN, 2006; FULLER et al., 2007; GOODRIDGE et al., 2009; ROGERS et al., 2005).

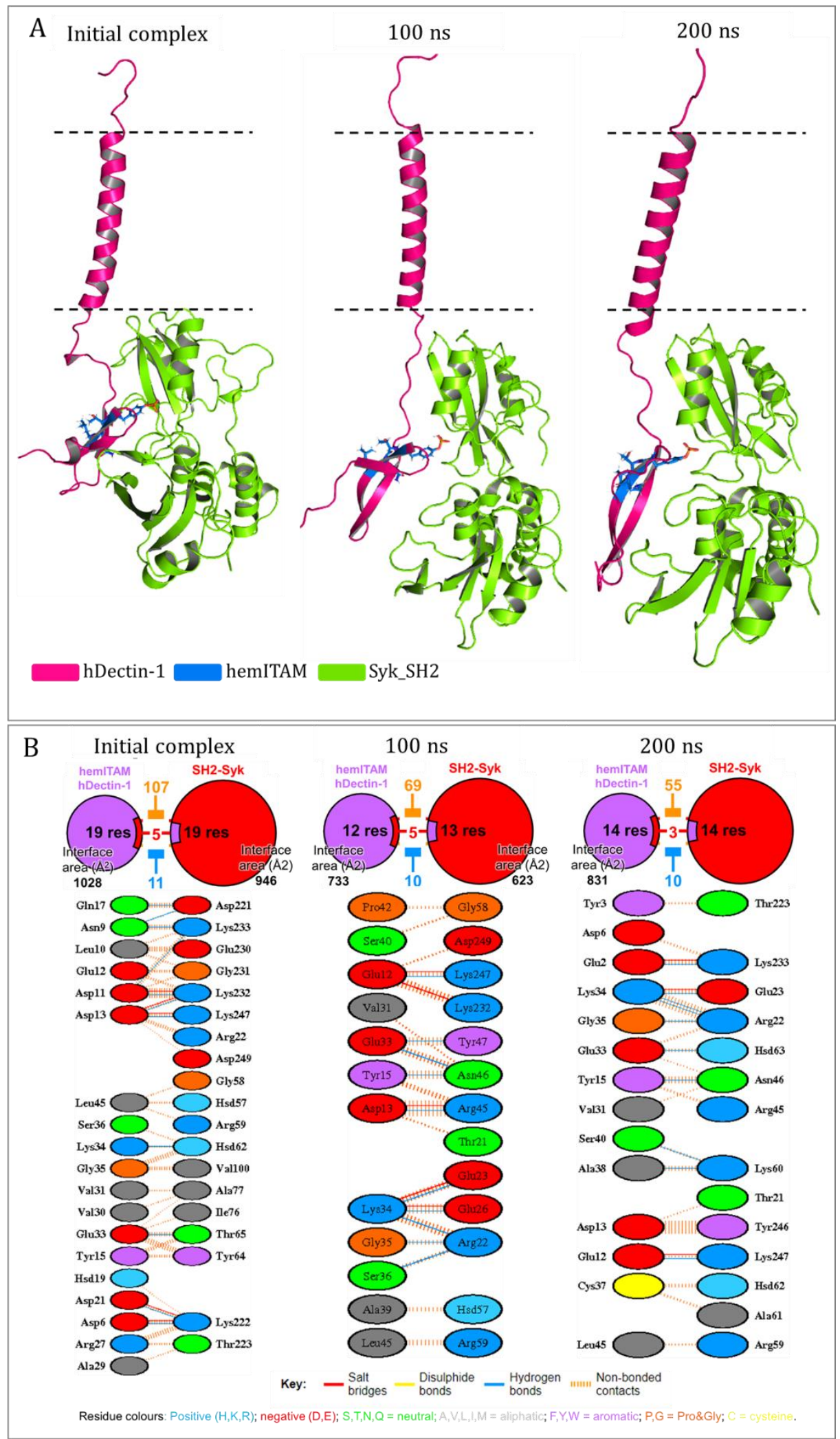

Figure 6: Structural behavior over time of the DM simulation of the hemITAM-SH2 complex. A) HemITAMSH2 complex. HDectin-1 structure in pink, hemITAM motif in blue and SH2 domains in green. Initial structure (on the left), $100 \mathrm{~ns}$ (in the center) and $200 \mathrm{~ns}$ (on the right). B) Diagram of the interactions between the hemITAM motif and SH2-1 domain with the initial structure of the hemITAM-SH2 complex, at $100 \mathrm{~ns}$ and $200 \mathrm{~ns}$. 
This result highlights the importance of the interaction between these amino acids of the hemITAM motif of hDectin-1 and Syk SH2-1 and provides important information regarding the cell signaling mechanism for the initiation of immune response initiated by hDectin-1 and triggered by Syk. The residues identified in the interaction of hDectin-1 with Syk described here can be used as a molecular target to amplify or inhibit this response, representing potential targets for the development of therapeutic strategies mediated by pharmacological interventions.

Initially, it was believed that two phosphorylated tyrosine residues were needed in the composition of a single peptide chain (as in a classic ITAM motif) for Syk recruitment and activation. However, some C-type lectin family receptors, including Dectin-1 and CLEC2, are able to activate Syk, although these receptors have only a single hemITAM motif in their cytoplasmic portion (ROGERS et al., 2005). Some studies also suggest that Syk is selfsufficient and can phosphorylate tyrosine from ITAMs or tyrosine from a hemITAM (MÓCSAI et al., 2010; ROGERS et al., 2005; TURNER et al., 2000).

The cooperative oligomerization that occurs through the Dectin-1 CTLD induced by $\beta$-glucans probably precedes the grouping of these receptors to form regions of high density of hemITAMs on the internal cell surface, facilitating the subsequent binding with the Syk protein. Although further structural information about these events is still lacking, oligomers of extracellular domains of Dectin-1 molecules on the cell surface may increase the chance of binding activities to the Syk kinase, more than that achieved by only receptor monomers (DULAL et al., 2018).

\section{Conclusion}

The results obtained in the present study expanded the structural knowledge of hDectin-1. To date, no study has experimentally determined the structure of hDectin-1, so the theoretical model presented here is of great value for the development of studies to expand knowledge about its function in the recognition of $\beta$-glucans, modulation of immune responses and it can be used as a template for the structural determination of other proteins in the lectin family, expanding the knowledge about their performance in the various cell signaling processes.

\section{Funding}

This work was supported by a CAPES Sponsorship.

\section{References}

ADACHI, Yoshiyuki et al. Characterization of $\beta$-glucan recognition site on C-type lectin, dectin 1. Infection and immunity, v. 72, n. 7, p. 4159-4171, 2004.

ALSAADI, Entedar AJ.; JONES, Ian M. Membrane binding proteins of coronaviruses. Future Virology, v. 14, n. 4, p. 275-286, 2019.

ANAYA, Eduardo U. et al. Dectin-1 Molecular Aggregation and Signaling is Sensitive to $\beta$ - 
Glucan Structure and Glucan Exposure on Candida albicans Cell Walls. bioRxiv, p. 824995, 2020.

BALDWIN, Katherine T. et al. Neuroinflammation triggered by $\beta$-glucan/dectin- 1 signaling enables CNS axon regeneration. Proceedings of the National Academy of Sciences, v. 112, n. 8, p. 2581-2586, 2015.

BAO, Hongkun et al. Lentinan produces a robust antidepressant-like effect via enhancing the prefrontal Dectin-1/AMPA receptor signaling pathway. Behavioural brain research, v. 317, p. 263-271, 2017.

BATBAYAR, Sainkhuu; LEE, Dong Hee; KIM, Ha Won. Immunomodulation of fungal $\beta$ glucan in host defense signaling by dectin-1. Biomolecules \& Therapeutics, v. 20, n. 5, p. 433, 2012.

BENKERT, Pascal; TOSATTO, Silvio CE; SCHOMBURG, Dietmar. QMEAN: A comprehensive scoring function for model quality assessment. Proteins: Structure, Function, and Bioinformatics, v. 71, n. 1, p. 261-277, 2008.

BROWN, Gordon D. Dectin-1: a signalling non-TLR pattern-recognition receptor. Nature reviews. Immunology, v. 6, n. 1, p. 33, 2006.

BROWN, Gordon D. Innate antifungal immunity: the key role of phagocytes. Annual review of immunology, v. 29, p. 1-21, 2011.

BROWN, Gordon D.; GORDON, Siamon. A new receptor for $\beta$-glucans. Nature, v. 413, n. 6851, p. 36-37, 2001.

BROWN, James et al. Structure of the fungal $\beta$-glucan-binding immune receptor dectin-1: Implications for function. Protein Science, v. 16, n. 6, p. 1042-1052, 2007.

BRYANT, Clare E. et al. International union of basic and clinical pharmacology. XCVI. Pattern recognition receptors in health and disease. Pharmacological Reviews, v. 67, n. 2, p. 462-504, 2015 .

CASTOLDI, Angela et al. Dectin-1 Activation Exacerbates Obesity and Insulin Resistance in the Absence of MyD88. Cell Reports, v. 19, n. 11, p. 2272-2288, 2017.

CHEN, Jintong et al. Dectin-1-activated dendritic cells: A potent Th9 cell inducer for tumor immunotherapy. Oncoimmunology, v. 5, n. 11, p. e1238558, 2016.

CHIBA, Shiho et al. Recognition of tumor cells by Dectin-1 orchestrates innate immune cells for anti-tumor responses. Elife, v. 3, p. e04177, 2014.

CHIFFOLEAU, Elise. C-type lectin-like receptors as emerging orchestrators of sterile inflammation represent potential therapeutic targets. Frontiers in Immunology, v. 9, p. 227, 2018.

COLOVOS, Chris; YEATES, Todd O. Verification of protein structures: patterns of nonbonded atomic interactions. Protein science, v. 2, n. 9, p. 1511-1519, 1993. 
DALEY, Donnele et al. Dectin 1 activation on macrophages by galectin 9 promotes pancreatic carcinoma and peritumoral immune tolerance. Nature Medicine, v. 23, n. 5, p. 556-567, 2017.

DE ARAÚJO, Maria Elisa Melo Branco et al. Enzymatic de-glycosylation of rutin improves its antioxidant and antiproliferative activities. Food chemistry, v. 141, n. 1, p. 266-273, 2013.

DE BREVERN, Alexandre G. 3D structural models of transmembrane proteins. In: Membrane Protein Structure Determination. Humana Press, Totowa, NJ, 2010. p. 387-401.

DRICKAMER, Kurt. C-type lectin-like domains. Current opinion in structural biology, v. 9, n. 5, p. 585-590, 1999.

DULAL, Hari P. et al. $\beta$-Glucan-induced cooperative oligomerization of Dectin-1 C-type lectin-like domain. Glycobiology, v. 28, n. 8, p. 612-623, 2018.

ELSORI, Deena $\mathrm{H}$. et al. Protein kinase $\mathrm{C} \delta$ is a critical component of Dectin- 1 signaling in primary human monocytes. Journal of leukocyte biology, v. 90, n. 3, p. 599-611, 2011.

FISER, András et al. Modeling of loops in protein structures. Protein science, v. 9, n. 9, p. 1753-1773, 2000.

FULLER, Gemma LJ et al. The C-type lectin receptors CLEC-2 and Dectin-1, but not DCSIGN, signal via a novel YXXL-dependent signaling cascade. Journal of Biological Chemistry, v. 282, n. 17, p. 12397-12409, 2007.

FÜTTERER, Klaus et al. Structural basis for Syk tyrosine kinase ubiquity in signal transduction pathways revealed by the crystal structure of its regulatory $\mathrm{SH} 2$ domains bound to a dually phosphorylated ITAM peptide. Journal of molecular biology, v. 281, n. 3, p. 523-537, 1998.

GOGUET, Matthieu et al. In silico analysis of Glanzmann variants of Calf- 1 domain of $\alpha$ IIb $\beta$ 3 integrin revealed dynamic allosteric effect. Scientific reports, v. 7, n. 1, p. 1-13, 2017.

GOODRIDGE, Helen S. et al. Activation of the innate immune receptor Dectin-1 upon formation of a "phagocytic synapse". Nature, v. 472, n. 7344, p. 471, 2011.

GOODRIDGE, Helen S.; WOLF, Andrea J.; UNDERHILL, David M. $\beta$-glucan recognition by the innate immune system. Immunological reviews, v. 230, n. 1, p. 38-50, 2009.

HESS, Berk et al. GROMACS 4: algorithms for highly efficient, load-balanced, and scalable molecular simulation. Journal of chemical theory and computation, v. 4, n. 3, p. 435-447, 2008.

HOLEC, P. V.; HACKEL, B. J. PyMOL360: Multi-user gamepad control of molecular visualization software. Journal of Computational Chemistry, v. 37, n. 30, p. 2667-2669, 2016.

HOLLMIG, S. Tyler; ARIIZUMI, Kiyoshi; CRUZ JR, Ponciano D. Recognition of non-selfpolysaccharides by C-type lectin receptors dectin-1 and dectin-2. Glycobiology, v. 19, n. 6, p. 568-575, 2009. 
HUANG, Jing et al. CHARMM36m: an improved force field for folded and intrinsically disordered proteins. Nature methods, v. 14, n. 1, p. 71-73, 2017.

HUEY, Ruth; MORRIS, Garrett M. Using AutoDock 4 with AutoDocktools: a tutorial. The Scripps Research Institute, USA, p. 54-56, 2008.

JO, Sunhwan; KIM, Taehoon; IM, Wonpil. Automated builder and database of protein/membrane complexes for molecular dynamics simulations. PloS one, v. 2, n. 9, p. e880, 2007.

KERRIGAN, Ann M.; BROWN, Gordon D. C-type lectins and phagocytosis. Immunobiology, v. 214, n. 7, p. 562-575, 2009.

KIM, David E.; CHIVIAN, Dylan; BAKER, David. Protein structure prediction and analysis using the Robetta server. Nucleic acids research, v. 32, n. suppl_2, p. W526-W531, 2004.

KIMURA, Yukihiro et al. Dectin-1-mediated signaling leads to characteristic gene expressions and cytokine secretion via spleen tyrosine kinase (Syk) in rat mast cells. Journal of Biological Chemistry, v. 289, n. 45, p. 31565-31575, 2014.

KOEHLER LEMAN, Julia; ULMSCHNEIDER, Martin B.; GRAY, Jeffrey J. Computational modeling of membrane proteins. Proteins: Structure, Function, and Bioinformatics, v. 83, n. 1 , p. 1-24, 2015.

KUMAR, Deepak Kumar Vijaya; EIMER, William A.; RAMAKRISHNAN, Sreejith. Specificity of Toll-like receptor 2 and Dectin-1 signaling in CNS macrophages. Journal of Neuroscience, v. 35, n. 49, p. 16015-16017, 2015.

LASKOWSKI, Roman A. et al. PROCHECK: a program to check the stereochemical quality of protein structures. Journal of applied crystallography, v. 26, n. 2, p. 283-291, 1993.

LEE, Jumin et al. CHARMM-GUI input generator for NAMD, GROMACS, AMBER, OpenMM, and CHARMM/OpenMM simulations using the CHARMM36 additive force field. Journal of chemical theory and computation, v. 12, n. 1, p. 405-413, 2015.

LEGENTIL, Laurent et al. Molecular interactions of $\beta$ - $(1 \rightarrow 3)$-glucans with their receptors. Molecules, v. 20, n. 6, p. 9745-9766, 2015.

LI, Weizhong et al. The EMBL-EBI bioinformatics web and programmatic tools framework. Nucleic acids research, v. 43, n. W1, p. W580-W584, 2015.

LIU, Juan; QIAN, Cheng; CAO, Xuetao. Post-translational modification control of innate immunity. Immunity, v. 45, n. 1, p. 15-30, 2016.

MARAKALALA, Mohlopheni J.; KERRIGAN, Ann M.; BROWN, Gordon D. Dectin-1: a role in antifungal defense and consequences of genetic polymorphisms in humans. Mammalian Genome, v. 22, n. 1-2, p. 55-65, 2011.

MCGUFFIN, L. J.; BUENAVISTA, M. T.; ROCHE, D. B. The ModFOLD4 server for the quality assessment of 3D protein models. Nucleic Acids Research, v. 41, n. Web Server issue, 
p. W368-372, 2013.

MÓCSAI, Attila; RULAND, Jürgen; TYBULEWICZ, Victor LJ. The SYK tyrosine kinase: a crucial player in diverse biological functions. Nature Reviews Immunology, v. 10, n. 6, p. $387,2010$.

MONTEIRO, João T.; LEPENIES, Bernd. Myeloid C-Type Lectin Receptors in Viral Recognition and Antiviral Immunity. Viruses, v. 9, n. 3, p. 59, 2017.

NGAN, Chi-Ho et al. FTSite: high accuracy detection of ligand binding sites on unbound protein structures. Bioinformatics, v. 28, n. 2, p. 286-287, 2011.

OVCHINNIKOV, Sergey et al. Improved de novo structure prediction in CASP11 by incorporating coevolution information into Rosetta. Proteins: Structure, Function, and Bioinformatics, v. 84, n. S1, p. 67-75, 2016.

PALMA, Angelina S. et al. Ligands for the $\beta$-glucan receptor, Dectin-1, assigned using "designer" microarrays of oligosaccharide probes (neoglycolipids) generated from glucan polysaccharides. Journal of Biological Chemistry, v. 281, n. 9, p. 5771-5779, 2006.

PARK, Sang-Jun et al. CHARMM-GUI glycan modeler for modeling and simulation of carbohydrates and glycoconjugates. Glycobiology, v. 29, n. 4, p. 320-331, 2019.

PARK, Sang-Jun et al. Glycan Reader is improved to recognize most sugar types and chemical modifications in the Protein Data Bank. Bioinformatics, v. 33, n. 19, p. 3051-3057, 2017.

PETREY, Donald et al. Template-based prediction of protein function. Current opinion in structural biology, v. 32, p. 33-38, 2015.

PETREY, Donald; HONIG, Barry. Structural bioinformatics of the interactome. Annual review of biophysics, v. 43, p.193, 2014.

PETTERSEN EF, GODDARD TD, HUANG CC, COUCH GS, GREENBLATT DM, MENG EC, FERRIN TE. UCSF Chimera-- a visualization system for exploratory research and analysis. J Comput Chem. 2004 Oct;25(13):1605-12.

PRYOR JR, Edward E.; WIENER, Michael C. A critical evaluation of in silico methods for detection of membrane protein intrinsic disorder. Biophysical journal, v. 106, n. 8, p. 16381649, 2014.

REDELINGHUYS, Pierre; BROWN, Gordon D. Inhibitory C-type lectin receptors in myeloid cells. Immunology letters, v. 136, n. 1, p. 1-12, 2011.

ROGERS, Neil C. et al. Syk-dependent cytokine induction by Dectin-1 reveals a novel pattern recognition pathway for $\mathrm{C}$ type lectins. Immunity, v. 22, n. 4, p. 507-517, 2005.

ROY, Ambrish; KUCUKURAL, Alper; ZHANG, Yang. I-TASSER: a unified platform for automated protein structure and function prediction. Nature protocols, v. 5, n. 4, p. 725, 2010.

RUTHES, Andrea Caroline; SMIDERLE, Fhernanda Ribeiro; IACOMINI, Marcello. D- 
Glucans from edible mushrooms: A review on the extraction, purification and chemical characterization approaches. Carbohydrate polymers, v. 117, p. 753-761, 2015.

SAPAY, Nicolas; TIELEMAN, D. Peter. Combination of the CHARMM27 force field with united-atom lipid force fields. Journal of computational chemistry, v. 32, n. 7, p. 1400-1410, 2011.

SMITH, Alyson J. et al. Immunoregulatory activity of the natural product laminarin varies widely as a result of its physical properties. The Journal of Immunology, v. 200, n. 2, p. 788799, 2018.

STUDER, Gabriel; BIASINI, Marco; SCHWEDE, Torsten. Assessing the local structural quality of transmembrane protein models using statistical potentials (QMEANBrane). Bioinformatics, v. 30, n. 17, p. i505-i511, 2014.

SUBRAMANI, A.; FLOUDAS, C. A. Structure prediction of loops with fixed and flexible stems. The Journal of Physical Chemistry B, v. 116, n. 23, p. 6670-6682, 2012.

SUN, Zhoutong et al. Utility of B-factors in protein science: interpreting rigidity, flexibility, and internal motion and engineering thermostability. Chemical reviews, v. 119, n. 3, p. 16261665, 2019.

SYNYTSYA, Andriy; NOVAK, Miroslav. Structural analysis of glucans. Annals of translational medicine, v. 2, n. 2, 2014.

SYNYTSYA, Andriy; NOVÁK, Miroslav. Structural diversity of fungal glucans. Carbohydrate polymers, v. 92, n. 1, p. 792-809, 2013.

TAKANO, Tomotsugu et al. Dectin-1 intracellular domain determines species-specific ligand spectrum by modulating receptor sensitivity. Journal of Biological Chemistry, v. 292, n. 41, p. 16933-16941, 2017.

THIAGARAJAN, Praveena S. et al. Vimentin is an endogenous ligand for the pattern recognition receptor Dectin-1. Cardiovascular research, v. 99, n. 3, p. 494-504, 2013.

TROTT, Oleg; OLSON, Arthur J. AutoDock Vina: improving the speed and accuracy of docking with a new scoring function, efficient optimization, and multithreading. Journal of computational chemistry, v. 31, n. 2, p. 455-461, 2010.

TSONI, S. Vicky; BROWN, Gordon D. $\beta$-Glucans and Dectin-1. Annals of the New York Academy of Sciences, v. 1143, n. 1, p. 45-60, 2008.

TURNER, Martin et al. Tyrosine kinase SYK: essential functions for immunoreceptor signalling. Immunology today, v. 21, n. 3, p. 148-154, 2000.

VAN ZUNDERT, G. C. P. et al. The HADDOCK2. 2 web server: user-friendly integrative modeling of biomolecular complexes. Journal of molecular biology, v. 428, n. 4, p. 720-725, 2016.

WALLACE, Andrew C.; LASKOWSKI, Roman A.; THORNTON, Janet M. LIGPLOT: a program to generate schematic diagrams of protein-ligand interactions. Protein engineering, 
design and selection, v. 8, n. 2, p. 127-134, 1995.

WARNECKE, Andreas et al. PyTMs: a useful PyMOL plugin for modeling common posttranslational modifications. BMC bioinformatics, v. 15, n. 1, p. 370, 2014.

WEBB, Benjamin; SALI, Andrej. Comparative protein structure modeling using MODELLER. Current protocols in bioinformatics, v. 54, n. 1, p. 5.6. 1-5.6. 32, 2016.

WEBB, Benjamin; SALI, Andrej. Protein structure modeling with MODELLER. In: Protein Structure Prediction. Humana Press, New York, NY, 2014. p. 1-15.

WEIL, Tanja; RENNER, Steffen. Homology model-based virtual screening for GPCR ligands using docking and target-biased scoring. Journal of chemical information and modeling, v. 48, n. 5, p. 1104-1117, 2008.

WIEDERSTEIN, Markus; SIPPL, Manfred J. ProSA-web: interactive web service for the recognition of errors in three-dimensional structures of proteins. Nucleic acids research, v. 35, n. suppl_2, p. W407-W410, 2007.

WU, Emilia L. et al. CHARMM-GUI Membrane Builder toward realistic biological membrane simulations. Journal of computational chemistry, v. 35, n. 27, p. 1997-2004, 2014.

XU, Dong; ZHANG, Yang. Ab initio protein structure assembly using continuous structure fragments and optimized knowledge-based force field. Proteins: Structure, Function, and Bioinformatics, v. 80, n. 7, p. 1715-1735, 2012.

XU, Dong; ZHANG, Yang. Toward optimal fragment generations for ab initio protein structure assembly. Proteins: Structure, Function, and Bioinformatics, v. 81, n. 2, p. 229-239, 2013.

YOKOTA, Koichi et al. Identification of a human homologue of the dendritic cell-associated C-type lectin-1, dectin-1. Gene, v. 272, n. 1-2, p. 51-60, 2001.

YU, Haoran et al. Two strategies to engineer flexible loops for improved enzyme thermostability. Scientific reports, v. 7, p. 41212, 2017.

ZHANG, C. H. I.; LIU, Song; ZHOU, Yaoqi. Accurate and efficient loop selections by the DFIRE-based all-atom statistical potential. Protein science, v. 13, n. 2, p. 391-399, 2004.

ZHAO, Yinghua et al. Dectin-1-activated dendritic cells trigger potent antitumour immunity through the induction of Th9 cells. Nature communications, v. 7, n. 1, p. 1-12, 2016. 